\title{
LIQUID PHASE FLUID DYNAMIC (METHANOL) RUN IN THE LAPORTE ALTERNATIVE FUELS DEVELOPMENT UNIT
}

\author{
Topical Report
}

\section{FINAL}

Task 1: Engineering Modifications (Fluid Dynamic/Methanol Demonstration)

and

Task 2: AFDU Shakedown, Operations, Deactivation and Disposal

(Fluid Dynamic/Methanol Demonstration)

Contractor:

AIR PRODUCTS AND CHEMICALS

Allentown, PA 18195

Bharat L. Bhatt

May 1997

Prepared for the United States Department of Energy

Under Contract No. DE-FC22-95PC93052

Contract Period January 1995 - December 1997 


\section{DISCLAIMER}

This report was prepared as an account of work sponsored by an agency of the United States Government. Neither the United States Government nor any agency thereof, nor any of their employees, make any warranty, express or implied, or assumes any legal liability or responsibility for the accuracy, completeness, or usefulness of any information, apparatus, product, or process disclosed, or represents that its use would not infringe privately owned rights. Reference herein to any specific commercial product, process, or service by trade name, trademark, manufacturer, or otherwise does not necessarily constitute or imply its endorsement, recommendation, or favoring by the United States Government or any agency thereof. The views and opinions of authors expressed herein do not necessarily state or reflect those of the United States Government or any agency thereof. 


\section{DISCLAIMER}

Portions of this document may be illegible in electronic image products. Images are produced from the best available original document. 
ABSTRACT 2

EXECUTIVE SUMMARY 3

INTRODUCTION

OBJECTIVES

ENGINEERING AND MODIFICATIONS 5

Process Description $\quad 5$

Bubble-Column Reactor 6

Analytical Setup 6

Hazards Reviews 6

Environmental Reviews 6

DEMONSTRATION RUN PLAN $\quad 7$

Improvements in Catalyst Activation Procedure 7

Alternate Catalyst Qualification $\quad 7$

Run Plan $\quad 7$

RESULTS AND DISCUSSION

Carbonyl Burnout $\quad 8$

Slurry Preparation for Operations with Baseline Catalyst $\quad 8$

Baseline Catalyst Reduction $\quad 8$

Process Variable/Fluid Dynamic Study with Baseline Catalyst 9

Slurry Preparation for Operations with Alternate Catalyst 10

Alternate Catalyst Reduction $\quad 10$

Process Variable/Fluid Dynamic Study with Alternate Catalyst 10

Tracer Study with Alternate Catalyst 12

Catalyst Performance Comparison $\quad 12$

Operations at High Velocities $\quad 13$

Mass Balance 13

Gas Holdup Estimates 13

Statistical Analysis of Gas Holdups and Dynamic Gas Disengagement 14

Reactor Temperature Control 15

CONCLUSIONS AND RECOMMENDATIONS 16

$\begin{array}{ll}\text { FUTURE PLANS } & 17\end{array}$

ACKNOWLEDGMENTS 17

$\begin{array}{ll}\text { REFERENCES } & 17\end{array}$

APPENDIX A: Improved Catalyst Activation Tests in Laboratory

B: Laboratory Testing of Alternate Methanol Catalyst

C: $\quad$ Fluid Dynamic (Methanol) Run Authorizations

D: Fluid Dynamic (Methanol) Run Chronology

E: $\quad$ Fluid Dynamic (Methanol) Run Mass Balances

F: $\quad$ Residual Oil Analysis of Methanol Liquid

G: Characterization of Slurry Phase Flow in the LaPorte AFDU using DP Measurements 


\begin{abstract}
A fluid dynamic study was successfully completed in a bubble column at DOE's Alternative Fuels Development Unit (AFDU) in LaPorte, Texas. Significant fluid dynamic information was gathered at pilot scale during three weeks of Liquid Phase Methanol (LPMEOH ${ }^{\mathrm{TM}}$ ) operations in June 1995. In addition to the usual nuclear density and temperature measurements, unique differential pressure data were collected using Sandia's high-speed data acquisition system to gain insight on flow regime characteristics and bubble size distribution. Statistical analysis of the fluctuations in the pressure data suggests that the column was being operated in the churn turbulent regime at most of the velocities considered. Dynamic gas disengagement experiments showed a different behavior than seen in low-pressure, cold-flow work. Operation with a superficial gas velocity of $1.2 \mathrm{ft} / \mathrm{sec}$ was achieved during this run, with stable fluid dynamics and catalyst performance. Improvements included for catalyst activation in the design of the Clean Coal III LPMEOH ${ }^{\mathrm{TM}}$ plant at Kingsport, Tennessee, were also confirmed. In addition, an alternate catalyst was demonstrated for $\mathrm{LPMEOH}^{\top \mathrm{M}}$.
\end{abstract}




\section{EXECUTIVE SUMMARY}

A fluid dynamic study was successfully completed in a bubble column at pilot scale. Significant fluid dynamic information was gathered during three weeks of Liquid Phase Methanol (LPMEOH ${ }^{\mathrm{TM}}$ ) operations. In addition to the usual nuclear density gauge and temperature measurements, differential pressure (DP) measurements were made to better understand the hydrodynamics of the system. The DP measurements worked very well mechanically, without anticipated plugging problems, throughout the run. Gas holdup estimates based on DP measurements followed the same trends as those indicated by NDG readings. However, there appeared to be a systematic difference between gas holdup estimates from the two methods. The NDG-based gas holdups were 15-20\% higher than the DP-based holdups. The difference can be explained if a radial profile for gas holdup exists in the bubble column with higher holdup in the center. Such a radial profile is expected to be prominent at the high velocities studied in this run.

Interesting differential pressure data were collected using Sandia's high-speed data acquisition system to gain insight on flow regime characteristics and bubble size distribution. Two types of statistical analyses of the fluctuations in the pressure data were performed, calculation of standard deviation and a Fourier spectrum analysis. The analysis suggests that the column was being operated in the churn turbulent regime at most of the velocities considered. High-speed differential pressure measurements were also used to perform dynamic gas disengagement (DGD) experiments. The DGD curves showed a single slope compared to two distinct slopes seen in low-pressure, cold-flow work corresponding to two classes of bubble sizes. A tracer study was conducted during the run to evaluate mixing in both gas and liquid phases at three different conditions. Results of the tracer study are included in a separate report (1).

High-velocity conditions were demonstrated during this run. Operation with a linear velocity of $1.2 \mathrm{ft} / \mathrm{sec}$ was achieved, with stable hydrodynamics and catalyst performance. Acceptable oil carry-over from the reactor was observed at this velocity. The magnitude of the velocity was limited only by the recycle gas compressor capacity, as the plant was designed for $1 \mathrm{ft} / \mathrm{sec}$ maximum velocity. Improvements for catalyst activation included in the design of the Clean Coal III LPMEOH ${ }^{T M}$ plant at Kingsport, Tennessee, were also confirmed. Successful activations were achieved using dilute $\mathrm{CO}$ as reductant, a faster temperature ramp, and smaller gas flow, compared to previous "standard" activation procedures. An alternate catalyst was demonstrated for LPMEOH $^{\top \mathrm{M}}$. Expected catalyst activity, by-product formation, and stability were obtained with the alternate catalyst. Overall, the catalyst appeared very comparable to the baseline catalyst. Stable performance was obtained at both high and very low (turndown) velocity.

Dephlegmator testing was conducted at various conditions during the run. During the carbonyl burnout period, tests were performed with a two-phase system which eliminated catalyst fouling considerations. Further measurements were made with a three-phase system. The heat transfer performance of the dephlegmator continued to be lower than expected. In addition, the oil carryover was significantly higher than expected at the operating temperatures. Although flooding was ruled out by calculations, variability in oil capture was still apparent. Further data analysis and additional tests are needed before a final decision can be made on inclusion of the dephlegmator in 
commercial flow sheets. Approximately 64,300 gallons of methanol were produced during this demonstration, which will be useful for product testing. 


\section{INTRODUCTION}

The Federal Energy Technology Center (FETC) at Pittsburgh sponsors an Indirect Liquefaction program as part of DOE's Coal Liquefaction program. The overall goal of the Coal Liquefaction program is to develop the scientific and engineering knowledge base with which industry can bring into the marketplace economically competitive and environmentally acceptable advanced technology for the manufacture of synthetic liquid fuels from coal. The specific area of interest for this project was to conduct a fluid dynamic study at pilot scale which would enhance the understanding of bubble column operation. This would improve design and trouble-shooting capabilities for commercial-scale bubble columns. Significant information exists in the literature for fluid dynamics of the bubble column in non-reactive, low-pressure, cold-flow systems. However, data for industrial scale reactive systems are lacking. The test run was conducted at DOE's Alternative Fuels Development Unit (AFDU) in LaPorte, Texas. The AFDU bubble column has been operated by Air Products and Chemicals in the past for slurry phase methanol, DME, water gas shift, Fischer-Tropsch, isobutylene and isobutanol synthesis. Slurry bubble columns provide improved performance for these reactions because they have significant heat effects.

\section{OBJECTIVES}

The main objective of this run was to perform a fluid dynamic study in a bubble column including:

(1) Differential pressure measurements along reactor height to estimate gas holdup, since nuclear density measurements for gas holdup are not feasible with large-diameter commercial reactors.

(2) Dynamic gas disengagement measurements during shutdown tests to understand flow regime and bubble size distribution.

(3) Radioactive tracer studies to evaluate mixing in both liquid and gas phases.

The study was conducted with liquid phase methanol (LPMEOH $\left.{ }^{T M}\right)$ technology, for which the additional objectives described below were pursued:

(1) Demonstrate operation at high-velocity conditions ( $1.2 \mathrm{ft} / \mathrm{sec})$ to improve commercial reactor design.

(2) Demonstrate improved reduction procedures developed for $\mathrm{LPMEOH}^{\mathrm{MM}}$ at Kingsport.

(3) Evaluate an alternate methanol catalyst.

(4) Produce methanol for end-use testing. 


\section{ENGINEERING AND MODIFICATIONS}

Modifications were conducted in the AFDU to measure relevant fluid dynamic parameters during the operation:

(1) Two nozzles (N1 and N2) were added to the new high-pressure 27.20 reactor for differential pressure (DP) measurements, as well as liquid tracer injections. A schematic of the reactor is provided in Figure 1.

(2) Six new DP transmitters were added and connected to both the existing Distributed Control System (DCS) and a new high-speed data acquisition system from Sandia National Laboratories.

(3) A new stronger 8-curie Cs-137 source was installed for the reactor nuclear density gauge (NDG) to improve the resolution of the NDG reading by a factor of four, and the NDG was calibrated with $\mathrm{N}_{2}$.

(4) The heater/cooler in the utility oil system were realigned to improve reactor temperature control by moving the heater downstream of the cooler. After a field inspection with Piping Design personnel, it was decided to install additional piping instead of physically moving the equipment. Installing the piping would be cheaper than moving the equipment, and the oil pump had enough capacity to handle the additional pressure drop caused by the piping. A process flow diagram for the utility system is provided in Figure 2.

(5) A sump and a pad were installed in the trailer area to enable better spill handling, and an overfill protection was installed for the trailers.

The data acquisition system was set up for methanol synthesis with the new measurements included.

\section{Process Description}

Changes were incorporated in the AFDU process flow diagrams to reflect the modifications; the new diagrams are shown in Figures 3 and 4. The operation of the plant is described as follows:

Hydrogen, carbon monoxide, carbon dioxide, and nitrogen are blended and compressed in the 01.10 feed gas compressor. This stream then mixes with recycle gas and additional hydrogen from a high-pressure pipeline to obtain the desired synthesis gas composition and flow. The reactor feed then passes through the 01.15 cooling water exchanger before compressing to approximately 1800 psig in the 01.30 booster compressor. The 01.34 aftercooler is used to control the inlet temperature to the $21.11 \mathrm{feed} /$ product economizer, which preheats the feed against the reactor effluent. The mixed feed is further preheated against high-pressure steam in the 02.63 before the synthesis gas blend is introduced into the bottom of the new 27.20 highpressure slurry reactor. 
The synthesis gas flows upward through the slurry of catalyst and mineral oil as the reaction proceeds. The heat of reaction is absorbed by the slurry and removed through the internal heat exchanger, which also uses mineral oil as its heat transfer fluid. The product gas passes through the reactor freeboard with the unconverted synthesis gas, and the gross reactor effluent cools against the feed in the 21.11 economizer. Any traces of slurry oil entrained or vaporized in the effluent condense and are returned to the bottom of the reactor by the 10.52 .02 pumps. The vapor leaving the 21.11 de-pressurizes across a valve to less than $1000 \mathrm{psig}$; chills against cooling water in the 21.30 hairpin exchangers; and passes into the 22.10 separator where liquid products (methanol, water, higher alcohols) collect. The liquids flash to near atmospheric pressure in the 22.11 degasser and collect in the 22.15 low-pressure separator before passing on to the 22.16 day tank and eventually a trailer for storage. To minimize the amount of gas sent to the flare, most of the synthesis gas leaving the 22.10 separator is recycled to the reactor. A small portion of this gas is purged to flare to prevent the buildup of inerts.

\section{Bubble Column Reactor}

The new 27.20 bubble column reactor for oxygenate synthesis measures $50 \mathrm{ft}$ flange-to-flange and $18 \mathrm{in}$. inside diameter. Its design slurry level is $40 \mathrm{ft}$, with the remainder being vapor disengagement space. The reactor contains an internal heat exchanger consisting of twelve $3 / 4$-in. U-tubes occupying $8 \%$ of the reactor cross section. In addition, 13 thermocouples measure the longitudinal temperature profile at 4- $\mathrm{ft}$ intervals. A nuclear density gauge, mounted on an external hoist mechanism, spans the space occupied by the internal exchanger to measure slurry level and gas holdup. The design pressure of the reactor is $2000 \mathrm{psig}$ at $700^{\circ} \mathrm{F}$.

\section{Analytical Setup}

The analytical system was set up for methanol synthesis. Two GCs with Flame Ionization Detectors (FIDs) monitored hydrocarbon and alcohol concentrations in the reactor feed and effluent streams. Two other GCs with Thermal Conductivity Detectors (TCDs) measured $\mathrm{H}_{2}, \mathrm{~N}_{2}$, $\mathrm{CO}, \mathrm{CO}_{2}, \mathrm{H}_{2} \mathrm{O}, \mathrm{MeOH}$, and DME in feed, product, purge, and intermediate streams. A small amount of $\mathrm{N}_{2}$ (approximately $1 \mathrm{~mol} \%$ ) was added to the reactor feed as an internal standard to verify flow measurements.

\section{Hazards Review}

A preliminary hazards review was conducted on 2 March 1995 for the modifications needed for this run. Facility Change Notice (FCN) forms were filled out and reviewed. A hazards review was conducted on 10 April 1995. FCNs on reactor differential pressure (DP) taps, flow totalizers, local HIC valves, trailer pad/sump and trailer overfill protection were approved.

\section{Environmental Reviews}

Radian Corporation was contracted to evaluate air permit requirements. Radian reviewed the proposed modifications and different operational options to determine whether we needed a new air permit exemption. No permit/exemption action was needed for the new reactor because its operation was covered by the 1994 exemption. 


\section{DEMONSTRATION RUN PLAN}

\section{Improvements in Catalyst Activation Procedure}

Improvements applied for catalyst activation in the design of Clean Coal III LPMEOH ${ }^{\mathrm{TM}}$ plant at Kingsport, Tennessee, were included in the demonstration plan. The improvements were previously tested by R\&D in an autoclave and found acceptable (see Appendix A for details). Activations for the two catalysts were conducted using dilute $\mathrm{CO}$ as reductant to minimize water formation and consequently avoid oil-water separation. Also a faster temperature ramp and smaller gas flow compared to previous "standard" activation procedures were used to reduce the cost of the reduction in commercial applications.

\section{Alternate Catalyst Qualification}

An alternate catalyst was first qualified by R\&D in the laboratory. Activity, stability and slurry properties of this catalyst were evaluated and found equivalent to the baseline catalyst (see Appendix B for details).

\section{Run Plan}

Several meetings were held between Process Engineering, Operations and R\&D to develop a run plan. It was decided to conduct two LPMEOH ${ }^{\mathrm{TM}}$ operations in the new reactor, a one-week run with the baseline catalyst and a two-week run with the alternate catalyst. The run conditions as adapted during the run are summarized in Table 1. Authorizations for the run are included in Appendix C. 


\section{RESULTS AND DISCUSSION}

Preliminary results from this run were summarized earlier at the First Joint Power and Fuel Systems Contractors Conference in Pittsburgh (2).

\section{Carbonyl Burnout}

The reactor was loaded with oil and heated up on 30 May 1995 to start carbonyl burnout and two-phase dephlegmator testing. The carbonyl levels were extremely low during the entire burnout, i.e., 2-10 ppbv iron carbonyl and undetectable ( $<10 \mathrm{ppbv})$ nickel carbonyl. A summary of the carbonyl data is shown in Table 2.

During the burnout period, extensive testing of the 21.11 dephlegmator was also conducted. The dephlegmator had been added during the 1993 modifications of the plant as a possible replacement for the cyclone, the feed-product economizer and the vapor-liquid separator. During the 1994 isobutanol run, the dephlegmator did not perform as designed. Data were collected in the two-phase system during the current burnout period to rule out fouling. The dephlegmator continued to perform below expectation, indicating catalyst fouling was not the main reason for lack of adequate performance. The heat transfer performance of the dephlegmator was lower than expected. In addition, the oil carry-over was significantly higher than expected at the operating temperatures. The carbonyl burnout was completed at 19:00 on 2 June 1995. At the end of the burnout, the plant was cooled and drained in preparation for catalyst loading and reduction.

\section{Slurry Preparation for Operations with Baseline Catalyst}

A $40 \mathrm{wt} \%$ oxide catalyst slurry was mixed in the 28.30 Prep Tank. The Prep Tank was charged with $1767 \mathrm{lbs}$ of Drakeol-10 oil at 09:00 on 2 June and $1179 \mathrm{lbs}$ of standard baseline methanol catalyst at 08:00 on 3 June. Catalyst was taken from four drums of lot \#94/15730. The slurry was heated and agitated in the Prep Tank for two hours prior to transfer to the reactor. A detailed chronology for the entire run is given in Appendix D.

\section{Baseline Catalyst Reduction}

Catalyst reduction began at 14:30 on 3 June. The reduction gas ( $4 \% \mathrm{CO}$ in $\mathrm{N}_{2}$ ) was set at 12,500 $\mathrm{SCFH}$ with the reactor pressure at $67 \mathrm{psig}$ (Run \# A9). The heat up commenced at 15:45 and proceeded from 197 to $464^{\circ} \mathrm{F}$ at a rate of $15^{\circ} \mathrm{F} / \mathrm{hr}$, as shown in Figure 5. The temperature ramp was significantly faster than the previous "standard" ramp to save time in commercial applications.

The reduction under $\mathrm{CO}$ was quite rapid, as shown in Figure 6, and the total uptake peaked out very close to the theoretical maximum value of $2.82 \mathrm{SCF} / \mathrm{b}$ oxide. This condition was obtained by about $360^{\circ} \mathrm{F}$, or $12-13$ hours on stream, which is an encouraging result for the Kingsport project. Reduction in the bubble column was faster compared to the autoclave. Despite the rapid uptake, the 27.20 internal heat exchanger was easily able to control temperature, and the ramp rate proceeded on schedule with no evidence of an exotherm. At $392^{\circ} \mathrm{F}$, the reduction gas flow was reduced to 9,375 SCFH as planned to reduce oil loss from the reactor and conserve on nitrogen usage. Gas holdup during the reduction was close to expected, i.e., 27-30 vol \% at 
$12,500 \mathrm{SCFH}$ and $24 \mathrm{vol} \%$ at $9,375 \mathrm{SCFH}$. The catalyst concentration was in the $39-41 \mathrm{wt} \%$ range.

\section{Process Variable/Fluid Dynamic Study with Baseline Catalyst}

Reduction was completed at 10:00 hours on 4 June, and synthesis gas was brought into the reactor at 11:45. The initial data indicated typical hyperactivity of the catalyst. Problems were experienced with analytical communication boxes during the evening of $4 \mathrm{June}$. The problems were resolved and data were collected at the conditions of Run No. AF-R13.1 (Texaco gas, 7100 $\mathrm{sl} / \mathrm{hr}-\mathrm{kg}, 750 \mathrm{psig}, 482^{\circ} \mathrm{F}, 0.85 \mathrm{ft} / \mathrm{sec}$ ). A production rate of $12.1 \mathrm{~T} / \mathrm{D}$ methanol was achieved, which was close to expected for fresh catalyst. Mass balance around the plant was excellent. Liquid analysis showed typical methanol product composition. Nuclear density gauge readings indicated a gas holdup of $50.5 \mathrm{vol} \%$, higher than the expected holdup of $43 \mathrm{vol} \%$. The catalyst concentration was estimated at $45.8 \mathrm{wt} \%$. Data were taken for an additional mass balance period to examine initial catalyst aging. Steady operations continued, and conversion to methanol showed an expected drop from 16.5 to $15.5 \%$. Nuclear density gauge readings indicated a gas holdup of $54.7 \mathrm{vol} \%$ and a catalyst concentration of $48.2 \mathrm{wt} \%$. These results were very steady during this period, after both parameters showed measurable increases throughout the previous data period.

Conditions were changed to those of Run No. AF-R13.2 (Kingsport gas, $4000 \mathrm{~s} / \mathrm{hr}-\mathrm{kg}, 735 \mathrm{psig}$, $482^{\circ} \mathrm{F}, 0.49 \mathrm{ft} / \mathrm{sec}$ ) shortly after noon on 6 June. The plant operated very steadily for three days at expected performance. CO conversion of $49.6 \%$ and methanol production of $9.9 \mathrm{~T} / \mathrm{D}$ were achieved. Liquid analysis showed stable methanol product composition comparable to that obtained in 1994 with Kingsport gas. Nuclear density gauge readings indicated a gas holdup of $42.7 \mathrm{vol} \%$ and a catalyst concentration of $41.9 \mathrm{wt} \%$. During operation at these conditions, some methanol condensation was observed in the 27.14 oil separator. With almost $17 \mathrm{~mol} \%$ methanol in the reactor effluent, the methanol dew point was $268^{\circ} \mathrm{F}$. Hence, the temperature of the 27.14 was increased from 280 to $295^{\circ} \mathrm{F}$ to avoid methanol condensation.

A shutdown test was conducted at the end of Run AF-R13.2 to obtain a more accurate holdup estimate. Based on liquid level measurement using nuclear density gauge (NDG) with flow shutdown, gas holdup was calculated at $32.9 \mathrm{vol} \%$. This compares with an estimate of $43.1 \mathrm{vol}$ $\%$ based on NDG measurements and $36.5 \mathrm{vol} \%$ based on DP measurements. An attempt was made to measure the rate of drop of liquid level immediately after the gas was shut down using the NDG. However, this drop was too fast compared to the response of the NDG as well as the speed at which the NDG could be moved. DP data were collected during the shutdown test with the Sandia data acquisition system to help sort out the distribution of large bubbles vs. small bubbles.

After the shutdown test, the unit was brought on-stream with Texaco gas in an attempt to reach the conditions of Run AF-R13.3: $10,000 \mathrm{sl} / \mathrm{hr}-\mathrm{kg}, 750 \mathrm{psig}, 482^{\circ} \mathrm{F}, 1.2 \mathrm{ft} / \mathrm{sec}$ gas inlet velocity. With Texaco gas, the 01.20 recycle compressor reached its limit at $0.95 \mathrm{ft} / \mathrm{sec}$. Operating at lower pressure helped little, since pressure drop through the plant increased. In order to achieve higher gas velocity, the feed composition was changed from Texaco gas to Kingsport gas. Higher methanol production was expected with Kingsport gas, which would lower the pressure drop in 
the back end. A linear velocity of $1.13 \mathrm{ft} / \mathrm{sec}$ was achieved with this gas. The reactor performance was stable, with a production rate of about $18 \mathrm{~T} / \mathrm{D}$. The NDG readings showed higher fluctuations compared to those typically observed at lower velocities. A gas holdup of $55.8 \mathrm{vol} \%$ with a catalyst concentration of $48.7 \mathrm{wt} \%$ was estimated from the NDG readings. The DP measurements indicated a holdup of $44.9 \mathrm{vol} \%$ and a catalyst concentration of $39.2 \mathrm{wt}$ $\%$. Oil loss rate from the reactor was measured at this velocity. A modest loss rate of about 10 gph was estimated from level rises in vessels 21.11 and 27.14 downstream of the reactor.

At 00:45 hours on 11 June, the plant experienced a shutdown due to loss of compression. Belts on the motor for the two compressors broke, shutting down the plant six hours earlier than scheduled. Since we had enough data at this last condition with the baseline catalyst, it was decided to cool down the reactor in preparation for a turnaround to the alternate catalyst run. The slurry was drained directly from the reactor.

\section{Slurry Preparation for Operations with Alternate Catalyst}

A 40 wt \% oxide catalyst slurry was mixed in the 28.30 Prep Tank. The Prep Tank was charged with $1766 \mathrm{lbs}$ of Drakeol-10 oil at 08:00 on 10 June and $1178 \mathrm{lbs}$ of the alternate methanol catalyst at 08:00 on 12 June. Catalyst was taken from 11 drums of lot \# 022811. The slurry was heated and agitated in the Prep Tank for two hours prior to transfer to the reactor.

\section{Alternate Catalyst Reduction \\ Catalyst reduction began at 14:30 on 12 June. The reduction gas ( $4 \% \mathrm{CO}$ in $\mathrm{N}_{2}$ ) was set at $12,500 \mathrm{SCFH}$, with the reactor pressure at $67 \mathrm{psig}$ (Run \# A10). The heat up commenced at $14: 45$ and proceeded from 193 to $464^{\circ} \mathrm{F}$ at a rate of $15^{\circ} \mathrm{F} / \mathrm{hr}$.}

Initially, the reduction seemed a little slower than the previous baseline catalyst reduction. The rate increased later, and most of the uptake was completed by about $360^{\circ} \mathrm{F}(12-13$ hours onstream, the same as the baseline catalyst). The total uptake peaked out close to the theoretical maximum value of $2.68 \mathrm{SCF} / \mathrm{lb}$ oxide (see Figure 7). Reduction in the bubble column was slightly slower compared to the autoclave. The 27.20 internal heat exchanger was easily able to control temperature, and the ramp rate proceeded on schedule with no evidence of an exotherm. At $392^{\circ} \mathrm{F}$, the reduction gas flow was reduced to $9,375 \mathrm{SCFH}$ as planned to reduce oil loss from the reactor and conserve on nitrogen usage. When the flow was reduced, the slow adjustment of $\mathrm{CO}$ concentration in the reduction gas caused the calculated uptake value to drift. Gas holdup during the reduction was slightly higher than expected, $29-34 \mathrm{vol} \%$ at $12,500 \mathrm{SCFH}$. The catalyst concentration was in the $41-42 \mathrm{wt} \%$ range.

\section{Process Variable/Fluid Dynamic Study with Alternate Catalyst}

Syngas flow to the reactor began at 11:00 on 13 June. The unit was fully lined out at the conditions of Run No. AF-R14.1 (Texaco gas, $7200 \mathrm{sl} / \mathrm{hr}-\mathrm{kg}, 750 \mathrm{psig}, 482^{\circ} \mathrm{F}, 0.84 \mathrm{ft} / \mathrm{sec}$ ) by 18:00. The initial data indicated typical hyperactivity of the catalyst. The operational results were very similar to those seen previously during AF-R13.1 with the baseline catalyst. The production rate was $12.0 \mathrm{~T} / \mathrm{D}$ of methanol, and the $\mathrm{CO}$ conversion rate was $16.4 \%$. The mass balance around the plant was excellent. Liquid analysis showed typical methanol product composition with some very slight variations in the impurity mix. Nuclear density gauge readings indicated a 
gas holdup of $49.6 \mathrm{vol} \%$, and a catalyst concentration estimated at $45.4 \mathrm{wt} \%$. Steady operations continued for another day at conditions of Run No. AF-R14.1. Compared to the baseline catalyst, the alternate catalyst showed even less decline in activity over its initial 24 hours of operation. The production rate decreased to $11.7 \mathrm{~T} / \mathrm{D}$ of methanol, and the CO conversion rate dropped to $16.2 \%$. Nuclear density gauge readings were identical to those of the previous data period. A shutdown test immediately following this run indicated 38.9 vol \% gas holdup.

Conditions were changed to those of Run No. AF-R 14.2 (Kingsport gas, $4000 \mathrm{sl} / \mathrm{hr}-\mathrm{kg}, 735 \mathrm{psig}$, $482^{\circ} \mathrm{F}, 0.48 \mathrm{ft} / \mathrm{sec}$ ) shortly after noon on $15 \mathrm{June}$. The plant ran smoothly at this condition for three days with stable catalyst performance. The alternate catalyst continued to perform very similarly to the baseline catalyst. The production rate was about $10 \mathrm{~T} / \mathrm{D}$ methanol. Nuclear density gauge readings indicated a gas holdup of $37.8 \mathrm{vol} \%$, and a catalyst concentration estimated at $39.6 \mathrm{wt} \%$.

Due to lack of availability of adequate CO supply, the originally planned conditions of Run No. 14.3 (Kingsport gas, $10,000 \mathrm{sl} / \mathrm{hr}-\mathrm{kg}, 735 \mathrm{psig}, 482^{\circ} \mathrm{F}, 1.2 \mathrm{ft} / \mathrm{sec}$ inlet gas velocity) could not be achieved. Instead, it was decided to operate at another high-velocity condition which would consume less $\mathrm{CO}$. Conditions were changed to $7,100 \mathrm{sl} / \mathrm{hr}-\mathrm{kg}, 520 \mathrm{psig}, 482^{\circ} \mathrm{F}$ and $1.18 \mathrm{ft} / \mathrm{sec}$ inlet gas velocity with Kingsport gas. The plant performed steadily at this condition. The catalyst performance was close to that expected. CO conversion was about $33 \%$ compared to a 2-CSTR expectation of $32.5 \%$. Nuclear density readings had some fluctuations similar to those observed with the baseline catalyst at high velocity. A gas holdup of $50.4 \mathrm{vol} \%$ and a catalyst concentration of $45.6 \mathrm{wt} \%$ were estimated based on the nuclear density readings. DP measurements on the reactor indicated a holdup of $36.6 \mathrm{vol} \%$. A shutdown test was conducted at the end of the mass balance period. Gas holdup of $36.6 \mathrm{vol} \%$ was measured during the shutdown test.

After the shutdown test, the unit was brought to the conditions of Run 14.4 (Texaco gas, 4,100 $\mathrm{s} 1 / \mathrm{hr}-\mathrm{kg}, 750 \mathrm{psig}, 482^{\circ} \mathrm{F}$, and $0.47 \mathrm{ft} / \mathrm{sec}$ inlet gas velocity). Catalyst activity was close to that expected. CO conversion was $17.5 \%$ compared to a 2-CSTR expectation of $17.7 \%$. Increased levels of higher alcohols, methyl formate and methyl acetate were observed at this low space velocity condition. Nuclear density readings had no fluctuations, as the superficial velocity at this condition was low as well. A gas holdup of $42.9 \mathrm{vol} \%$ and catalyst concentration of $42.2 \mathrm{wt} \%$ were estimated based on the nuclear density readings. DP measurements on the reactor indicated a holdup of $33.3 \mathrm{vol} \%$.

The operating conditions of the unit were changed to initial baseline conditions (Run No. AFR14.5: Texaco gas, $7,200 \mathrm{sl} / \mathrm{hr}-\mathrm{kg}, 750 \mathrm{psig}, 482^{\circ} \mathrm{F}$, and $0.83 \mathrm{ft} / \mathrm{sec}$ inlet gas velocity) on the morning of 21 June. Catalyst activity was very close to that observed initially at the same condition (Run No. AF-R14.1). The CO conversion dropped only slightly from 16.2 to $15.9 \%$. Also, the by-product formation was down to the same level as that of Run 14.1 A gas holdup of $50.8 \mathrm{vol} \%$ and catalyst concentration of $46.5 \mathrm{wt} \%$ were estimated based on the nuclear density readings. 
Further measurements were made on the 21.11 dephlegmator at the baseline condition. The heat transfer performance of the dephlegmator continued to be lower than expected. In addition, the oil carry-over was significantly higher than expected at the operating temperatures. Although flooding was ruled out by calculations, variability in oil capture was still apparent. Oil carry-over was higher at higher velocity. It is possible that oil was not coalescing and forming droplets efficiently. Further data analysis and additional tests are needed before a final decision can be made on inclusion of the dephlegmator in commercial flow sheets.

\section{Tracer Study with Alternate Catalyst}

ICI Tracerco personnel started setting up on 21 June for a 3-day tracer study. The study was started on 22 June at the baseline conditions (Run AF-R14.6: $0.83 \mathrm{ft} / \mathrm{sec}$ inlet velocity, $7200 \mathrm{~s} / \mathrm{hr}$ $\mathrm{kg}, 750 \mathrm{psig}, 482^{\circ} \mathrm{F}$, Texaco gas). Detectors were set up at various locations outside the reactor, as shown in Figure 1. Sets of four detectors at $90^{\circ}$ angles were set up at seven different heights. In addition, detectors were set up at the reactor inlet, the reactor outlet, the vapor space near the reactor top and the recycle feed line. During liquid injection, the detector at the reactor inlet was moved to the liquid injection nozzle.

A vapor residence time distribution study was initiated by injecting Argon- 41 into the inlet gas line and monitoring its progress through the reactor. Excellent pulses were obtained at the inlet and sharp responses were observed at other locations. It appeared that the pulse moved through the reactor at a velocity that was equivalent to the superficial gas velocity. This was in contrast to the previous study during the 1993 isobutylene run, when the pulse appeared to move up more slowly.

Four injections of radioactive manganese oxide were made in the reactor slurry to study liquid phase mixing. Portions of radioactive $\mathrm{Mn}_{2} \mathrm{O}_{3}$ mixed in Drakeol-10 were injected at: (1) nozzle N2-4.5 in. from wall, (2) nozzle N2-wall, (3) nozzle N1-4.5 in. from wall, and (4) nozzle N1-wall. The data showed some of the tracer flowing in both an upward as well as downward direction. There appeared to be more downward movement at the wall.

Both gas and liquid injections were made at the two other conditions: low-velocity condition (Run AF-R14.7: $0.47 \mathrm{ft} / \mathrm{sec}, 4100 \mathrm{sl} / \mathrm{hr}-\mathrm{kg}, 750 \mathrm{psig}, 482^{\circ} \mathrm{F}$, Texaco gas) and high-velocity condition (Run AF-R14.8: $1.18 \mathrm{ft} / \mathrm{sec}, 7100 \mathrm{sl} / \mathrm{hr}-\mathrm{kg}, 520 \mathrm{psig}, 482^{\circ} \mathrm{F}$, Kingsport gas). A detailed analysis on data collected was conducted at Washington University in St. Louis. A topical report (1) and a paper (3) have been published on the results. Interpretation of the data based on an axial dispersion model (ADM), lumping different mixing mechanisms into a single dispersion coefficient, indicated an increase in both liquid and gas axial dispersion coefficients with superficial gas velocity. However, responses of detectors located at various column heights pointed to the inadequacy of the ADM to properly interpret the gas and liquid mixing. A twodimensional model, which accounts for convective as well as turbulence effects, was proposed by the Washington University group. Initial results indicated that the model was able to predict both the radial and axial movement of the tracer in the column.

Following the tracer study, a very low-velocity condition (Run No. AF-R14.9: $0.15 \mathrm{ft} / \mathrm{sec}, 1270$ $\mathrm{sl} / \mathrm{hr}-\mathrm{kg}, 750 \mathrm{psig}, 482^{\circ} \mathrm{F}$, Texaco gas) was operated briefly to evaluate the bed stability at the 
expected minimum velocity. Hydrodynamic information was gathered at this condition to ensure the same turndown capability with this catalyst as we had with the baseline catalyst. All the fluid dynamic data such as nuclear density readings, differential pressure readings and reactor temperature appeared uniform and extremely stable, suggesting acceptable turndown capability. Following this test, the unit was shut down at 23:10 hours on 24 June. The plant was cooled overnight and liquid was drained on 25 June.

\section{Catalyst Performance Comparison}

Expected catalyst performance was obtained with both catalysts. The two catalysts are compared in Table 3 at two different conditions. Very similar $\mathrm{CO}$ conversion and methanol production rate are evident. Lower gas holdup was obtained with the alternate catalyst. CO conversions derived with both catalysts at different conditions are shown in Figure 8. In addition to the similarity of the two catalysts, the plot shows stable operation with the alternate catalyst, when conversion for R14.5 is compared with that for R14.1.

By-product data were analyzed more closely as increased levels of higher alcohols, methyl formate and methyl acetate were observed with the alternate catalyst at low space velocity conditions (Run No. AF-R14.4). The baseline catalyst was not operated at these conditions in the recent run; however, comparison of the two catalysts was available at two other sets of conditions: Run Nos. 13.1/14.1 and 13.2/14.2 (see Table 4). The by-product formation was very similar for the two catalysts at these conditions.

\section{Operations at High Velocities}

During both operations, attempts were made to operate at superficial gas velocities higher than the $1 \mathrm{ft} / \mathrm{sec}$ design velocity. Results obtained with the two catalysts at high velocity are presented in Table 5. A direct comparison cannot be made because the two conditions were different. However, some similarities are notable. During both runs, the NDG readings had high fluctuations compared to those typically observed at lower velocities, but average readings were stable. Also, the oil loss rate from the reactor was moderate. A superficial gas velocity of 1.13 $\mathrm{ft} / \mathrm{sec}$ was achieved at 720 psig during the baseline run, limited by the capacity of the recycle compressor. The reactor performance was stable with a production rate of about $18 \mathrm{~T} / \mathrm{D}$. A modest loss rate of about $10 \mathrm{gph}$ was estimated from level rises in vessels downstream of the reactor. During the run with the alternate catalyst, a superficial gas velocity of $1.18 \mathrm{ft} / \mathrm{sec}$ was achieved at a lower pressure (520 psig). The limitation for this case was CO supply. The plant performed steadily at this condition, with expected catalyst performance. CO conversion was about $33 \%$ compared to a 2-CSTR expectation of $32.5 \%$. The two runs at high velocities demonstrated that we had not reached slurry reactor limitations at $1.2 \mathrm{ft} / \mathrm{sec}$, and that operations at higher velocities were possible.

\section{Mass Balance}

Because some of the flow meters were not accurate, known chemistry was used along with measured gas concentrations to calculate correction factors for those flow rates. A run time table, which provides a cross-reference between run numbers, actual times and on-stream times, is given in Table 6. Mass balances for each data period are included in Appendix E. The elemental balance generally ranged from 98 to $102 \%$, while the mass balance ranged from 99 to $101 \%$. A 
residual oil content of $0.2 \%$ for the methanol liquid was assumed initially, and this was later confirmed by analysis of various samples (see Appendix F).

\section{Gas Holdup Estimates}

The differential pressure (DP) measurements appeared to be working well mechanically throughout the run, without the anticipated plugging problems. The measurement locations on the reactor are shown in Figure 1. Gas holdup estimates based on DP measurements followed the same trends as those indicated by nuclear density gauge (NDG) readings. However, there appeared to be a systematic difference between the two estimates. To check the accuracy of the DP readings, the DP transmitters were calibrated at the end of the run by filling the reactor with water. The calibrations resulted in only minor corrections in the zero and the span. The NDGbased gas holdups remained 15-25\% higher than the DP-based holdups (37-56 vol \% vs. $28-48$ vol \%; see Figures 9-10 and Table 7). Holdups based on shutdown tests conducted at three different conditions compared well with the DP-based holdups. The holdups based on shutdown tests were estimated using liquid levels measured by NDG before and after the shutdown tests. The NDG is considered highly accurate in measuring liquid levels. The estimated holdups from correlations based on NDG data at low velocities also had a better match with holdups from DP data. The systematic error in the densitometry readings can be linked to the measurement technique, which relies on data obtained at a single chord (diameter). This method would be accurate if the gas holdup were uniform radially. However, a radial distribution of gas holdup is generally observed in two- and three-phase flows, such that gas holdup is highest at the centerline and decreases toward the wall $(4,5)$. For such a profile, the data averaged along the diameter would give too much weight to the area with highest gas holdup at the center, and therefore would overestimate the average gas holdup. This appears to be the case for the gamma densitometer measurements at the AFDU. The effect was more prominent during this run, since most of the operations were carried out at higher velocities.

Axial variations in gas holdup based on NDG are provided in Figures 11 and 12. The gas holdup showed an initial decrease and then an increase at the top, which is consistent with the profiles observed during the 1994 isobutanol run in the same reactor (6). The initially high gas holdup may have been a sparger effect, and the holdup decreased as the flow developed. There could also have been an effect of the gas encountering the heat exchanger tubes and their support. The holdup increase at the top is probably due to gas disengagement.

\section{Statistical Analysis of Gas Holdups and Dynamic Gas Disengagement}

The high-speed data acquisition system installed by Sandia National Laboratories personnel to monitor the DPs on the reactor column was operated throughout the run. Detailed analysis on data collected was conducted by Sandia personnel. A report written by Kim Shollenberger and Timothy O'Hern discussing the results is attached in Appendix G. Statistical analysis was performed on the gas holdup data to discern flow regime transitions. The standard deviation of the gas holdup increased with velocity as expected, possibly showing that the largest gas bubbles are increasing in size and/or number. A frequency spectrum obtained from Fourier transform analysis of the DP data at high velocity showed a wide band of frequencies, but also the existence of a discernible peak at about $0.05 \mathrm{~Hz}$, suggesting that a large pocket of gas either enters or leaves the region between the pressure nozzles every 20 seconds. The strongest frequency was 
found to increase with velocity, and there did not appear to be a dominant frequency for velocity less than $0.15 \mathrm{~m} / \mathrm{sec}$. The beginning of the appearance of a dominant frequency is an indication that large bubbles are present and that a transition to churn-turbulent flow has begun. Thus, the flow appears to be in the churn-turbulent regime for all conditions, except for the two lowvelocity cases. A dynamic gas disengagement analysis was performed on DP data collected during the shutdown tests to determine bubble size distributions. High-speed differential pressure measurements were also used to perform dynamic gas disengagement (DGD) experiments. The DGD curves showed a single slope compared to two distinct slopes seen in low-pressure, coldflow work, corresponding to two classes of bubble sizes. One explanation for the difference in the curves could be that the gas shutdown at the AFDU was too slow to measure bubble classes.

\section{Reactor Temperature Control}

The heater/cooler realignment in the utility oil system was tested during the run to check for any improvement in reactor temperature control. Valves were switched during Run 13.2B to shift the 15.40 and 02.83 heaters downstream of the 21.40 and 21.20 coolers (see Figure 2). Reactor control temperatures before and after the switch are shown in Figure 13. As expected for methanol synthesis, the temperature control was quite good with the old alignment, with a standard deviation of $0.27^{\circ} \mathrm{F}$. The new alignment showed an improvement in control, with a standard deviation of $0.15^{\circ} \mathrm{F}$. Significantly higher improvement is expected in Fischer-Tropsch operations, which involve higher heat effects and reactions that are not equilibrium limited. 


\section{CONCLUSIONS AND RECOMMENDATIONS}

- A fluid dynamic study was successfully completed in a bubble column, gathering significant information at pilot scale. Differential pressure (DP) measurements made to better understand the dynamics of the system worked very well mechanically throughout the run, without the anticipated plugging problems.

- Gas holdup estimates based on DP measurements followed the same trends as those indicated by nuclear density gauge (NDG) readings. However, the NDG-based gas holdups were 15-20\% higher than the DP-based holdups. The difference can be explained if a radial profile for gas holdup exists in the bubble column, with higher holdup in the center. Such a radial profile is expected to be prominent at the high velocities studied in this run.

- Differential pressure data collected using Sandia's high-speed data acquisition system provided insight on flow regime characteristics and bubble size distribution. Standard deviation and a Fourier spectrum analysis of the DP fluctuations suggested that the column was being operated in the churn turbulent regime at most of the velocities considered. Dynamic gas disengagement (DGD) experiments conducted during the run showed DGD curves with a single slope compared to two distinct slopes seen in low-pressure, cold-flow work corresponding to two classes of bubble sizes.

- Operation with a superficial gas velocity of $1.2 \mathrm{ft} / \mathrm{sec}$ was achieved with stable fluid dynamics and catalyst performance. Acceptable oil carry-over from the reactor was observed at this velocity.

- Improvements included for catalyst activation in the design of the Clean Coal III LPMEOH $^{\mathrm{TM}}$ plant at Kingsport, Tennessee, were also confirmed. Successful activations were achieved using dilute $\mathrm{CO}$ as reductant, a faster temperature ramp, and smaller gas flow, compared to the previous "standard" activation procedure.

- An alternate catalyst was demonstrated for $\mathrm{LPMEOH}^{\mathrm{TM}}$. Expected catalyst activity, byproduct formation, and stability were obtained with the alternate catalyst. Overall, the catalyst appeared very comparable to the baseline catalyst. Stable performances were obtained at both high and very low (turndown) velocities.

- Approximately 64,300 gallons of methanol were produced during this demonstration, which will be useful for end-use testing. 


\section{FUTURE PLANS}

It is recommended that the fluid dynamic measurements be continued during subsequent AFDU operations. High-speed data, as well as tracer injections, will be particularly interesting in a Fischer-Tropsch system, where gas contraction is greater and there is a net liquid velocity if external filtration is used.

\section{ACKNOWLEDGMENTS}

The development work described here was supported in part under a contract (No. DE-FC2295PC93052) from the United States Department of Energy. The author would like to thank Edward Heydorn, David Hanauer, and the Air Products operators for efficient operation of the pilot plant. Chris Chen, VanEric Stein, Elizabeth Schaub, and Mina Mazdai provided 24-hour process engineering coverage throughout the operation. We received laboratory data and valuable technical assistance from Bernard Toseland and X. D. Peng, while Dean Chin-Fatt and Robert Staskowski provided analytical support. Kim Shollenberger and Tim O'Hern from Sandia National Laboratory acquired and analyzed the high-speed data from the run.

\section{REFERENCES}

1. Degaleesan S., Dudukovic, M. P., Toseland, B. A. and Bhatt, B. L., "Tracer Studies of the LaPorte AFDU Reactor During Methanol Synthesis," Topical Report prepared for DOE by Washington University in St. Louis and Air Products and Chemicals, Inc., Contract No. DEAC22-95PC95051, September 1996.

2. Bhatt, B. L., Heydorn, E. C., Toseland, B. A., O'Hern, T. J. and Shollenberger, K. A., "Recent Results from the LaPorte Alternative Fuels Development Unit," First Joint Power and Fuel Systems Contractors Conference, Pittsburgh, PA, July 9-11,1996.

3. Degaleesan S., Kumar, S., Wang, Q., Dudukovic, M. P., Toseland, B. A. and Bhatt, B. L., "Progress in Understanding the Fluid Dynamics of Bubble Column Reactors," First Joint Power and Fuels Systems Contractors Conference, Pittsburgh, PA, July 9-11, 1996.

4. Dudukovic, M. P., Devanathan, N. and Holub, R., "Multiphase Reactors: Models and Experimental Verification," Revue De L'Institut Francais Du Petrole, Vol. 46, No. 4, 1991.

5. Bukur, D. B., Patel, S. A. and Matheo, R., "Hydrodynamic Studies in Fischer-Tropsch Derived Waxes in a Bubble Column," Chemical Engineering Communication, Vol. 60, pp. 63-78, 1987.

6. Stein V. E., "Demonstration of a One-Step Slurry-Phase Process for the Co-Production of Methanol and Isobutanol," Topical Report prepared for DOE by Air Products and Chemicals, Inc., Contract No. DE-AC22-91PC90018, June 1996. 
Table 1

\begin{tabular}{|c|c|c|c|c|c|c|c|c|c|}
\hline & & & \multicolumn{7}{|c|}{ FLUID DYNAMIC / METHANOL RUN AT THE LAPORTE AFDU - JUNE 1995} \\
\hline & & & & Reactor & Reactor & & & Inlet & \\
\hline \multirow[t]{2}{*}{ Run No. } & No. of & Comment & Gas Type & Pressure & Temp. & Space Vel. & React. Fd. & Sup. Vel. & Slurry wt\% \\
\hline & Days & & & psia & $\operatorname{deg} \mathbf{F}$ & sL/kg-hr & lbmol/hr & $\mathrm{ft} / \mathrm{sec}$ & oxide \\
\hline & & & & & & & & & \\
\hline \multicolumn{10}{|c|}{ NEW REACTOR (27.20) / BASELINE CATALYST } \\
\hline & 3 & $\begin{array}{c}\text { Dephlegmator Testing, } \\
\text { Carbonyl Burnout }\end{array}$ & $\begin{array}{l}\text { Nitrogen, } \\
\text { Texaco }\end{array}$ & & & & & & \\
\hline AF-A9 & 1 & Kingsport Reduction & $4 \% \mathrm{CO}$ in $\mathrm{N} 2$ & 67 & & 615 & 32.3 & 0.62 & 40 \\
\hline AF-R13.1 & 2 & Base Case & Texaco & 765 & 482 & 7100 & 375 & 0.85 & 46 \\
\hline AF-R13.2 & 3 & Kingsport Design & Kingsport & 750 & 482 & 4000 & 210 & 0.49 & 41 \\
\hline AF-R13.3 & 2 & High Velocity & Kingsport & 735 & 482 & 9100 & 480 & 1.13 & 48 \\
\hline Sub-total & 11 & & & & & & & & \\
\hline \multicolumn{10}{|c|}{ NEW REACTOR (27.20) / ALTERNATE CATALYST } \\
\hline AF-A10 & 1 & Kingsport Reduction & $4 \% \mathrm{CO}$ in N2 & 67 & & 615 & 32.3 & 0.62 & 40 \\
\hline AF-R14.1 & 2 & Base Case & Texaco & 765 & 482 & 7200 & 370 & 0.84 & 44 \\
\hline AF-R14.2 & 3 & Kingsport Design & Kingsport & 750 & 482 & 4000 & 210 & 0.48 & 39 \\
\hline AF-R14.3 & 1.5 & High Velocity & Kingsport & 535 & 482 & 7100 & 365 & 1.18 & 44 \\
\hline AF-R14.4 & 1.5 & & Texaco & 765 & 482 & 4100 & 210 & 0.47 & 41 \\
\hline AF-R14.5 & 1 & Base Case & Texaco & 765 & 482 & 7200 & 370 & 0.83 & 45 \\
\hline AF-R14.6 & 0.8 & Tracer Study & Texaco & 765 & 482 & 7200 & 370 & 0.83 & 45 \\
\hline AF-R14.7 & 1 & Tracer Study & Texaco & 765 & 482 & 4100 & 210 & 0.47 & 41 \\
\hline AF-R14.8 & 1 & Tracer Study & Kingsport & 535 & 482 & 7100 & 365 & 1.18 & 44 \\
\hline AF-R14.9 & 0.2 & Turn-down & Kingsport & 765 & 482 & 1300 & 67 & 0.15 & 44 \\
\hline Sub-total & 13 & & & & & & & & \\
\hline TOTAL & 24 & & & & & & & & \\
\hline
\end{tabular}




\section{Table 2}

\section{Metal Carbonyl Analysis Results}

Nickel Tetracarbonyl: not detected in any samples (lower detection limit is $10 \mathrm{ppbv}$ ).

Iron Pentacarbonyl (ppbv): Averages of 2 injections

\begin{tabular}{|l|c|c|c|}
\hline $\begin{array}{l}\text { Reactor Temp }=482^{\circ} \mathrm{F} \\
\text { Reactor Pressure }=750 \mathrm{psig}\end{array}$ & $\begin{array}{c}\text { Sample Point 3A } \\
\text { Economizer } \\
\text { Product Outlet }\end{array}$ & $\begin{array}{c}\text { Sample Point 4 } \\
\text { Combined Fresh } \\
\text { Feed + Recycle }\end{array}$ & $\begin{array}{c}\text { Sample Point 15 } \\
\text { Inlet to Reactor }\end{array}$ \\
\hline $\begin{array}{l}\text { 5/31/95 16:30-17:30 } \\
\text { Once-through syngas (12 KSCFH) }\end{array}$ & 4 & 8 & 8 \\
\hline $\begin{array}{l}\text { 5/31/95 21:30-22:30 } \\
\text { Once-through syngas (12 KSCFH) }\end{array}$ & 3 & 2 & 3 \\
\hline $\begin{array}{l}\text { 6/1/95 08:30-09:30 } \\
\text { Once-through syngas (12 KSCFH) }\end{array}$ & 4 & 3 & 3 \\
\hline $\begin{array}{l}\text { 6/1/95 11:30-12:00 } \\
\text { Recycle syngas (84 KSCFH) }\end{array}$ & 6 & 4 & 7 \\
\hline $\begin{array}{l}6 / 1 / 95 ~ 15: 30-16: 00 \\
\text { Recycle syngas (84 KSCFH) }\end{array}$ & 7 & 6 & 8 \\
\hline $\begin{array}{l}6 / 1 / 95 ~ 20: 30-21: 00 \\
\text { Recycle syngas (84 KSCFH) }\end{array}$ & 9 & 7 & 10 \\
\hline $\begin{array}{l}6 / 2 / 95 \text { 08:30-09:00 } \\
\text { Recycle syngas (132 KSCFH) }\end{array}$ & 10 & 6 & 10 \\
\hline $\begin{array}{l}6 / 2 / 95 ~ 11: 30-12: 00 \\
\text { Recycle syngas (132 KSCFH) }\end{array}$ & 3 & 3 & 5 \\
\hline
\end{tabular}


Table 3

\begin{tabular}{|c|c|c|c|c|}
\hline \multicolumn{4}{|c|}{ CATALYST PERFORMANCE COMPARISON FOR LPMEOH } & \\
\hline CATALYST & BASELINE & ALTERNATE & BASELINE & ALTERNATE \\
\hline RUN NO. & AF-R13.1B & AF-R14.1B & AF-R13.2B & AF-R14.2B \\
\hline SYNGAS COMPOSITION & TEXACO & TEXACO & KINGSPORT & KINGSPORT \\
\hline SPACE VEL, SL/HR-KG & 7130 & 7200 & 4000 & 4030 \\
\hline PRESSURE, PSIG & 751 & 754 & 735 & 735 \\
\hline TEMPERATURE, DEG F & 484 & 482 & 483 & 483 \\
\hline INLET LINEAR VELOCITY (FT/S) & 0.85 & 0.84 & 0.49 & 0.48 \\
\hline CO CONVERSION TO MEOH (\%) & 15.5 & 16.2 & 49.6 & 48.6 \\
\hline METHANOL PRODUCTION (T/D) & 11.6 & 11.7 & 9.9 & 9.8 \\
\hline SLURRY CONCENTRATION BASED ON NDG (WT\%) & 48.2 & 45.3 & 42 & 39.7 \\
\hline GAS HOLD-UP BASED ON NDG (VOL\%) & 54.7 & 49.9 & 43.1 & 38.1 \\
\hline
\end{tabular}


$\underline{\text { Table } 4}$

\begin{tabular}{|l|c|c|c|c|c|}
\hline \multicolumn{5}{|c|}{ BY-PRODUCT ANALYSIS COMPARISON FOR LPMEOH } & \\
\hline CATALYST & & & & & \\
\hline & BASELINE & ALTERNATE & & BASELINE & ALTERNATE \\
\hline RUN NO. & AF-R13.1B & AF-R14.1B & & AF-R13.2B & AF-R14.2B \\
\hline SYNGAS COMPOSITION & & & & & \\
\hline SPACE VEL, SLHR-KG & TEXACO & TEXACO & & KINGSPORT & KINGSPORT \\
\hline PRESSURE, PSIG & 7000 & 7000 & & 4000 & 4000 \\
\hline TEMPERATURE, DEG F & 750 & 750 & & 735 & 735 \\
\hline & 482 & 482 & & 482 & 482 \\
\hline PRODUCT ANALYSIS, WT\% & & & & & \\
\hline methanol & & & & & \\
\hline ethanol & 96.72 & 96.73 & & 97.31 & 97.42 \\
\hline 1-propanol & 0.89 & 0.91 & & 0.32 & 0.35 \\
\hline iso-propanol & 0.25 & 0.26 & & 0.08 & 0.10 \\
\hline 1-butanol & 0.02 & 0.02 & & 0.01 & 0.00 \\
\hline 2-butanol & 0.17 & 0.17 & & 0.09 & 0.08 \\
\hline iso-butanol & 0.06 & 0.05 & & 0.03 & 0.03 \\
\hline 2-Methyl 1Buoh & 0.06 & 0.05 & & 0.01 & 0.02 \\
\hline 1-pentanol & 0.00 & 0.00 & & 0.00 & 0.00 \\
\hline 2-Methyl 1-Peoh & 0.08 & 0.08 & & 0.03 & 0.03 \\
\hline 1-hexanol & 0.00 & 0.00 & & 0.00 & 0.00 \\
\hline 2-Methyl 1-Isobutyrate & 0.04 & 0.04 & & 0.00 & 0.00 \\
\hline meAc & 0.00 & 0.00 & & 0.00 & 0.00 \\
\hline etAc & 0.20 & 0.22 & & 0.06 & 0.07 \\
\hline meFm & 0.00 & 0.00 & & 0.00 & 0.00 \\
\hline DME & 0.91 & 0.99 & & 0.42 & 0.44 \\
\hline CO2 & 0.00 & 0.00 & & 0.00 & 0.00 \\
\hline water & 0.00 & 0.00 & & 0.00 & 0.00 \\
\hline oil & 0.43 & 0.42 & & 1.46 & 1.30 \\
\hline & 0.19 & 0.06 & & 0.19 & 0.16 \\
\hline Total & & & & & \\
\hline & 100.00 & 100.00 & & 100.00 & 100.00 \\
\hline
\end{tabular}


Table 5

\begin{tabular}{|c|c|c|}
\hline \multicolumn{2}{|c|}{ LPMEOH RESULTS AT HIGH VELOCITY } & \\
\hline CATALYST & BASELINE & ALTERNATE \\
\hline RUN NO. & AF-R13.3B & AF-R14.3 \\
\hline SYNGAS COMPOSITION & KINGSPORT & KINGSPORT \\
\hline SPACE VEL, SLHR-KG & 9110 & 7090 \\
\hline PRESSURE, PSIG & 720 & 521 \\
\hline TEMPERATURE, DEG F & 482 & 482 \\
\hline INLET LINEAR VELOCITY (FT/S) & 1.13 & 1.18 \\
\hline CO CONVERSION TO MEOH (\%) & 39.9 & 33 \\
\hline METHANOL PRODUCTION (T/D) & 18.3 & 11.1 \\
\hline SLURRY CONCENTRATION (WT\%) & 48.9 & 45.6 \\
\hline GAS HOLD-UP (VOL\%) & 55.8 & 50.4 \\
\hline LIMITATION & RECYCLE COMPRESSOR & CO SUPPLY \\
\hline NDG READINGS & HIGH FLUCTUATIONS & HIGH FLUCTUATIONS \\
\hline & STABLE AVERAGE & STABLE AVERAGE \\
\hline OIL LOSS RATE FROM REACTOR & MODERATE & MODERATE \\
\hline REACTOR DESIGN BASIS & KINGSPORT: & $0.64 \mathrm{FT} / \mathrm{SEC}$ \\
\hline & RECENT COMMERCIAL DESIGNS: & $0.80-0.85 \mathrm{FT} / \mathrm{SEC}$ \\
\hline & NEW COMMERCIAL DESIGN: & $\sim 1.0 \mathrm{FT} / \mathrm{SEC}$ \\
\hline
\end{tabular}


Table 6

RUN TIME TABLE

FLUID DYNAMIC / METHANOL RUN

ACTIVATION (\#A9) START

3-Jun-95 $14: 30$

RUN (\#AF-R13) START

4-Jun-95 12:00

WIH BASELINE CATALYST

TIME

RUN NO. AVG TIME

START START

HRS

$\mathrm{R} 13.1 \mathrm{~A}$

R13.1B

R13.2A

R13.2B

$\mathrm{R} 13.3 \mathrm{~A}$

R13.3B

20
38.5
80
102
136
150.5

DATE

TIME

FLUID DYNAMIC / METHANOL RUN

WITH ALTERNATE CATALYST

\begin{tabular}{|ccc|ccc|c|} 
& \multicolumn{1}{c}{ HRS } & \multicolumn{3}{c|}{ HRS } & HRS \\
\hline 4-Jun & $23: 00$ & 11 & 5-Jun & $17: 00$ & 29 & 18 \\
5-Jun & $17: 00$ & 29 & 6-Jun & $12: 00$ & 48 & 19 \\
7-Jun & $11: 00$ & 71 & 8-Jun & $5: 00$ & 89 & 18 \\
8-Jun & $5: 00$ & 89 & 9-Jun & $7: 00$ & 115 & 26 \\
9-Jun & $19: 00$ & 127 & 10-Jun & $13: 00$ & 145 & 18 \\
10-Jun & $13: 00$ & 145 & 11-Jun & $0: 00$ & 156 & 11 \\
\hline
\end{tabular}

\begin{tabular}{|c|c|c|c|c|c|c|c|c|}
\hline \multirow{2}{*}{\multicolumn{4}{|c|}{$\begin{array}{l}\text { FLUID DYNAMIC / METHANOL RUN } \\
\text { WITH ALTERNATE CATALYST }\end{array}$}} & \multirow{2}{*}{\multicolumn{3}{|c|}{$\begin{array}{l}\text { ACTIVATION (\#A10) START } \\
\text { RUN (\#AF-R14) START }\end{array}$}} & \multirow{3}{*}{$\begin{array}{c}12-\text { Jun-95 } \\
13 \text {-Jun-95 } \\
\text { TIME } \\
\text { ON-STR, } \\
\text { HRS }\end{array}$} & \multirow{3}{*}{$\begin{array}{c}14: 45 \\
11: 00 \\
\text { TIME } \\
\text { PERIOD, } \\
\text { HRS }\end{array}$} \\
\hline & & & & & & & & \\
\hline RUN NO. & $\begin{array}{c}\text { AVG TIME } \\
\text { ON-STR, } \\
\text { HRS }\end{array}$ & $\begin{array}{l}\text { START } \\
\text { DATE }\end{array}$ & $\begin{array}{l}\text { START } \\
\text { TIME }\end{array}$ & $\begin{array}{c}\text { TIME } \\
\text { ON-STR, } \\
\text { HRS }\end{array}$ & $\begin{array}{l}\text { END } \\
\text { DATE }\end{array}$ & $\begin{array}{l}\text { END } \\
\text { TIME }\end{array}$ & & \\
\hline $\mathrm{R} 14.1 \mathrm{~A}$ & 16 & 13-Jun & $18: 00$ & 7 & 14-Jun & $12: 00$ & 25 & 18 \\
\hline $\mathrm{R} 14.1 \mathrm{~B}$ & 37 & 14-Jun & $12: 00$ & 25 & 15-Jun & $12: 00$ & 49 & 24 \\
\hline $\mathrm{R} 14.2 \mathrm{~A}$ & 71 & 15-Jun & $19: 00$ & 56 & 17-Jun & $1: 00$ & 86 & 30 \\
\hline $\mathrm{R} 14.2 \mathrm{~B}$ & 99.5 & 17-Jun & $1: 00$ & 86 & 18-Jun & $4: 00$ & 113 & 27 \\
\hline $\mathrm{R} 14.3$ & 138 & 18-Jun & $18: 00$ & 127 & 19-Jun & $16: 00$ & 149 & 22 \\
\hline R14.4 & 172 & 19-Jun & $23: 00$ & 156 & 21-Jun & $7: 00$ & 188 & 32 \\
\hline $\mathrm{R} 14.5$ & 202 & 21-Jun & $10: 00$ & 191 & 22-Jun & $8: 00$ & 213 & 22 \\
\hline
\end{tabular}

TIMETABI.XLS 
Iable 7

\begin{tabular}{|c|c|c|c|c|c|c|}
\hline & \multicolumn{4}{|c|}{ Gas Hold-up Comparison (vol\%) } & & \\
\hline \multirow[t]{3}{*}{ Run No. } & Time & From & From & $\%$ & From & Expected \\
\hline & On-stream & NDG & DP & Difference & Shut-down & from \\
\hline & Hrs & & & & Test & Correlations \\
\hline \multicolumn{7}{|c|}{ Gas Hold-up with Baseline Catalyst } \\
\hline R13.1A & 20 & 50.5 & 43.8 & 13.3 & & \\
\hline R13.1B & 38.5 & 54.7 & 48 & 12.2 & & 43 \\
\hline R13.2A & 80 & 42.3 & 36.3 & 14.2 & & \\
\hline R13.2B & 102 & 43.1 & 36.5 & 15.3 & 32.9 & 34.7 \\
\hline R13.3A & 136 & 55.7 & 45.1 & 19.0 & & \\
\hline \multirow[t]{2}{*}{ R13.3B } & 150.5 & 55.8 & 44.7 & 19.9 & & 41.8 \\
\hline & & & & 15.7 & avg & \\
\hline \multicolumn{7}{|c|}{ Gas Hold-up with Alternate Catalyst } \\
\hline R14.1A & 16 & 49.6 & 39.8 & 19.8 & & \\
\hline R14.1B & 37 & 49.9 & 39.8 & 20.2 & 38.9 & 41.1 \\
\hline R14.2A & 71 & 37.5 & 28.3 & 24.5 & & \\
\hline R14.2B & 99.5 & 38.1 & 28.6 & 24.9 & & 34.1 \\
\hline R14.3 & 138 & 50.4 & 36.6 & 27.4 & 36.6 & 35.3 \\
\hline R14.4 & 172 & 42.9 & 33.3 & 22.4 & & 37.8 \\
\hline \multirow[t]{2}{*}{ R14.5 } & 202 & 50.8 & 39.8 & 21.7 & & 41.1 \\
\hline & & & & 23.2 & avg & \\
\hline
\end{tabular}




\section{Figure 1}

LAPORTE AFDU OXYGENATES HIGH PRESSURE REACTOR DIFFERENTIAL PRESSURE TRANSMITTER \& TRACER STUDY DETECTOR POSITIONS

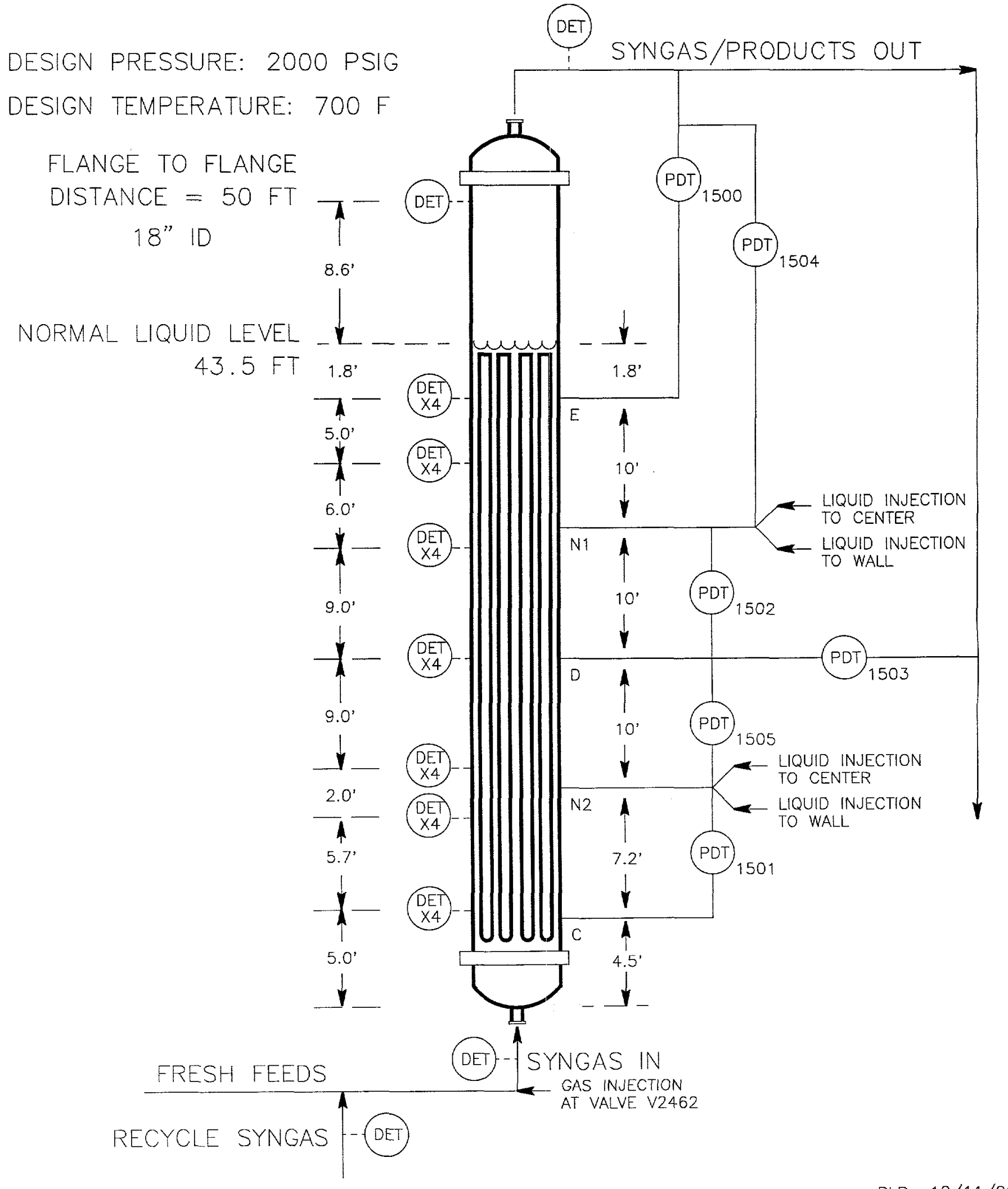




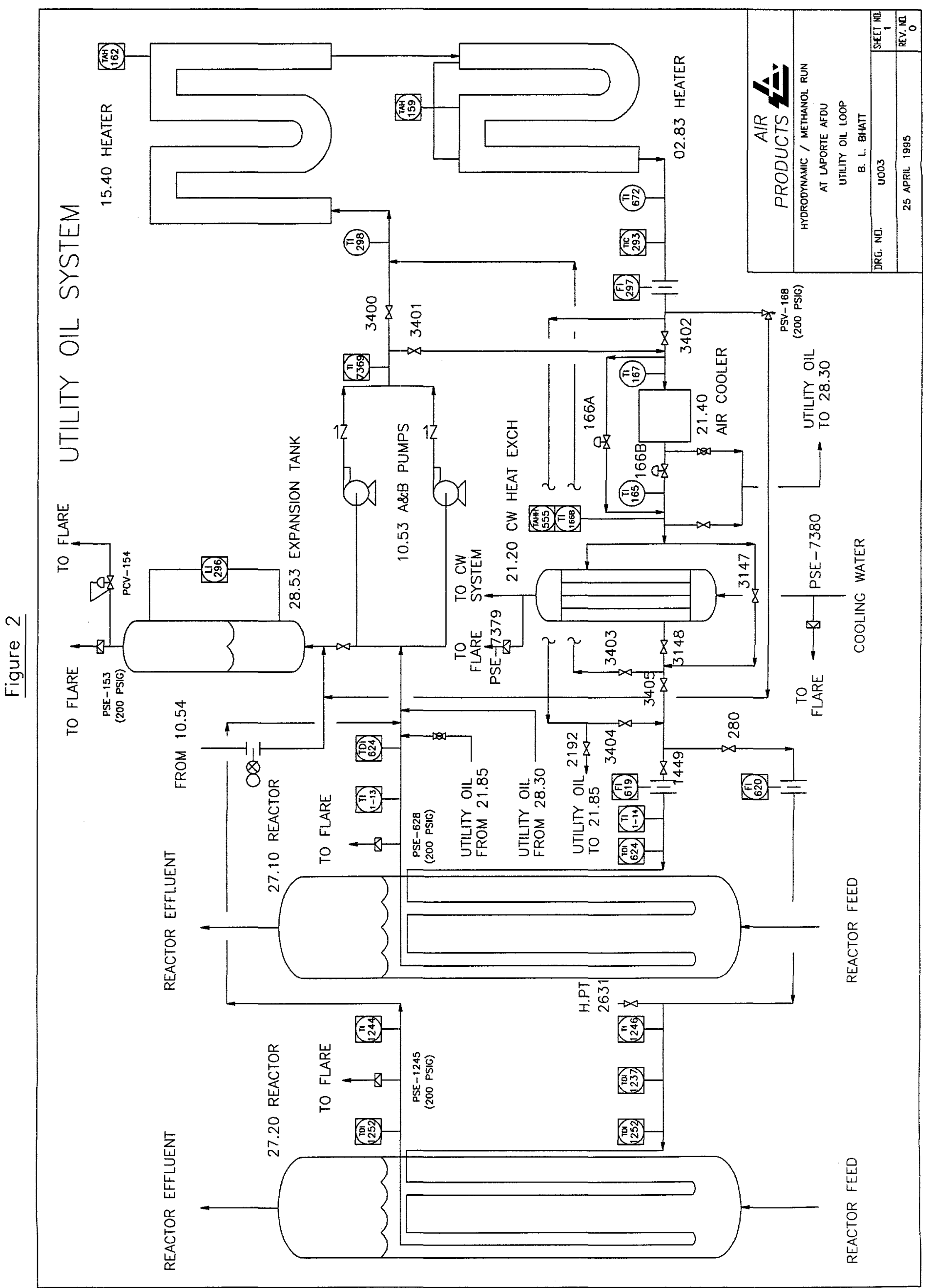




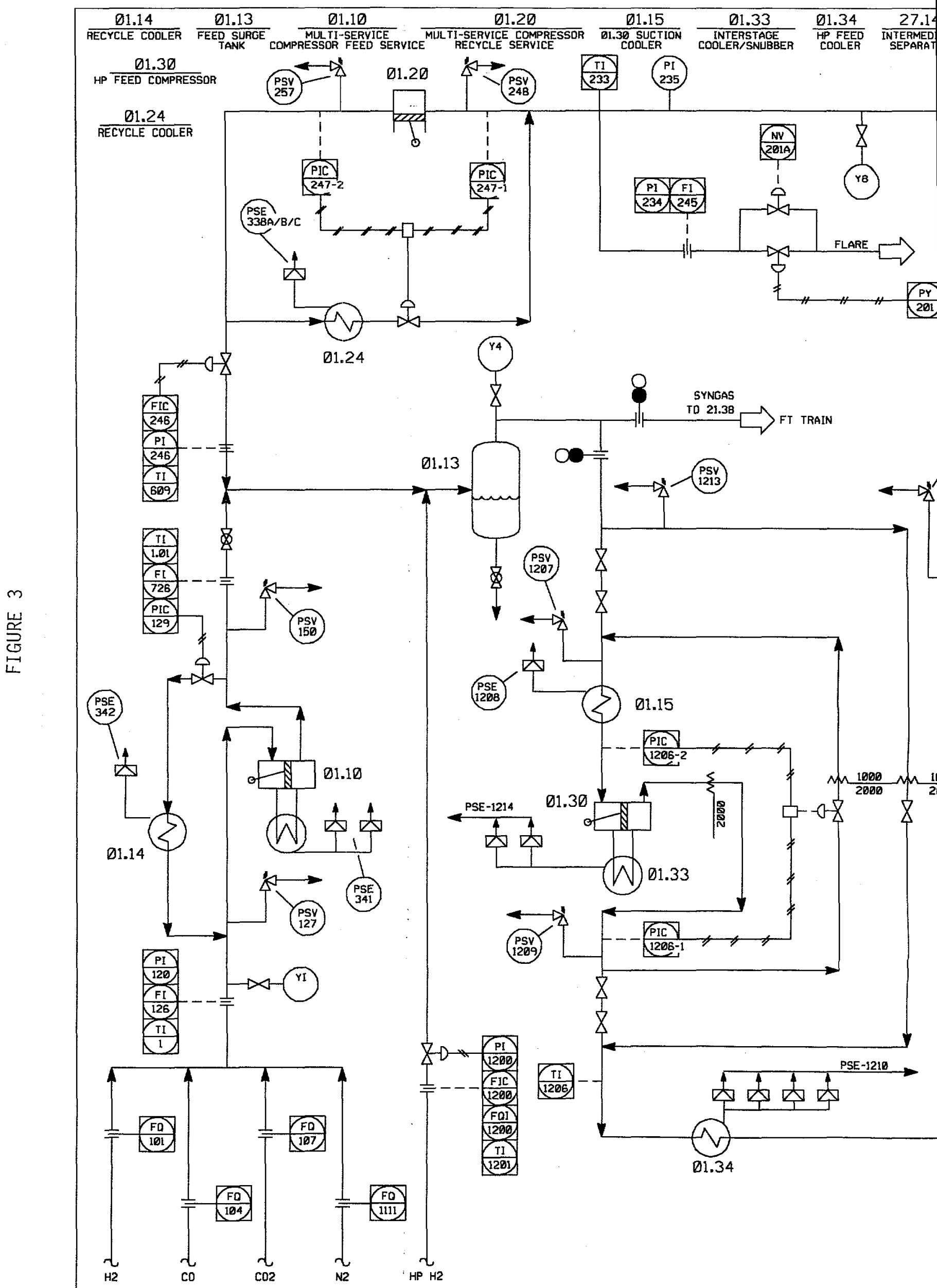




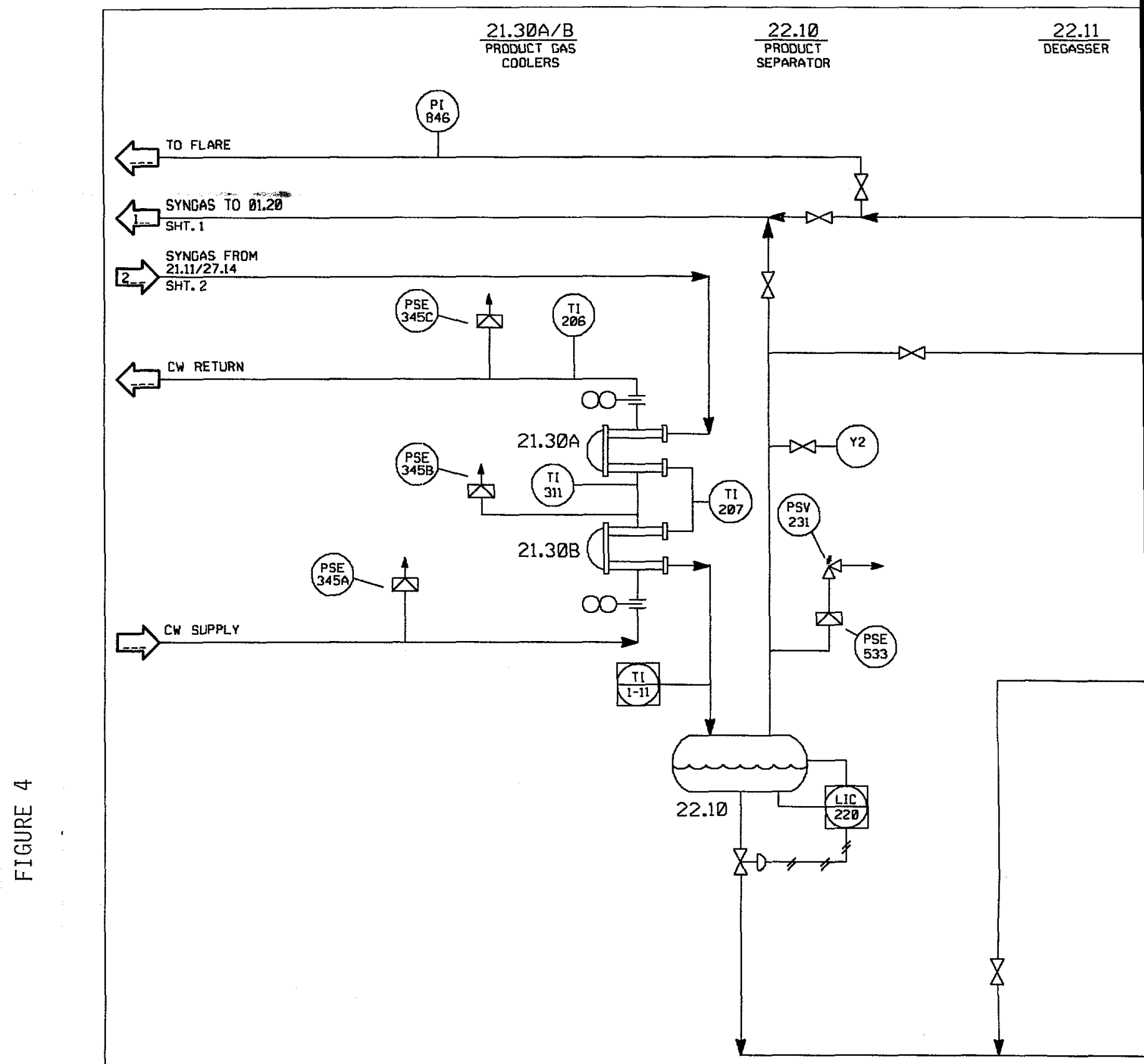




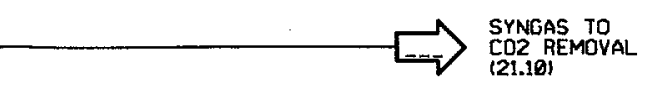

METHANOL DRAIN FRDM CO2 REMDVAL SYSTEM

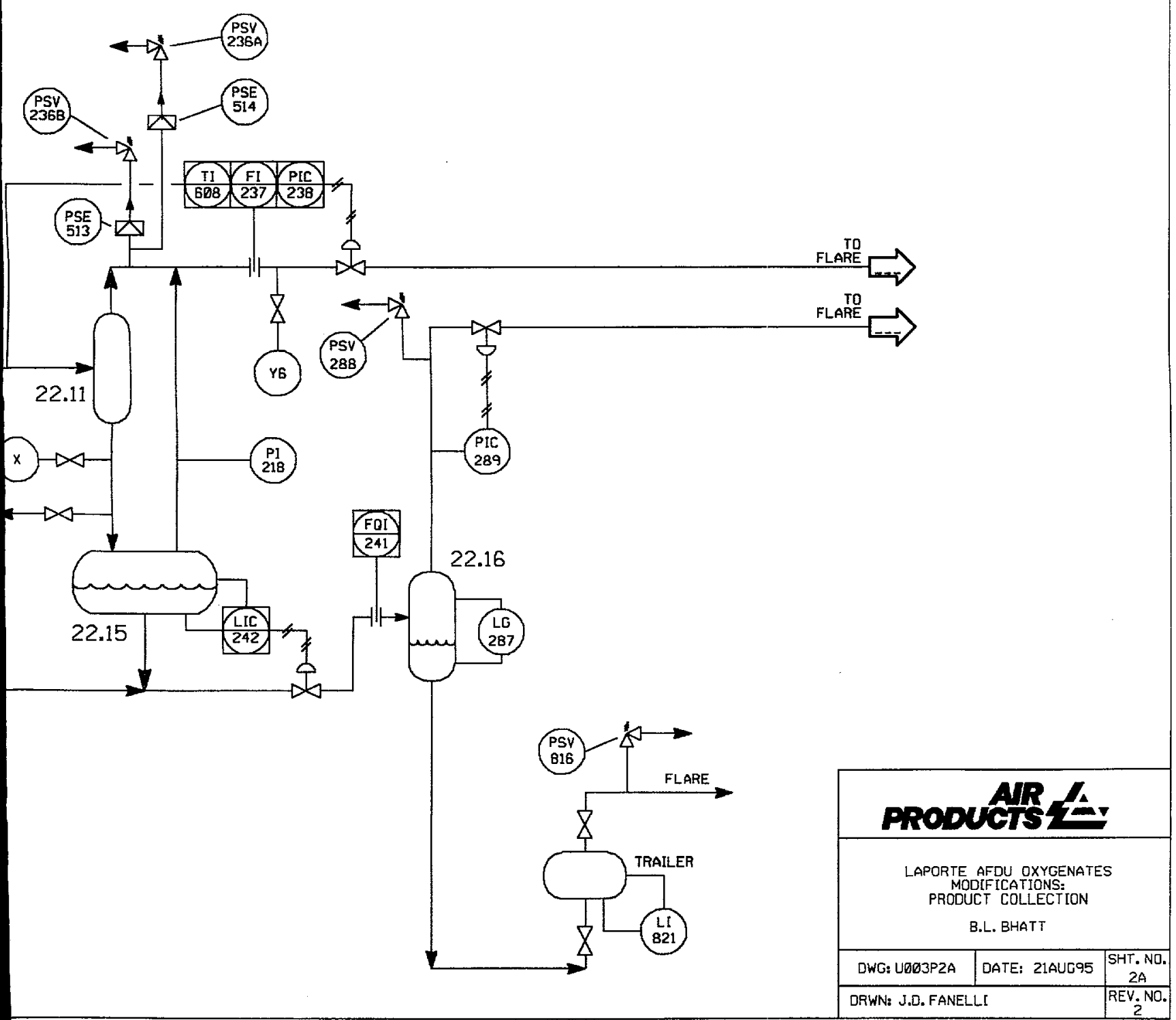




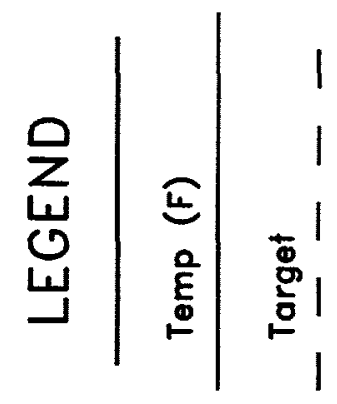

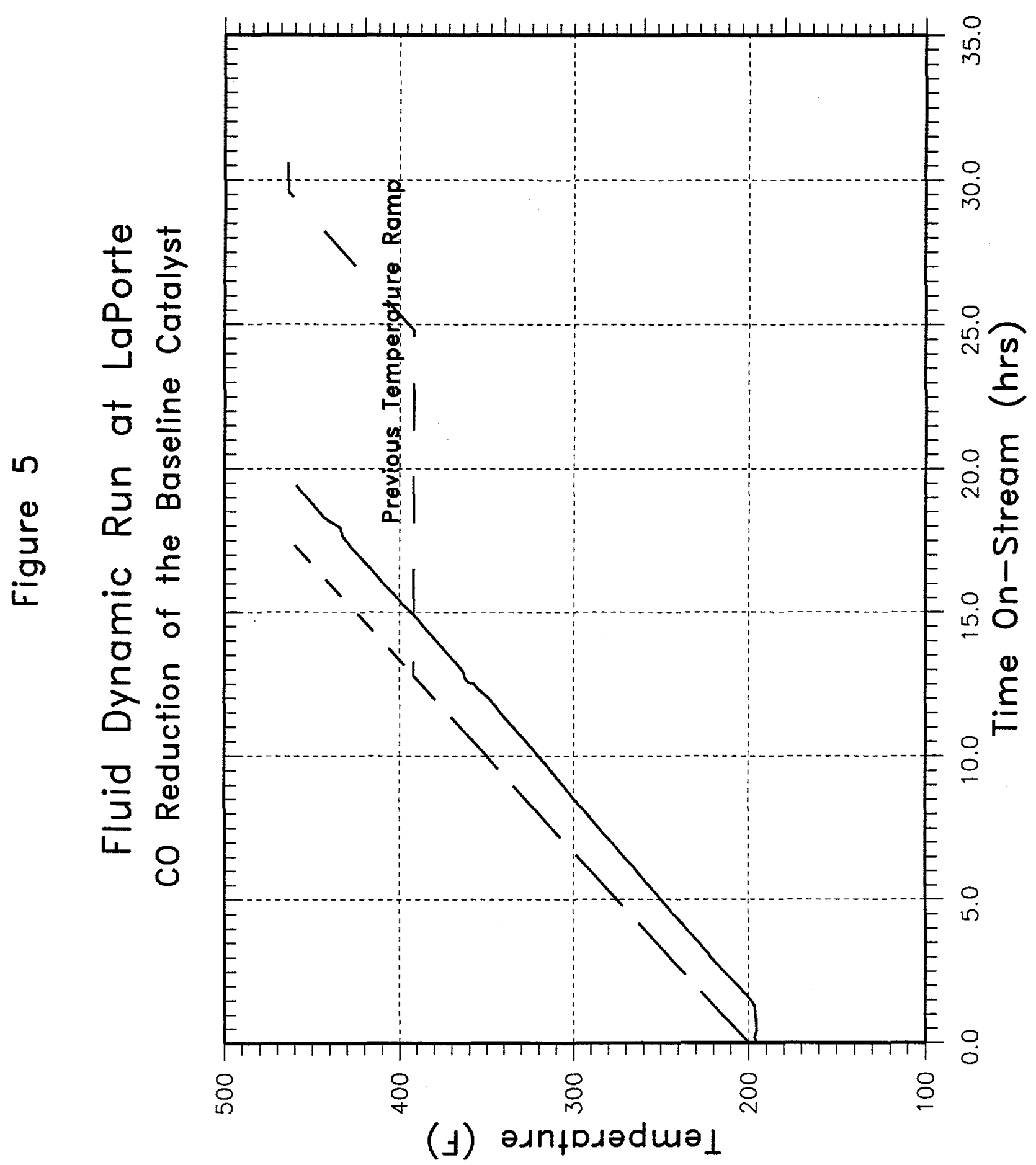




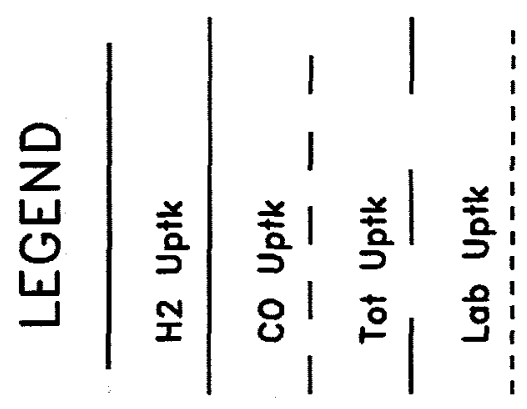

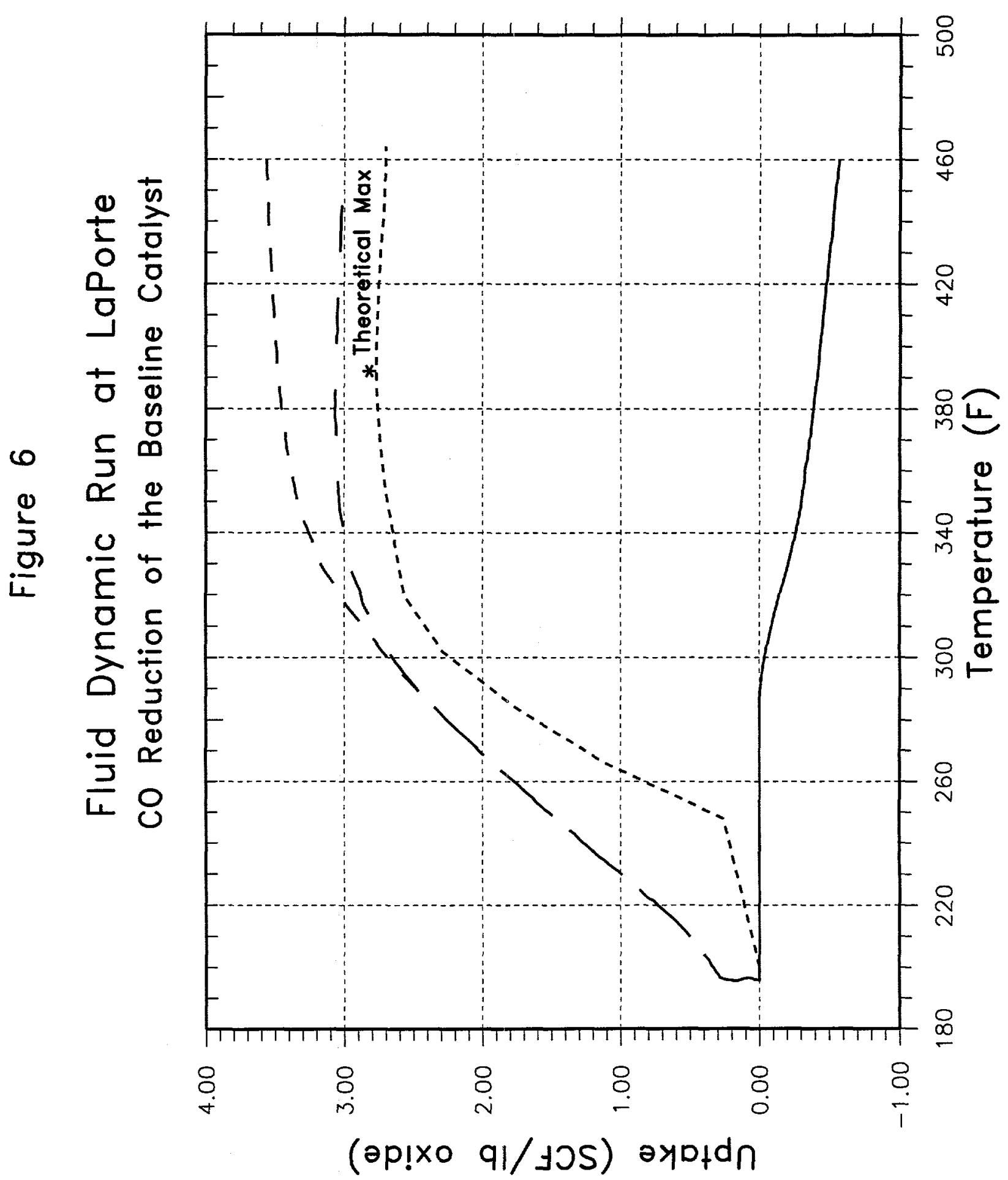




\section{FIGURE 7}

Fluid Dynamic Run at LaPorte CO Reduction of the Alternate Catalyst

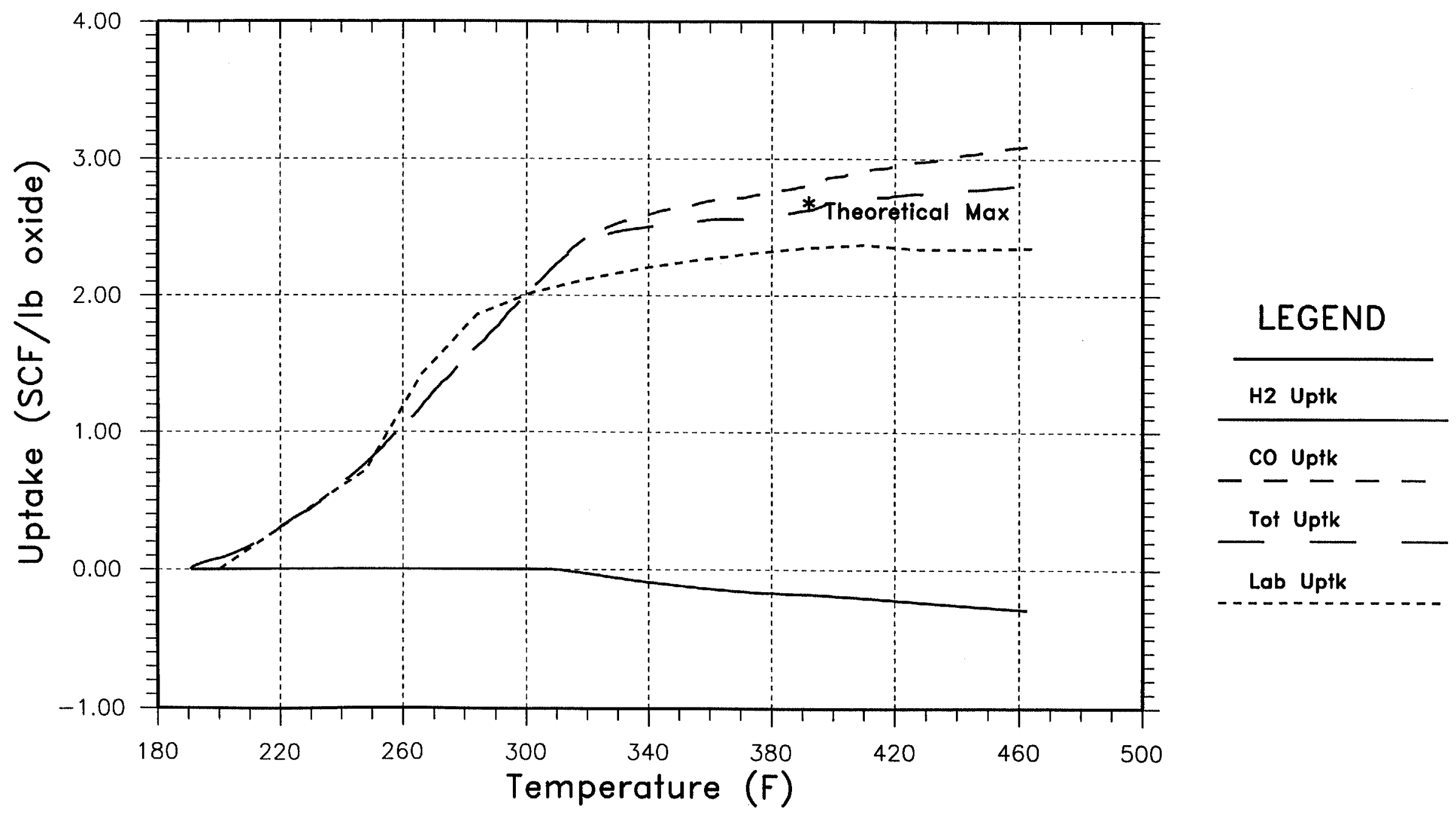




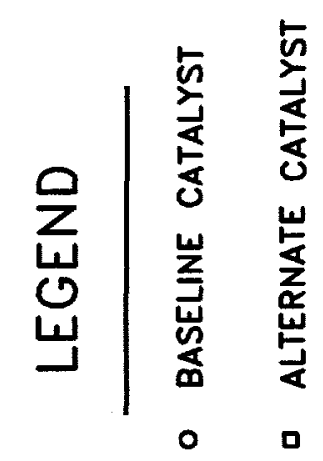

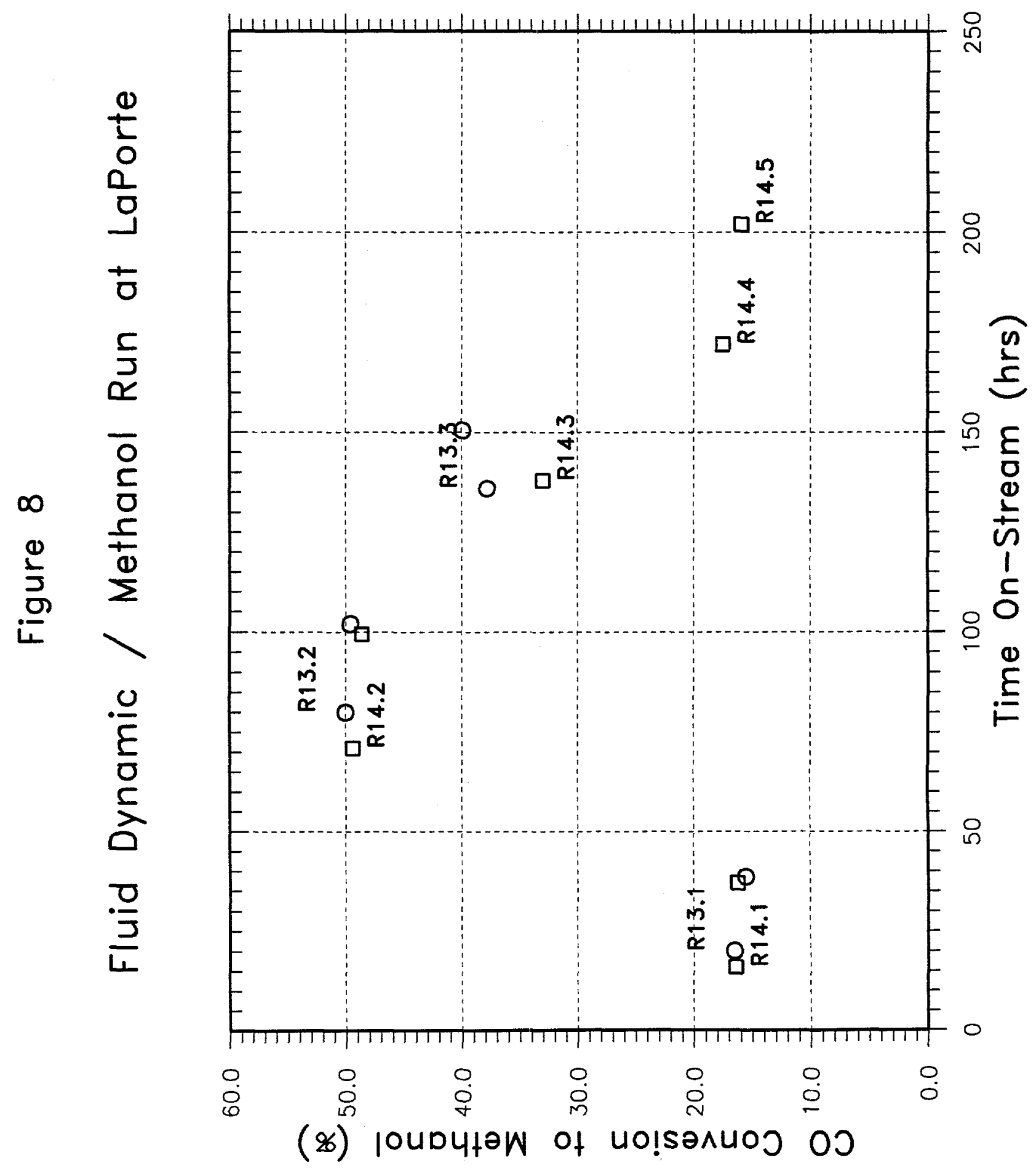


Figure 9

Fluid Dynamic / Methanol Run at LaPorte

Baseline Catalyst (Run No. AF-R13)

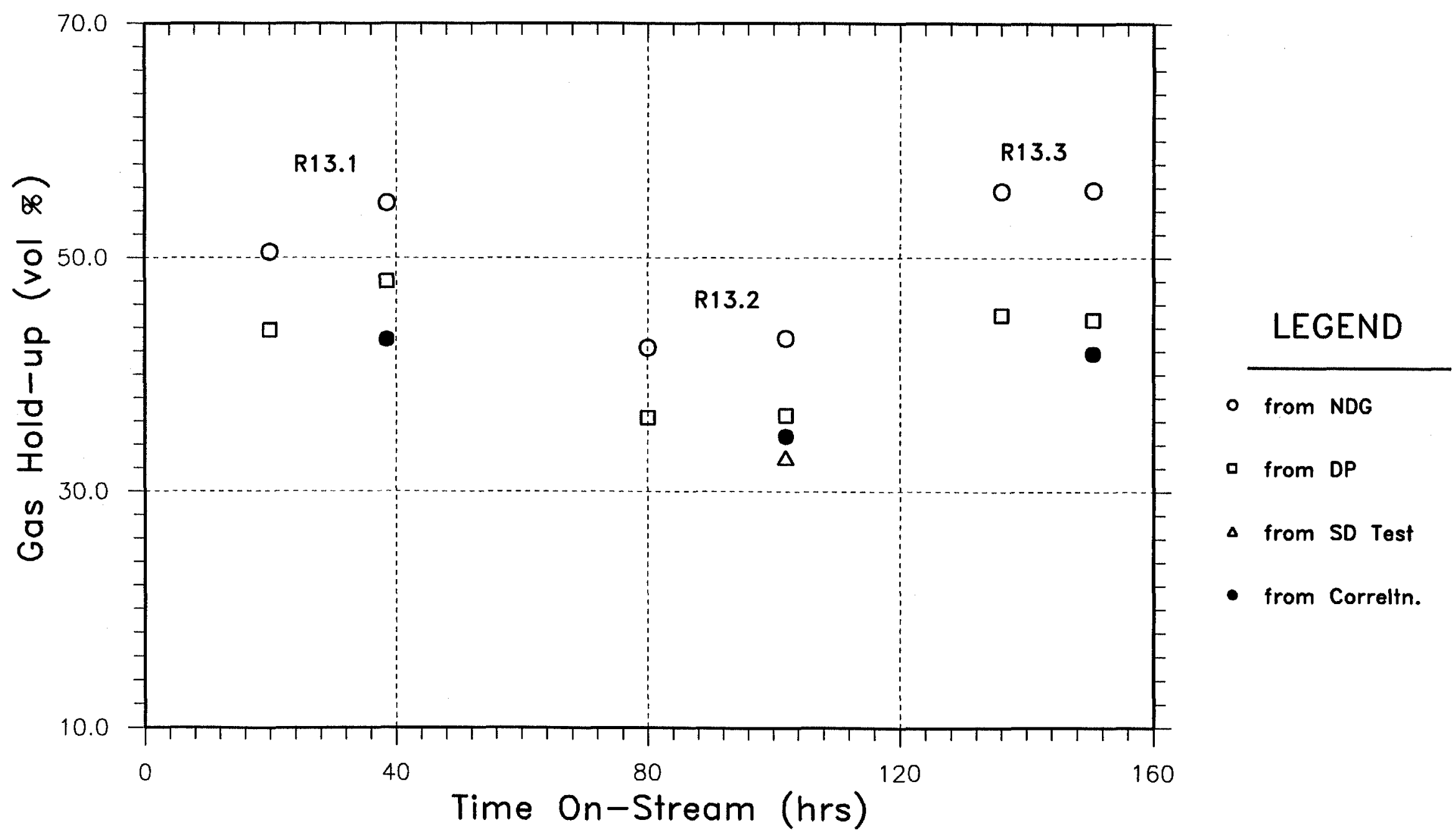




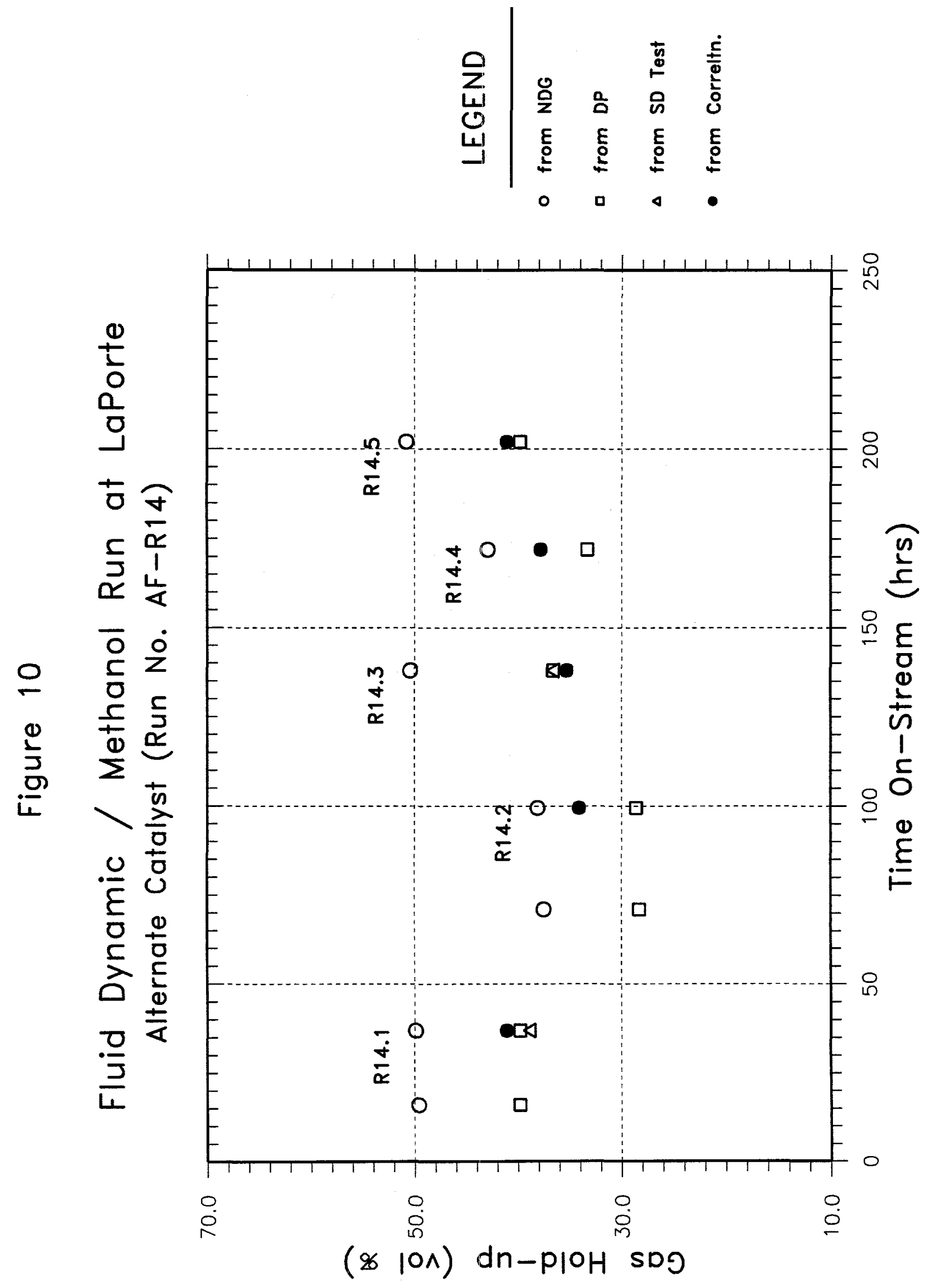




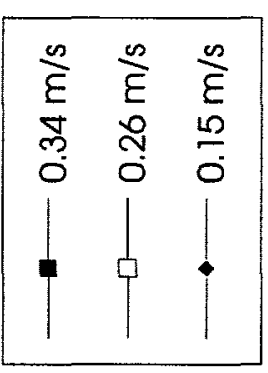

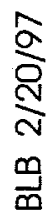

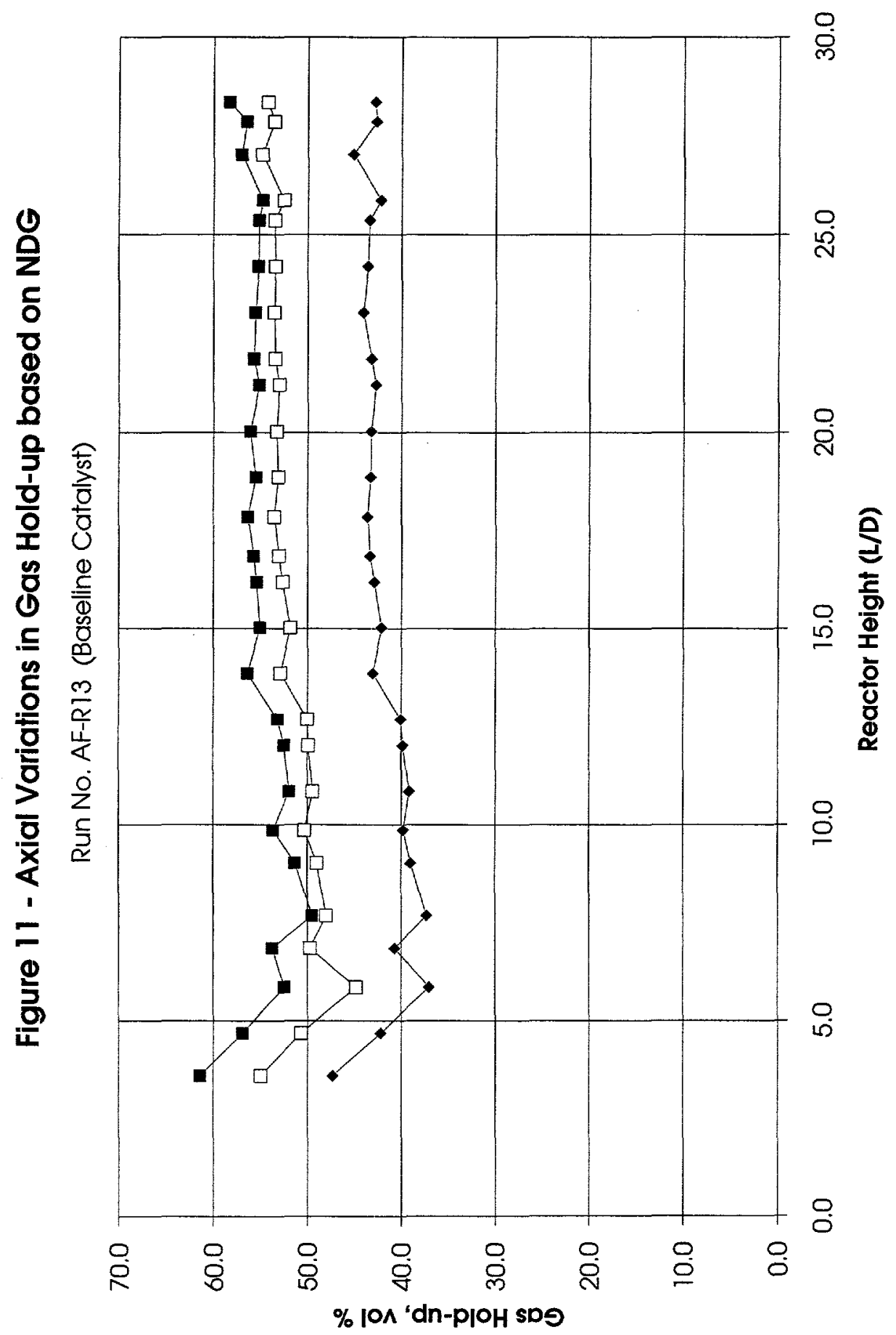


Figure 12 - Axial Variations in Gas Hold-up based on NDG

Run No. AF-R14 (Alternate Catalyst)

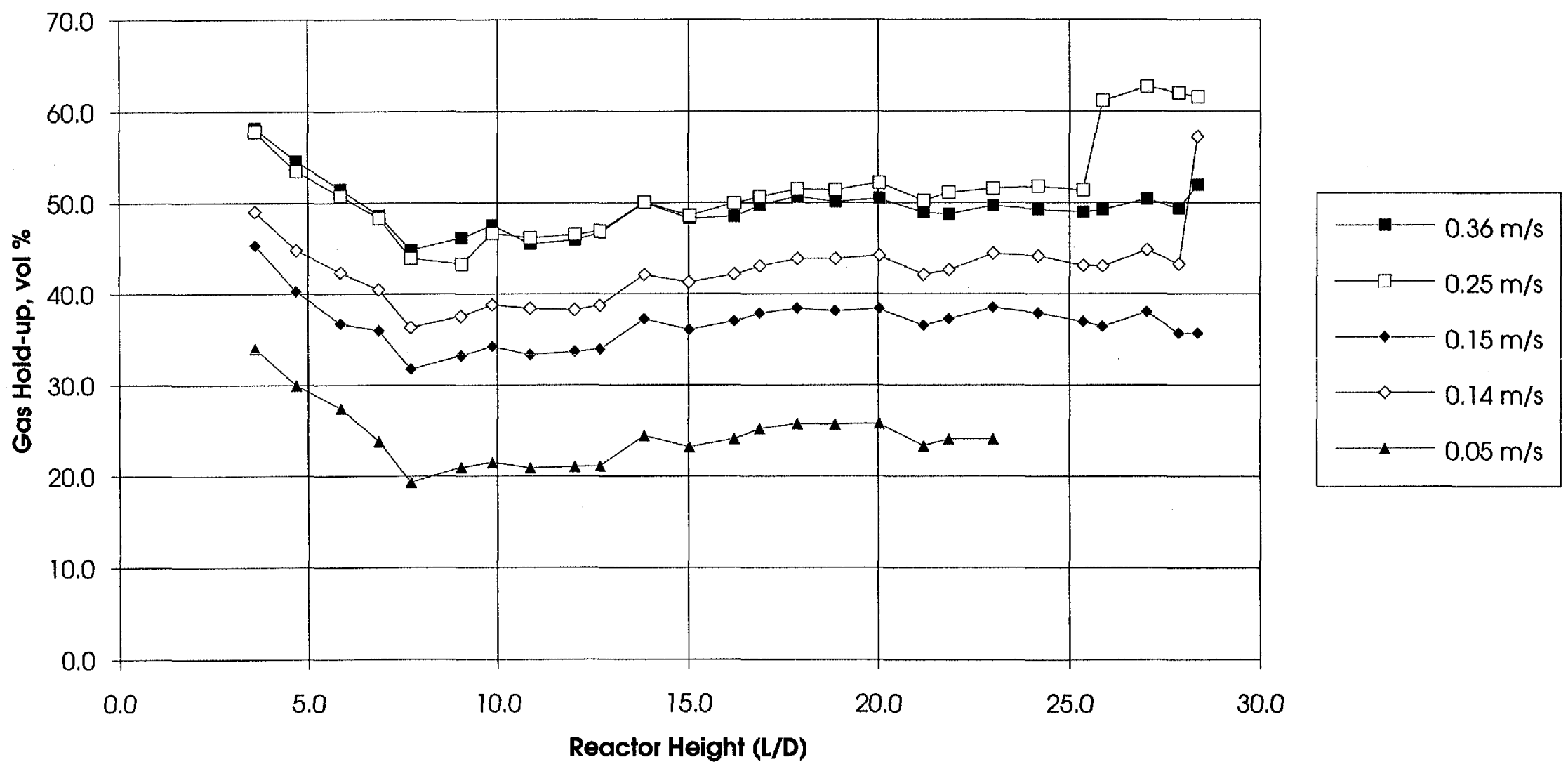


Figure 13 - Utility Oil System Heater/Cooler Realignment

(Run No. 13.2B)

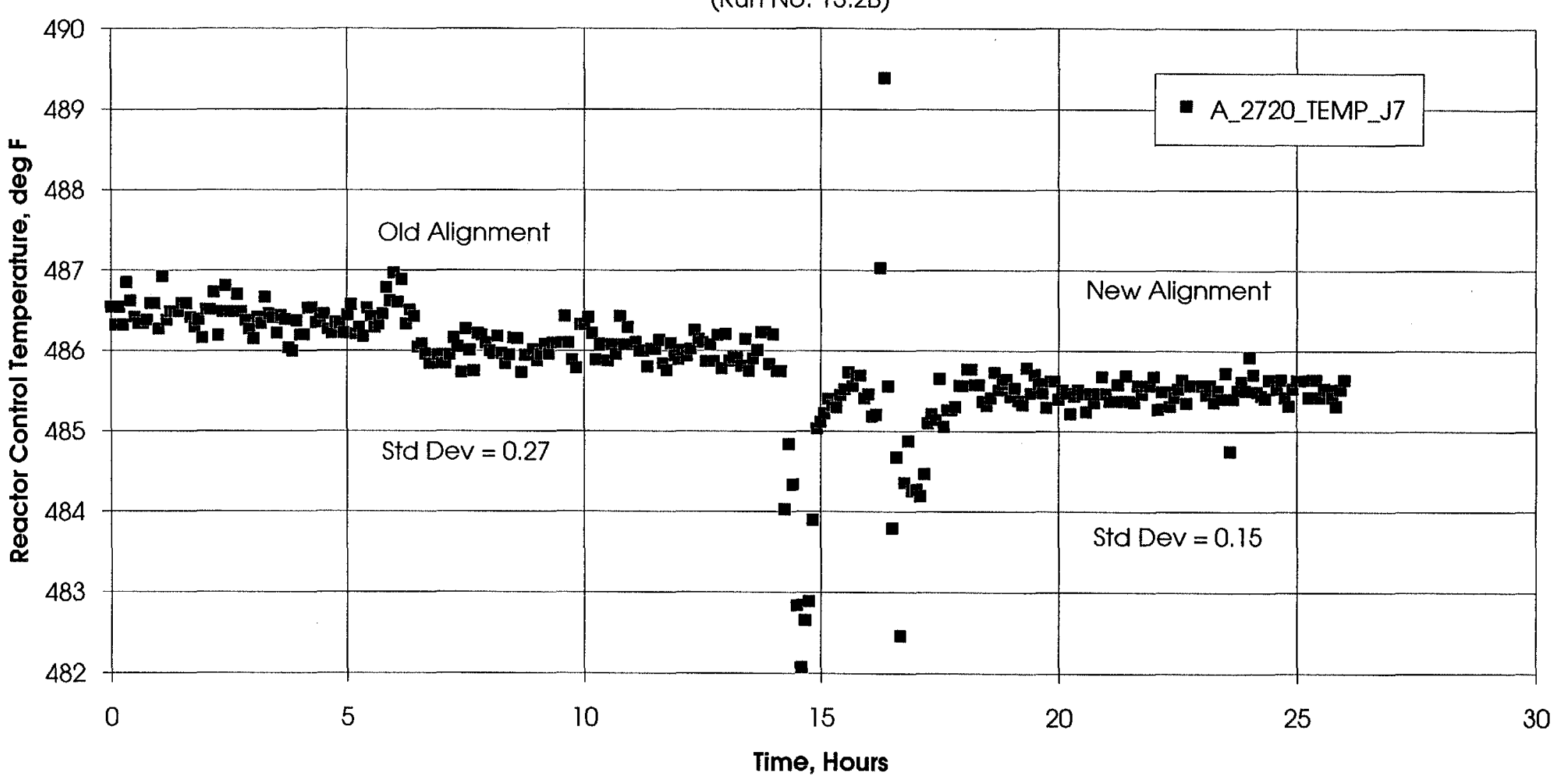




\section{APPENDIX A}

Improved Catalyst Activation Tests in Laboratory 


\section{Improved Catalyst Activation Tests in Laboratory}

One of the objectives of the methanol/fluid dynamics run in the AFDU at LaPorte was to demonstrate new technology proposed for Kingsport. To simplify the process equipment and procedure for catalyst reduction in the Liquid Phase Methanol plant design for Eastman, a new reduction procedure for the standard baseline catalyst was investigated in the lab. The goal of the new reduction procedure was to eliminate $\mathrm{H}_{2} \mathrm{O}$ production during reduction by using $\mathrm{H}_{2}$-free reduction feed gas, decrease the time required for reduction, and simplify the temperature ramping procedure. To this end, reduction of the baseline catalyst was carried out in the lab autoclave using $\mathrm{CO}$ in $\mathrm{N}_{2}$ feed gas $\left(\mathrm{H}_{2}\right.$-free). The activity and life of the catalyst were also tested.

\section{Background}

The current design for the Liquid Phase Methanol plant at the Eastman Chemical Company complex includes a catalyst reduction vessel from which slurry containing fresh, reduced catalyst will be supplied to the process. The heretofore established reduction procedure for the baseline catalyst involves an empirically established temperature ramping protocol and the use of $\mathrm{H}_{2}$-containing reduction gases (either $2 \%$ $\mathrm{H}_{2}$ in $\mathrm{N}_{2}$ or $4 \%$ Texaco syngas in $\mathrm{N}_{2}$ ). The use of $\mathrm{H}_{2}$ as a reductant results in the production of $\mathrm{H}_{2} \mathrm{O}$ via $\mathrm{CuO}$ reduction:

$$
\mathrm{H}_{2}+\mathrm{CuO} \rightarrow \mathrm{Cu}+\mathrm{H}_{2} \mathrm{O}
$$

However, $\mathrm{H}_{2} \mathrm{O}$ production during reduction complicates downstream processing since slurry mineral oil vaporized and entrained during reduction and $\mathrm{H}_{2} \mathrm{O}$ may form two phases and the $\mathrm{H}_{2} \mathrm{O}$ produced must be processed as waste water.

To investigate the possibility of simplifying the process equipment and operating procedure for catalyst reduction, a new reduction procedure was investigated in the $300 \mathrm{cc} \mathrm{lab}$ autoclave. The goal of the new reduction procedure is to minimize water production during reduction, decrease the time required for reduction, and simplify the temperature ramping procedure. In this experiment, a nominal $2 \% \mathrm{CO}$ in $\mathrm{N}_{2}$ reduction gas was used. Thus, $\mathrm{CuO}$ is reduced by $\mathrm{CO}$ :

$$
\mathrm{CO}+\mathrm{CuO} \rightarrow \mathrm{Cu}+\mathrm{CO}_{2}
$$

which eliminates $\mathrm{H}_{2} \mathrm{O}$ as a direct product of reduction.

\section{Experimental}

The time-temperature ramp was simplified. The previously established procedure involved a $12 \mathrm{hr}$ temperature hold at $200^{\circ} \mathrm{C}$ during the overall increase from $100^{\circ} \mathrm{C}$ to $240^{\circ} \mathrm{C}$. For the present experiment, the temperature was increased from $100^{\circ} \mathrm{C}$ to $240^{\circ} \mathrm{C}$ 
at $10^{\circ} \mathrm{C} / \mathrm{hr}$ continuously, thereby saving $12 \mathrm{hr}$ in the reduction procedure. A feed flow rate of 1500 std.lit./kg-hr and a pressure of 50 psig were chosen.

\section{Reduction with $2 \% \mathrm{CO}-98 \% \mathrm{~N}_{2}$}

Figure A.1 shows the time temperature profile used for this experiment.

\section{Figure A.1. Temperature Ramp Used for Catalyst Reduction}

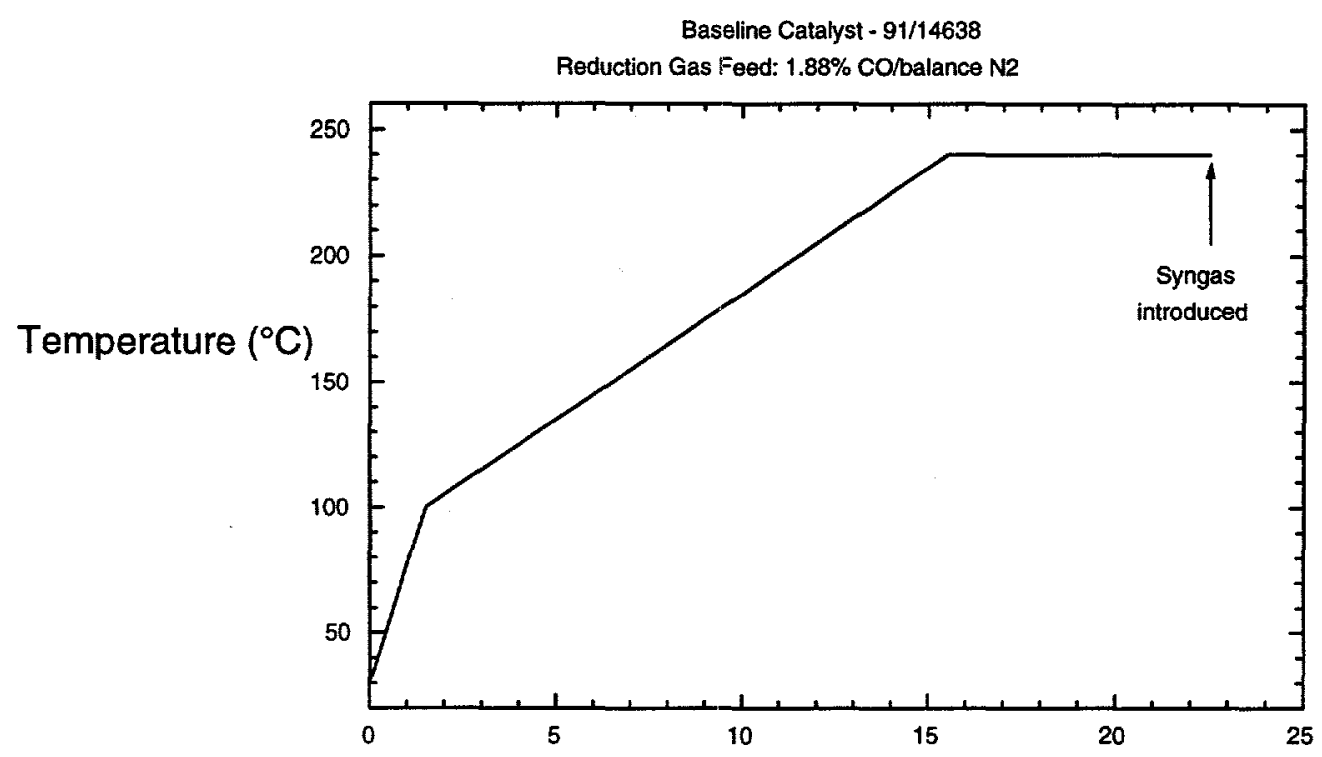

Syngas introduction was delayed for several hours after $240^{\circ} \mathrm{C}$ was reached so that the feed could be switched during normal working hours. As shown below, very little occurs during the $240^{\circ} \mathrm{C}$ hold. In practice, the feed could be switched as soon as the reactor temperature reaches $240^{\circ} \mathrm{C}$.

The reactor effluent concentrations of $\mathrm{CO}, \mathrm{CO}_{2}, \mathrm{H}_{2} \mathrm{O}$, and $\mathrm{H}_{2}$ during reduction were obtained by $\mathrm{GC}$. The $\mathrm{GC}$ was calibrated for $\mathrm{H}_{2} \mathrm{O}$ using a controlled temperature and pressure $\mathrm{H}_{2} \mathrm{O}$ saturator. For low concentrations, a sub- $0^{\circ} \mathrm{C}$ condenser (freezer) was used downstream of the $\mathrm{H}_{2} \mathrm{O}$ saturator. Water concentration was calculated from the vapor pressure of liquid or solid $\mathrm{H}_{2} \mathrm{O}$ at the saturator or freezer temperature. The $\mathrm{GC}$ response was slightly non-linear, necessitating the use of a calibration curve. Quantitation accuracy for $\mathrm{H}_{2} \mathrm{O}$ was $\pm 10 \%$ (relative) for $\mathrm{H}_{2} \mathrm{O}$ concentrations greater than 0.1 mol\%, but the detection limit was about $0.025 \mathrm{~mol} \%$.

Figure A.2 shows the reactor effluent concentrations of $\mathrm{CO}, \mathrm{CO}_{2}, \mathrm{H}_{2} \mathrm{O}$, and $\mathrm{H}_{2}$ during reduction plotted as a function of the reduction temperature. 
Figure A.2. Reactor Exit Concentration versus Reduction Temperature

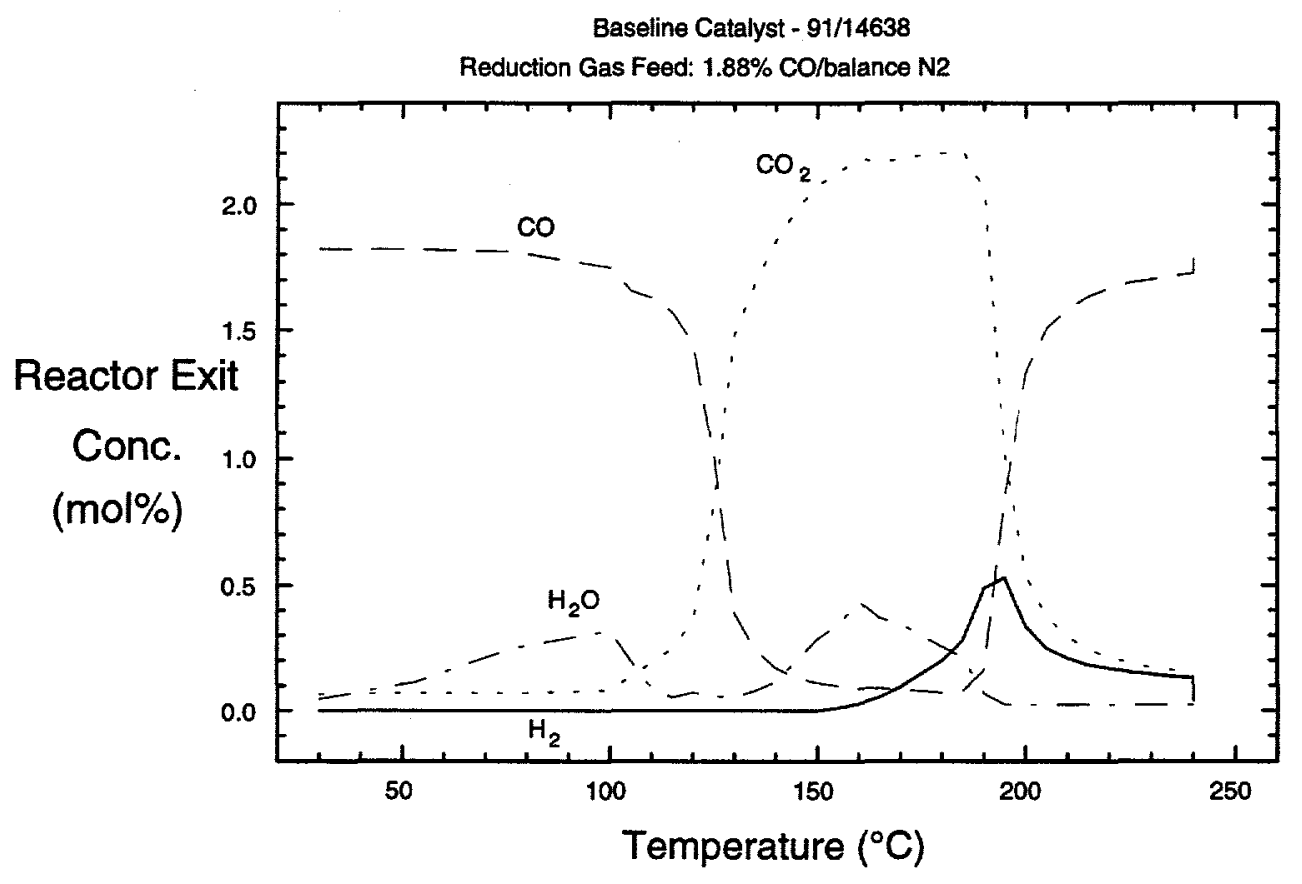

Clearly, $\mathrm{CO}$ is consumed, while $\mathrm{CO}_{2}, \mathrm{H}_{2} \mathrm{O}$, and $\mathrm{H}_{2}$ are produced during reduction.

Figure A.3 shows the cumulative consumption of $\mathrm{CO}$ and the cumulative production of $\mathrm{CO}_{2}, \mathrm{H}_{2} \mathrm{O}$, and $\mathrm{H}_{2}$ versus reduction temperature.

Figure A.3. Cumulative Consumption/Production versus Reduction Temperature

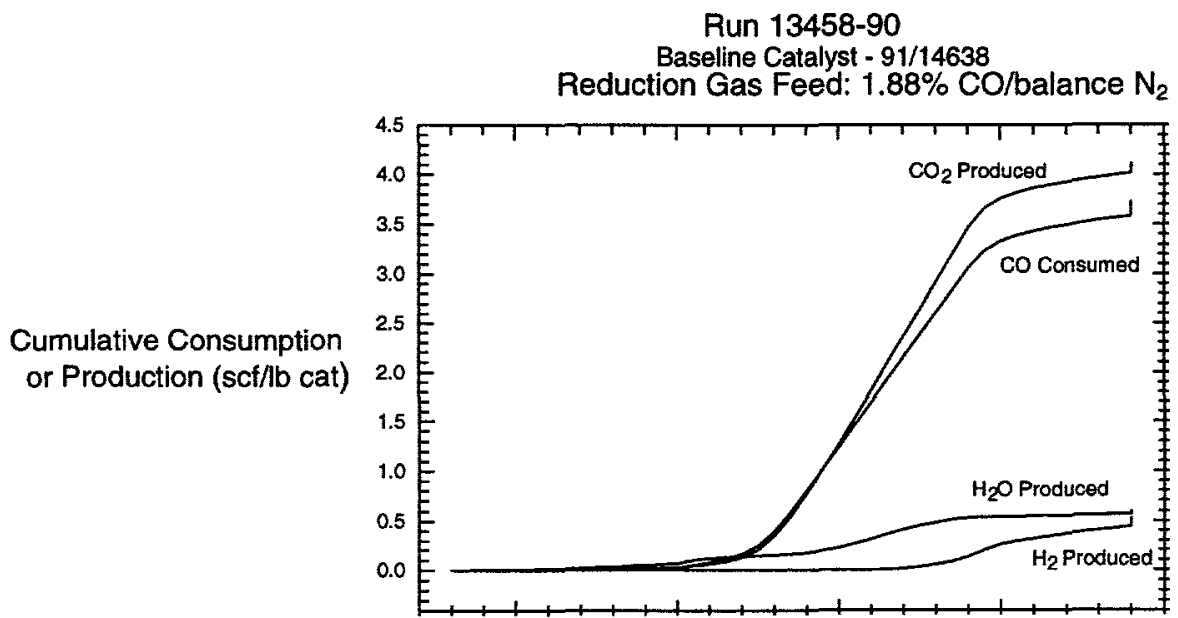

The use of the $\mathrm{CO} / \mathrm{N}_{2}$ feed gas did not completely eliminate $\mathrm{H}_{2} \mathrm{O}$ production during reduction. Approximately $0.55 \mathrm{scf}$ of $\mathrm{H}_{2} \mathrm{O} / \mathrm{lb}$ of as-received catalyst was produced during reduction. This detection of unexpected $\mathrm{H}_{2} \mathrm{O}$ was examined in detail. 
The presence of two peaks in the water concentration profile in Figure A.2 suggests that $\mathrm{H}_{2} \mathrm{O}$ is derived from two different sources during reduction. The low temperature peak probably corresponds to the loss of physically adsorbed $\mathrm{H}_{2} \mathrm{O}$ that has been retained after calcination or adsorbed during handling after calcination. The second peak is probably produced from decomposition of the "hydroxy-carbonate" precursor that constitutes the as-received catalyst. This hydroxy-carbonate precursor eliminates hydroxide groups as $\mathrm{H}_{2} \mathrm{O}$ during heat-up.

The $\mathrm{H}_{2}$ produced in the later stage of reduction results from $\mathrm{H}_{2} \mathrm{O}$ reacting with $\mathrm{CO}$ via the water-gas shift reaction:

$$
\mathrm{CO}+\mathrm{H}_{2} \mathrm{O} \leftrightarrow \mathrm{H}_{2}+\mathrm{CO}_{2} .
$$

Thermodynamic equilibrium for the exothermic shift reaction lies very far to the right for the temperature range of reduction, thereby representing a possible "sink" for $\mathrm{H}_{2} \mathrm{O}$ during reduction. The equilibrium constant, $\mathrm{Kp}$, ranges from 3600 at $100^{\circ} \mathrm{C}$ to 105 at $240^{\circ} \mathrm{C}$. However, the data show that the shift reaction was far from equilibrium at any point during reduction up to $190^{\circ} \mathrm{C}$. At temperatures greater than $190^{\circ} \mathrm{C}$, the $\mathrm{H}_{2} \mathrm{O}$ concentration was below the detection limit, so it was impossible to determine whether the shift reaction was close to equilibrium.

Comparison of the present results with results from a "standard" reduction using $4 \%$ syngas in $\mathrm{N}_{2}$, for which a slower temperature ramp was also used, reveals corroborating evidence. Figure A.4 shows the cumulative consumption of $\mathrm{CO}$ and $\mathrm{H}_{2} \mathrm{CH}_{2}$ is first consumed and then produced during reduction with syngas) and the cumulative production of $\mathrm{CO}_{2}$ and $\mathrm{H}_{2} \mathrm{O}$.

Figure A.4. Cumulative Consumption/Production versus Temperature for Reduction Using $4 \%$ Syngas in $\mathbf{N}_{2}$

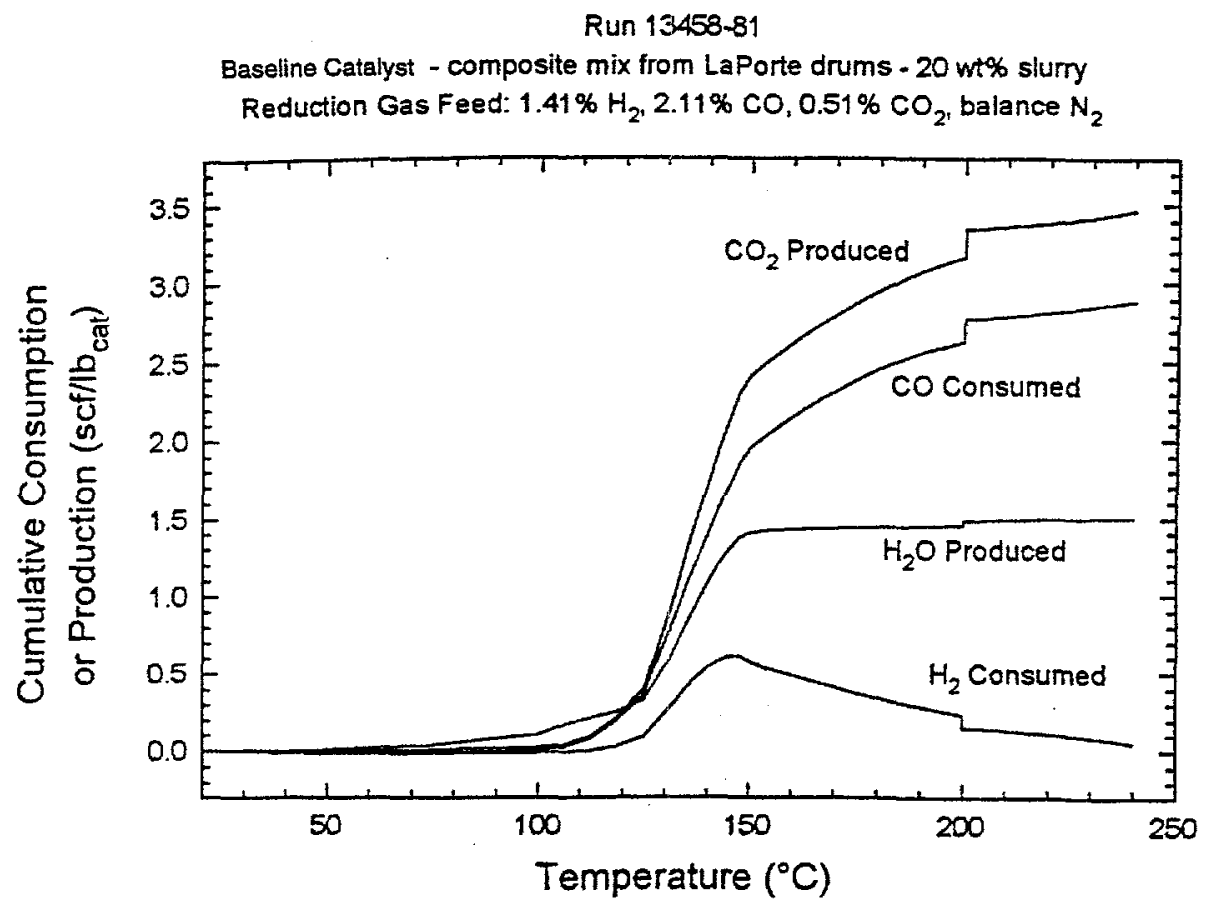


As expected, the $\mathrm{H}_{2} \mathrm{O}$ produced for the $\mathrm{H}_{2}$-containing reduction feed gas is higher: $1.5 \mathrm{scf}$ of $\mathrm{H}_{2} \mathrm{O} / \mathrm{lb}$ versus $0.55 \mathrm{scf}$ of $\mathrm{H}_{2} \mathrm{O} / \mathrm{hb}$ for the $2 \% \mathrm{CO} / \mathrm{N}_{2}$ reduction gas. Again, the shift reaction is far from equilibrium for data points where the $\mathrm{H}_{2} \mathrm{O}$ concentration was above the detection limit.

\section{Activity of CO-Reduced ( $2 \% \mathrm{CO}$ in $\mathrm{N}_{2}$ )}

The catalyst activity after reduction using $2 \% \mathrm{CO} / \mathrm{N}_{2}$ was measured at $250^{\circ} \mathrm{C}$ and 750 psig using Texaco syngas feed $\left(35 \% \mathrm{H}_{2} / 51 \% \mathrm{CO} / 13 \% \mathrm{CO}_{2} / 1 \% \mathrm{~N}_{2}\right)$ at GHSVs of 5,000 and 10,000 std.lit./kg-hr. The expected performance and the results for the activity tests after reduction using $2 \% \mathrm{CO} / \mathrm{N}_{2}$ are shown in Figure A.5.

\section{Figure A.5. Performance of Catalyst After Reduction Using $2 \% \mathrm{CO}$ in $\mathrm{N}_{2}$ Run 13458-90 \\ $250^{\circ} \mathrm{C}, 750 \mathrm{psig}$, Texaco Gas}

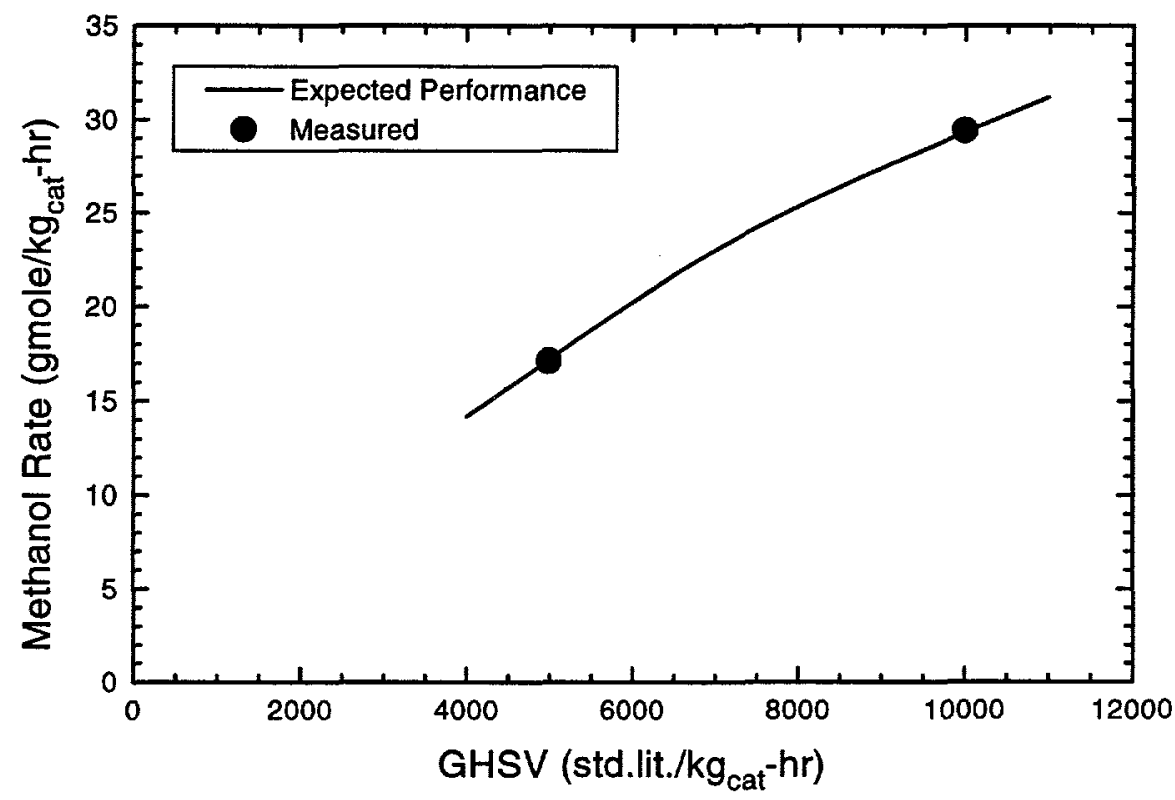

The expected performance curve was established by previous lab data for the baseline catalyst after reduction in $4 \%$ syngas in $\mathrm{N}_{2}$ or $2 \% \mathrm{H}_{2}$ in $\mathrm{N}_{2}$ using slower temperature ramps. Clearly, reduction using $2 \% \mathrm{CO} / \mathrm{N}_{2}$ and the faster temperature ramp produced a catalyst with the same performance as that obtained using the $\mathrm{H}_{2}$-containing reduction gases.

\section{Reduction and Performance Using 4\% CO (Balance $\mathrm{N}_{2}$ )}

$\mathrm{H}_{2} \mathrm{O}$ production during reduction was not entirely eliminated but reduced by $63 \%$ compared to reduction by $4 \%$ syngas in $\mathrm{N}_{2}$ (contains $\mathrm{H}_{2}$ ). Even though the $2 \% \mathrm{CO}$ reduction gas was $\mathrm{H}_{2}$-free, $\mathrm{H}_{2} \mathrm{O}$ was still produced from thermal desorption of physically adsorbed $\mathrm{H}_{2} \mathrm{O}$ and dehydroxylation of the hydroxy-carbonate catalyst precursor. Also 
evident in this experiment was that the $\mathrm{CO}$ concentration was nearly zero during a portion of the temperature ramp, indicating almost complete consumption of the reductant.

In an attempt to avoid the complete consumption of reductant and to further reduce the production of $\mathrm{H}_{2} \mathrm{O}$ during reduction, in situ reduction was done in the lab autoclave using a feed gas with a higher $\mathrm{CO}$ content $\left(4 \% \mathrm{CO}\right.$ in $\mathrm{N}_{2}$ ). The hypothesis was that the higher $\mathrm{CO}$ concentration may drive the water-gas shift reaction, $\mathrm{CO}+\mathrm{H}_{2} \mathrm{O}=\mathrm{CO}_{2}+\mathrm{H}_{2}$, to the right, thereby reducing $\mathrm{H}_{2} \mathrm{O}$ production during reduction. Moreover, the use of higher $\mathrm{CO}$ concentration may avoid complete consumption of reductant, a situation that has an unknown, but possibly deleterious, effect on catalyst activation.

In situ reduction of the baseline catalyst was carried out using the $300 \mathrm{cc}$ autoclave system. The temperature ramp, pressure, and feed flow rate were the same as those used for the $2 \% \mathrm{CO}$ in $\mathrm{N}_{2}$ reduction experiment. Figure A.6 compares the $\mathrm{CO}$ uptake and reactor exit $\mathrm{CO}$ concentration as a function of temperature for reduction using $2 \% \mathrm{CO}$ and $4 \% \mathrm{CO}$. The final consumption of $\mathrm{CO}$ is slightly higher for the $4 \% \mathrm{CO}$ case, but probably not significantly different within the accuracy of the measurements. Also, the rate of $\mathrm{CO}$ consumption is faster for the $4 \% \mathrm{CO}$ case, indicating a positive dependence of reduction rate on $\mathrm{CO}$ concentration. Note also that the lowest reactor exit $\mathrm{CO}$ concentration for the $4 \% \mathrm{CO}$ feed case dropped to a minimum of $1 \mathrm{~mol} \%$, in contrast to the $2 \% \mathrm{CO}$ feed case in which the reactor exit $\mathrm{CO}$ concentration fell nearly to zero.

\section{Figure A.6. The Effect of CO Feed Concentration on CO Consumption and Reactor Exit CO Concentration}
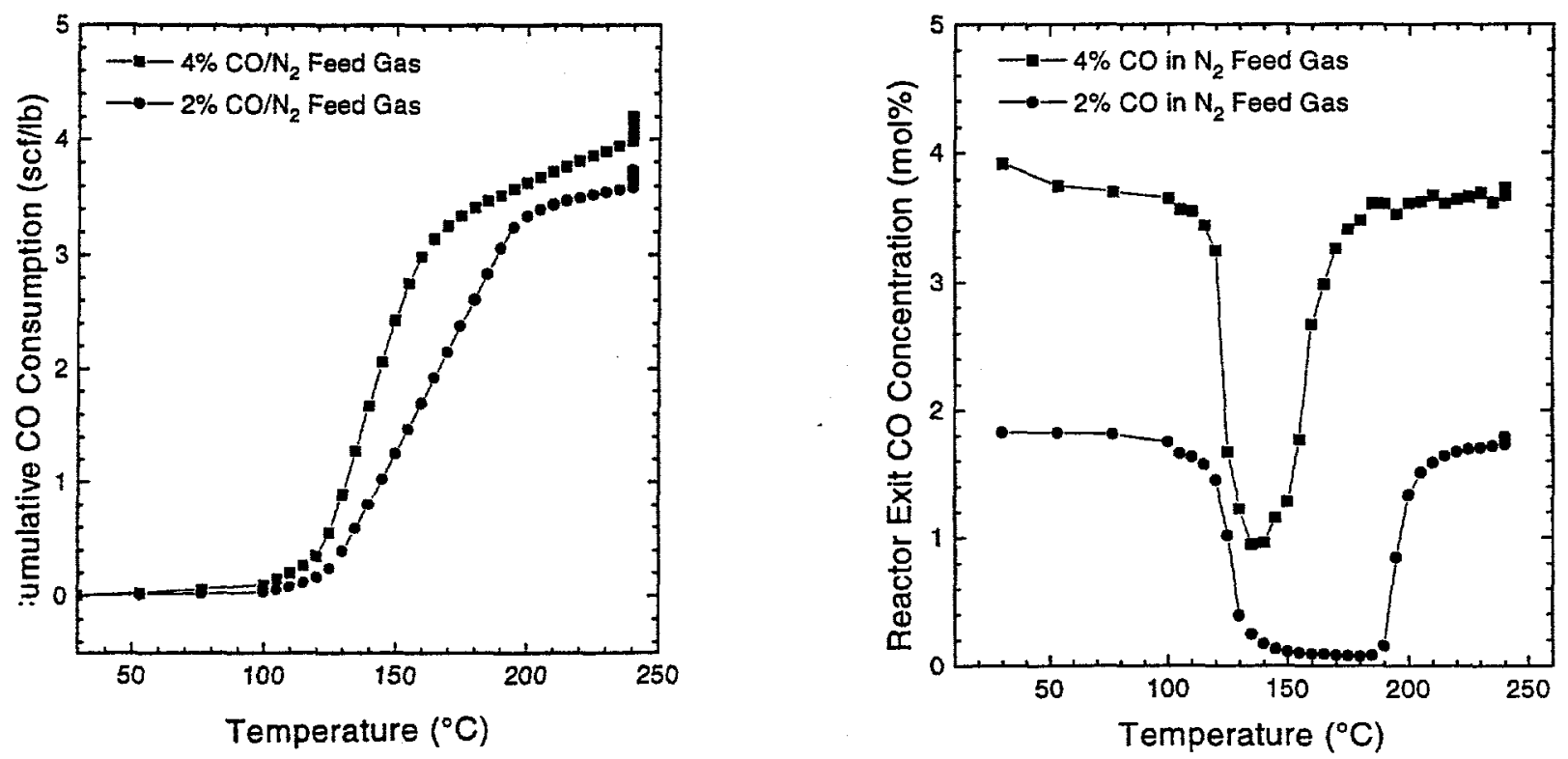

The fact that the $\mathrm{CO}$ concentration in the reactor was higher for $4 \% \mathrm{CO}$ reduction apparently had no effect on the $\mathrm{H}_{2} \mathrm{O}$ produced. The cumulative $\mathrm{H}_{2} \mathrm{O}$ produced for the 
$4 \% \mathrm{CO}$ reduction was estimated to be $0.65 \mathrm{scf} / \mathrm{b}$, which is comparable (within the experimental accuracy of the GC measurements) to the $0.55 \mathrm{scf} / \mathrm{lb}$ measured for the $2 \% \mathrm{CO}$ reduction. Of course, these values are much lower than the $1.5 \mathrm{scf} / \mathrm{b}$ measured for reduction using $4 \%$ Texaco gas in $\mathrm{N}_{2}$. Evidently, the higher reactor $\mathrm{CO}$ concentration did not have a measurable effect on $\mathrm{H}_{2} \mathrm{O}$ conversion via the water-gas shift reaction.

Reduction with $4 \%$ CO resulted in a catalyst with the same methanol synthesis activity as that obtained after reduction using the standard $\mathrm{H}_{2}$-containing reduction gases.

Figure A.7 shows the measured performance after reduction with $4 \% \mathrm{CO}$ and the expected performance curve after reduction using previously established reduction procedures and $\mathrm{H}_{2}$-containing reduction gases. Clearly, the performance of the catalyst after the new reduction procedure equals that obtained for the previously established reduction procedure. Thus, in situ reduction of the baseline catalyst with $4 \% \mathrm{CO}$ in $\mathrm{N}_{2}$ is a viable way of activating the catalyst.

Figure A.7 Methanol Synthesis Rate after 4\% CO Reduction $250^{\circ} \mathrm{C}, 750 \mathrm{psig}$, Texaco Gas

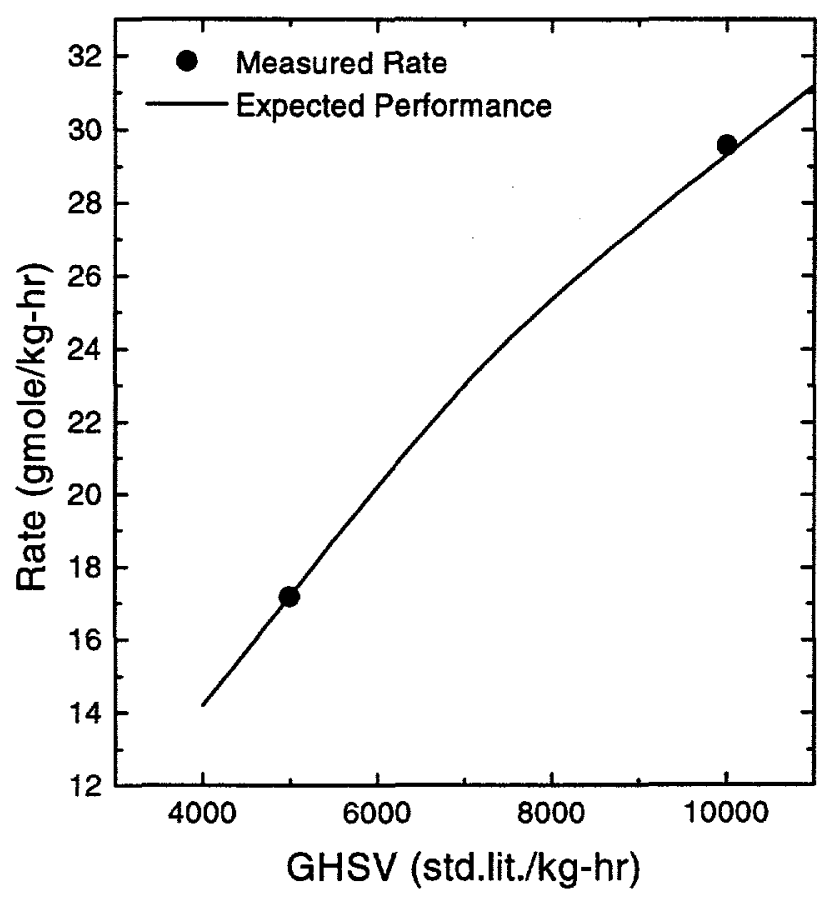

A new procedure that was changed slightly from the initial procedure to conserve $\mathrm{CO}$ was implemented. The data for the run are summarized in Figures A.8-A.11. The heating rate and gas flow rate have been slightly modified from the initial run (Run 8--Figure A.8). Gas uptake rate and product generation (Figs. A.9-11) were satisfactory for all runs. The new procedure is substantially similar to the old procedure. 
Figure A.8 Reduction Temperature Profiles $4 \% \mathrm{CO} /$ Balance $\mathrm{N}_{2}$;

SV: $1,500 \mathrm{~s} / \mathrm{kg}-\mathrm{hr}$ for $14191-50,1,600$ for $14045-08$

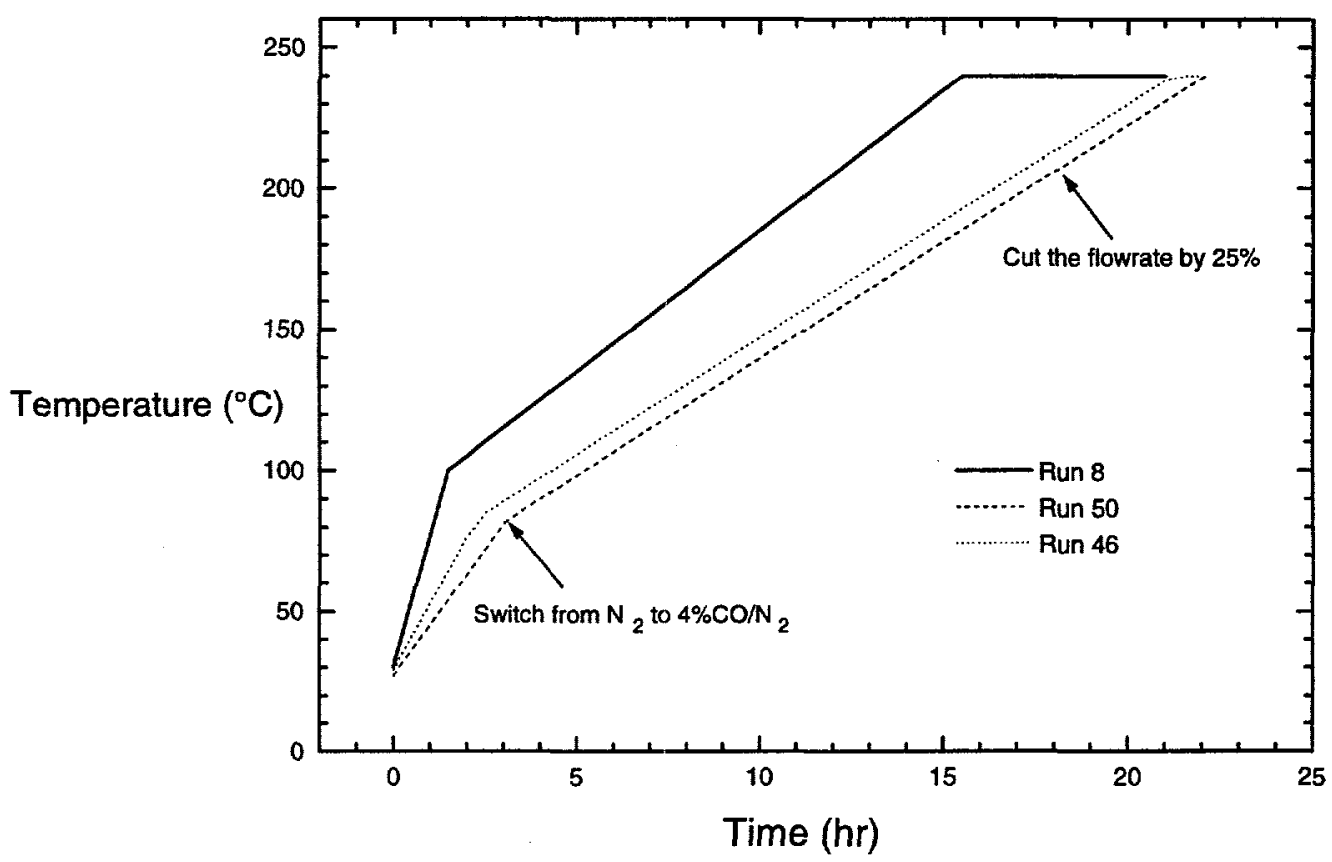

Figure A.9 Runs 14191-50 and 14045-08

Reduction Gas Feed: $4 \% \mathrm{CO} / \mathrm{Balance}_{2}$;

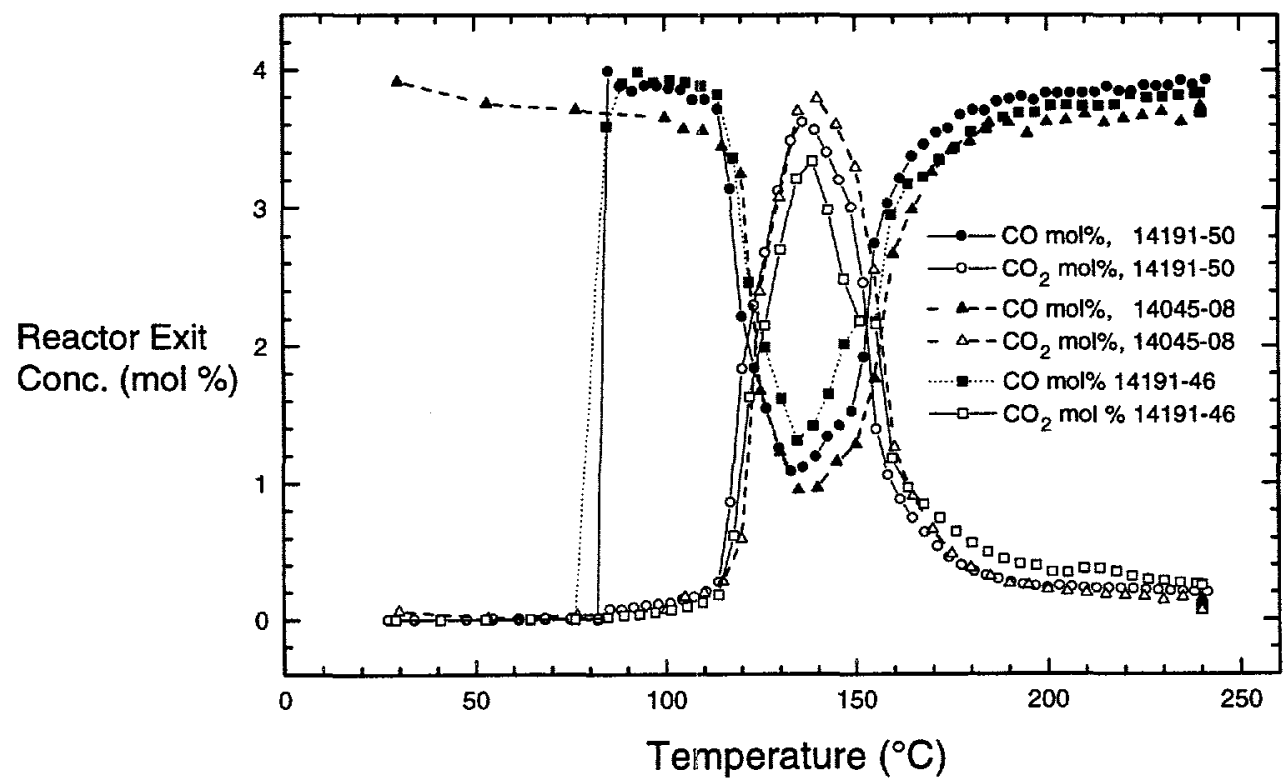


Figure A.10 Runs 14191-50, 14191-46, and 14045-08 Reduction Gas Feed: $4 \% \mathrm{CO} /$ Balance $\mathrm{N}_{2}$

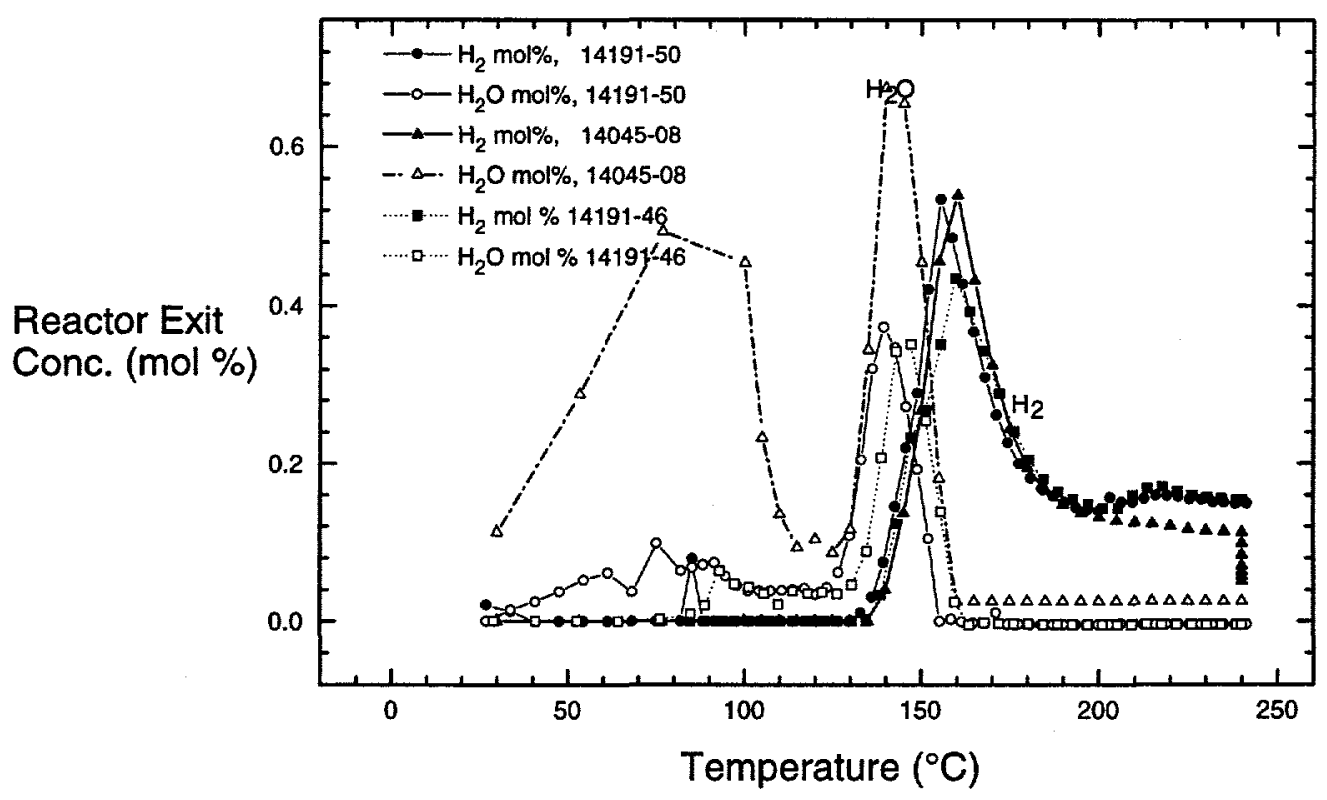

Figure A.11 Comparison of Different Procedures Runs 14191-50 and 14045-8 14191-46

Baseline Catalyst - 91/14638

Cumulative CO Consumption (scf cat)

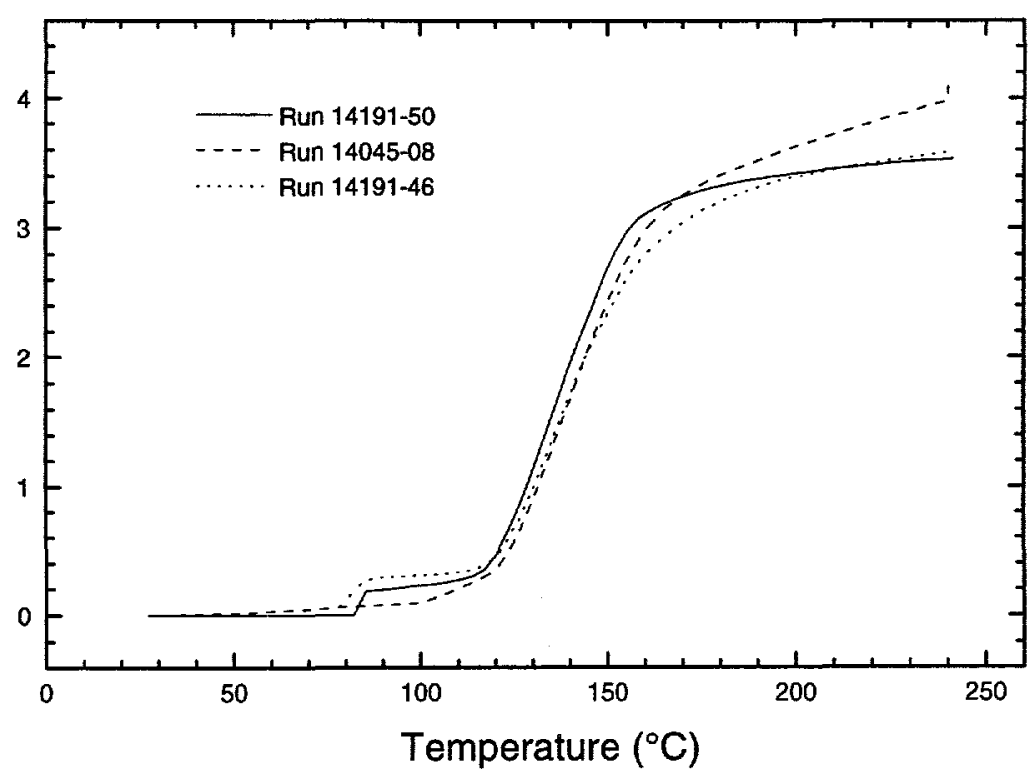




\section{Life Test of Catalyst Activated Using CO}

The final check on the $\mathrm{CO}$ activation procedure was to test the life of a $\mathrm{CO}-$ activated catalyst. Test results were analyzed by noting the change in specific rate constant with time. A decrease in rate constant translates to catalyst aging. To account for small differences in initial activity, aging is expressed as a $\%$ of the initial activity/unit time.

While the best kinetic expression available for methanol formation is not perfect, the correlation is good enough so that aging data can be compared. Since a CSTR is used for the rate measurement, the reaction conditions depend upon the activity of the catalyst. Using the rate expression allows comparison with experiments done at other conditions and accounts for small changes in operating conditions and catalyst activity.

Figure A.12 shows historical data of activation with $\mathrm{H}_{2}$ taken for the baseline catalyst. The slope of the line is a direct measurement of aging. The laboratory tests always show a higher aging rate than measured in the LaPorte test. The reasons for this difference are not clear. The laboratory test gives a fairly constant value for aging and thus, may be used as an indication of the relative stability of the catalysts.

Figure A.12. Baseline Catalyst Deactivation in \#1 300 cc Autoclave

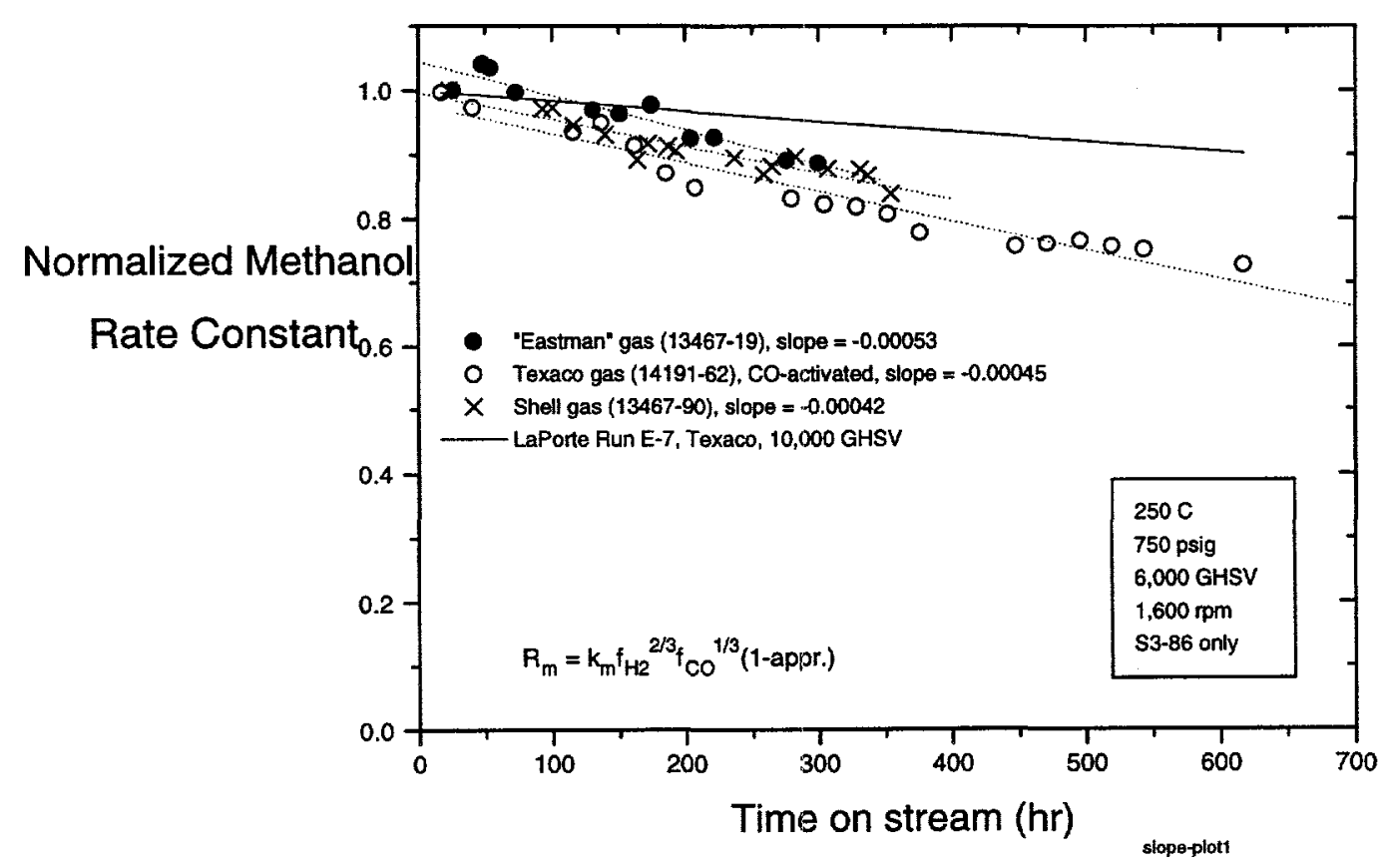


The data for $\mathrm{CO}$ activated catalyst are shown in Figure A.13. The slope of the line from the laboratory data is about the same as for the laboratory data using the standard activation method. Therefore, we conclude that $\mathrm{CO}$ activation does not adversely affect the performance of the catalyst.

Figure 1.4.13. CO Reduction Comparison

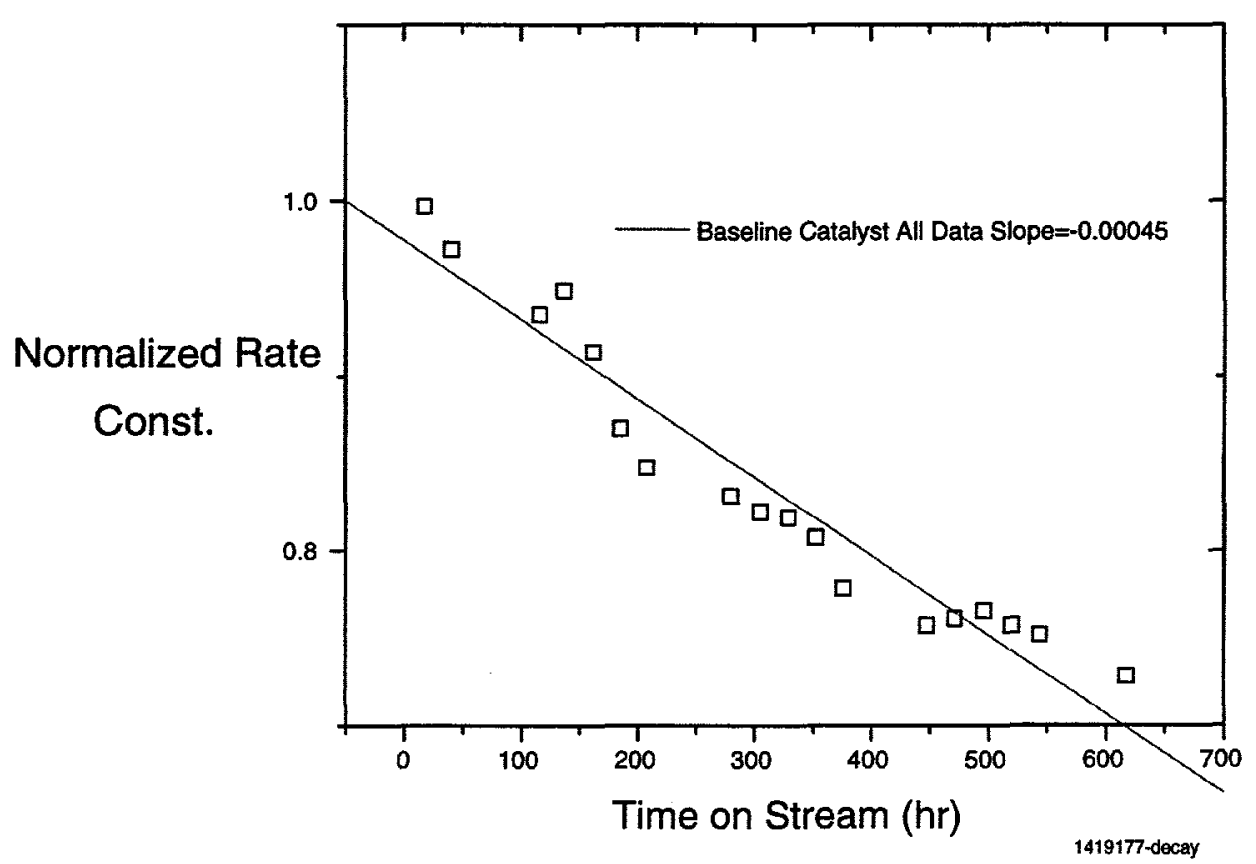


APPENDIX B

\section{Laboratory Testing of Alternate Methanol Catalyst}




\section{Laboratory Testing of Alternate Methanol Catalyst}

Establishment of a tested, alternate catalyst supply is part of any process development. For the LPMEOH ${ }^{\top M}$ process, demonstration must be made at the LaPorte scale. One of the objectives of the methanol/fluid dynamic run in the AFDU at LaPorte was to demonstrate the performance of an alternate catalyst.

After initial testing of old samples of this catalyst showed good performance, a new sample was obtained for LaPorte. The laboratory life data for this catalyst is compared to the LPMEOH Baseline catalyst in Figure B.1. The catalyst performed well, showing slightly higher activity than the Baseline catalyst. Also, the Alternate catalyst aged slightly slower than the Baseline catalyst.

Figure B.1 Life Test Results

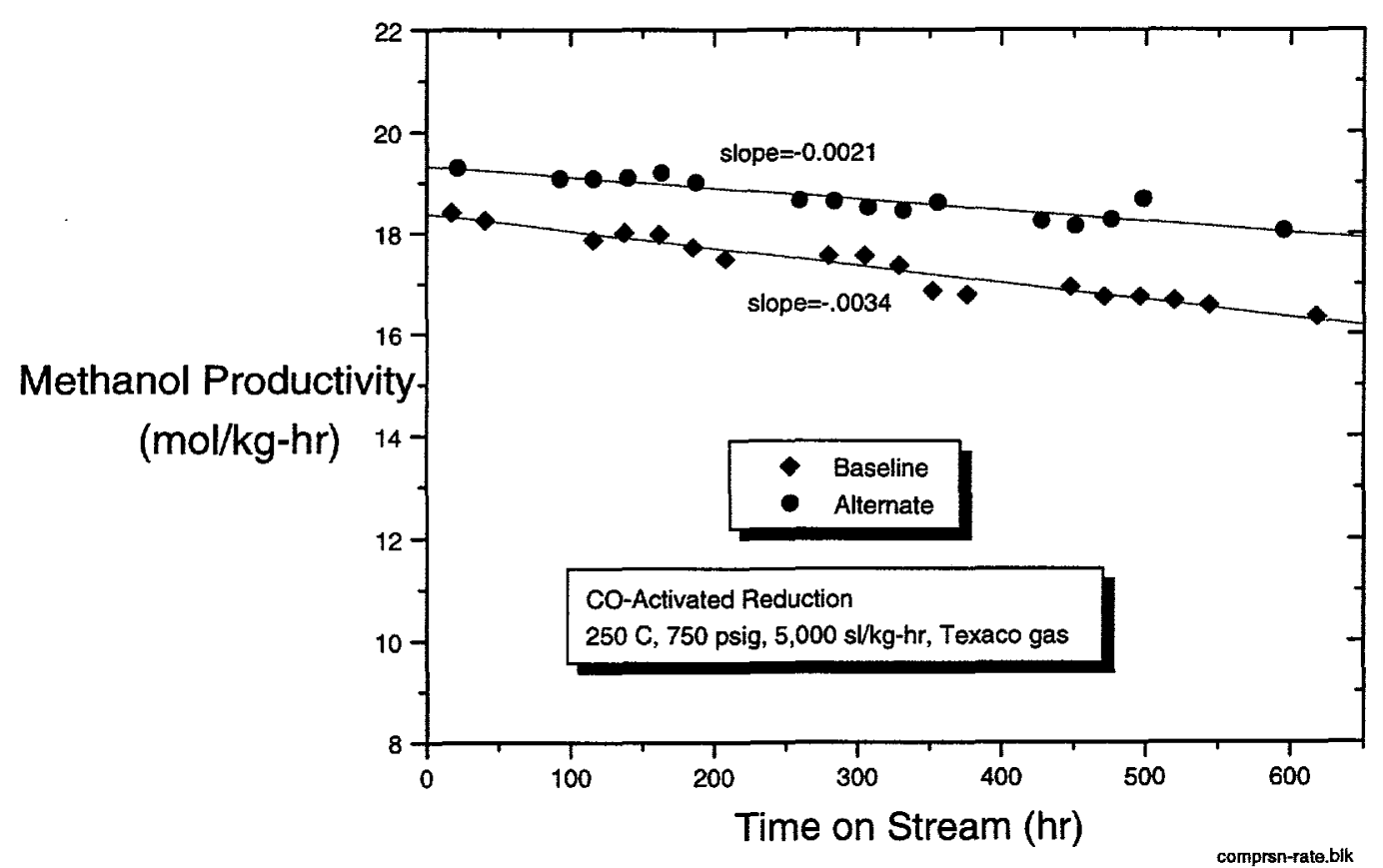

Reduction of the catalyst was accomplished by the new $C O$ reduction procedure discussed in Appendix A. The reduction temperature profile is shown in Figure B.2, and the off-gas profiles for the catalyst are shown in Figure B.3. Both $\mathrm{CO}$ uptake and $\mathrm{CO}_{2}$ generation were lower for the Alternate catalyst than for the Baseline catalyst, possibly because of a different copper content, and with less water being generated in this reduction, it is possible that the water gas shift reaction, which can occur at a late stage of the activation, was less important for the Alternate catalyst. 
Figure B.2 Reduction Temperature Profiles

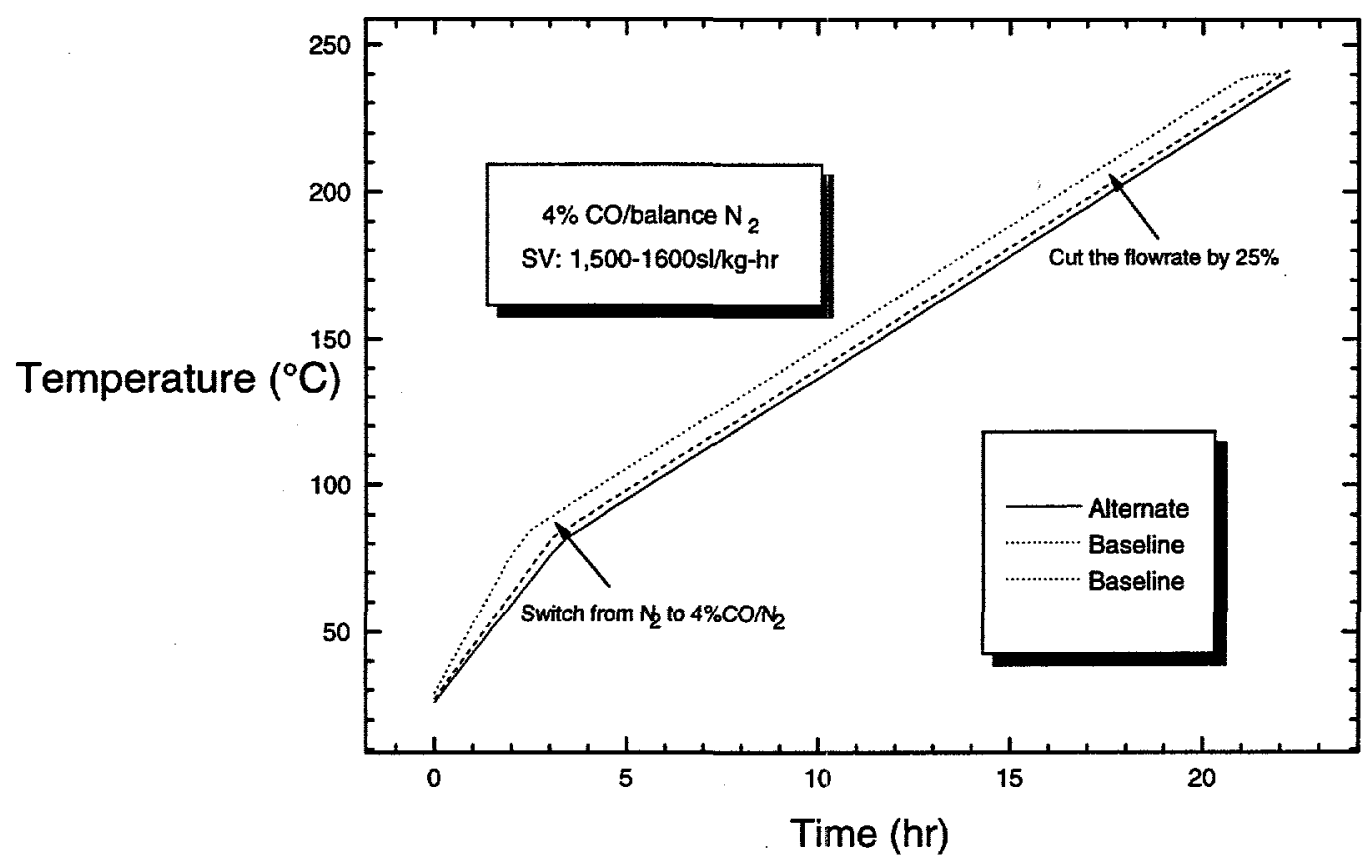

Figure B.3 Off-Gas Profiles for Two Catalysts

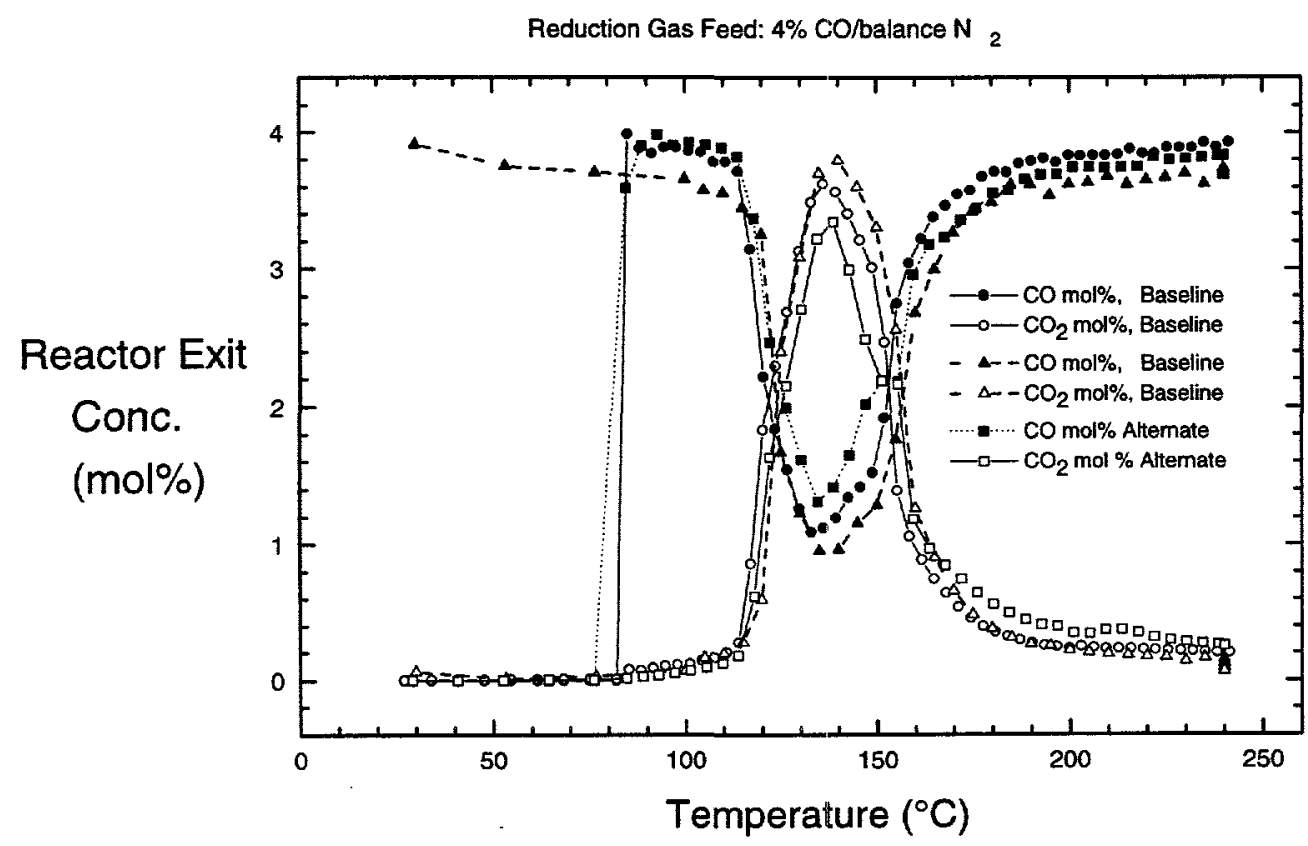


Figure B.4 shows water evolution, which was much lower for the Alternate catalyst than for the Baseline catalyst. At low temperatures, the sorbed water driven off both catalysts was similar. However, the difference was pronounced during the higher temperature portion of the reduction. Water evolution is attributed to the breakdown of hydroxycarbonates in this higher temperature region. The previous sample of the Alternate catalyst, which was taken from a different place in the production line, showed higher water evolution and therefore possibly a higher level of hydroxycarbonates. (In fact, the level was higher than for the typical Baseline catalyst.)

\section{Figure B.4 Comparison of Water Concentration for Two Catalysts}

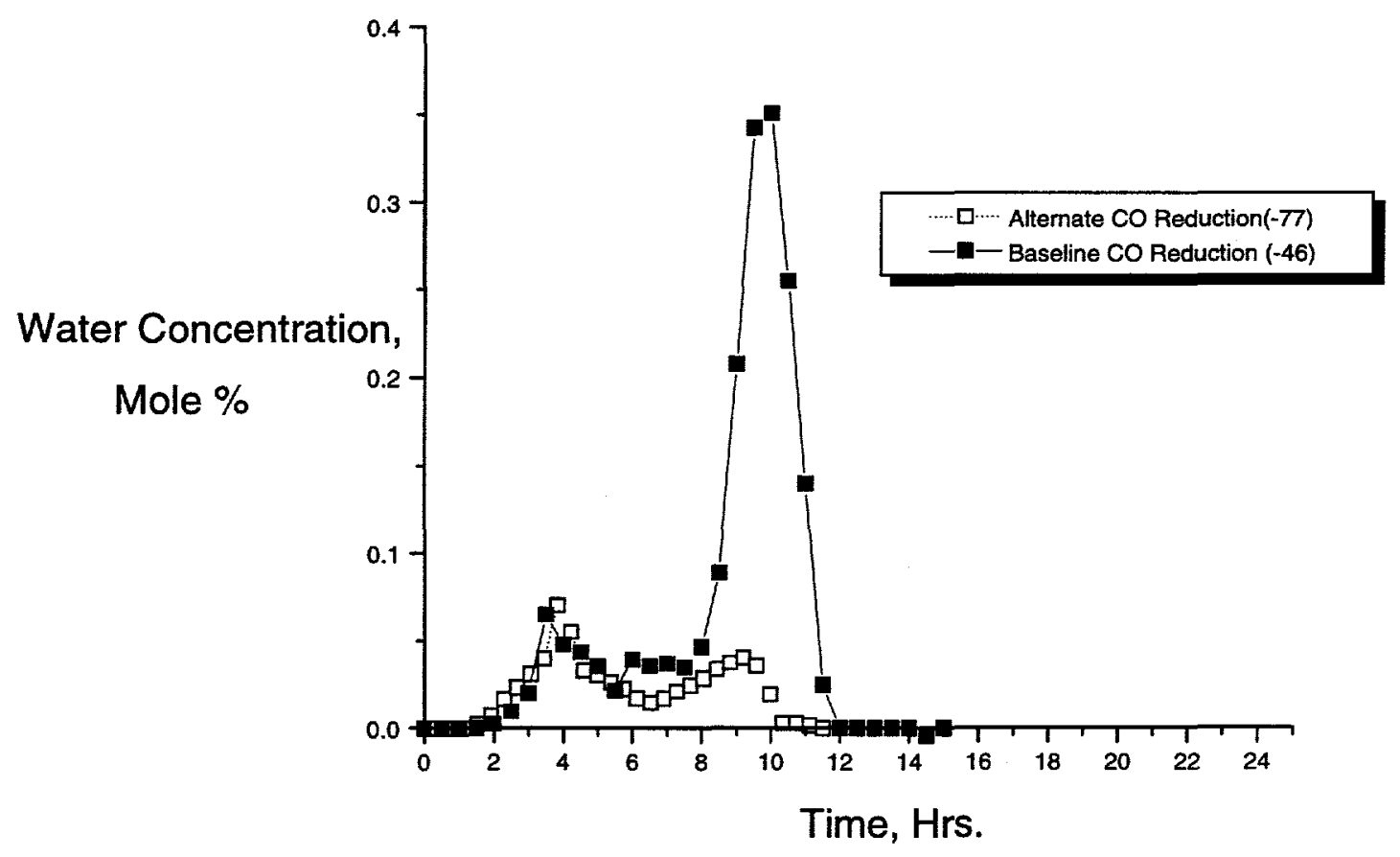

In addition to activity and life considerations, a candidate catalyst must pass the previously developed slurrification test, which indicates the suitability of a catalyst for use in a slurry bubble-column reactor. The rate of settling of the catalyst is compared to settling rates of standard catalysts. In this case the settling characteristics of the previous sample of the Alternate catalyst, as well as the one representative of the current production, were tested and are compared to the results from the standard (see Figure B.5). The candidate catalyst showed a satisfactory settling rate, and should perform well in the slurry reactor. 
Figure B.5 Results of Slurrification Test

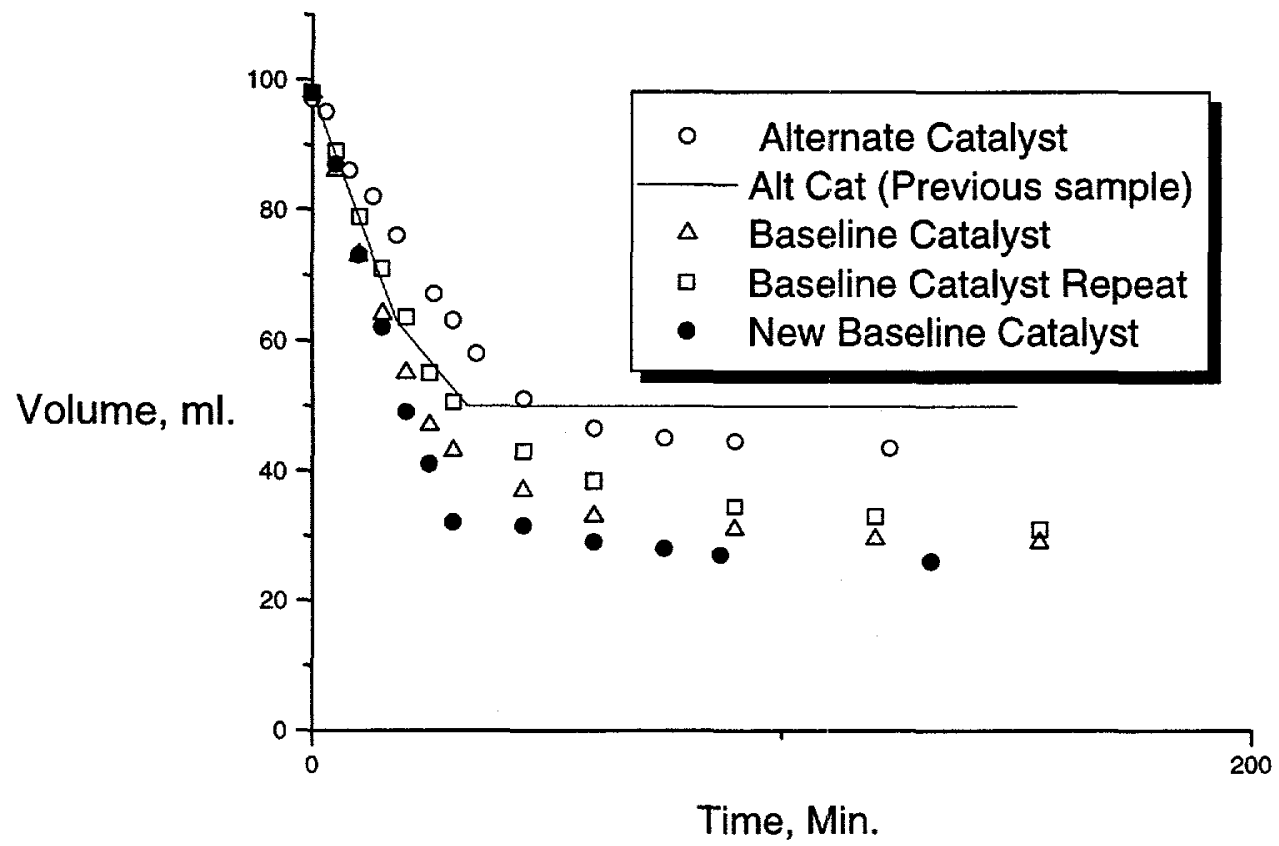

\section{Summary and Recommendation}

All recent data on the activation of the Baseline catalyst and the Alternate catalyst are summarized in Table B.1 and compared to historic data. The data are presented as the value of the specific rate constant for the methanol formation reaction and the productivity of the catalyst.

Based on the productivity of the initial two runs (14045-8 and 13458-90), we concluded that the $\mathrm{CO}$ activation leads to a catalyst with the same activity as does the standard activation procedure with hydrogen.

The life runs show some periodic difficulty in analytical measurement as described in the footnote to Table B.1. However, as there is only a small difference in results, the CO activation is considered to be essentially the same as the standard. In addition, based on this run, catalyst life is adequate.

The Alternate catalyst exhibits at least as good an initial activity as the Baseline catalyst. Also, the catalyst ages slightly slower than the Baseline catalyst.

The variation in the calculated value of the rate constant is interesting. We calculate rate constant from the concentration data. There may be a difference in water-gas shift activity for $\mathrm{CO}$ activated catalysts and, perhaps, between the various catalysts.

The alternate catalyst showed adequate activity, life and slurriability in the laboratory tests and was considered suitable for testing in the AFDU in the upcoming trial. 
Table B.1 Catalyst Activation on Texaco Gas

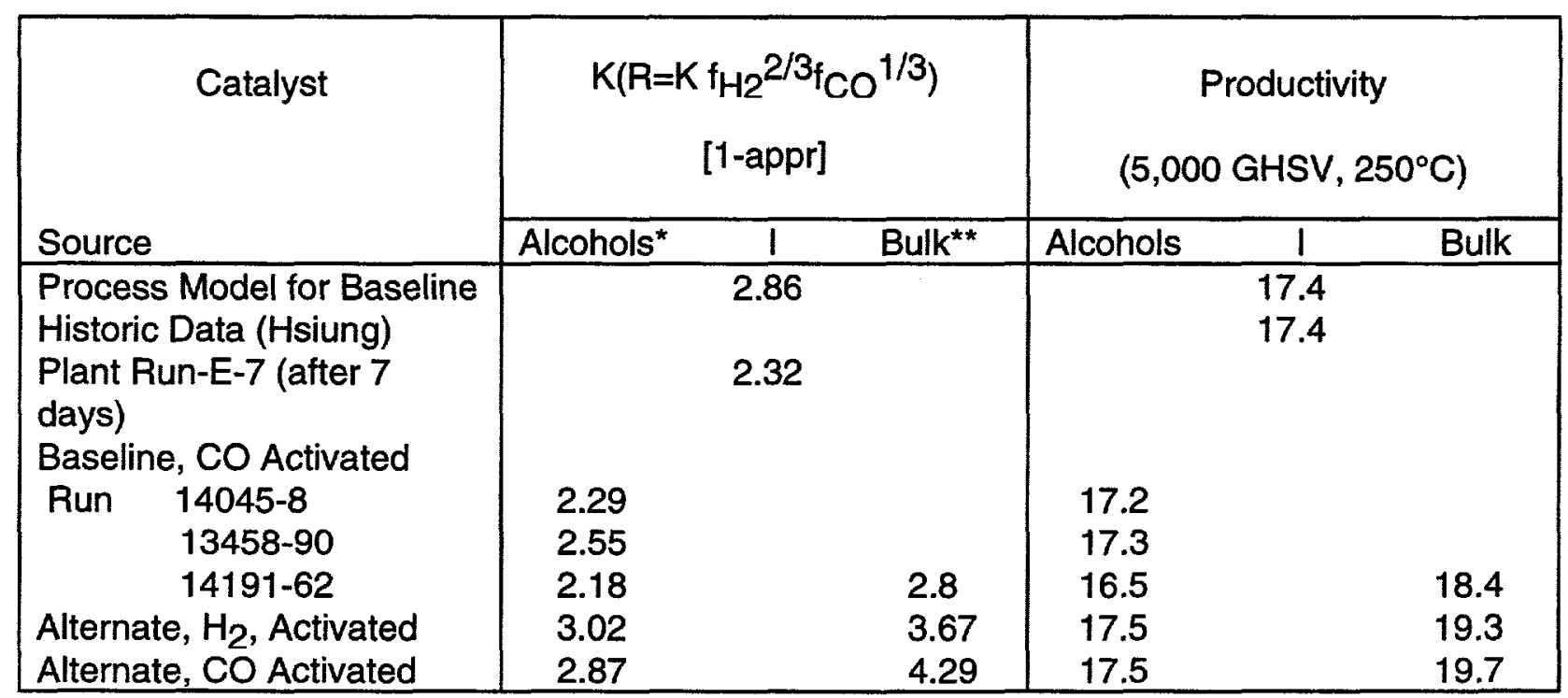

*, ** Data after Run 62 are shown for both Alcohols and Bulk GC. This is indicative of our analytical problem. The Bulk GC data gives good material balances and shows low variation with time. The Bulk $\mathrm{GC}$ is the method that has been used to gather historical data.

Halfway into Run 62 the Alcohol GC calibration factor changed significantly and the day to day variability of the results became less steady. It is suspected that there is a leak that we have not yet been able to find.

Complicating the issue is that our calibration mixtures have only $5 \% \mathrm{MEOH}$, while $\mathrm{MEOH}$ concentrations in the reaction product are as high as $9 \%$. We suspect the Bulk GC is not linear. We will soon receive a new calibration standard, at which time, the linearity of both GCs will be checked and we will use CRSD analytical help to find the GC stability problem in the Alcohols GC. 
APPENDIX C

Fluid Dynamic (Methanol) Run Authorizations 


$\begin{array}{ll}\text { Sheet: } & 1 \text { of } 4 \\ \text { Date : } & \text { 06/03/95 } \\ \text { By: } & \text { BLB }\end{array}$

RUN NUMBER:

APPROX. START DATE:
AF-A9

3 June, 1995

TITLE: $\quad$ IN-SITU METHANOL CATALYST ACTIVATION USING DILUTE CO PRIOR TO HYDRODYNAMIC RUN

OBJECTIVE:

To activate the Liquid-Phase Methanol (LPMEOH) synthesis catalyst.

SUMMARY:

Approximately $1177 \mathrm{lbs}$ of standard baseline catalyst is to be slurried with Drakeol-10 oil, transferred to the 27.20 reactor and activated with dilute $\mathrm{CO}$ ( $4 \%$ in nitrogen). Approximate run time is 2 days.

TEST DETAILS:

ANALYTICAL COMMENTS:

\section{SAFETY IMPLICATIONS:}

Operators should wear protective gear while loading catalyst to protect them from the dust and hot vapor which may be released from the loading nozzle. Protective gear including face shield should be worn during slurry sampling.

This operation will require the venting of unreacted $\mathrm{CO}$. During a previous activation (performed under TEST AUTHORIZATION \#29) the off-gas was blended with methane and burned in the flare. Previous calculations (for TA \#23) indicated that in the event a combustible mixture could not be maintained, there would be no danger to personnel from venting. The reduction gas flow rates to be used in this run are less than those used in TA \#23.

\section{ENVIRONMENTAL IMPLICATIONS:}

Minimal, a flame will be maintained at the flare. At $98 \%$ destruction efficiency, the $\mathrm{CO}$ emission rate would be $0.72 \mathrm{lb} / \mathrm{hr}$.

\section{SPECIAL REMARKS:}

$\mathrm{CO}$ and $\mathrm{H}_{2}$ concentrations in and out of the reactor must be monitored closely during the reduction. Reactor temperature must be closely monitored and controlled per the attached TEST DETAILS. The utility oil inlet temperature ( $\mathrm{TI} 1244$ ) to the 27.20 internal heat exchanger must not exceed a $200^{\circ} \mathrm{F}$ difference from the utility oil outlet temperature (TI-1246) or the reactor slurry temperature. These two temperature differentials are measured directly by TDI-1252 \& TDI-1237. When adjusting flows or pressure, care should be taken to minimize catalyst carryover (caused by high gas velocity).

AUTHORIZATIONS:
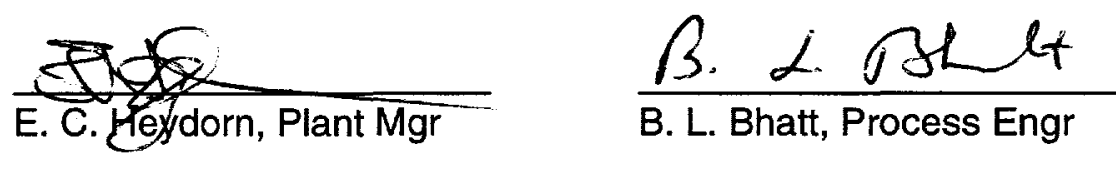


$\begin{array}{ll}\text { Sheet: } & 2 \text { of } 4 \\ \text { Date : } & \text { 06/03/95 } \\ \text { By: } & \text { BLB }\end{array}$

\section{TEST DETAILS:}

1. This reduction procedure follows previous methanol catalyst reductions from the LPIII ER-6 reduction (TEST AUTHORIZATION \#23), 1991 DME run (\#25), 1992 LPSHIFT run (\#29), and the 1994 methanol run (\#37).

2. Charge the 28.30 prep tank with $1766 \mathrm{lb}$ of oil ( 250 gallons of Drakeol-10 at $80^{\circ} \mathrm{F}$ ). The oil should be transferred to drums and weighed using the scale for accurate measurement. As an approximation, meter the oil with FQI-334 using a meter correction factor of actual $=1.027^{*}$ meter (meter should read $243 \mathrm{gal}$ ). If the temperature differs from $80^{\circ} \mathrm{F}$ a corrected oil volume should be used. Heat this oil to $150-200^{\circ} \mathrm{F}$.

3. Fill the 27.14 intermediate V/L separator to 25 nuts on LG-358 with approximately 100 gallons of Drakeol-10 oil from storage. Note the FQI-334 readings before and after the addition.

4. When the prep tank oil is at $150-200^{\circ} \mathrm{F}$, add $1177 \mathrm{lb}$ of baseline methanol catalyst ( 3 full drums and a small portion from a fourth drum). Add the catalyst very slowly to make a $40 \mathrm{wt} \%$ oxide slurry. Keep the slurry well stirred to prevent agglomeration of the catalyst.

5. Heat the slurry to $200^{\circ} \mathrm{F}$ and continue agitation, under nitrogen, for at least 2 hours to ensure good mixing.

6. When the catalyst and oil have been completely mixed, withdraw a sample of slurry.

7. Establish gas flow through the reactor using nitrogen through V-2627 to prevent slurry back-flow into the distributor. Vent the gas through PV-1261.

8. Pressure transfer the slurry to the reactor and verify operation by noting level with the nuclear density gauge (NDG- estimated level: 23 to $27 \mathrm{ft}$.)

9. Flush out the prep tank with $283 \mathrm{lb}$ of oil ( 40 gallons of Drakeol-10 at $80^{\circ} \mathrm{F}$ ). Measure the oil as in step 2 (meter should read approximately $38.9 \mathrm{gal}$ ). Pressure transfer the flush oil to the reactor and verify level with the NDG (LI-1242).

10. Close V-645 to prevent utility oil flow back to the prep tank and establish full utility oil flow through the 27.20 internal heat exchanger.

11. Pressurize the reactor loop to 67 psig.

12. Begin heating the slurry to $200^{\circ} \mathrm{F}$, following TAVR on the DEC console. Check that the slurry temperatures are in reasonable agreement. Verify that the slurry is well mixed by performing a NDG scan. 


$\begin{array}{ll}\text { Sheet: } & 3 \text { of } 4 \\ \text { Date : } & \text { 06/03/95 } \\ \text { By: } & \text { BLB }\end{array}$

13. Establish Dilute $\mathrm{CO}$ reduction gas flow at $12500 \mathrm{SCFH}$ (on $\mathrm{Fl}-126$ ) and vent the flow through PV170. Establish the following composition:

$$
\begin{array}{ccc} 
& \text { Composition } & \text { Est. Flows (SCFH) } \\
\text { CO } & 4.0 & 500 \\
\text { N2 } & \frac{96.0}{100.0} & \frac{12000}{12500} \\
M W=28, \text { SCF evaluated at } 70^{\circ} \mathrm{F}, 14.7 \text { psia } \\
M \text { S }
\end{array}
$$

14. When the reactor temperature reaches $200^{\circ} \mathrm{F}$, bring reduction gas to the reactor slowly and close the nitrogen purge (V-2627). Establish a final flow to the reactor of 12,500 SCFH. Maintain flow and reducing gas composition as specified in step 13. The temperature-programmed activation consists of the following steps:

- Heat the slurry at a target rate of $15^{\circ} \mathrm{F} / \mathrm{hr}$ (no more than $18^{\circ} \mathrm{F} / \mathrm{hr}, 10^{\circ} \mathrm{C}$ ) until the slurry temperature reaches $464^{\circ} \mathrm{F}\left(240^{\circ} \mathrm{C}\right)$.

$\mathrm{H} 2$ and $\mathrm{CO}$ concentrations are to be measured continuously for the feed and effluent streams. As long as the cumulative $\mathrm{CO}$ consumption minus $\mathrm{H}_{2}$ Production at a given temperature is equal to or greater than the autoclave reduction data then the activation is proceeding well. Figure 1 shows the consumption profile vs temperature from the labs. If the cumulative consumption curve falls below the autoclave curve, consult the process or research engineer to reduce the heat up rate.

If the $\mathrm{CO}$ concentration in the effluent falls below 0.1 mole $\%$, increase the inlet $\mathrm{CO}$ concentration per the instructions of the process or research engineer. The objective here is to prevent reduction gas starvation.

Once a slurry temperature of $392^{\circ} \mathrm{F}$ is reached decrease the dilute $\mathrm{CO}$ reduction gas flow to 9375 SCFH (on Fl-126). Maintain the following composition:

$$
\text { Composition }
$$

CO

N2

$$
4.0
$$$$
96.0
$$

100.0
Est. Flows (SCFH)

375

$\underline{9000}$

9375

$\mathrm{MW}=28, \mathrm{SCF}$ evaluated at $70^{\circ} \mathrm{F}, 14.7 \mathrm{psia}$

Target space velocity $=461 \mathrm{sL} / \mathrm{h}-\mathrm{kg}$; Target starting inlet superficial velocity $=0.47 \mathrm{ft} / \mathrm{sec}$

The reduction is expected to be complete before reaching $464^{\circ} \mathrm{F}$. It may become necessary to hold slurry at this temperature until the difference between inlet and outlet $\mathrm{CO}$ concentration falls below 0.05 mole $\%$. 
TEST AUTHORIZATION \# 46

LaPorte Alternative Fuels Development Unit (AFDU)

$\begin{array}{ll}\text { Sheet: } & 4 \text { of } 4 \\ \text { Date : } & 06 / 03 / 95 \\ \text { By: } & \text { BLB }\end{array}$

15. The slurry level should be maintained between 90 and $95 \%$ of NDG range (approximately $40 \mathrm{ft}$.) by using LIC 1242 to control the makeup oil rate. Note that as the reactor is heated to $464 \mathrm{~F}$, the slurry will expand. At the same time, some of the oil will be lost in the reactor effluent. If authorized by the process engineer or the plant manager, additional makeup oil can be added to the system via the 27.14 by following the standard procedure; FQI-334 readings and the change in level of the 27.14 should be recorded before and after each addition. It is important to note that the discharge valve of the 10.52 .01 and 02 pumps should be used to throttle to the 67 psig reactor pressure. The pressure in the sump of the 21.11 should be at $150 \mathrm{psig}$ or less.

16. Record any indication of density or viscosity change, such as a change in the pressure drop across the reactor or shaking of the reactor during heat up and reduction.

17. During the reduction, scan the reactor with the NDG, record levels in the 21.11 and 27.14 every 4 hrs. At the end of the reduction, add fresh oil to 27.14 to bring the level up to 25 nuts on LG-358. This charge should be drawn from storage; note the FQI-334 readings before and after addition.

TA \#46 is done, consult TEST AUTHORIZATION \#47 for the next step.

\section{ANALYTICAL REQUIREMENTS:}

1. Catalyst sampling requirements:

- slurried oxide catalyst from prep tank before reduction,

Exact quantities to be determined by operations, process, and research.

2. Composition sampling requirements:

- reactor in and out continuously

- $\mathrm{H} 2$ and $\mathrm{CO}$ are critical

- $\mathrm{CO} 2$ and N2 are also required

3. Flow measurement requirements:

- reactor in at $\mathrm{Fl}-126$ and $\mathrm{FI}-299$

\section{REFERENCES:}

1. TEST AUTHORIZATION \# 23 : Procedure for previous in-situ activation. 
RUN PLAN FOR FLUID DYNAMIC / METHANOL RUN (JUNE, 1995)

\begin{tabular}{|c|c|c|c|c|c|c|}
\hline RUN & & & AF-A9 & AF-R13.1 & AF-R.13.2 & AF-R.13.3 \\
\hline Description & $\cdots$ & $\cdots$ & BSLN (REDTN) & BSLN (PVS) & BSLN (PVS) & BSLN (PVS) \\
\hline Duration & $\cdots$ & days & 1 & 2 & 3 & 2 \\
\hline Syngas & $\cdots$ & $\cdots$ & $\cdots$ & TEXACO & KINGSPORT & TEXACO \\
\hline Inlet Space Velocity & $\cdots$ & $\mathrm{sL} / \mathrm{kg}-\mathrm{hr}$ & 615 & 7,000 & 4,000 & 10,000 \\
\hline Reactor Pressure & PIC-1247 & psig & 67 & 750 & 735 & 750 \\
\hline \multicolumn{7}{|l|}{ REACTOR } \\
\hline Pressure & $\mathrm{PIC}-1247$ & psig & 67 & 750 & 735 & 750 \\
\hline Temperature & $\mathrm{TI}-1233$ & $F$ & $-\cdots$ & 482 & 482 & 482 \\
\hline Heat Duty & \multicolumn{2}{|c|}{ MM BTU/hr } & $\cdots$ & 1.10 & 1.14 & 1.31 \\
\hline Inlet Superficial Velocity & $\cdots$ & $\mathrm{ft} / \mathrm{sec}$ & 0.62 & 0.83 & 0.48 & 1.20 \\
\hline Outlet Superficial Velocity & $\cdots$ & $\mathrm{ft} / \mathrm{sec}$ & 0.62 & 0.68 & 0.35 & 1.01 \\
\hline Liquid Level & $\mathrm{LI}-2142$ & $\%$ span & $80 \%$ & $100 \%$ & $100 \%$ & $100 \%$ \\
\hline Catalyst Load & $\cdots$ & $\mathrm{Ib}$ & 1,177 & 1,177 & 1,177 & 1,177 \\
\hline Cat Weight Fraction & $\cdots$ & $\%$ & $40 \%$ & $42 \%$ & $40 \%$ & $43 \%$ \\
\hline Vapor Void Fraction & $\cdots$ & $\%$ & $24 \%$ & $43 \%$ & $35 \%$ & $48 \%$ \\
\hline \multicolumn{7}{|l|}{ FRESH FEED FLOWS } \\
\hline LPH2 & FIC-101 & scfh & 0 & 18,342 & 21,495 & 14,774 \\
\hline CO & $\mathrm{FIC}-104$ & scth & 500 & 15,217 & 11,995 & 18,598 \\
\hline $\mathrm{CO} 2$ & FIC-107 & scth & 0 & 1,185 & 1,040 & 1,373 \\
\hline N2 & FIC-111 & scfh & 12,000 & 56 & 270 & 55 \\
\hline 01.10 Total Flow & $\mathrm{FI}-726$ & scth & 12,500 & 34,800 & 34,800 & 34,800 \\
\hline $\mathrm{HP} \mathrm{H2}$ & FIC- 1200 & scth & 0 & 7,283 & 2,467 & 17,837 \\
\hline 01.20 Recycle & FIC-246 & scth & 0 & 100,929 & 43,670 & 151,825 \\
\hline \multicolumn{7}{|l|}{ REACTOR FEED } \\
\hline Target Feed Temp & Tl-1253 & $\mathbf{F}$ & $\cdots$ & 362 & 392 & 357 \\
\hline Feed Dewpoint & $\cdots$ & $\mathbf{F}$ & $\cdots$ & 89 & 78 & 91 \\
\hline Total Dry Flow & Fl-1216 & scfh & 12,500 & 143,012 & 80,937 & 204,462 \\
\hline $\mathrm{H} 2$ & $\cdots$ & $\mathrm{mol} \%$ & $0.0 \%$ & $34.70 \%$ & $60.90 \%$ & $34.70 \%$ \\
\hline $\mathrm{CO}$ & $\cdots$ & $\mathrm{mol} \%$ & $4.0 \%$ & $50.56 \%$ & $24.49 \%$ & $50.56 \%$ \\
\hline $\mathrm{N} 2$ & $\cdots$ & $\mathrm{mol} \%$ & $96.0 \%$ & $0.99 \%$ & $3.90 \%$ & $0.99 \%$ \\
\hline $\mathrm{CO} 2$ & $\cdots$ & $\mathrm{mol} \%$ & $0.0 \%$ & $12.88 \%$ & $10.02 \%$ & $12.88 \%$ \\
\hline MEOH & $\cdots$ & $\mathrm{mol} \%$ & $0.0 \%$ & $0.71 \%$ & $0.42 \%$ & $0.75 \%$ \\
\hline ETOH & $\cdots$ & mol\% & $0.0 \%$ & $0.00 \%$ & $0.00 \%$ & $0.00 \%$ \\
\hline $\mathrm{PROH}$ & $\cdots$ & $\mathrm{mol} \%$ & $0.0 \%$ & $0.00 \%$ & $0.00 \%$ & $0.00 \%$ \\
\hline$C 1$ & $\cdots$ & $\mathrm{mol} \%$ & $0.0 \%$ & $0.00 \%$ & $0.08 \%$ & $0.02 \%$ \\
\hline & & & $100.0 \%$ & $99.84 \%$ & $99.81 \%$ & $99.90 \%$ \\
\hline
\end{tabular}




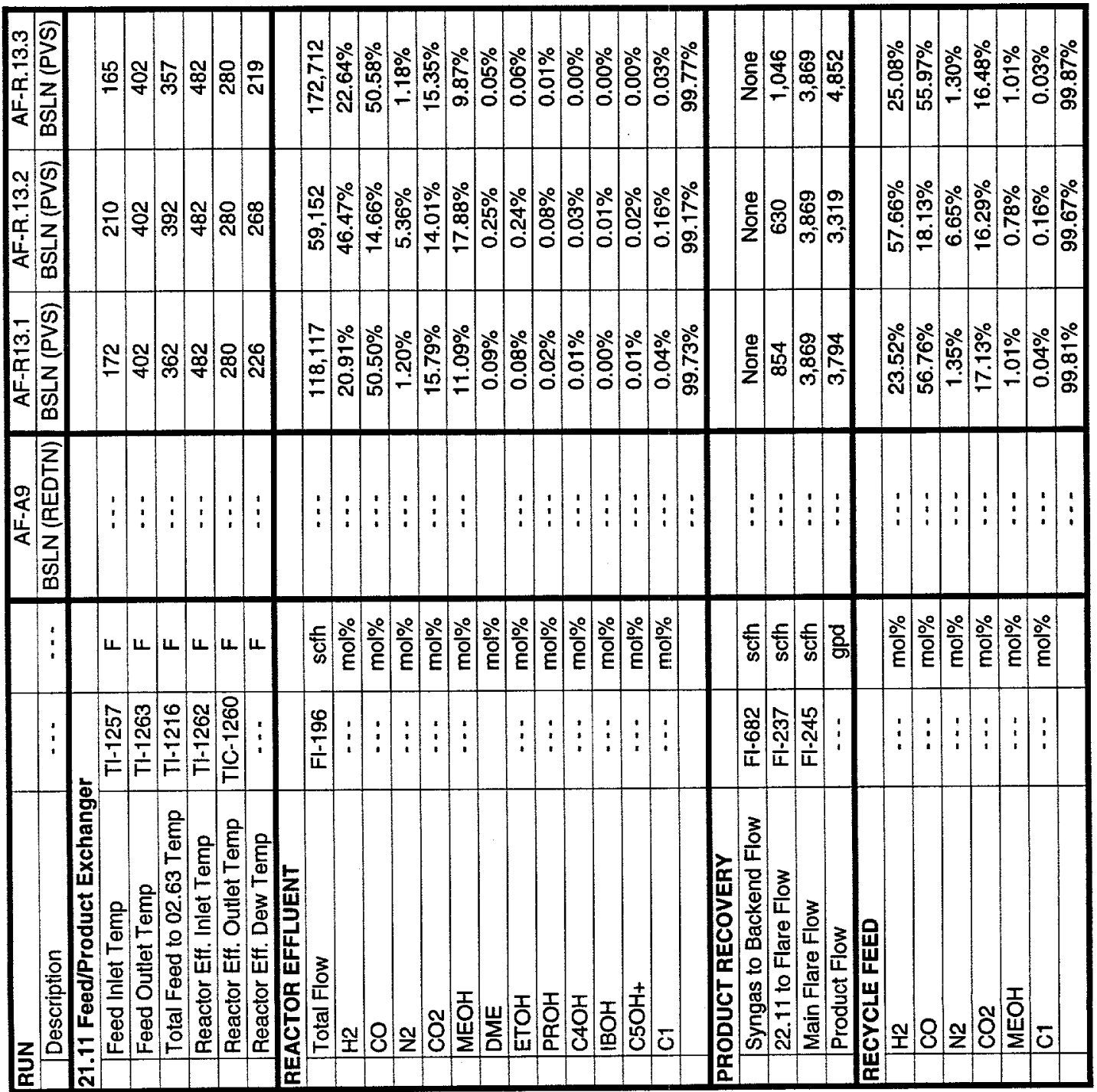




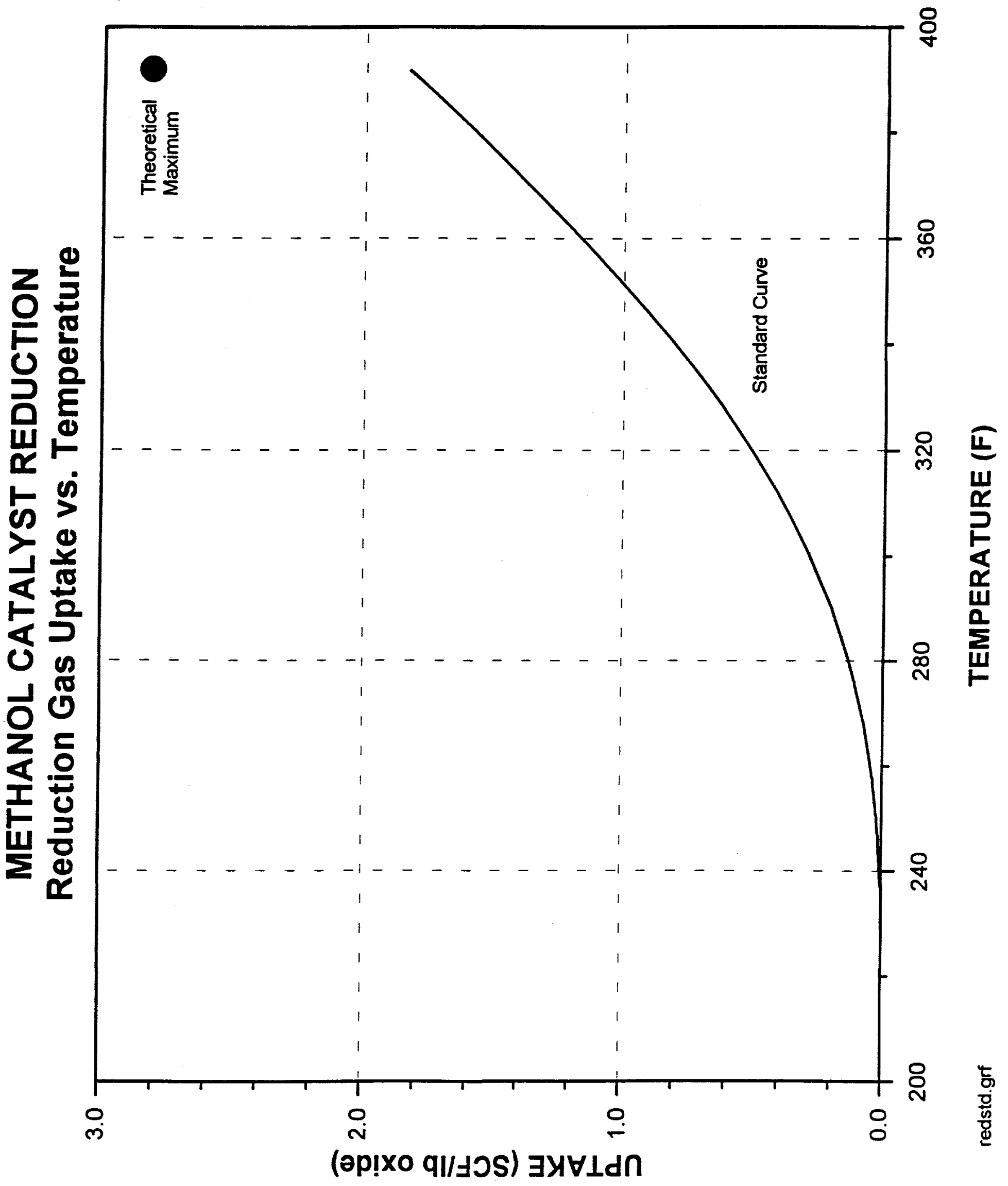


Sheet: 1 of 3

Date : 06/04/95

By: BLB

RUN NUMBER:

APPROX. START DATE:
AF-R13

5 June, 1995

\section{TITLE: $\quad$ METHANOL SYNTHESIS WITH BASELINE CATALYST}

\section{OBJECTIVE:}

To study the performance of the baseline methanol catalyst in the 27.20 reactor train.

\section{SUMMARY:}

Upon completion of the activation step (AF-A9), the reactor feed will be adjusted to a Texaco gas composition $(35 \% \mathrm{H} 2,51 \% \mathrm{CO}, 13 \% \mathrm{CO} 2,1 \% \mathrm{~N} 2)$. For approximately 2 days, the conditions will be targeted at $750 \mathrm{psig}, 482^{\circ} \mathrm{F}, 7,000 \mathrm{sL} / \mathrm{kg}$-hr space velocity, and $40 \mathrm{wt} \%$ oxide in oil. After 2 days, the gas composition will be switched to a Kingsport LPMEOH gas composition for three days of operation $(60.7 \% \mathrm{H} 2,24.4 \% \mathrm{CO}, 10.0 \% \mathrm{CO} 2,3.89 \% \mathrm{~N} 2)$. Finally, a high velocity condition will be tested $(1.2$ $\mathrm{ft} / \mathrm{sec}$ ) with Texaco gas for 2 days. The main objective of this run is to evaluate the catalyst performance with the modified reduction procedure.

\section{TEST DETAILS: $\quad$ See page 2.}

ANALYTICAL COMMENTS: See page 3.

\section{SAFETY IMPLICATIONS:}

Protective gear including face shield should be worn during slurry sampling.

ENVIRONMENTAL IMPLICATIONS:

Minimal.

\section{SPECIAL REMARKS:}

The high pressure hydrogen pipe line will be in use during run AF-R13. The $\mathrm{CO} 2$ removal system will not be in operation. Special sample bombs will be used to collect samples of the methanol product produced during case AF-R13.2.

\section{AUTHORIZATIONS:}
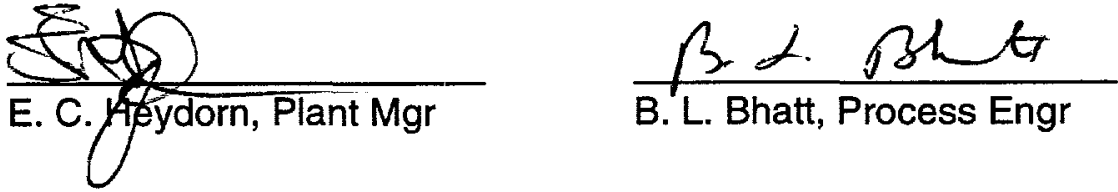
Sheet: 2 of 3

Date : 06/04/95

By: $\quad$ BLB

TEST DETAILS:

1. Upon completion of the catalyst activation (AF-A9), switch from reduction gas to Texaco-type gas by following the standard procedure. The $\mathrm{CO} 2$ removal section should NOT be operating during this run (V-2001,V-2003,V-2004,V-2006 shut; V-2000 open). In the event of a premature shutdown, consult TA \#20 (RUN E-05) for appropriate standby conditions.

2. Increase the reactor pressure to $750 \mathrm{psig}$ and control the slurry temperature at $482^{\circ} \mathrm{F}$. Slowly increase the reactor feed rate to 25,000 SCFH while maintaining slurry level at $95 \%$ of NDG span. When the plant has lined out, the reactor feed composition should correspond closely to case AFR13.1 (refer to Table). Once the compositions are lined out, slowly introduce recycle flow and back off the fresh feed flowrates until they match the targets outlined in the Table for case AF-R13.1. Note that the HP hydrogen pipeline is in service during all the three cases.

3. When the target feed rate has been achieved, put LIC-1242 in automatic to control slurry level at $95 \%$. Adjust the fresh feed flow to achieve an initial purge flow rate of approximately $3,000 \mathrm{SCFH}$. Maintain reactor feed flow and reactor temperature and pressure at the case AF-R13.1 values for a nominal 24 hour period.

4. During the first 24 hours, the syngas conversion across the reactor will fall as the catalyst loses its hyperactivity. The purge flow will increase and the reactor feed composition will be changing during this period. When these rates of change diminish, fine tune the fresh feed flow to reach the desired reactor feed composition as specified for case AF-R13.1. The ultimate purge rate should be around $3,900 \mathrm{SCFH}$.

5. After the initial break-in period, begin to increase rates to maximize production of methanol. Monitor the air-cooler loading and temperature difference between the utility oil and the slurry and utility oil inlet \& outlet using TDI-1237 and TDI-1252. Both of these temperature differences must be below $200^{\circ} \mathrm{F}$.

6. The composition of the methanol product is to be monitored every 8 hours. The target oil content of the methanol product should be $<=0.2 \mathrm{wt} \%$. If the oil content is higher, lower the 21.11 effluent outlet TIC-1260 set point.

7. Maintain conditions for approximately 2 days. After conferring with the process engineer or plant manager, switch to AF-R13.2 run conditions (Kingsport gas). Run this data period for approximately 3 days.

8. Liquid samples of the methanol product will be collected in special sample bombs and shipped to Allentown for detailed analysis during case AF-R13.2. The samples will be collected downstream of the 22.11 separator. Consult with the process engineer and analytical representative for the frequency and manner of taking the samples. 
Sheet: 3 of 3

Date : 06/04/95

By: BLB

9. After conferring with the process engineer or plant manager, switch to AF-R13.3 run conditions (Texaco gas). Run this data period for approximately 2 days.

10. When notified by the plant manager that case AF-R13.3 is complete, de-pressurize the plant, and drain the slurry from the 27.20 reactor using the prep tank as an intermediate hold point using the standard shutdown procedures. Drain the 22.10, 22.15 and 22.16. Proceed with TEST AUTHORIZATION \#48.

\section{ANALYTICAL COMMENTS:}

1. Catalyst sampling requirements:

- slurried catalyst at end-of-run.

Exact quantities to be determined by operations, process, and research.

2. Continuous composition sampling requirements (GC):

- fresh feed,

- reactor in,

- reactor out,

- recycle

- 22.10 overheads

3. Periodic composition sampling requirements $(G C)$ :

- 22.11 off-gas (frequency to be determined by operations \& process)

Periodic composition sampling requirements (LC):

- methanol product (every 8 hours during first two days, twice a day thereafter)

4. Flow measurement requirements:

- fresh feed,

- reactor in,

- reactor out,

- recycle,

- purge,

- 22.11 off-gas,

- methanol product

\section{REFERENCES:}

1. TEST AUTHORIZATION \#20 - Procedures for reactor standby during shutdown.

2. STANDARD STARTUP PROCEDURES FOR MEOH-ONLY OPERATION 
RUN PLAN FOR FLUID DYNAMIC / METHANOL RUN (JUNE, 1995)

\begin{tabular}{|c|c|c|c|c|c|c|}
\hline RUN & & & AF-A9 & AF-R13.1 & AF-R.13.2 & AF-R.13.3 \\
\hline Description & $\cdots$ & $\cdots$ & BSLN (REDTN) & BSLN (PVS) & BSLN (PVS) & BSLN (PVS) \\
\hline Duration & $\ldots$ & days & 1 & 2 & 3 & 2 \\
\hline Syngas & $\cdots$ & $\cdots$ & $\cdots$ & TEXACO & KINGSPORT & TEXACO \\
\hline Inlet Space Velocity & $\ldots$ & $\mathrm{sl} / \mathrm{kg} \cdot \mathrm{hr}$ & 615 & 7,000 & 4,000 & 10,000 \\
\hline Reactor Pressure & PIC-1247 & psig & 67 & 750 & 735 & 750 \\
\hline \multicolumn{7}{|l|}{ REACTOR } \\
\hline Pressure & PIC-1247 & psig & 67 & 750 & 735 & 750 \\
\hline Temperature & $\mathrm{Tl}-1233$ & $\mathbf{F}$ & $\cdots$ & 482 & 482 & 482 \\
\hline Heat Duty & \multicolumn{2}{|c|}{ MM BTU/hr } & $\cdots$ & 1.10 & 1.14 & 1.31 \\
\hline Inlet Superficial Velocity & $\cdots$ & $\mathrm{ft} / \mathrm{sec}$ & 0.62 & 0.83 & 0.48 & 1.20 \\
\hline Outlet Superficial Velocity & $\cdots$ & $\mathrm{ft} / \mathrm{sec}$ & 0.62 & 0.68 & 0.35 & 1.01 \\
\hline Liquid Level & 나-2142 & $\%$ span & $80 \%$ & $100 \%$ & $100 \%$ & $100 \%$ \\
\hline Catalyst Load & $\cdots$ & $\mathrm{Ib}$ & 1,177 & 1,177 & 1,177 & 1,177 \\
\hline Cat Weight Fraction & $\cdots$ & $\%$ & $40 \%$ & $42 \%$ & $40 \%$ & $43 \%$ \\
\hline Vapor Void Fraction & $\cdots$ & $\%$ & $24 \%$ & $43 \%$ & $35 \%$ & $48 \%$ \\
\hline \multicolumn{7}{|l|}{ FRESH FEED FLOWS } \\
\hline LP H2 & FIC-101 & scfh & 0 & 18,342 & 21,495 & 14,774 \\
\hline $\mathrm{CO}$ & FIC-104 & scfh & 500 & 15,217 & 11,995 & 18,598 \\
\hline $\mathrm{CO} 2$ & FIC-107 & scth & 0 & 1,185 & 1,040 & 1,373 \\
\hline N2 & FIC-111 & scfh & 12,000 & 56 & 270 & 55 \\
\hline 01.10 Total Flow & Fl-726 & scth & 12,500 & 34,800 & 34,800 & 34,800 \\
\hline & & & & & & \\
\hline $\mathrm{HP} \mathrm{H} 2$ & FIC-1200 & scfh & 0 & 7,283 & 2,467 & 17,837 \\
\hline 01.20 Recycle & FIC-246 & scth & 0 & 100,929 & 43,670 & 151,825 \\
\hline \multicolumn{7}{|l|}{ REACTOR FEED } \\
\hline Target Feed Temp & TI-1253 & $\mathrm{F}$ & $\cdots$ & 362 & 392 & 357 \\
\hline Feed Dewpoint & $\cdots$ & $\mathrm{F}$ & $\ldots$ & 89 & 78 & 91 \\
\hline Total Dry Flow & Fl-1216 & scth & 12,500 & 143,012 & 80,937 & 204,462 \\
\hline $\mathrm{H} 2$ & $\cdots$ & $\mathrm{mol} \%$ & $0.0 \%$ & $34.70 \%$ & $60.90 \%$ & $34.70 \%$ \\
\hline $\mathrm{CO}$ & $\cdots$ & $\mathrm{mol} \%$ & $4.0 \%$ & $50.56 \%$ & $24.49 \%$ & $50.56 \%$ \\
\hline N2 & $\cdots$ & mol\% & $96.0 \%$ & $0.99 \%$ & $3.90 \%$ & $0.99 \%$ \\
\hline $\mathrm{CO} 2$ & $\cdots$ & $\mathrm{mol} \%$ & $0.0 \%$ & $12.88 \%$ & $10.02 \%$ & $12.88 \%$ \\
\hline $\mathrm{MEOH}$ & $\cdots$ & mol\% & $0.0 \%$ & $0.71 \%$ & $0.42 \%$ & $0.75 \%$ \\
\hline ETOH & $\cdots$ & $\mathrm{mol} \%$ & $0.0 \%$ & $0.00 \%$ & $0.00 \%$ & $0.00 \%$ \\
\hline PROH & $\cdots$ & $\mathrm{mol} \%$ & $0.0 \%$ & $0.00 \%$ & $0.00 \%$ & $0.00 \%$ \\
\hline C1 & $\cdots$ & $\mathrm{mol} \%$ & $0.0 \%$ & $0.00 \%$ & $0.08 \%$ & $0.02 \%$ \\
\hline & & & $100.0 \%$ & $99.84 \%$ & $99.81 \%$ & $99.90 \%$ \\
\hline
\end{tabular}


RUN PLAN FOR FLUID DYNAMIC / METHANOL RUN (JUNE, 1995)

\begin{tabular}{|c|c|c|c|c|c|c|}
\hline RUN & & & AF-A9 & $\mathrm{AF}-\mathrm{R} 13.1$ & AF-R.13.2 & AF-R.13.3 \\
\hline Description & $\cdots$ & $\cdots$ & BSLN (REDTN) & BSLN (PVS) & BSLN (PVS) & BSLN (PVS) \\
\hline \multicolumn{7}{|l|}{ 21.11 Feed/Product Exchanger } \\
\hline Feed Inlet Temp & $\mathrm{TI}-1257$ & $\mathbf{F}$ & $\cdots$ & 172 & 210 & 165 \\
\hline Feed Outlet Temp & $\mathrm{TH}-1263$ & $F$ & $\cdots$ & 402 & 402 & 402 \\
\hline Total Feed to 02.63 Temp & $\mathrm{Tl}-1216$ & $F$ & $\cdots$ & 362 & 392 & 357 \\
\hline Reactor Eff. Inlet Temp & $\mathrm{Tl}-1262$ & $\mathbf{F}$ & $\cdots$ & 482 & 482 & 482 \\
\hline Reactor Eff. Outlet Temp & TIC-1260 & $\mathbf{F}$ & $\cdots$ & 280 & 280 & 280 \\
\hline Reactor Eff. Dew Temp & $\cdots$ & $\mathrm{F}$ & $\cdots$ & 226 & 268 & 219 \\
\hline \multicolumn{7}{|l|}{ REACTOR EFFLUENT } \\
\hline Total Flow & FI-196 & scfh & $\cdots$ & 118,117 & 59,152 & 172,712 \\
\hline $\mathrm{H} 2$ & $\cdots$ & $\mathrm{mol} \%$ & $\cdots$ & $20.91 \%$ & $46.47 \%$ & $22.64 \%$ \\
\hline $\mathrm{CO}$ & $\cdots$ & $\mathrm{mol} \%$ & $\cdots$ & $50.50 \%$ & $14.66 \%$ & $50.58 \%$ \\
\hline N2 & $\cdots$ & $\mathrm{mol} \%$ & $\cdots$ & $1.20 \%$ & $5.36 \%$ & $1.18 \%$ \\
\hline $\mathrm{CO} 2$ & $\cdots$ & $\mathrm{mol} \%$ & $\cdots$ & $15.79 \%$ & $14.01 \%$ & $15.35 \%$ \\
\hline MEOH & $\cdots$ & $\mathrm{mol} \%$ & $\ldots$ & $11.09 \%$ & $17.88 \%$ & $9.87 \%$ \\
\hline DME & & $\mathrm{mol} \%$ & & $0.09 \%$ & $0.25 \%$ & $0.05 \%$ \\
\hline ETOH & $\cdots$ & $\mathrm{mol} \%$ & $\cdots$ & $0.08 \%$ & $0.24 \%$ & $0.06 \%$ \\
\hline $\mathrm{PROH}$ & $\cdots$ & $\mathrm{mol} \%$ & $\cdots$ & $0.02 \%$ & $0.08 \%$ & $0.01 \%$ \\
\hline $\mathrm{C} 4 \mathrm{OH}$ & $\cdots$ & $\mathrm{mol} \%$ & $\cdots$ & $0.01 \%$ & $0.03 \%$ & $0.00 \%$ \\
\hline $\mathrm{IBOH}$ & $-\cdots$ & $\mathrm{mol} \%$ & $\cdots$ & $0.00 \%$ & $0.01 \%$ & $0.00 \%$ \\
\hline $\mathrm{C} 5 \mathrm{OH}+$ & $\cdots$ & $\mathrm{mol} \%$ & $\cdots$ & $0.01 \%$ & $0.02 \%$ & $0.00 \%$ \\
\hline C1 & $\cdots$ & $\mathrm{mol} \%$ & $\cdots$ & $0.04 \%$ & $0.16 \%$ & $0.03 \%$ \\
\hline & & & $\ldots$ & $99.73 \%$ & $99.17 \%$ & $99.77 \%$ \\
\hline \multicolumn{7}{|l|}{ PRODUCT RECOVERY } \\
\hline Syngas to Backend Flow & $\mathrm{FI}-682$ & scfh & $\cdots$ & None & None & None \\
\hline 22.11 to Flare Flow & $\mathrm{Fl}-237$ & scfh & $\cdots$ & 854 & 630 & 1,046 \\
\hline Main Flare Flow & $\mathrm{FI}-245$ & scfh & $\cdots$ & 3,869 & 3,869 & 3,869 \\
\hline Product Flow & $\cdots$ & gpd & $\cdots$ & 3,794 & 3,319 & 4,852 \\
\hline \multicolumn{7}{|l|}{ RECYCLE FEED } \\
\hline $\mathrm{H} 2$ & $\cdots$ & $\mathrm{mol} \%$ & $\cdots$ & $23.52 \%$ & $57.66 \%$ & $25.08 \%$ \\
\hline $\mathrm{CO}$ & $\cdots$ & $\mathrm{mol} \%$ & $\cdots$ & $56.76 \%$ & $18.13 \%$ & $55.97 \%$ \\
\hline N2 & $\cdots$ & $\mathrm{mol} \%$ & $\cdots$ & $1.35 \%$ & $6.65 \%$ & $1.30 \%$ \\
\hline $\mathrm{CO} 2$ & $\cdots$ & $\mathrm{mol} \%$ & $-\cdots$ & $17.13 \%$ & $16.29 \%$ & $16.48 \%$ \\
\hline $\mathrm{MEOH}$ & $\cdots$ & $\mathrm{mol} \%$ & $\cdots$ & $1.01 \%$ & $0.78 \%$ & $1.01 \%$ \\
\hline C1 & $\cdots$ & $\mathrm{mol} \%$ & $\cdots$ & $0.04 \%$ & $0.16 \%$ & $0.03 \%$ \\
\hline & & & $\cdots$ & $99.81 \%$ & $99.67 \%$ & $99.87 \%$ \\
\hline
\end{tabular}




$\begin{array}{ll}\text { Sheet: } & 1 \text { of } 4 \\ \text { Date : } & \text { 06/12/95 } \\ \text { By: } & \text { BLB }\end{array}$

RUN NUMBER:

APPROX. START DATE:
AF-A10

12 June, 1995

TITLE: IN-SITU METHANOL CATALYST ACTIVATION USING DILUTE CO PRIOR TO HYDRODYNAMIC RUN

\section{OBJECTIVE:}

To activate the Liquid-Phase Methanol (LPMEOH) synthesis catalyst.

SUMMARY:

Approximately $1177 \mathrm{lbs}$ of an alternate methanol catalyst is to be slurried with Drakeol-10 oil, transferred to the 27.20 reactor and activated with dilute $\mathrm{CO}$ ( $4 \%$ in nitrogen). Approximate run time is 2 days.

TEST DETAILS: $\quad$ See pages 2 to 4 for details.

ANALYTICAL COMMENTS: See page 4.

SAFETY IMPLICATIONS:

Operators should wear protective gear while loading catalyst to protect them from the dust and hot vapor which may be released from the loading nozzle. Protective gear including face shield should be worn during slurry sampling.

This operation will require the venting of unreacted $C O$. During a previous activation (performed under TEST AUTHORIZATION \#29) the off-gas was blended with methane and burned in the flare. Previous calculations (for TA \#23) indicated that in the event a combustible mixture could not be maintained, there would be no danger to personnel from venting. The reduction gas flow rates to be used in this run are less than those used in TA \#23.

\section{ENVIRONMENTAL IMPLICATIONS:}

Minimal, a flame will be maintained at the flare. At $98 \%$ destruction efficiency, the $\mathrm{CO}$ emission rate would be $0.72 \mathrm{lb} / \mathrm{hr}$.

\section{SPECIAL REMARKS:}

$\mathrm{CO}$ and $\mathrm{H}_{2}$ concentrations in and out of the reactor must be monitored closely during the reduction. Reactor temperature must be closely monitored and controlled per the attached TEST DETAILS. The utility oil inlet temperature ( $\mathrm{TI} 1244$ ) to the 27.20 internal heat exchanger must not exceed a $200^{\circ} \mathrm{F}$ difference from the utility oil outlet temperature (TI-1246) or the reactor slurry temperature. These two temperature differentials are measured directly by TDI-1252 \& TDI-1237. When adjusting flows or pressure, care should be taken to minimize catalyst carryover (caused by high gas velocity).

AUTHORIZATIONS:

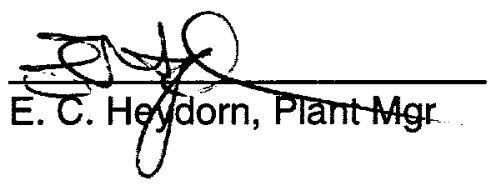

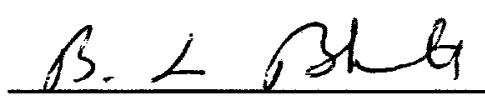

B. L. Bhatt, Process Engr 
Sheet: $\quad 2$ of 4

Date : $\quad 06 / 12 / 95$

By: $\quad$ BLB

\section{TEST DETAILS:}

1. This reduction procedure follows previous methanol catalyst reductions from the LPIII ER-6 reduction (TEST AUTHORIZATION \#23), 1991 DME run (\#25), 1992 LPSHIFT run (\#29), 1994 methanol run (\#37) and the recent hydrodynamic run with baseline catalyst (\#46).

2. Charge the 28.30 prep tank with $1766 \mathrm{lb}$ of oil ( 250 gallons of Drakeol-10 at $80^{\circ} \mathrm{F}$ ). The oil should be transferred to drums and weighed using the scale for accurate measurement. As an approximation, meter the oil with FQI-334 using a meter correction factor of actual $=1.027^{*}$ meter (meter should read $243 \mathrm{gal}$ ). If the temperature differs from $80^{\circ} \mathrm{F}$ a corrected oil volume should be used. Heat this oil to $150-200^{\circ} \mathrm{F}$.

3. Fill the 27.14 intermediate V/L separator to 25 nuts on LG-358 with approximately 100 gallons of Drakeol-10 oil from storage. Note the FQI-334 readings before and after the addition.

4. When the prep tank oil is at $150-200^{\circ} \mathrm{F}$, add $1177 \mathrm{lb}$ of alternate methanol catalyst ( 10 full drums and a portion from an eleventh drum). Add the catalyst very slowly to make a $40 \mathrm{wt} \%$ oxide slurry. Keep the slurry well stirred to prevent agglomeration of the catalyst.

5. Heat the slurry to $200^{\circ} \mathrm{F}$ and continue agitation, under nitrogen, for at least 2 hours to ensure good mixing.

6. When the catalyst and oil have been completely mixed, withdraw a sample of slurry.

7. Establish gas flow through the reactor using nitrogen through V-2627 to prevent slurry back-flow into the distributor. Vent the gas through PV-1261.

8. Pressure transfer the slurry to the reactor and verify operation by noting level with the nuclear density gauge (NDG- estimated level: 23 to $27 \mathrm{ft}$.)

9. Flush out the prep tank with $283 \mathrm{lb}$ of oil ( 40 gallons of Drakeol-10 at $80^{\circ} \mathrm{F}$ ). Measure the oil as in step 2 (meter should read approximately $38.9 \mathrm{gal}$ ). Pressure transfer the flush oil to the reactor and verify level with the NDG (LI-1242).

10. Close V-645 to prevent utility oil flow back to the prep tank and establish full utility oil flow through the 27.20 internal heat exchanger.

11. Pressurize the reactor loop to $67 \mathrm{psig.}$

12. Begin heating the slurry to $200^{\circ} \mathrm{F}$, following TAVR on the DEC console. Check that the slurry temperatures are in reasonable agreement. Verify that the slurry is well mixed by performing a NDG scan. 
LaPorte Alternative Fuels Development Unit (AFDU)

$\begin{array}{ll}\text { Sheet: } & 3 \text { of } 4 \\ \text { Date : } & \text { 06/12/95 } \\ \text { By: } & \text { BLB }\end{array}$

13. Establish Dilute $\mathrm{CO}$ reduction gas flow at $12500 \mathrm{SCFH}$ (on $\mathrm{Fl}-126$ ) and vent the flow through PV170. Establish the following composition:

$$
\begin{array}{ccc} 
& \text { Composition } & \text { Est. Flows (SCFH) } \\
\text { NO } & 4.0 & 500 \\
\text { N2 } & \frac{96.0}{100.0} & \frac{12000}{12500} \\
M W=28, \text { SCF evaluated at } 70^{\circ} \mathrm{F}, 14.7 \text { psia } \\
M \text { S }
\end{array}
$$

14. When the reactor temperature reaches $200^{\circ} \mathrm{F}$, bring reduction gas to the reactor slowly and close the nitrogen purge (V-2627). Establish a final flow to the reactor of $12,500 \mathrm{SCFH}$. Maintain flow and reducing gas composition as specified in step 13. The temperature-programmed activation consists of the following steps:

- Heat the slurry at a target rate of $15^{\circ} \mathrm{F} / \mathrm{hr}$ (no more than $18^{\circ} \mathrm{F} / \mathrm{hr}, 10^{\circ} \mathrm{C}$ ) until the slurry temperature reaches $464^{\circ} \mathrm{F}\left(240^{\circ} \mathrm{C}\right)$.

$\mathrm{H} 2$ and $\mathrm{CO}$ concentrations are to be measured continuously for the feed and effluent streams. As long as the cumulative $\mathrm{CO}$ consumption minus $\mathrm{H}_{2}$ Production at a given temperature is equal to or greater than the autoclave reduction data then the activation is proceeding well. Figure 1 shows the consumption profile vs temperature from the labs. If the cumulative consumption curve falls below the autoclave curve, consult the process or research engineer to reduce the heat up rate.

If the $\mathrm{CO}$ concentration in the effluent falls below 0.1 mole \%, increase the inlet $\mathrm{CO}$ concentration per the instructions of the process or research engineer. The objective here is to prevent reduction gas starvation.

Once a slurry temperature of $392^{\circ} \mathrm{F}$ is reached decrease the dilute $\mathrm{CO}$ reduction gas flow to $9375 \mathrm{SCFH}$ (on Fl-126). Maintain the following composition:

\section{Composition}

$\mathrm{CO}$
$\mathrm{N} 2$

$\mathrm{MW}=28, \mathrm{SCF}$ evaluated at $70^{\circ} \mathrm{F}, 14.7 \mathrm{psia}$

Target space velocity $=461 \mathrm{sL} / \mathrm{h}-\mathrm{kg}$; Target starting inlet superficial velocity $=0.47 \mathrm{ft} / \mathrm{sec}$

\section{Est. Flows (SCFH)}

375

$\underline{9000}$

9375

The reduction is expected to be complete before reaching $464^{\circ} \mathrm{F}$. It may become necessary to hold slurry at this temperature until the difference between inlet and outlet $\mathrm{CO}$ concentration falls below 0.05 mole $\%$. 


$\begin{array}{ll}\text { Sheet: } & 4 \text { of } 4 \\ \text { Date : } & 06 / 12 / 95 \\ \text { By: } & \text { BLB }\end{array}$

15. The slurry level should be maintained between 90 and $95 \%$ of NDG range (approximately $40 \mathrm{ft}$.) by using LIC 1242 to control the makeup oil rate. Note that as the reactor is heated to $464 \mathrm{~F}$, the slurry will expand. At the same time, some of the oil will be lost in the reactor effluent. If authorized by the process engineer or the plant manager, additional makeup oil can be added to the system via the 27.14 by following the standard procedure; FQI-334 readings and the change in level of the 27.14 should be recorded before and after each addition. It is important to note that the discharge valve of the 10.52 .01 and 02 pumps should be used to throttle to the $67 \mathrm{psig}$ reactor pressure. The pressure in the sump of the 21.11 should be at $150 \mathrm{psig}$ or less.

16. Record any indication of density or viscosity change, such as a change in the pressure drop across the reactor or shaking of the reactor during heat up and reduction.

17. During the reduction, scan the reactor with the NDG, record levels in the 21.11 and 27.14 every 4 hrs. At the end of the reduction, add fresh oil to 27.14 to bring the level up to 25 nuts on LG-358. This charge should be drawn from storage; note the FQI-334 readings before and after addition.

TA \#48 is done, consult TEST AUTHORIZATION \#49 for the next step.

\section{ANALYTICAL REQUIREMENTS:}

1. Catalyst sampling requirements:

- slurried oxide catalyst from prep tank before reduction,

Exact quantities to be determined by operations, process, and research.

2. Composition sampling requirements:

- reactor in and out continuously

- $\mathrm{H} 2$ and $\mathrm{CO}$ are critical

- $\mathrm{CO} 2$ and N2 are also required

3. Flow measurement requirements:

- reactor in at $\mathrm{Fl}-126$ and $\mathrm{Fl}-299$

\section{REFERENCES:}

1. TEST AUTHORIZATION \# 23 : Procedure for previous in-situ activation. 
RUN PLAN FOR FLUID DYNAMIC / METHANOL RUN (JUNE, 1995)

\begin{tabular}{|c|c|c|c|c|c|c|c|c|c|c|c|}
\hline RUN & & & $A F-A 10$ & AF-R14.1 & AF-R14.2 & AF-R14.3 & AF-P14.4 & AF-R14.5 & AF-R14.6 & AF-A14.7 & AF-R14.8 \\
\hline Description & $\cdots$ & $\cdots$ & ALT (REDTN) & ALT (PVS) & ALT (PVS) & ALT (PVS) & ALT (PVS) & ALT (PVS) & ALT (TRC) & ALT (TRC) & $\mathrm{ALT}(\mathrm{TRC})$ \\
\hline Duration & $\cdots$ & days & 1 & 2 & 3 & 1.5 & 1.5 & 1 & 1 & 1 & 1 \\
\hline Syngas & $\cdots$ & $\cdots$ & $\cdots$ & TEXACO & KINGSPORT & KINGSPORT & TEXACO & TEXACO & TEXACO & TEXACO & KINGSPORT \\
\hline Inlet Space Velocity & $\cdots$ & sL/kg-hr & 615 & 7,000 & 4,000 & 10,000 & 4,000 & 7,000 & 7,000 & 4,000 & 7,000 \\
\hline Reactor Pressure & PIC-1247 & psig & 67 & 750 & 735 & 735 & 750 & 750 & 750 & 750 & 520 \\
\hline & & & & & & & & & & & \\
\hline \multicolumn{12}{|l|}{ REACTOR } \\
\hline Pressure & PIC-1247 & psig & 67 & 750 & 735 & 735 & 750 & 750 & 750 & 750 & 520 \\
\hline Temperature & TI-1233 & $\mathrm{F}$ & $\cdots$ & 482 & 482 & 482 & 482 & 482 & 482 & 482 & 482 \\
\hline Heat Duty & \multicolumn{2}{|c|}{ MM BTU/hr } & $\cdots$ & 1.10 & 1.14 & 2.00 & 0.73 & 1.10 & 1.10 & 0.73 & \\
\hline Inlet Superficial Velocity & $\cdots$ & $\mathrm{ft} / \mathrm{sec}$ & 0.62 & 0.83 & 0.48 & 1.21 & 0.47 & 0.83 & 0.83 & 0.47 & 1.18 \\
\hline Outlet Superficial Velocity & $\cdots$ & $\mathrm{ft} / \mathrm{sec}$ & 0.62 & 0.68 & 0.35 & 0.95 & 0.38 & 0.68 & 0.68 & 0.38 & 0.94 \\
\hline Liquid Level & LI-2142 & $\%$ span & $80 \%$ & $100 \%$ & $100 \%$ & $100 \%$ & $100 \%$ & $100 \%$ & $100 \%$ & $100 \%$ & $100 \%$ \\
\hline Catalyst Load & $\ldots$ & Ib & 1,177 & 1,177 & 1,177 & 1,177 & 1,177 & 1,177 & 1,177 & 1,177 & 1,158 \\
\hline Cat Weight Fraction & $\ldots$ & $\%$ & $40 \%$ & $42 \%$ & $40 \%$ & $41 \%$ & $41 \%$ & $42 \%$ & $42 \%$ & $41 \%$ & $44 \%$ \\
\hline Vapor Void Fraction & $\cdots$ & $\%$ & $24 \%$ & $43 \%$ & $35 \%$ & $42 \%$ & $39 \%$ & $43 \%$ & $43 \%$ & $39 \%$ & $49 \%$ \\
\hline \multicolumn{12}{|l|}{ FRESH FEED FLOWS } \\
\hline LP H2 & $\mathrm{FIC}-101$ & scth & 0 & 18,342 & 21,495 & 11,080 & 16,029 & 18,342 & 18,342 & 16,029 & 1,620 \\
\hline $\mathrm{CO}$ & FIC-104 & scth & 500 & 15,217 & 11,995 & 21,420 & 10,469 & 15,217 & 15,217 & 10,469 & 10,000 \\
\hline $\mathrm{CO} 2$ & $\mathrm{FIC}-107$ & scth & 0 & 1,185 & 1,040 & 2,050 & 914 & 1,185 & 1,185 & 914 & 772 \\
\hline N2 & FIC-111 & scfh & 12,000 & 56 & 270 & 250 & 56 & 56 & 56 & 56 & 61 \\
\hline 01.10 Total Flow & FI-726 & scth & 12,500 & 34,800 & 34,800 & 34,800 & 27,468 & 34,800 & 34,800 & 27,468 & 12,453 \\
\hline & & & & & & & & & & & \\
\hline $\mathrm{HP} \mathrm{H} 2$ & FIC-1200 & scth & 0 & 7,283 & 2,467 & 33,730 & 0 & 7,283 & 7,283 & 0 & 18,930 \\
\hline 01.20 Recycle & FIC-246 & scfh & 0 & 100,929 & 43,670 & 134,220 & 54,113 & 100,929 & 100,929 & 54,113 & 110,160 \\
\hline \multicolumn{12}{|l|}{ REACTOR FEED } \\
\hline Target Feed Temp & TI-1253 & $\mathbf{F}$ & $\cdots$ & 362 & 392 & 373 & 369.0 & 362 & 362 & 369.0 & 373 \\
\hline Feed Dewpoint & $\ldots$ & $F$ & $\ldots$ & 89 & 78 & 86 & 87.0 & 89 & 89 & 87.0 & 86 \\
\hline Total Dry Flow & FI-1216 & scfh & 12,500 & 143,012 & 80,937 & 203,230 & 81,581 & 143,012 & 143,012 & 81,581 & 141,690 \\
\hline $\mathrm{H} 2$ & $\cdots$ & $\mathrm{mol} \%$ & $0.0 \%$ & $34.70 \%$ & $60.90 \%$ & $60.92 \%$ & $34.68 \%$ & $34.70 \%$ & $34.70 \%$ & $34.68 \%$ & $60.92 \%$ \\
\hline $\mathrm{CO}$ & $\cdots$ & $\mathrm{mol} \%$ & $4.0 \%$ & $50.56 \%$ & $24.49 \%$ & $24.50 \%$ & $50.54 \%$ & $50.56 \%$ & $50.56 \%$ & $50.54 \%$ & $24.50 \%$ \\
\hline N2 & $\cdots$ & $\mathrm{mol} \%$ & $96.0 \%$ & $0.99 \%$ & $3.90 \%$ & $3.90 \%$ & $0.99 \%$ & $0.99 \%$ & $0.99 \%$ & $0.99 \%$ & $3.90 \%$ \\
\hline $\mathrm{CO} 2$ & $\cdots$ & $\mathrm{mol} \%$ & $0.0 \%$ & $12.88 \%$ & $10.02 \%$ & $10.03 \%$ & $12.88 \%$ & $12.88 \%$ & $12.88 \%$ & $12.88 \%$ & $10.03 \%$ \\
\hline $\mathrm{MEOH}$ & $\cdots$ & $\mathrm{mol} \%$ & $0.0 \%$ & $0.71 \%$ & $0.42 \%$ & $0.53 \%$ & $0.67 \%$ & $0.71 \%$ & $0.71 \%$ & $0.67 \%$ & $0.53 \%$ \\
\hline ETOH & $\cdots$ & $\mathrm{mol} \%$ & $0.0 \%$ & $0.00 \%$ & $0.00 \%$ & $0.00 \%$ & $0.00 \%$ & $0.00 \%$ & $0.00 \%$ & $0.00 \%$ & $0.00 \%$ \\
\hline PROH & $\cdots$ & $\mathrm{mol} \%$ & $0.0 \%$ & $0.00 \%$ & $0.00 \%$ & $0.00 \%$ & $0.00 \%$ & $0.00 \%$ & $0.00 \%$ & $0.00 \%$ & $0.00 \%$ \\
\hline C1 & $\cdots$ & $\mathrm{mol} \%$ & $0.0 \%$ & $0.00 \%$ & $0.08 \%$ & $0.04 \%$ & $0.04 \%$ & $0.00 \%$ & $0.00 \%$ & $0.04 \%$ & $0.04 \%$ \\
\hline & & & $100.0 \%$ & $99.84 \%$ & $99.81 \%$ & $99.92 \%$ & $99.80 \%$ & $99.84 \%$ & $99.84 \%$ & $99.80 \%$ & $99.92 \%$ \\
\hline
\end{tabular}


RUN PLAN FOR FLUID DYNAMIC / METHANOL RUN (JUNE, 1995)

\begin{tabular}{|c|c|c|c|c|c|c|c|c|c|c|c|}
\hline RUN & & & AF-A10 & AF-R14.1 & AF-R14.2 & AF-R14.3 & AF-R14.4 & AF-R14.5 & AF-R14.6 & AF-R14.7 & AF-R14.8 \\
\hline Description & $\cdots$ & $\cdots$ & ALT (REDTN) & ALT (PVS) & ALT (PVS) & ALT (PVS) & ALT (PVS) & ALT (PVS) & ALT (TRC) & ALT (TRC) & ALT (TRC) \\
\hline \multicolumn{12}{|l|}{ 21.11 Feed/Product Exchanger } \\
\hline Feed Inlet Temp & $\mathrm{Tl}-1257$ & $\mathrm{~F}$ & $-\cdots$ & 172 & 210 & 197 & 180 & 172 & 172 & 180 & 197 \\
\hline Feed Outlet Temp & $\mathrm{TI}-1263$ & $\mathrm{~F}$ & $\cdots$ & 402 & 402 & 402 & 403 & 402 & 402 & 403 & 402 \\
\hline Total Feed to 02.63 Temp & $\mathrm{Tl}-1216$ & $\mathrm{~F}$ & $\cdots$ & 362 & 392 & 373 & 369 & 362 & 362 & 369 & 373 \\
\hline Reactor Eff. Inlet Temp & $\mathrm{TI}-1262$ & $\mathrm{~F}$ & $\cdots$ & 482 & 482 & 482 & 482 & 482 & 482 & 482 & 482 \\
\hline Reactor Eff. Outlet Temp & $\mathrm{TIC}-1260$ & $F$ & $\cdots$ & 280 & 280 & 280 & 280 & 280 & 280 & 280 & 280 \\
\hline Reactor Eff. Dew Temp & $\cdots$ & $F$ & $\cdots$ & 226 & 268 & 247 & 232 & 226 & 226 & 232 & \\
\hline \multicolumn{12}{|l|}{ REACTOR EFFLUENT } \\
\hline Total Flow & $\mathrm{Fl}-196$ & scth & $\cdots$ & 118,117 & 59,152 & 172,712 & 66,177 & 118,117 & 118,117 & 66,177 & 116,380 \\
\hline $\mathrm{H} 2$ & $\cdots$ & $\mathrm{mol} \%$ & $\cdots$ & $20.91 \%$ & $46.47 \%$ & $50.31 \%$ & $19.50 \%$ & $20.91 \%$ & & & \\
\hline $\mathrm{CO}$ & $\cdots$ & $\mathrm{mol} \%$ & $\cdots$ & $50.50 \%$ & $14.66 \%$ & $18.18 \%$ & $50.29 \%$ & $50.50 \%$ & & & \\
\hline N2 & $\cdots$ & $\mathrm{mol} \%$ & $\cdots$ & $1.20 \%$ & $5.36 \%$ & $4.93 \%$ & $1.23 \%$ & $1.20 \%$ & & & \\
\hline $\mathrm{CO} 2$ & $\cdots$ & $\mathrm{mol} \%$ & $\cdots$ & $15.79 \%$ & $14.01 \%$ & $12.27 \%$ & $16.28 \%$ & $15.79 \%$ & & & \\
\hline $\mathrm{MEOH}$ & $\cdots$ & $\mathrm{mol} \%$ & $\cdots$ & $11.09 \%$ & $17.88 \%$ & $13.64 \%$ & $11.94 \%$ & $11.09 \%$ & & & \\
\hline DME & & $\mathrm{mol} \%$ & & $0.09 \%$ & $0.25 \%$ & $0.04 \%$ & $0.18 \%$ & $0.09 \%$ & & & \\
\hline ETOH & $\cdots$ & $\mathrm{mol} \%$ & $\cdots$ & $0.08 \%$ & $0.24 \%$ & $0.01 \%$ & $0.12 \%$ & $0.08 \%$ & & & \\
\hline PROH & $\cdots$ & $\mathrm{mol} \%$ & $\cdots$ & $0.02 \%$ & $0.08 \%$ & $0.00 \%$ & $0.03 \%$ & $0.02 \%$ & & & \\
\hline $\mathrm{C} 4 \mathrm{OH}$ & $\cdots$ & $\mathrm{mol} \%$ & $\cdots$ & $0.01 \%$ & $0.03 \%$ & $0.00 \%$ & $0.01 \%$ & $0.01 \%$ & & & \\
\hline $\mathrm{IBOH}$ & $\cdots$ & $\mathrm{mol} \%$ & $\cdots$ & $0.00 \%$ & $0.01 \%$ & $0.00 \%$ & $0.00 \%$ & $0.00 \%$ & & & \\
\hline $\mathrm{C} 5 \mathrm{OH}+$ & $\cdots$ & $\mathrm{mol} \%$ & $\cdots$ & $0.01 \%$ & $0.02 \%$ & $0.00 \%$ & $0.01 \%$ & $0.01 \%$ & & & \\
\hline C1 & $\cdots$ & $\mathrm{mol} \%$ & $\cdots$ & $0.04 \%$ & $0.16 \%$ & $0.07 \%$ & $0.07 \%$ & $0.04 \%$ & & & \\
\hline & & & $\cdots$ & $99.73 \%$ & $99.17 \%$ & $99.45 \%$ & $99.66 \%$ & $99.73 \%$ & & & \\
\hline \multicolumn{12}{|l|}{ PRODUCT RECOVERY } \\
\hline Syngas to Backend Flow & FI-682 & scth & $\cdots$ & None & None & None & None & None & None & None & None \\
\hline 22.11 to Flare Flow & Fl-237 & scth & $\cdots$ & 854 & 630 & 1,050 & 552 & 854 & 854 & 552 & 500 \\
\hline Main Flare Flow & $\mathrm{Fl}-245$ & scth & $\cdots$ & 3,869 & 3,869 & 3,869 & 3,869 & 3,869 & 3,869 & 3,869 & 1,000 \\
\hline Product Flow & $\ldots$ & gpd & $\cdots$ & 3,794 & 3,319 & 6,510 & 2,337 & 3,794 & 3,794 & 2,337 & 3,247 \\
\hline \multicolumn{12}{|l|}{ RECYCLE FEED } \\
\hline $\mathrm{H} 2$ & $\cdots$ & $\mathrm{mol} \%$ & $\cdots$ & $23.52 \%$ & $57.66 \%$ & $58.53 \%$ & $22.20 \%$ & $23.52 \%$ & & & \\
\hline CO & $\cdots$ & $\mathrm{mol} \%$ & $\cdots$ & $56.76 \%$ & $18.13 \%$ & $21.22 \%$ & $57.21 \%$ & $56.76 \%$ & & & \\
\hline N2 & $\cdots$ & $\mathrm{mol} \%$ & $\cdots$ & $1.35 \%$ & $6.65 \%$ & $5.72 \%$ & $1.40 \%$ & $1.35 \%$ & & & \\
\hline $\mathrm{CO} 2$ & $\cdots$ & $\mathrm{mol} \%$ & $\cdots$ & $17.13 \%$ & $16.29 \%$ & $13.65 \%$ & $17.82 \%$ & $17.13 \%$ & & & \\
\hline $\mathrm{MEOH}$ & $\cdots$ & $\mathrm{mol} \%$ & $\cdots$ & $1.01 \%$ & $0.78 \%$ & $0.81 \%$ & $1.01 \%$ & $1.01 \%$ & & & \\
\hline C1 & $\cdots$ & $\mathrm{mol} \%$ & $\cdots$ & $0.04 \%$ & $0.16 \%$ & $0.06 \%$ & $0.06 \%$ & $0.04 \%$ & & & \\
\hline & & & $\cdots$ & $99.81 \%$ & $99.67 \%$ & $99.99 \%$ & $99.70 \%$ & $99.81 \%$ & & & \\
\hline
\end{tabular}




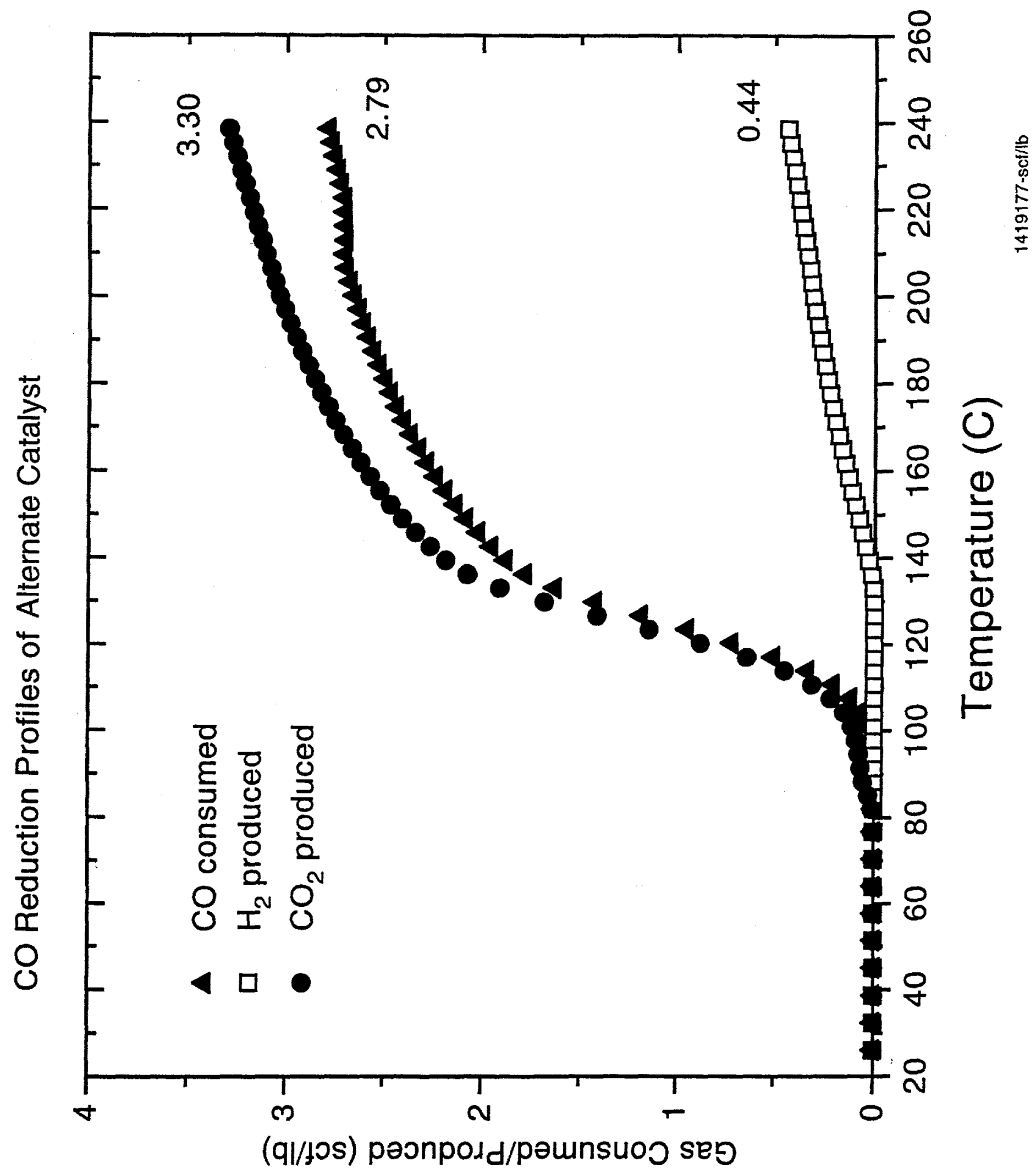


TEST AUTHORIZATION \# 49

LaPorte Alternative Fuels Development Unit (AFDU)

Sheet: 1 of 3

Date : 06/13/95

By: $\quad$ BLB

RUN NUMBER:

APPROX. START DATE:
AF-R14

13 June, 1995

\section{TITLE: $\quad$ METHANOL SYNTHESIS WITH ALTERNATE CATALYST}

\section{OBJECTIVE:}

To study the performance of the alternate methanol catalyst in the 27.20 reactor train.

\section{SUMMARY:}

Upon completion of the activation step (AF-A10), the reactor feed will be adjusted to a Texaco gas composition ( $35 \% \mathrm{H} 2,51 \% \mathrm{CO}, 13 \% \mathrm{CO} 2,1 \% \mathrm{~N} 2)$. For approximately 2 days, the conditions will be targeted at $750 \mathrm{psig}, 482^{\circ} \mathrm{F}, 7,000 \mathrm{sL} / \mathrm{kg}$-hr space velocity, and $40 \mathrm{wt} \%$ oxide in oil. The gas composition will then be switched to a Kingsport LPMEOH gas composition for three days of operation $(60.7 \% \mathrm{H} 2,24.4 \% \mathrm{CO}, 10.0 \% \mathrm{CO} 2,3.89 \% \mathrm{~N} 2)$. A high velocity condition will be tested next (1.2 ft/sec) with Kingsport gas for 1.5 days. Over following 3 days, two different gas velocity will be studied with Texaco gas. The initial baseline condition will then be repeated to check for any catalyst deactivation. A tracer study (Run Authorization \#50) will follow the process variable study.

The main objectives of this run are to evaluate the alternate catalyst performance in comparison with the baseline catalyst and perform hydrodynamic studies on the reactor.

TEST DETAILS:

See page 2.

ANALYTICAL COMMENTS: $\quad$ See page 3.

SAFETY IMPLICATIONS:

Protective gear including face shield should be worn during slurry sampling.

ENVIRONMENTAL IMPLICATIONS:

Minimal.

\section{SPECIAL REMARKS:}

The high pressure hydrogen pipe line will be in use during run AF-R14. The $\mathrm{CO} 2$ removal system will not be in operation. Special sample bombs will be used to collect samples of the methanol product produced during case AF-R14.2.

AUTHORIZATIONS:
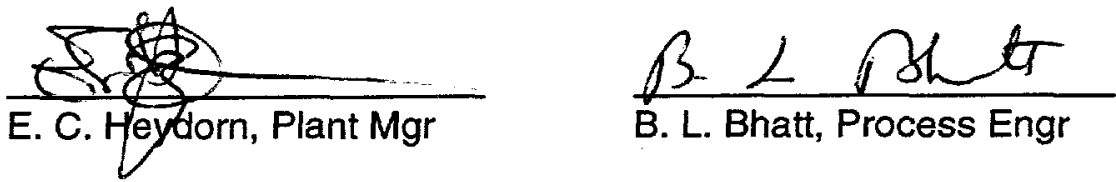

B. L. Bhatt, Process Engr 


\section{TEST DETAILS:}

1. Upon completion of the catalyst activation (AF-A10), switch from reduction gas to Texaco-type gas by following the standard procedure. The $\mathrm{CO}_{2}$ removal section should NOT be operating during this run (V-2001,V-2003,V-2004,V-2006 shut; V-2000 open). In the event of a premature shutdown, consult TA \#20 (RUN E-05) for appropriate standby conditions.

2. Increase the reactor pressure to $750 \mathrm{psig}$ and control the slurry temperature at $482^{\circ} \mathrm{F}$. Slowly increase the reactor feed rate to 25,000 SCFH while maintaining slurry level at $95 \%$ of NDG span. When the plant has lined out, the reactor feed composition should correspond closely to case AFR14.1 (refer to Table). Once the compositions are lined out, slowly introduce recycle flow and back off the fresh feed flowrates until they match the targets outlined in the Table for case AF-R14.1. Note that the HP hydrogen pipeline is in service during all the cases.

3. When the target feed rate has been achieved, put LIC-1242 in automatic to control slurry level at $95 \%$. Adjust the fresh feed flow to achieve an initial purge flow rate of approximately $3,000 \mathrm{SCFH}$. Maintain reactor feed flow and reactor temperature and pressure at the case AF-R14.1 values for a nominal 24 hour period.

4. During the first 24 hours, the syngas conversion across the reactor will fall as the catalyst loses its hyperactivity. The purge flow will increase and the reactor feed composition will be changing during this period. When these rates of change diminish, fine tune the fresh feed flow to reach the desired reactor feed composition as specified for case AF-R14.1. The ultimate purge rate should be around $3,900 \mathrm{SCFH}$.

5. After the initial break-in period, begin to increase rates to maximize production of methanol. Monitor the air-cooler loading and temperature difference between the utility oil and the slurry and utility oil inlet \& outlet using TDI-1237 and TDI-1252. Both of these temperature differences must be below $200^{\circ} \mathrm{F}$.

6. The composition of the methanol product is to be monitored every 8 hours. The target oil content of the methanol product should be $<=0.2 \mathrm{wt} \%$. If the oil content is higher, lower the 21.11 effluent outlet TIC-1260 set point.

7. Maintain conditions for approximately 2 days. After conferring with the process engineer or plant manager, switch to AF-R14.2 run conditions (Kingsport gas). Run this data period for approximately 3 days.

8. Liquid samples of the methanol product will be collected in special sample bombs and shipped to Allentown for detailed analysis during case AF-R14.2. The samples will be collected downstream of the 22.11 separator. Consult with the process engineer and analytical representative for the frequency and manner of taking the samples.

9. After conferring with the process engineer or plant manager, switch to AF-R14.3 run conditions (Kingsport gas). Run this data period for approximately 1.5 days. 
Sheet: 3 of 3

Date : 06/13/95

By: BLB

10. After conferring with the process engineer or plant manager, switch to AF-R14.4 run conditions (Texaco gas). Run this data period for approximately 1.5 days.

11. After conferring with the process engineer or plant manager, switch to AF-R14.5 run conditions (Texaco gas). Run this data period for approximately 1 day.

10. When notified by the plant manager that case AF-R14.5 is complete, refer to Run Authorization \#50 to proceed to the tracer study.

\section{ANALYTICAL COMMENTS:}

1. Catalyst sampling requirements:

- slurried catalyst at end-of-run.

Exact quantities to be determined by operations, process, and research.

2. Continuous composition sampling requirements (GC):

- fresh feed,

- reactor in,

- reactor out,

- recycle

-22.10 overheads

3. Periodic composition sampling requirements (GC):

- 22.11 off-gas (frequency to be determined by operations \& process)

Periodic composition sampling requirements (LC):

- methanol product (every 8 hours during first two days, twice a day thereafter)

4. Flow measurement requirements:

- fresh feed,

- reactor in,

- reactor out,

- recycle,

- purge,

- 22.11 off-gas,

- methanol product

\section{REFERENCES:}

1. TEST AUTHORIZATION \#20 - Procedures for reactor standby during shutdown.

2. STANDARD STARTUP PROCEDURES FOR MEOH-ONLY OPERATION 
RUN PLAN FOR FLUID DYNAMIC / METHANOL RUN (JUNE, 1995)

\begin{tabular}{|c|c|c|c|c|c|c|c|c|c|c|c|}
\hline RUN & & & AF-A10 & AF-R14.1 & AF-R14.2 & AF-R14.3 & AF-R14.4 & AF-R14.5 & AF-R14.6 & AF-R14.7 & AF-R14.8 \\
\hline Description & $\cdots$ & $\cdots$ & ALT (REDTN) & ALT (PVS) & ALT (PVS) & ALT (PVS) & ALT (PVS) & ALT (PVS) & ALT (TRC) & ALT (TRC) & ALT (TRC) \\
\hline Duration & $\cdots$ & days & 1 & 2 & 3 & 1.5 & 1.5 & 1 & 1 & 1 & 1 \\
\hline Syngas & $\cdots$ & $\cdots$ & $\cdots$ & TEXACO & KINGSPORT & KINGSPORT & TEXACO & TEXACO & TEXACO & TEXACO & KINGSPORT \\
\hline Inlet Space Velocity & $\cdots$ & $\mathrm{sL} / \mathrm{kg}-\mathrm{hr}$ & 615 & 7,000 & 4,000 & 10,000 & 4,000 & 7,000 & 7,000 & 4,000 & 7,000 \\
\hline Reactor Pressure & $\mathrm{PIC}-1247$ & psig & 67 & 750 & 735 & 735 & 750 & 750 & 750 & 750 & 520 \\
\hline \multicolumn{12}{|l|}{ REACTOR } \\
\hline Pressure & PIC-1247 & psig & 67 & 750 & 735 & 735 & 750 & 750 & 750 & 750 & 520 \\
\hline Temperature & $\mathrm{Tl}-1233$ & $\mathrm{~F}$ & $\cdots$ & 482 & 482 & 482 & 482 & 482 & 482 & 482 & 482 \\
\hline Heat Duty & \multicolumn{2}{|c|}{ MM BTU/hr } & $\cdots$ & 1.10 & 1.14 & 2.00 & 0.73 & 1.10 & 1.10 & 0.73 & \\
\hline Inlet Superficial Velocity & $\cdots$ & $\mathrm{ft} / \mathrm{sec}$ & 0.62 & 0.83 & 0.48 & 1.21 & 0.47 & 0.83 & 0.83 & 0.47 & 1.18 \\
\hline Outlet Superficial Velocity & $\cdots$ & $\mathrm{ft} / \mathrm{sec}$ & 0.62 & 0.68 & 0.35 & 0.95 & 0.38 & 0.68 & 0.68 & 0.38 & 0.94 \\
\hline Liquid Level & $\mathrm{LI}-2142$ & $\%$ span & $80 \%$ & $100 \%$ & $100 \%$ & $100 \%$ & $100 \%$ & $100 \%$ & $100 \%$ & $100 \%$ & $100 \%$ \\
\hline Catalyst Load & $\cdots$ & $\mathrm{Ib}$ & 1,177 & 1,177 & 1,177 & 1,177 & 1,177 & 1,177 & 1,177 & 1,177 & 1,158 \\
\hline Cat Weight Fraction & $\cdots$ & $\%$ & $40 \%$ & $42 \%$ & $40 \%$ & $41 \%$ & $41 \%$ & $42 \%$ & $42 \%$ & $41 \%$ & $44 \%$ \\
\hline Vapor Void Fraction & $\cdots$ & $\%$ & $24 \%$ & $43 \%$ & $35 \%$ & $42 \%$ & $39 \%$ & $43 \%$ & $43 \%$ & $39 \%$ & $49 \%$ \\
\hline \multicolumn{12}{|l|}{ FRESH FEED FLOWS } \\
\hline \begin{tabular}{|l|l|} 
LP H2 \\
\end{tabular} & FIC-101 & scfh & 0 & 18,342 & 21,495 & 11,080 & 16,029 & 18,342 & 18,342 & 16,029 & 1,620 \\
\hline $\mathrm{CO}$ & FIC-104 & scth & 500 & 15,217 & 11,995 & 21,420 & 10,469 & 15,217 & 15,217 & 10,469 & 10,000 \\
\hline $\mathrm{CO} 2$ & FIC-107 & scfh & 0 & 1,185 & 1,040 & 2,050 & 914 & 1,185 & 1,185 & 914 & 772 \\
\hline N2 & FIC-111 & scth & 12,000 & 56 & 270 & 250 & 56 & 56 & 56 & 56 & 61 \\
\hline 01.10 Total Flow & $\mathrm{FI}-726$ & scfh & 12,500 & 34,800 & 34,800 & 34,800 & 27,468 & 34,800 & 34,800 & 27,468 & 12,453 \\
\hline & & & & & & & & & & & \\
\hline HP H2 & FIC-1200 & scfh & 0 & 7,283 & 2,467 & 33,730 & 0 & 7,283 & 7,283 & 0 & 18,930 \\
\hline 01.20 Recycle & FIC-246 & scfh & 0 & 100,929 & 43,670 & 134,220 & 54,113 & 100,929 & 100,929 & 54,113 & 110,160 \\
\hline \multicolumn{12}{|l|}{ REACTOR FEED } \\
\hline Target Feed Temp & $\mathrm{TI}-1253$ & $F$ & $\cdots$ & 362 & 392 & 373 & 369.0 & 362 & 362 & 369.0 & 373 \\
\hline Feed Dewpoint & $\cdots$ & $F$ & $\cdots$ & 89 & 78 & 86 & 87.0 & 89 & 89 & 87.0 & 86 \\
\hline Total Dry Flow & $\mathrm{Fl}-1216$ & scfh & 12,500 & 143,012 & 80,937 & 203,230 & 81,581 & 143,012 & 143,012 & 81,581 & 141,690 \\
\hline $\mathrm{H} 2$ & $\cdots$ & $\mathrm{mol} \%$ & $0.0 \%$ & $34.70 \%$ & $60.90 \%$ & $60.92 \%$ & $34.68 \%$ & $34.70 \%$ & $34.70 \%$ & $34.68 \%$ & $60.92 \%$ \\
\hline $\mathrm{CO}$ & $\cdots$ & mol\% & $4.0 \%$ & $50.56 \%$ & $24.49 \%$ & $24.50 \%$ & $50.54 \%$ & $50.56 \%$ & $50.56 \%$ & $50.54 \%$ & $24.50 \%$ \\
\hline N2 & $\cdots$ & mol\% & $96.0 \%$ & $0.99 \%$ & $3.90 \%$ & $3.90 \%$ & $0.99 \%$ & $0.99 \%$ & $0.99 \%$ & $0.99 \%$ & $3.90 \%$ \\
\hline $\mathrm{CO} 2$ & $\cdots$ & $\mathrm{mol} \%$ & $0.0 \%$ & $12.88 \%$ & $10.02 \%$ & $10.03 \%$ & $12.88 \%$ & $12.88 \%$ & $12.88 \%$ & $12.88 \%$ & $10.03 \%$ \\
\hline $\mathrm{MEOH}$ & $\cdots$ & $\mathrm{mol} \%$ & $0.0 \%$ & $0.71 \%$ & $0.42 \%$ & $0.53 \%$ & $0.67 \%$ & $0.71 \%$ & $0.71 \%$ & $0.67 \%$ & $0.53 \%$ \\
\hline ETOH & $\cdots$ & $\mathrm{mol} \%$ & $0.0 \%$ & $0.00 \%$ & $0.00 \%$ & $0.00 \%$ & $0.00 \%$ & $0.00 \%$ & $0.00 \%$ & $0.00 \%$ & $0.00 \%$ \\
\hline $\mathrm{PROH}$ & $\cdots$ & $\mathrm{mol} \%$ & $0.0 \%$ & $0.00 \%$ & $0.00 \%$ & $0.00 \%$ & $0.00 \%$ & $0.00 \%$ & $0.00 \%$ & $0.00 \%$ & $0.00 \%$ \\
\hline C1 & $\cdots$ & $\mathrm{mol} \%$ & $0.0 \%$ & $0.00 \%$ & $0.08 \%$ & $0.04 \%$ & $0.04 \%$ & $0.00 \%$ & $0.00 \%$ & $0.04 \%$ & $0.04 \%$ \\
\hline & & & $100.0 \%$ & $99.84 \%$ & $99.81 \%$ & $99.92 \%$ & $99.80 \%$ & $99.84 \%$ & $99.84 \%$ & $99.80 \%$ & $99.92 \%$ \\
\hline
\end{tabular}


RUN PLAN FOR FLUID DYNAMIC / METHANOL RUN (JUNE, 1995)

\begin{tabular}{|c|c|c|c|c|c|c|c|c|c|c|c|}
\hline RUN & & & AF-A10 & AF-R14.1 & AF-R14.2 & AF-R14.3 & AF-R14.4 & AF-R14.5 & AF-R14.6 & AF-R14.7 & AF-R14.8 \\
\hline Description & $\cdots$ & $\cdots$ & ALT (REDTN) & ALT (PVS) & ALT (PVS) & ALT (PVS) & ALT (PVS) & ALT (PVS) & ALT (TRC) & ALT (TRC) & ALT (TRC) \\
\hline \multicolumn{12}{|l|}{ 21.11 Feed/Product Exchanger } \\
\hline Feed Inlet Temp & $\mathrm{TI}-1257$ & $F$ & $\cdots$ & 172 & 210 & 197 & 180 & 172 & 172 & 180 & 197 \\
\hline Feed Outlet Temp & TI-1263 & $\mathrm{F}$ & $\cdots$ & 402 & 402 & 402 & 403 & 402 & 402 & 403 & 402 \\
\hline Total Feed to 02.63 Temp & $\mathrm{TI}-1216$ & $F$ & $\cdots$ & 362 & 392 & 373 & 369 & 362 & 362 & 369 & 373 \\
\hline Reactor Eff. Inlet Temp & $\mathrm{TI}-1262$ & $F$ & $\cdots$ & 482 & 482 & 482 & 482 & 482 & 482 & 482 & 482 \\
\hline Reactor Eff. Outlet Temp & TIC-1260 & $\mathrm{F}$ & $\cdots$ & 280 & 280 & 280 & 280 & 280 & 280 & 280 & 280 \\
\hline Reactor Eff. Dew Temp & $\cdots$ & $F$ & $\cdots$ & 226 & 268 & 247 & 232 & 226 & 226 & 232 & \\
\hline \multicolumn{12}{|l|}{ REACTOR EFFLUENT } \\
\hline Total Flow & $\mathrm{Fl}-196$ & scfh & $\cdots$ & 118,117 & 59,152 & 172,712 & 66,177 & 118,117 & 118,117 & 66,177 & 116,380 \\
\hline $\mathrm{H} 2$ & $\cdots$ & $\mathrm{mol} \%$ & $\cdots$ & $20.91 \%$ & $46.47 \%$ & $50.31 \%$ & $19.50 \%$ & $20.91 \%$ & & & \\
\hline $\mathrm{CO}$ & $\cdots$ & $\mathrm{mol} \%$ & $\ldots$ & $50.50 \%$ & $14.66 \%$ & $18.18 \%$ & $50.29 \%$ & $50.50 \%$ & & & \\
\hline N2 & $\cdots$ & $\mathrm{mol} \%$ & $\cdots$ & $1.20 \%$ & $5.36 \%$ & $4.93 \%$ & $1.23 \%$ & $1.20 \%$ & & & \\
\hline $\mathrm{CO} 2$ & $\cdots$ & $\mathrm{mol} \%$ & $\cdots$ & $15.79 \%$ & $14.01 \%$ & $12.27 \%$ & $16.28 \%$ & $15.79 \%$ & & & \\
\hline $\mathrm{MEOH}$ & $\cdots$ & $\mathrm{mol} \%$ & $\cdots$ & $11.09 \%$ & $17.88 \%$ & $13.64 \%$ & $11.94 \%$ & $11.09 \%$ & & & \\
\hline DME & & $\mathrm{mol} \%$ & & $0.09 \%$ & $0.25 \%$ & $0.04 \%$ & $0.18 \%$ & $0.09 \%$ & & & \\
\hline ETOH & $\cdots$ & $\mathrm{mol} \%$ & $\cdots$ & $0.08 \%$ & $0.24 \%$ & $0.01 \%$ & $0.12 \%$ & $0.08 \%$ & & & \\
\hline PROH & $\cdots$ & $\mathrm{mol} \%$ & $\cdots$ & $0.02 \%$ & $0.08 \%$ & $0.00 \%$ & $0.03 \%$ & $0.02 \%$ & & & \\
\hline $\mathrm{C} 4 \mathrm{OH}$ & $\cdots$ & $\mathrm{mol} \%$ & $\cdots$ & $0.01 \%$ & $0.03 \%$ & $0.00 \%$ & $0.01 \%$ & $0.01 \%$ & & & \\
\hline $\mathrm{IBOH}$ & $\cdots$ & $\mathrm{mol} \%$ & $\cdots$ & $0.00 \%$ & $0.01 \%$ & $0.00 \%$ & $0.00 \%$ & $0.00 \%$ & & & \\
\hline $\mathrm{C} 5 \mathrm{OH}+$ & $\cdots$ & $\mathrm{mol} \%$ & $\cdots$ & $0.01 \%$ & $0.02 \%$ & $0.00 \%$ & $0.01 \%$ & $0.01 \%$ & & & \\
\hline C1 & $\cdots$ & mol\% & $\cdots$ & $0.04 \%$ & $0.16 \%$ & $0.07 \%$ & $0.07 \%$ & $0.04 \%$ & & & \\
\hline & & & $\cdots$ & $99.73 \%$ & $99.17 \%$ & $99.45 \%$ & $99.66 \%$ & $99.73 \%$ & & & \\
\hline \multicolumn{12}{|l|}{ PRODUCT RECOVERY } \\
\hline Syngas to Backend Flow & $\mathrm{FI}-682$ & scth & $\cdots$ & None & None & None & None & None & None & None & None \\
\hline 22.11 to Flare Flow & $\mathrm{Fl}-237$ & scfh & $\cdots$ & 854 & 630 & 1,050 & 552 & 854 & 854 & 552 & 500 \\
\hline Main Flare Flow & $\mathrm{Fl}-245$ & scfh & $\cdots$ & 3,869 & 3,869 & 3,869 & 3,869 & 3,869 & 3,869 & 3,869 & 1,000 \\
\hline Product Flow & $\cdots$ & gpd & $\cdots$ & 3,794 & 3,319 & 6,510 & 2,337 & 3,794 & 3,794 & 2,337 & 3,247 \\
\hline \multicolumn{12}{|l|}{ RECYCLE FEED } \\
\hline $\mathrm{H} 2$ & $\cdots$ & $\mathrm{mol} \%$ & $\cdots$ & $23.52 \%$ & $57.66 \%$ & $58.53 \%$ & $22.20 \%$ & $23.52 \%$ & & & \\
\hline $\mathrm{CO}$ & $\cdots$ & $\mathrm{mol} \%$ & $\cdots$ & $56.76 \%$ & $18.13 \%$ & $21.22 \%$ & $57.21 \%$ & $56.76 \%$ & & & \\
\hline N2 & $\cdots$ & $\mathrm{mol} \%$ & $\cdots$ & $1.35 \%$ & $6.65 \%$ & $5.72 \%$ & $1.40 \%$ & $1.35 \%$ & & & \\
\hline $\mathrm{CO} 2$ & $\cdots$ & $\mathrm{mol} \%$ & $\cdots$ & $17.13 \%$ & $16.29 \%$ & $13.65 \%$ & $17.82 \%$ & $17.13 \%$ & & & \\
\hline MEOH & $\cdots$ & $\mathrm{mol} \%$ & $\cdots$ & $1.01 \%$ & $0.78 \%$ & $0.81 \%$ & $1.01 \%$ & $1.01 \%$ & & & \\
\hline $\mathrm{C} 1$ & $\cdots$ & $\mathrm{mol} \%$ & $\cdots$ & $0.04 \%$ & $0.16 \%$ & $0.06 \%$ & $0.06 \%$ & $0.04 \%$ & & & \\
\hline & & & $\cdots$ & $99.81 \%$ & $99.67 \%$ & $99.99 \%$ & $99.70 \%$ & $99.81 \%$ & & & \\
\hline
\end{tabular}


TEST AUTHORIZATION \# 50

LaPorte Alternative Fuels Development Unit (AFDU)
RUN NUMBER:
AF-R14.6/14.7/14.8
APPROX START DATE:
21 JUNE, 1995

Sheet: 1 of 4

Date : 06/20/95

By: BLB

TITLE: TRACER STUDY FOR LIQUID PHASE METHANOL DEMONSTRATION RUN WITH ALTERNATE CATALYST

\section{OBJECTIVE:}

To conduct a 3-day radioactive tracer study for the Methanol synthesis run in a bubble column reactor.

\section{SUMMARY:}

A slurry of an alternate methanol catalyst and Penreco Drakeol-10 oil will be activated in the reactor (Test Authorization \# 48). Upon completion of the activation, a process variable study will be conducted (Test Authorization \# 49). A three day tracer study will follow the process variable study. Radioactive gas and liquid tracers will be injected at three process conditions to study the mixing in both the phases. The unit will be shut down following the tracer study.

\section{TEST DETAILS:}

ANALYTICAL COMMENTS:
See pages 2 to 4 for details.

See page 4 .

\section{SAFETY IMPLICATIONS:}

Safety information available from ICI Tracerco is attached (Letters from D. A. Bucior to B. L. Bhatt, "Radiation Safety Analysis of Proposed Methanol Reactor Residence Time and Distribution Study", 3 June 1993; "Radiation Safety Analysis of Proposed LaPorte Pilot Plant Radioactive Tracer Study", 10 February 1994; "Tracerco Radiation Analysis", 15 June 1995). Barricades will be erected by $\mathrm{ICl}$ Tracerco to prevent access to areas containing radioactive materials. Radiation film badges will be worn by all personnel present during the study.

\section{ENVIRONMENTAL IMPLICATIONS:}

A flame will be maintained at the flare.

SPECIAL REMARKS:

The radioactive tracer injection will be performed by $I C I$ Tracerco personnel using their injection equipment. APCI personnel will be present during the injection and operate AFDU equipment.

\section{AUTHORIZATIONS:}
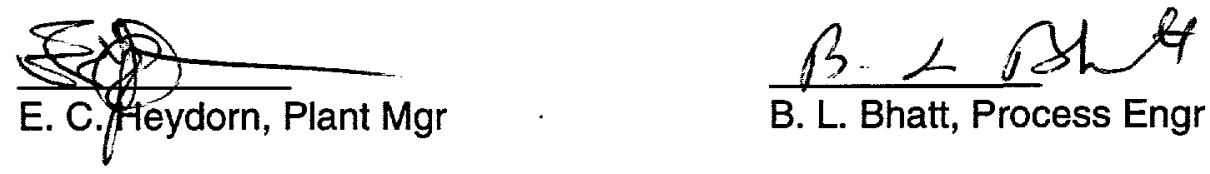


\section{TEST DETAILS:}

1. Upon completion of the Process Variable Study (Run AF-R14.1 thru 14.5), start the Tracer Study. A vapor residence time distribution study will be performed by injecting Argon-41 into the inlet gas line and monitoring its progress through the reactor by several detectors. Three different gas velocities will be tested. Also, four injections of radioactive $\mathrm{Mn}_{2} \mathrm{O}_{3}$ will be made in the reactor slurry at each condition to study liquid phase mixing.

$\mathrm{ICI}$ Tracerco is licensed to conduct these tests and will conform to guidelines prescribed by the Texas Department of Health. Texas A\&M will irradiate the Argon and Manganese on the morning of the tests, and it will be delivered to the LaPorte site by courier. The radioactive Ar-41 has a half life of $1.8 \mathrm{hrs}$ and will be injected into the reactor and vented to the atmosphere in levels acceptable to the Texas Department of Health. The radioactive manganese is expected to have a half life of 2.5 hours; only small amounts acceptable to the Texas Department of Health will be injected. An irradiation test will be performed on $\mathrm{Mn}_{2} \mathrm{O}_{3}$ by Texas $\mathrm{A} \& \mathrm{M}$ to ensure that the radiation will decay to very low levels within several days.

2. Operating conditions of Run Nos. AF-R14.6, 14.7 and 14.8 will be studied. Process and control targets for the study are tabulated in the attached table. The run descriptors are presented below:

\begin{tabular}{|c|c|c|c|c|c|}
\hline RUN NO. & INJECTIONS & $\begin{array}{c}\text { SPACE VEL } \\
\text { SL/HR - KG } \\
\text { CAT } \\
\end{array}$ & $\begin{array}{c}\text { PRESSURE } \\
\text { PSIG }\end{array}$ & $\begin{array}{c}\text { TEMPERATURE } \\
\text { DEG C }\end{array}$ & $\begin{array}{c}\text { INLET GAS } \\
\text { VEL, } \\
\text { FT/SEC }\end{array}$ \\
\hline AF-R14.6A & GAS-INLET (2) & 7000 & 750 & 250 & 0.83 \\
\hline AF-R14.6B & $\begin{array}{l}\text { LIQUID-TOP (2) } \\
\text { CENTER/WALL }\end{array}$ & 7000 & 750 & 250 & 0.83 \\
\hline AF-R14.6C & $\begin{array}{l}\text { LIQUID-BOT (2) } \\
\text { CENTER/WALL }\end{array}$ & 7000 & 750 & 250 & 0.83 \\
\hline AF-R14.7A & GAS-INLET (2) & 4000 & 750 & 250 & 0.47 \\
\hline AF-R14.7B & $\begin{array}{l}\text { LIQUID-TOP (2) } \\
\text { CENTER/WALL }\end{array}$ & 4000 & 750 & 250 & 0.47 \\
\hline AF-R14.7C & $\begin{array}{l}\text { LIQUID-BOT (2) } \\
\text { CENTERMWLL }\end{array}$ & 4000 & 750 & 250 & 0.47 \\
\hline AF-R14.8A & GAS-INLET (2) & 7000 & 520 & 250 & 1.20 \\
\hline AF-R14.8B & $\begin{array}{l}\text { LIQUID-TOP (2) } \\
\text { CENTER/WALL }\end{array}$ & 7000 & 520 & 250 & 1.20 \\
\hline AF-R14.8C & $\begin{array}{l}\text { LIQUID-BOT (2) } \\
\text { CENTER/WALL }\end{array}$ & 7000 & 520 & 250 & 1.20 \\
\hline
\end{tabular}


TEST AUTHORIZATION \# 50

LaPorte Alternative Fuels Development Unit (AFDU)

Sheet: 3 of 4

Date : 06/20/95

By: $\quad$ BLB

3. The slurry level should be maintained between 80 and $100 \%$ of NDG range, as specified in Table 1. Leave the Nuclear Density Gauge at the normal controlling reactor height. Shut off the gauge for 10-15 minutes during the injections as cross-interference is expected. Put LIC-1242 on manual during the injections but bring it back on auto between runs. Pump 10.52.02 should be on all the time to bring oil back to the reactor. Pump 10.52.01 should be on all the time to circulate oil thru 27.14. Maintain 27.14 separator between $270-290^{\circ} \mathrm{F}$. Maintain 22.10 separator between $90-115^{\circ} \mathrm{F}$.

\section{Day 1 (Approx. Date: 6/21/95)}

Preparation and initial testing of the equipment will be conducted on the last day of the Process Variable Study. The electronic equipment includes 28 detectors connected to a data acquisition system. The process equipment includes a gas sample cylinder with adequate valves to allow filling of the cylinder with Ar-41 and subsequent injection into the reactor via a nitrogen flush. The Ar-41 will be injected thru valve $\mathrm{V}-2462$. The radioactive manganese will be sluried in Drakeol-10 and injected with a hand-powered piston pump. The liquid injections will be made at two locations on the side of the reactor: Top N1nozzle and Bottom N2-nozzle.

During day 1 , the electronic equipment will be connected and power supplied to it. A preliminary calibration will be performed to verify the equipment is operational.

Arrangements will be made to support the detectors in their proper location, detectors will not be placed until day 2 .

Personnel available during the study will include two persons from Tracerco, one operator, one PSG process engineer and the plant manager. A catalyst inventory will be determined during day 1 using the nuclear density gauge with no gas flow through the reactor.

\section{Day 2 (Approx. Date: 6/22/95)}

Prior to day 2, arrangements will be made to irradiate Ar-41 and $\mathrm{Mn}_{2} \mathrm{O}_{3}$ in a reactor at Texas A\&M. The irradiation will take place on the morning of day 2 and be transported to LaPorte by $1 \mathrm{pm}$. The radioactive materials produced during day 2 can only be used during this day since the half life of these compounds is less than three hours.

During the morning of day 2, the Tracerco crew will calibrate and hang the 28 detectors at the LaPorte AFDU. Each detector will be subjected to a gamma-ray source, and the response will be measured. All the detectors will then be normalized relative to the most sensitive detector.

After the calibration is complete, the detectors will be placed at specified locations. Conditions of Run No. AF-R14.6 will be studied during the day. Two Ar-41 injections will be made into the feed gas. A reasonable amount of time must exist between injections so that either Ar-41 has left the system or a steady level of radiation is available to use as a baseline. Two liquid injections will be made at the top nozzle (one near the wall and 
TEST AUTHORIZATION \# 50

LaPorte Alternative Fuels Development Unit (AFDU)

Sheet: 4 of 4

Date : 06/20/95

By: BLB

another half way between the wall and the center). Two more injections (wall and center) will be made at the bottom.

At the beginning and end of each condition, liquid level, gas hold up and slurry concentration will be measured with the nuclear density gauge (NDG). Two sets of detectors below the liquid level will have to be removed for the NDG measurements.

Day 3 (Approx. Date: 6/23/95)

Conditions of Run No. AF-R14.7 will be studied during the day. Two Ar-41 injections will be made into the feed gas. Two liquid injections will be made both at the top and the bottom.

Day 4 (Approx. Date: 6/24/95)

Conditions of Run No. AF-R14.8 will be studied during the day. Two Ar-41 injections will be made into the feed gas. Two liquid injections will be made both at the top and the bottom.

After completing the study, Tracerco will remove their equipment from the LaPorte site.

5. Upon completion of the Tracer Study, the plant will be shut down.

\section{ANALYTICAL COMMENTS:}

Since the gas and liquid will contain radioactive materials, NO sampling will be done while the tracers are being injected. Reactor feed gas analysis will be conducted between two process conditions. According to calculations performed by $\mathrm{ICl}$ Tracerco, the gas is safe to analyze 6 hours after the last gas injection (see attached letter dated 6/15/95). 
RUN PLAN FOR FLUID DYNAMIC / METHANOL RUN (JUNE, 1995)

\begin{tabular}{|c|c|c|c|c|c|c|c|c|c|c|c|}
\hline RUN & & & AF-A10 & AF-R14.1 & $\mathrm{AF}-\mathrm{R} 14.2$ & AF-R14.3 & AF-R14.4 & AF-R14.5 & AF-R14.6 & AF-R14.7 & AF-R14.8 \\
\hline Description & $\cdots$ & $\cdots$ & ALT (REDTN) & ALT (PVS) & ALT (PVS) & ALT (PVS) & ALT (PVS) & ALT (PVS) & ALT (TRC) & ALT (TRC) & ALT (TRC) \\
\hline Duration & $\cdots$ & days & 1 & 2 & 3 & 1.5 & 1.5 & 1 & 1 & 1 & 1 \\
\hline Syngas & $\cdots$ & $\cdots$ & $\cdots$ & TEXACO & KINGSPORT & KINGSPORT & TEXACO & TEXACO & TEXACO & TEXACO & KINGSPORT \\
\hline Inlet Space Velocity & $\ldots$ & $\mathrm{sL} / \mathrm{kg}-\mathrm{hr}$ & 615 & 7,000 & 4,000 & 10,000 & 4,000 & 7,000 & 7,000 & 4,000 & 7,000 \\
\hline Reactor Pressure & PIC-1247 & psig & 67 & 750 & 735 & 735 & 750 & 750 & 750 & 750 & 520 \\
\hline \multicolumn{12}{|l|}{ REACTOR } \\
\hline Pressure & PIC-1247 & psig & 67 & 750 & 735 & 735 & 750 & 750 & 750 & 750 & 520 \\
\hline Temperature & TI-1233 & $\mathrm{F}$ & $\cdots$ & 482 & 482 & 482 & 482 & 482 & 482 & 482 & 482 \\
\hline Heat Duty & \multicolumn{2}{|c|}{ MM BTU/hr } & $\cdots$ & 1.10 & 1.14 & 2.00 & 0.73 & 1.10 & 1.10 & 0.73 & \\
\hline Inlet Superficial Velocity & $\cdots$ & $\mathrm{ft} / \mathrm{sec}$ & 0.62 & 0.83 & 0.48 & 1.21 & 0.47 & 0.83 & 0.83 & 0.47 & 1.18 \\
\hline Outlet Superficial Velocity & $\cdots$ & $\mathrm{ft} / \mathrm{sec}$ & 0.62 & 0.68 & 0.35 & 0.95 & 0.38 & 0.68 & 0.68 & 0.38 & 0.94 \\
\hline Liquid Level & 니-2142 & \% span & $80 \%$ & $100 \%$ & $100 \%$ & $100 \%$ & $100 \%$ & $100 \%$ & $100 \%$ & $100 \%$ & $100 \%$ \\
\hline Catalyst Load & $\cdots$ & $\mathrm{lb}$ & 1,177 & 1,177 & 1,177 & 1,177 & 1,177 & 1,177 & 1,177 & 1,177 & 1,158 \\
\hline Cat Weight Fraction & $\cdots$ & $\%$ & $40 \%$ & $42 \%$ & $40 \%$ & $41 \%$ & $41 \%$ & $42 \%$ & $42 \%$ & $41 \%$ & $44 \%$ \\
\hline Vapor Void Fraction & $\cdots$ & $\%$ & $24 \%$ & $43 \%$ & $35 \%$ & $42 \%$ & $39 \%$ & $43 \%$ & $43 \%$ & $39 \%$ & $49 \%$ \\
\hline \multicolumn{12}{|l|}{ FRESH FEED FLOWS } \\
\hline $\mathrm{LPH} 2$ & FIC-101 & scth & 0 & 18,342 & 21,495 & 11,080 & 16,029 & 18,342 & 18,342 & 16,029 & 1,620 \\
\hline $\mathrm{CO}$ & FIC-104 & scth & 500 & 15,217 & 11,995 & 21,420 & 10,469 & 15,217 & 15,217 & 10,469 & 10,000 \\
\hline $\mathrm{CO} 2$ & FIC-107 & scth & 0 & 1,185 & 1,040 & 2,050 & 914 & 1,185 & 1,185 & 914 & 772 \\
\hline N2 & FIC-111 & scfh & 12,000 & 56 & 270 & 250 & 56 & 56 & 56 & 56 & 61 \\
\hline 01.10 Total Flow & $\mathrm{FI}-726$ & scfh & 12,500 & 34,800 & 34,800 & 34,800 & 27,468 & 34,800 & 34,800 & 27,468 & 12,453 \\
\hline & & & & & & & & & & & \\
\hline $\mathrm{HP} \mathrm{H} 2$ & FIC-1200 & scth & 0 & 7,283 & 2,467 & 33,730 & 0 & 7,283 & 7,283 & 0 & 18,930 \\
\hline 01.20 Recycle & FIC-246 & scfh & 0 & 100,929 & 43,670 & 134,220 & 54,113 & 100,929 & 100,929 & 54,113 & 110,160 \\
\hline \multicolumn{12}{|l|}{ REACTOR FEED } \\
\hline Target Feed Temp & TI-1253 & $F$ & $\cdots$ & 362 & 392 & 373 & 369.0 & 362 & 362 & 369.0 & 373 \\
\hline Feed Dewpoint & $\cdots$ & $F$ & $\cdots$ & 89 & 78 & 86 & 87.0 & 89 & 89 & 87.0 & 86 \\
\hline Total Dry Flow & $\mathrm{FI}-1216$ & scth & 12,500 & 143,012 & 80,937 & 203,230 & 81,581 & 143,012 & 143,012 & 81,581 & 141,690 \\
\hline $\mathrm{H} 2$ & $\cdots$ & mol\% & $0.0 \%$ & $34.70 \%$ & $60.90 \%$ & $60.92 \%$ & $34.68 \%$ & $34.70 \%$ & $34.70 \%$ & $34.68 \%$ & $60.92 \%$ \\
\hline CO & $\cdots$ & $\mathrm{mol} \%$ & $4.0 \%$ & $50.56 \%$ & $24.49 \%$ & $24.50 \%$ & $50.54 \%$ & $50.56 \%$ & $50.56 \%$ & $50.54 \%$ & $24.50 \%$ \\
\hline $\mathrm{N} 2$ & $\cdots$ & $\mathrm{mol} \%$ & $96.0 \%$ & $0.99 \%$ & $3.90 \%$ & $3.90 \%$ & $0.99 \%$ & $0.99 \%$ & $0.99 \%$ & $0.99 \%$ & $3.90 \%$ \\
\hline $\mathrm{CO} 2$ & $\cdots$ & $\mathrm{mol} \%$ & $0.0 \%$ & $12.88 \%$ & $10.02 \%$ & $10.03 \%$ & $12.88 \%$ & $12.88 \%$ & $12.88 \%$ & $12.88 \%$ & $10.03 \%$ \\
\hline $\mathrm{MEOH}$ & $\cdots$ & $\mathrm{mol} \%$ & $0.0 \%$ & $0.71 \%$ & $0.42 \%$ & $0.53 \%$ & $0.67 \%$ & $0.71 \%$ & $0.71 \%$ & $0.67 \%$ & $0.53 \%$ \\
\hline ETOH & $\cdots$ & $\mathrm{mol} \%$ & $0.0 \%$ & $0.00 \%$ & $0.00 \%$ & $0.00 \%$ & $0.00 \%$ & $0.00 \%$ & $0.00 \%$ & $0.00 \%$ & $0.00 \%$ \\
\hline PROH & $\cdots$ & $\mathrm{mol} \%$ & $0.0 \%$ & $0.00 \%$ & $0.00 \%$ & $0.00 \%$ & $0.00 \%$ & $0.00 \%$ & $0.00 \%$ & $0.00 \%$ & $0.00 \%$ \\
\hline C1 & $\ldots$ & $\mathrm{mol} \%$ & $0.0 \%$ & $0.00 \%$ & $0.08 \%$ & $0.04 \%$ & $0.04 \%$ & $0.00 \%$ & $0.00 \%$ & $0.04 \%$ & $0.04 \%$ \\
\hline & & & $100.0 \%$ & $99.84 \%$ & $99.81 \%$ & $99.92 \%$ & $99.80 \%$ & $99.84 \%$ & $99.84 \%$ & $99.80 \%$ & $99.92 \%$ \\
\hline
\end{tabular}


RUN PLAN FOR FLUID DYNAMIC / METHANOL RUN (JUNE, 1995)

\begin{tabular}{|c|c|c|c|c|c|c|c|c|c|c|c|}
\hline RUN & & & AF-A10 & AF-R14.1 & AF-R14.2 & AF-R14.3 & AF-R14.4 & AF-R14.5 & AF-R14.6 & AF-R14.7 & AF-R14.8 \\
\hline Description & $\cdots$ & $\cdots$ & ALT (REDTN) & ALT (PVS) & ALT (PVS) & ALT (PVS) & ALT (PVS) & ALT (PVS) & ALT (TRC) & ALT (TRC) & ALT (TRC) \\
\hline \multicolumn{12}{|c|}{ 21.11 Feed/Product Exchanger } \\
\hline Feed Inlet Temp & $\mathrm{TI}-1257$ & $\mathrm{~F}$ & $\cdots$ & 172 & 210 & 197 & 180 & 172 & 172 & 180 & 197 \\
\hline Feed Outlet Temp & $\mathrm{Tl}-1263$ & $\mathrm{~F}$ & $\cdots$ & 402 & 402 & 402 & 403 & 402 & 402 & 403 & 402 \\
\hline Total Feed to 02.63 Temp & TI-1216 & $\mathbf{F}$ & $\cdots$ & 362 & 392 & 373 & 369 & 362 & 362 & 369 & 373 \\
\hline Reactor Eff. Inlet Temp & $\mathrm{Tl}-1262$ & $F$ & $\ldots$ & 482 & 482 & 482 & 482 & 482 & 482 & 482 & 482 \\
\hline Reactor Eff. Outlet Temp & TIC-1260 & $\mathbf{F}$ & $\cdots$ & 280 & 280 & 280 & 280 & 280 & 280 & 280 & 280 \\
\hline Reactor Eff. Dew Temp & $\cdots$ & $F$ & $\because$ & 226 & 268 & 247 & 232 & 226 & 226 & 232 & \\
\hline \multicolumn{12}{|l|}{ REACTOR EFFLUENT } \\
\hline Total Flow & Fl-196 & scfh & $\cdots$ & 118,117 & 59,152 & 172,712 & 66,177 & 118,117 & 118,117 & 66,177 & 116,380 \\
\hline $\mathrm{H} 2$ & $\cdots$ & $\mathrm{mol} \%$ & $\cdots$ & $20.91 \%$ & $46.47 \%$ & $50.31 \%$ & $19.50 \%$ & $20.91 \%$ & & & \\
\hline $\mathrm{CO}$ & $\cdots$ & $\mathrm{mol} \%$ & $\cdots$ & $50.50 \%$ & $14.66 \%$ & $18.18 \%$ & $50.29 \%$ & $50.50 \%$ & & & \\
\hline N2 & $\cdots$ & $\mathrm{mol} \%$ & $\cdots$ & $1.20 \%$ & $5.36 \%$ & $4.93 \%$ & $1.23 \%$ & $1.20 \%$ & & & \\
\hline $\mathrm{CO} 2$ & $\cdots$ & $\mathrm{mol} \%$ & $-\cdots$ & $15.79 \%$ & $14.01 \%$ & $12.27 \%$ & $16.28 \%$ & $15.79 \%$ & & & \\
\hline $\mathrm{MEOH}$ & $\cdots$ & $\mathrm{mol} \%$ & $\cdots$ & $11.09 \%$ & $17.88 \%$ & $13.64 \%$ & $11.94 \%$ & $11.09 \%$ & & & \\
\hline DME & & $\mathrm{mol} \%$ & & $0.09 \%$ & $0.25 \%$ & $0.04 \%$ & $0.18 \%$ & $0.09 \%$ & & & \\
\hline ETOH & $\cdots$ & $\mathrm{mol} \%$ & $-\cdots$ & $0.08 \%$ & $0.24 \%$ & $0.01 \%$ & $0.12 \%$ & $0.08 \%$ & & & \\
\hline $\mathrm{PROH}$ & $\cdots$ & $\mathrm{mol} \%$ & $\cdots$ & $0.02 \%$ & $0.08 \%$ & $0.00 \%$ & $0.03 \%$ & $0.02 \%$ & & & \\
\hline $\mathrm{C} 4 \mathrm{OH}$ & $\ldots$ & $\mathrm{mol} \%$ & $\cdots$ & $0.01 \%$ & $0.03 \%$ & $0.00 \%$ & $0.01 \%$ & $0.01 \%$ & & & \\
\hline $\mathrm{IBOH}$ & $\cdots$ & $\mathrm{mol} \%$ & $\cdots$ & $0.00 \%$ & $0.01 \%$ & $0.00 \%$ & $0.00 \%$ & $0.00 \%$ & & & \\
\hline $\mathrm{C} 5 \mathrm{OH}+$ & $\cdots$ & $\mathrm{mol} \%$ & $\cdots$ & $0.01 \%$ & $0.02 \%$ & $0.00 \%$ & $0.01 \%$ & $0.01 \%$ & & & \\
\hline C1 & $\cdots$ & $\mathrm{mol} \%$ & $\cdots$ & $0.04 \%$ & $0.16 \%$ & $0.07 \%$ & $0.07 \%$ & $0.04 \%$ & & & \\
\hline & & & $\cdots$ & $99.73 \%$ & $99.17 \%$ & $99.45 \%$ & $99.66 \%$ & $99.73 \%$ & & & \\
\hline \multicolumn{12}{|l|}{ PRODUCT RECOVERY } \\
\hline Syngas to Backend Flow & $\mathrm{Fl}-682$ & scfh & $\ldots$ & None & None & None & None & None & None & None & None \\
\hline 22.11 to Flare Flow & $\mathrm{Fl}-237$ & scfh & $\cdots$ & 854 & 630 & 1,050 & 552 & 854 & 854 & 552 & 500 \\
\hline Main Flare Flow & $\mathrm{Fl}-245$ & scfh & $\cdots$ & 3,869 & 3,869 & 3,869 & 3,869 & 3,869 & 3,869 & 3,869 & 1,000 \\
\hline Product Flow & $\cdots$ & gpd & $\cdots$ & 3,794 & 3,319 & 6,510 & 2,337 & 3,794 & 3,794 & 2,337 & 3,247 \\
\hline \multicolumn{12}{|l|}{ RECYCLE FEED } \\
\hline $\mathrm{H} 2$ & $\cdots$ & $\mathrm{mol} \%$ & $\cdots$ & $23.52 \%$ & $57.66 \%$ & $58.53 \%$ & $22.20 \%$ & $23.52 \%$ & & & \\
\hline $\mathrm{CO}$ & $\cdots$ & $\mathrm{mol} \%$ & $\ldots$ & $56.76 \%$ & $18.13 \%$ & $21.22 \%$ & $57.21 \%$ & $56.76 \%$ & & & \\
\hline N2 & $\cdots$ & $\mathrm{mol} \%$ & $\cdots$ & $1.35 \%$ & $6.65 \%$ & $5.72 \%$ & $1.40 \%$ & $1.35 \%$ & & & \\
\hline $\mathrm{CO} 2$ & $\cdots$ & $\mathrm{mol} \%$ & $\cdots$ & $17.13 \%$ & $16.29 \%$ & $13.65 \%$ & $17.82 \%$ & $17.13 \%$ & & & \\
\hline MEOH & $\cdots$ & $\mathrm{mol} \%$ & $\cdots$ & $1.01 \%$ & $0.78 \%$ & $0.81 \%$ & $1.01 \%$ & $1.01 \%$ & & & \\
\hline $\mathrm{C1}$ & $\cdots$ & $\mathrm{mol} \%$ & $\cdots$ & $0.04 \%$ & $0.16 \%$ & $0.06 \%$ & $0.06 \%$ & $0.04 \%$ & & & \\
\hline & & & $\cdots$ & $99.81 \%$ & $99.67 \%$ & $99.99 \%$ & $99.70 \%$ & $99.81 \%$ & & & \\
\hline
\end{tabular}




\section{Tracerco}

June 3,1993

$$
-\because E \quad \vee E
$$

$$
\text { !lli }
$$

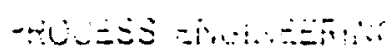

Tracerco

Suite 200

1100 Hercules

Houston, TX 77058

Telephone (713) 488-0039

Fax (713) 488-1646

Mr. Bharat Bhatt

Air Products and Chemicals

7201 Hamilton Blvd.

Allentown, PA 18195

RE: RADIATION BAFETY ANALYSIS OF PROPOSED METHANOL REACTOR RESIDENCE TIME AND DISTRIBUTION STUDIES

Dear Mr. Bhatt:

The proposed radiotracer fluid distribution studies of the Methanol Reactor will be performed under ICI Tracerco's Texas Radioactive Materials License, L03096. I have included a copy of our current license for your files.

ICI Tracerco operates within strict guidelines, established by the Texas Bureau of Radiation Control, regarding how radioactive materials are to be handled, how much activity may be injected into the process system, exposure limits for non-radiation workers, and barricades around the area in which radiation is being used.

By regulation, barricades must be posted such that radiation exposure to non-radiation workers will not exceed 2 millirem in any 1 hour and/or 100 millirem in any seven consecutive seven days. Radiation workers, such as Tracerco employees, are limited to exposures of 1250 miliirem per calendar quarter.

ICI Tracerco's operating standards are considerably higher than those required by law. We operate under the ALARA radiation principal. ALARA, simply put, states the any radiation exposure will be limited to As Low As Reasonably Achievable. An example of this philosophy in action is that should a Tracerco employee receive $1 / 10$ th the acceptable regulatory limit in a calendar quarter, an internal investigation will be performed to determine the cause of the "excessive" exposure. As you will appreciate, the principals of ALARA are equally applicable to possible radiation exposures of non-radiation workers. During our on-site investigation, we establish our radiation barricades such that possible exposures of non-radiation workers would be considerably less than legally allowable.

At Air Products request, radiation dosimetry was provided for each non-radiation worker on the plant site during the 1989 studies. Included is a copy of the radiation exposure analysis. There was no recordable radiation exposure to any plant employees during the study.

The other potential concern regarding the radiation safety of the project addresses the allowable concentration of the residual activity of the radiotracers and environmental impact. All accounting and 
disposal of radioactive materials are accomplished under provisions of ICI Tracerco's License. Again, ICI Tracerco is guided by regulations established by the state of Texas. (Incidentally, the applicable concentration limits are identical to those established as "fit" for human consumption.)

Two radiotracers will be used during the studies of the reactor. Vapor phase studies will be performed using Ar-41, an inert gas with a half-life of 1.8 hours. The liquid phase studies will be performed using Mn-56. Mn-56 has a half-life of 2.5 hours.

The Ar-41 radiotracer will vent the system via a 35 foot tall stack downstream of the reactor. Texas regulations allow an Ar-4I disposable concentration of $4 * 10^{-8} \mathrm{uCi} / \mathrm{mL}$. This equates to an allowable injection of $2880 \mathrm{mCi}$ per 8 hour day. The actual amount of radiotracer required during the previous studies was approximately $1 / 10$ the allowable limit.

Disposal of the Mn-56 liquid tracer will be accomplished via dilution of the radiotracer within the 550 gallon liquid inventory and then via decay. Texas regulations allow a $\mathrm{Mn}-56$ concentration of $3 * 10^{-3} \mathrm{uCi} / \mathrm{mL}$. A strict dilution into product inventory allows injection of $6.2 \mathrm{mCi}$. The 1989 project required injection of $3 \mathrm{mCi} \mathrm{Mn}-56$. When decay of the radioisotope is factored into the equation, the actual radiotracer concentration is considerably lower. For instance assuming $6.2 \mathrm{mCi}$ were injected into the system, in 24 hours the actual concentration will be $3.8 * 10^{-6} \mathrm{uCi} / \mathrm{mL}$, or 1000 times lower than the applicable regulatory limit.

I hope that I have addressed all you concerns. Please contact us if you need further information.

During the 1989 study, Air Produces provided "Manganese Oxide of a proper particle size", which we then irradiated and mixed in solution to provide the liquid radiotracer. I have limited details of the base stock, particularly regarding partial size. Can you look into proviaing a sample. We would want to perform a test irradiation prior to the project to insure proper decay and no undesirable by-products. I will continue researching our records as well.

sincerely,

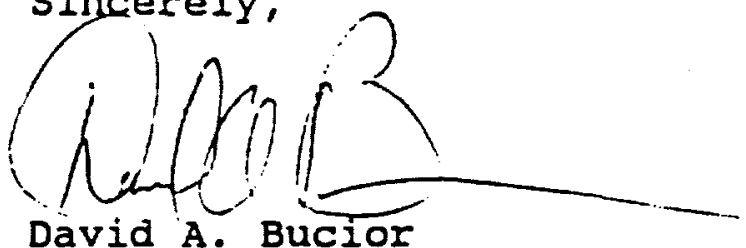

David A. Bucior

Senior Project Leader

$\mathrm{DAB} / j \mathrm{js}$

93-016.dab

1007 
February 10, 1994

Tracerco

Suite 200

1100 Hercules

Houston, TX 77058

Telephone (713) 488-0039

Dr. Bharat I. Bhatt

Fax (713) 488-1646

Air Products and Chemicals, Inc.

7201 Hamilton Boulevard

Allentown, PA 18195-1501

RE: RADIATION SAFETY ANALYSIS OF PROPOSED LAPORTE PILOT PLANT RADIOTRACER STUDY

Dear Dr. Bhatt:

On January 25, 1994, a preliminary safety analysis associated with performing a radiotracer diagnostic flow distribution study of the reactor in the La Porte Pilot Plant was held. Present at the meeting were Dr. Bharat Bhatt, Dr. Bernie Tosland, Edward Heydorn and myself.

Three areas of concern were identified which required further investigation. These included worst case scenarios where all catalyst radiotracer injected would accumulate in 1 filter or ended up in the product stream exiting the column. The third concern was the amount of vapor phase tracer which could be absorbed into the catalyst slurry.

The calculations presented in this text are based upon consuming an identical amount of radiotracer as during a study of this equipment preformed in August 1993. The catalyst radiotracer was Mn-56 with has a half-life of 2.5 hours. The vapor radiotracer was Ar-41 with a half-life of 1.8 hours.

\section{Reactor slurry \& Product stream}

During the August studies $2 \mathrm{mCi}$ of $\mathrm{Mn}-56$ were consumed during each days testing. Given the reactor volume of 550 gallon the radiotracer concentration upon mixing with the reactor volume:

$\frac{2 \mathrm{mCi}}{550 \mathrm{GaI}} * \frac{1 \mathrm{GaI}}{3,785 \mathrm{mI}} * \frac{1000 \mu \mathrm{Ci}}{1 \mathrm{mCi}}=9.6 \mathrm{E}-04 \mu \mathrm{Ci} / \mathrm{ml}$

The maximum concentration at which the general public may contact Mn-56 allowable under Texas Regulations is $7 \mathrm{E}-05 \mu \mathrm{Ci} / \mathrm{ml}$. The previous study showed considerable mixing occurring in the reactor. since the product draw is located so high on the reactor I believe it safe to assume that product stream concentration would not be greater than the mixed inventory concentration.

It will be necessary to allow 10 hours to elapse after test completion prior to allowaing non-radiation personnel to come into direct contact 
Dr. Bharat I. Bhatt

Air Products and Chemicals, Inc.

Page 2

with the reactor slurry and/or product stream. This will allow the injected material to have passed through 4 half-lives. After 10 hours decay the Mn-56 concentration will be $6 \mathrm{E}-05 \mu \mathrm{Ci} / \mathrm{ml}$.

\section{Filter}

Four filters are in place on the slurry stream. The following analysis is based upon all Mn-56 injected short circuiting the reactor and collecting in one filter. It is assumed that the radiotracer material is deposited on the filter in combination with a 1/8" thick "cake" layer of density $70 \mathrm{lbs} / \mathrm{ft}^{3}$. This would result in an accumulation of 193.17 grams of material. Thus the initial concentration would be:

$\frac{2 \mathrm{mCi}}{193.17 \mathrm{~g}} * \frac{1000 \mu \mathrm{Ci}}{\mathrm{mCi}}=10.35 \mu \mathrm{Ci} / \mathrm{g}$

Texas Regulations establish a concentration of $7 \mathrm{E}-04 \mu \mathrm{Ci} / \mathrm{ml}$ for solid Mn-56 as acceptable for contact by the general public. Therefore, if all material was deposited in one filter, 36 hours would be required (after injection) for the material deposited on the filters to decay to the regulatory limit. If all tracer material were trapped on four filters, 31 hours would be required (after injection) to decay to the regulator limit.

In an alternate scenario, after 4 hours of circulation (inventory turnover time), 4 hours of filter cooling time, and all four filters in operation; the filters would be acceptable for immediate handling provided less than 2.5 percent of the total tracer injected was trapped on the filters.

\section{Vapor Tracer solubility}

A final concern was the potential for Ar-41, the vapor phase tracer, being absorbed into the catalyst slurry stream. I have insufficient information to calculate a realistic Argon absorption in the reactor. During each process rate study approximately 0.025 moles of Argon with a radiation activity of $250 \mathrm{mCi}$ will be consumed. If you can calculate what percentage of the injected material might be absorbed by the process stream, the radiation concentration would be in an identical ratio. The available information indications that Argon absorption, if any, would be minimal.

According to D. Vermeer and R. Krishna's "Hydrodynamics and Mass Transfer in Bubble Columns operating in the Churn-Turbulent Regime", we may expect some Argon absorption. Figure 1 of the paper showed an Argon mole fraction of 0.00235 dissolved in turpentine 5 at 1 atmosphere. I assume this represented a saturation concentration. To saturate 550 gallons of slurry, we would have to inject 31 moles of argon.

A more practical representation was presented in Figure 4, which showed Residence Time Distributions (pulse injections) with tracer 


\section{(ai) Tracerco}

Dr. Bharat L. Bhatt

Air Products and Chemicals, Inc.

Page 3

gases of varying solubility. During these studies Argon cleared the test vessel in approximately 30 seconds.

This was also the observation during the previous studies of the reactor. If any argon was absorbed, its' concentration was lower than the detectable limits using our extremely sensitive equipment.

Argon is not typically recognized as being a soluble material. Texas Regulations for the Control of Radioactive Materials provide no concentration limits for Ar-41 being in anything other than a vapor phase, i.e.; there are no regulatory provisions which address Argon being in either a solution or solid mixture.

I trust that I have addressed your concerns. Please contact us if we may be of further service.

sincerely,

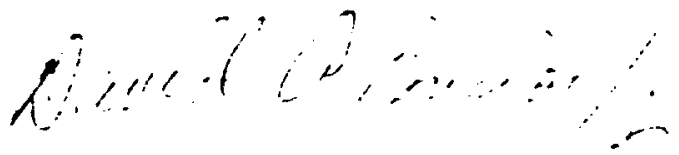

David A. Bucior

Senior Project Leader

$\mathrm{DAB} / \mathrm{j} \mathbf{l s}$

1007

9421.1tr 


\section{Tracerco}

\section{TRACERCO RADIATION SAFETY ANALYSIS}

\section{AIR PRODUCTS AND CHEMICALS}

Alternate Fuels Pilot Plant

Pasadena, TX

\section{Job Description}

Flow distribution studies of the Pilot Plant High Pressure Reactor. Testing will be performed on three consecutive days, June $22,23, \& 24$. Each day's study will consist of two injections of $25 \mathrm{mCi} A \mathrm{r}^{41}$ into the reactor feed and four injections of $1 \mathrm{mCi} \mathrm{Mn}^{56}$ into the reactor liquid.

\section{Details of Disposal}

Vapor Traffic - Ar41

The system inventory is approximately 15000 SCF with a purge rate of 5000 SCFH.

$\frac{50 \mathrm{mCi}}{15000 \mathrm{Ft}^{3}} * \frac{10}{\mathrm{mCi}} \frac{\mathrm{uCi}}{2.832} * \frac{\mathrm{Ft}}{10^{4} \mathrm{ml}} \quad=1.17 * 10^{-4} \mathrm{uCi} / \mathrm{ml}$

Argon Decay Halflife $=1.8 \mathrm{Hr}$ \& System Purge Rate Halflife $=1.7 \mathrm{Hr}$

Therefore, every 1.8 hours the system concentration will be reduced by $75 \%$, resulting in:

Time After

Injection (Hr)

\begin{tabular}{|c|c|}
\hline $\begin{array}{r}1.8 \\
3.6 \\
5.4 \\
7.2 \\
9.0 \\
10.8 \\
12.6\end{array}$ & $\begin{array}{l}4.2 \\
1.0 \\
2.6 \\
6.6 \\
1.6 \\
4.1 \\
1.0\end{array}$ \\
\hline
\end{tabular}

Regulatory Limits

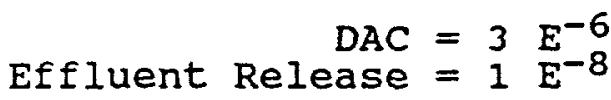

Liquid Traffic $-\mathrm{Mn}^{56}$ (Halflife $=2.5 \mathrm{Hr}$ )

$4 \mathrm{mCi} \mathrm{Mn}^{56}$ diluted into 375 gallon inventory

$\frac{4 \mathrm{mCi}}{375 \mathrm{gal}} * \frac{10}{\frac{3}{\mathrm{mCi}}} \frac{\mathrm{uCi}}{3.785 \mathrm{l}} * \frac{\mathrm{gal}}{10^{3} \mathrm{mI}}=2.81 \mathrm{E}^{-3} \mathrm{uCi} / \mathrm{ml}$

$2.81 \mathrm{E}^{-3} \mathrm{uci} / \mathrm{ml}$ will decay to regulatory release limit of $7.0 \mathrm{E}^{-5}$ in 13 hours and 22 minutes.

System Accumulation is negligible.

$$
\begin{array}{rrr}
\text { Time } & \multicolumn{2}{c}{\text { New }} \\
\text { Hr } & \multicolumn{2}{c}{\text { Addition }} \\
& & \\
0 & 2.81 & E^{-3} \\
24 & 2.81 & E^{-3} \\
36 & 2.81 & E^{-3} \\
48 & 0 &
\end{array}
$$

Prepared by
Concentration

at start At End
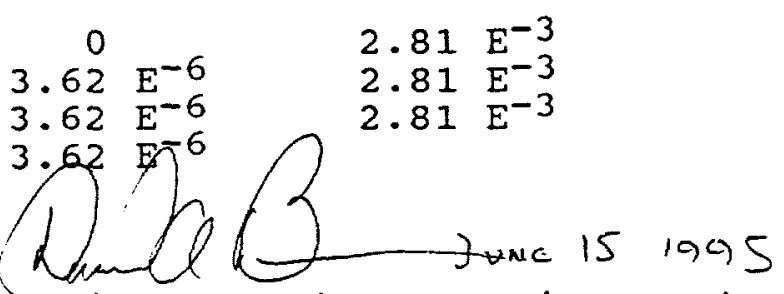

David A. Bucior Senior Project Leader 
APPENDIX D

Fluid Dynamic (Methanol) Run Chronology 
Fluid Dynamic/Methanol Run - June, 1995

Run Chronology

2 June 1995

09:00 Loaded 28.30 Prep Tank:

\begin{tabular}{ccccc} 
Drum & Full Wt. $(\mathbf{l b})$ & Empty Wt. (lb) & Net Wt. (lb) & Subtotal (lb) \\
1 & 472 & 121 & 351 & 351 \\
2 & 482 & 121 & 361 & 712 \\
3 & 478 & 121 & 357 & 1069 \\
4 & 483 & 120 & 363 & 1432 \\
5 & 456 & 121 & 335 & 1767 \\
\multicolumn{4}{c}{ TOTAL OIL ADDED $=1767 \mathrm{lb}$}
\end{tabular}

19:00 Backed syngas out of plant at conclusion of carbonyl study.

3 June 1995

08:00 Baseline Catalyst Loading and Activation

Lot \# 94/15730

Colli: 8592859

Samples of catalyst were taken from each drum (1 through 4).

$\begin{array}{ccccc}\text { Drum } & \text { Full Wt. (lb) } & \text { Empty Wt. (lb) } & \text { Net Wt. (lb) } & \text { Subtotal (lb) } \\ 1 & 510 & 128 & 382 & 382 \\ 2 & 512 & 126 & 386 & 768 \\ 3 & 510 & 128 & 384 & 1152 \\ 4 & & & 27 & 1179\end{array}$

TOTAL CATALYST ADDED $=1179 \mathrm{lbs}$

11:55 Transferred slurry from prep tank to 27.20 reactor.

12:26 Transferred $284 \mathrm{lb}$. flush oil to prep tank and flushed residual catalyst to 27.20 reactor.

14:30 Started reduction gas flow.

15:44 Started heat - up.

17:30 Stopped pump back of oil from 27.14 to 21.11 .

$22: 2027.20$ level down from $390^{\prime \prime}$ to 371 "; however, catalyst concentration increased only to $40 \%$.

02:25 Reactor level at 350". Started pumping oil back from 21.11 to 27.20 to raise reactor level.

05:25 Backed down on flow rates per test authorization. 
08:00 Discovered manual block valve was shut on oil make-up to 27.20. Haven't pumped backed any oil all night. Brought level up to $360 "$.

09:15 Transferred oil from 27.14 to 21.11 .

4 June 1995

10:12 Reduction complete. Swinging N2 to cool down reactor to $420^{\circ} \mathrm{F}$. Liquid level of reactor at 290 (w/o flow).

11:45 Syngas once thru on to the reactor

$\mathrm{CO}=9300 \mathrm{SCFH}$

$\mathrm{H} 2=9400 \mathrm{SCFH}$

$\mathrm{CO} 2=1500 \mathrm{SCFH}$

Average reactor temperature $431^{\circ} \mathrm{F}$

Reactor pressure $=171$ psig.

12:15 Started oil back from 21.11 to 27.20 .

15:25 Reactor feed close to target. 27.20 placed on auto liquid control.

18:00 GC/DEC communication problems. Communications re-established approximately 21:30.

22:00 Rob restarted the Dennis GC because it was out of sequence (D02 was coming across as D04).

5 June 1995

00:50 Day tank transfer from 102" to $20 " .1445$ gals. into trailer \#7486.

01:15 Bharat GC lost MeOH peak on DEC. Rocco GS still shows MeOH peak.

11:50 Day tank transfer from 121.5" to 46". 1330 gals. into trailer \#7486.

16:15 Day tank transfer from $83 "$ to $20 " .1110$ gals. into trailer \#7486.

6 June 1995

01:30 Day tank transfer from $103.5^{\prime \prime}$ to $20^{\prime \prime} .1472$ gals. into trailer \#7486.

8:50 Day tank transfer from 54" to $20 " .599$ gals. into trailer \#7486.

12:10 Ended condition AF-R13.1. Started AF-R13.2.

19:05 Total reactor feed flow was $89,000 \mathrm{SCFH}$. Target $80,937 \mathrm{SCFH}$. Reduced recycle.

7 June 1995

00:20 Day tank transfer from $115^{\prime \prime}$ to $20 " .1674$ gals. into trailer \#7454.

01:00 Plant lined out at AF-R13.2 conditions.

09:30 Switched G02 to SP6. 
11:00 Feed composition steady.

12:15 Day tank transfer from 116" to $20^{\prime \prime} .1692$ gals. into trailer \#7454.

14:45 Increased 21.11 product out temp from 280 to $290^{\circ} \mathrm{F}$.

16:24 Dropped pressure in 27.14 from 724 to 675 psig to stop methanol from condensing in 27.14.

8 June 1995

00:35 Day tank transfer from $120^{\prime \prime}$ to $20^{\prime \prime} .1762$ gals. into trailer \#7454.

00:21 D04 shot lost H2 peak, but other Dennis GC ports ok.

07:30 Changed TIC-1260 on 21.11 from 290 to $295^{\circ} \mathrm{F}$.

11:50 Day tank transfer from $112.5 "$ to $20^{\prime \prime} .1630$ gals. into trailer \#7454.

21:00 Swapped heater/cooler order in UO circuit. Average 27.20 temperature only upset $+4 /-2^{\circ} \mathrm{F}$ during swing.

22:35 Day tank transfer from $117^{\prime \prime}$ to $20 "$. 1710 gals. into trailer \#7488. DEC stopped receiving updates from $\mathrm{HP}$.

22:55 Rob shutdown and restarted the lab.

9 June 1995

07:30 Performed slump test on reactor 27.20.

08:00 Started move to AF-R3.3 conditions.

12:20 Day tank transfer from 116" to 20". 1692 gals. into trailer \#7488. Tried to reach high velocity $91.2 \mathrm{ft} / \mathrm{sec}$ ) using TEXACO gas composition at lower pressure. Only got up to 160,000 SCFH (target 204,462 SCFH).

15:45 Changed gas composition back to Kingsport gas to reach $1.2 \mathrm{ft} / \mathrm{sec}$. REVISED CONDITION AF-R13.3 for Kingsport gas at $\mathrm{SV}=10,000 \mathrm{std} .1 / \mathrm{hr}-\mathrm{kg}$. Reduced reactor pressure to $718 \mathrm{psig}$.

19:10 Day tank transfer from $88.5^{\prime \prime}$ to $20 " .1207$ gals. into trailer \#7488.

IO June 1995

00:05 Day tank transfer from 89.5" to $20^{\prime \prime} .1225$ gals. into trailer \#7488.

02:52 Printer in lab stopped printing. DEC stopped getting updates from HP.

04:05 Rob stopped and restarted everything.

04:45 Printer dumped all its data (DEC received it all). 
05:45 Day tank transfer from $99^{\prime \prime}$ to $20^{\prime \prime} .1392$ gals. into trailer \#7484.

08:00 Loaded oil in 28.30 prep tank.

\begin{tabular}{ccccc} 
Drum & Full Wt. (lb) & Empty Wt. (lb) & Net Wt. (lb) & Subtotal (lb) \\
1 & 500 & 121 & 379 & 379 \\
2 & 500 & 121 & 379 & 758 \\
3 & 500 & 121 & 379 & 1137 \\
4 & 500 & 121 & 378 & 1516 \\
5 & 372 & 121 & 251 & 1766 \\
\multicolumn{4}{c}{ TOTAL OIL ADDED $=1766$ lbs }
\end{tabular}

11:00 Started Dephlegmator testing. Shut pump back from 27.14 to 21.11.

$\begin{array}{lllll}\text { Time } & \text { 27.14 (nuts) } & \begin{array}{l}\text { 21.11 (in) } \\ \text { 11:00 }\end{array} & \text { Reactor Ht. (in) } & \begin{array}{l}\text { Reading \% } \\ 35.71\end{array} \\ 11: 03 & 16 & & & 62.43 \\ 11: 05 & & & 480 & \\ 11: 38 & 17.4 & & & 66.13 \\ 11: 40 & & 21.75 / 33.25 & & 29.23\end{array}$

11:30 Day tank transfer from $98^{\prime \prime}$ to $20^{\prime \prime} .1375$ gals. into trailer \#7484.

$13: 00 \quad 27.14 @ 20$ nuts $(74.31 \%)$

$21.11 @ 23.5^{\prime \prime}(?)(16.65 \%)$

14:0327.14@22 nuts $(80.94 \%)$

$21.11 @ 17.5^{\prime \prime}(8.25 \%)$

$27.20 @ 480^{\prime \prime}$

Shut pump back from 21.11 to 27.20 . Pump back from 27.14 still off.

14:2127.20@ 467.5" on tape.

14:2627.20@ 467.5" on tape.

14:4427.20@ 458.3" on tape.

14:46 27.20@ 458.3" on tape.

15:0727.14@ 24 nuts $(87.22 \%)$

$21.11 @ 20.5^{\prime \prime}(13.58 \%)$

$27.20 @ 446.8 "$

17:30 Day tank transfer from $102.75^{\prime \prime}$ to $20 " .1459$ gal. into trailer \#7484. 
22:30 Started another dephlegmator test

$27.14 @ 15.75$ nuts

$21.11 @ 22.5 / 33.25 "$

Stopped pump back from 27.14 to 21.11 and bypassed demister.

23:27 Day tank transfer from 101" to $20^{\prime \prime} .1428$ gal. into trailer \#7484.

23:3027.14@18.0 nuts

$21.11 @ / 26.25^{\prime \prime}$

11 June 1995

$00: 3027.14 @ 19.75$ nuts

$21.11 @ / 18.5^{\prime \prime}$

00:35 Stopped pumpback from 21.11 to 27.20 (still bypassing the demister). Starting reactor level at 476".

00:45 PLANT TRIPPED! 01.10 ate it belts.

06:00 Day tank transfer from $46 "$ to empty. 705 gal. into trailer \#7484.

11:00 Day tank transfer from $<17.5^{\prime \prime}$ to empty. $<201$ gal. into trailer \#7484. Small amount of $\mathrm{MeOH}$ found in 22.1 and dumped into waste $\mathrm{MeOH}$. Approximately 14 gal.

11:40 Blocked all feed valves from HYCO. Flare out.

12:30 Fill 21.11 with flush oil to $47^{\prime \prime}$.

13:00 Drained spent slurry into drums. Collected 3-5 gal. buckets of spent slurry as samples. Filled 5 drums of spent slurry.

13:30 Some rainwater ( $\sim$ cup) left in each 55 gal. drum before slurry 6 was drained into the drums (even though water was poured out of the drums before charging slurry). Expect that water will settle to bottom or near bottom of drums. 5 gal. "buckets" were dry before filling with spent slurry.

14:30 Draining oil from 27.14 into 55 gal. drum. Flush 27.20 reactor with oil from 21.11. Drain flush oil into 55 gal. drums.

12 June 1995

08:45 Loaded alternate methanol catalyst powder (target amount is $1177 \mathrm{lb}$ ).

Lot 022811 (net $50 \mathrm{~kg}$; gross $63 \mathrm{~kg}$ ). Drums were numbered: \#/95.

A sample from each drum was collected. 


\begin{tabular}{ccccc} 
Drum & Full Wt. (lb) & Empty Wt. (lb) & Net Wt. (lb) & Subtotal (lb) \\
31 & 162 & 53 & 109 & \\
30 & 163 & 53 & 110 & 219 \\
27 & 163 & 53 & 110 & 329 \\
26 & 164 & 53 & 111 & 440 \\
28 & 164 & 53 & 111 & 551 \\
29 & 164 & 53 & 111 & 662 \\
39 & 163.5 & 53 & 110.5 & 772.5 \\
34 & 164 & 53 & 111 & 883.5 \\
32 & 163 & 53 & 110 & 993.5 \\
33 & 164 & 53 & 111 & 1104.5 \\
35 & 126 & 53 & 73 & 1177.5 \\
& \multicolumn{5}{r}{} \\
\end{tabular}

11:30 Weighed out flush oil (to flush catalyst slurry remaining in prep. tank to 27.20 reactor). Full drum: $\quad 403 \mathrm{lb}$ Emptydrum: $121 \mathrm{lb}$ FLUSH OIL: $282 \mathrm{lb}$ (target: $283 \mathrm{lb}$ )

13:00 Transferred slurry from 28.30 to 27.20 , Liquid $\mathrm{Ht}=241$ "

13:20 Transferred flush oil to 27.20 , Liquid $\mathrm{Ht}=289.4 "$

13:50 $\mathrm{N}_{2}$ flow increasing.

14:30 Starting CO flow.

14:44 Started heating up.

15:00 Rxt Avg Temp $=193.3^{\circ} \mathrm{F}$, Rxt $\mathrm{Pr}=68.7 \mathrm{psig}$, FI-126A Flow $=12,569 \mathrm{SCFH} \mathrm{N}_{2}$, Rxt Level $=344.7^{\prime \prime}$

20:15 CO composition in feed has been creeping up. Line pressure is also running high. Matt made a move to decrease $\mathrm{CO}$ flow.

Uptake @ 20:00 (5.25 hr's into redtn.) was 1.2 SCF/lb.

21:00 Uptake 6.25 hours into redtn $=1.53 \mathrm{SCF} / \mathrm{lb}\left(281^{\circ} \mathrm{F}\right)$.

22:00 Uptake 7.25 hours into redtn $=1.86 \mathrm{SCF} / \mathrm{lb}\left(295^{\circ} \mathrm{F}\right)$.

Still no $\mathrm{H}_{2}$ production, everything else steady.

22:45 Did a nuke scan. Reading did not seem a steady as they should have been at these rates.

23:00 Uptake 8.25 hours into redtn $=2.20 \mathrm{SCF} / \mathrm{lb}\left(309^{\circ} \mathrm{F}\right)$.

Still no $\mathrm{H}_{2}$ production.

24:00 Uptake 9.25 hours into redtn $=2.40 \mathrm{SCF} / \mathrm{lb}\left(322^{\circ} \mathrm{F}\right)$. 
13 June 1995

01:00 Uptake 10.25 hours into redtn $=2.44 \mathrm{SCF} / \mathrm{lb}\left(336^{\circ} \mathrm{F}\right)$.

02:00 Uptake 11.25 hours into redtn $=2.48 \mathrm{SCF} / \mathrm{lb}\left(351^{\circ} \mathrm{F}\right)$.

03:00 Uptake 12.25 hours into redtn $=2.52 \mathrm{SCF} / \mathrm{lb}\left(365^{\circ} \mathrm{F}\right)$.

04:00 Uptake 13.25 hours into redtn $=2.53 \mathrm{SCF} / \mathrm{lb}\left(380^{\circ} \mathrm{F}\right)$.

04:50 Cut Rates 25\% per Test Authorization.

05:00 Uptake 14.25 hours into redtn $=2.59 \mathrm{SCF} / \mathrm{lb}\left(395^{\circ} \mathrm{F}\right)$.

This sudden jump up looked anomalous, so I checked the download files and found that D03 lost its $\mathrm{H}_{2}$ peak for two consecutive shots around 0400. Deleting these points from the .dwn file resulted in an uptake calc'n of $2.55 \mathrm{SCF} / \mathrm{b}$.

09:45 Reduction complete. Rxt Avg. $\mathrm{T}=464^{\circ} \mathrm{F}$

Switching to once-thru syngas.

10:55 Reactor level at $288^{\prime \prime}$ just before syngas flow started. It was at $315^{\prime \prime}$ to $350^{\prime \prime}$ with $\mathrm{N}_{2}$ flow through reactor.

11:17 Started 01.20 recycle flow, Reactor Level up to '395".

15:30 Unit almost at R14.1 condition.

15:40 Approx. $20 \mathrm{lbs}$ of alternate catalyst was washed out of prep tank (not transferred to 27.20 reactor).

15:50 Yesterday noticed that TI-311 (21.30A shellside) was reading $98^{\circ} \mathrm{F}$ without hot process gas (pipe was at ambient). Ray pulled TI-311 and confirmed that it was not working. TI311 was replaced with a new TI. Previous measurements from TI-311 should be considered unreliable!

16:00 Ray drained sight glass on 21.11. When refilled sight glass, it filled with black slurry. After approx. 5 mins, the black solids (catalyst) started to settle. It was decided not to redrain the sight glass.

17:30 Have reached conditions for AF-R14.1. Reactor T\&P are at target. Reactor feed composition and flow are also essentially at target. Suggest start data period AF-R14.1A at 18:00.

20:00 Matt pulled a liquid sample off 22.11.

14 June 1995

01:00 Day tank transfer 123.25" to $20^{\prime \prime} .1819$ gallons into trailer \#7486.

04:05 Matt grabbed a liquid sample of 22.11. 
09:00 Dean is taking Rocco down to replace valves. Rocco had been reading low methanol $(\sim 1 \%)$. Dean thinks this is because sample is not getting in.

09:30 Dean has fixed and restarted Rocco.

09:45 271.4 level $\quad 8.25$ nuts $\quad 37.94 \%$

21.11 level $38.25 " \quad 37.21 \%$

Stopped oil pump back from 27.14 to 21.11 .

Demister (21.11) is on-line

Reactor level is $480^{\prime \prime}$.

10:40 21.11 Temperatures

Feed Gas inlet $(\mathrm{TI}-1257)=147.7^{\circ} \mathrm{F}$

Feed Gas outlet $(\mathrm{TI}-1263)=367.9^{\circ} \mathrm{F}$

Product Gas Inlet $\left(\right.$ TI-1262) $=467.7^{\circ} \mathrm{F}$

Product Gas Outlet $\left(\right.$ TIC-1260) $=281.6^{\circ} \mathrm{F}$

11:10 Ray pulled a liquid sample off 22.11

11:20 271.4 level $\quad 10.5$ nuts $\quad 45.74 \%$

21.11 level 21.5" $26.09 \%$

Stopped oil pump back from 21.11 to 27.20 .

Still no oil pump back from 27.14 to 21.11 .

Demister (21.11) is on-line

Reactor level is $480 "$.

11:30 Day tank transfer 118" to $20 " 1727$ gal. into trailer \#7486

$12: 20$ Reactor level at $450^{\prime \prime}$

12:35 Reactor level at 441"

12:45 Reactor level at $436 "$

$12: 50 \quad 21.11$ level at $363 / 4^{\prime \prime} \quad 36.51 \%$

27.14 level at $\sim 121 / 2$ nuts $\quad 53.25 \%$

DEC/Bailey shows level being at same rate as during 9:45 to 11:20 test. Assume same rate of oil carry-over from 21.11 to 27.14 .

Resume oil pumpback from $27.14 \rightarrow 21.11$ and $21.11 \rightarrow 27.20$.

Could not wait for oil level in 27.14 to rise further because concerned that level in reactor would get too low.

14:45 Swing valves to bypass 21.11 demister.

15:12 2.11 level 37" $\quad 35.34 \%$

27.14 level $8+$ nuts $\quad 38.59 \%$

Reactor level at $480^{\prime \prime}$. Stopped oil pumpback from 27.14 to 21.11 . 
16:15 21.11 temperatures

Feed gas inlet

(TI-1257) $144.1^{\circ} \mathrm{F}\left(147^{\circ} \mathrm{F}\right.$ before $\left.15: 45\right)$

Feed gas outlet

(TI-1263) $368.3^{\circ} \mathrm{F}$

Product gas inlet

(TI-1262) $466.7^{\circ} \mathrm{F}$

Product gas outlet

(TIC-1260) $279.1^{\circ} \mathrm{F}\left(280.5^{\circ} \mathrm{F}\right.$ before $\left.15: 45\right)$

16:48 21.11 level 26" $20.41 \%$

27.14 level $11+$ nuts $\quad 47.59 \%$

Reactor level at 480".

Stop oil pumpback from 21.11 to 27.20 .

Still no oil pumpback from 27.14 to 21.11 .

18:04 Reactor level at 441".

18:10 21.11 level $311 / 4 " \quad 28.94 \%$

27.14 level $13+$ nuts $\quad 55.20 \%$

Resume oil pumpback from $27.14 \rightarrow 21.11$ and from $21.11 \rightarrow 27.20$

18:20 Day tank transfer from 83" to $20^{\prime \prime} 1110$ gal into trailer \#7486

18:30 Started to ramp down 21.11 product gas outlet temp (TIC-1260) from $280^{\circ} \mathrm{F}$ towards $260^{\circ} \mathrm{F}$

18:50 Swing valves to return 21.11 demister to service.

19:30 Matt pulled a liquid sample of the 22.11 .

20:00 Dec crashed! Rebooted itself.

20:30 D04 came through, so we still have HP/DEC communications.

15 June 1995

03:05 Matt grabbed a liquid sample off 22.11

Have been lax on liquid loss and nuke scans because Matt and I have been fighting with the plant all night. The back end is constipated and we have been fighting a losing battle with the levels in the 22.10 and 22.15 .

04:45 Matt pulled a piece of junk out of LV-242. We are finally able to really unload 22.10 and 22.15 into the day tank.

05:45 Day tank transfer 121" to 20", 1780 gal. into trailer \#7486.

07:20 Started dephlegmator testing with TIC- 1260 set at $255^{\circ} \mathrm{F}$. Plant has been running all night at this condition, but we never got a chance to do the test because of back-end problems.

21.11 level $41 "$ " (15 nuts) $\quad 40.04 \%$

27.14 level $51 / 2$ nuts $29.58 \%$

Stop oil pumpback from $27.14 \rightarrow 21.11$ 
Reactor level is at $480^{\prime \prime}$

(21.11 demister is on-line)

08:45 21.11 temperatures

Feed gas inlet

(TI-1257)

$144.5^{\circ} \mathrm{F}$

Feed gas outlet

(TI-1263)

348.8

Product gas inlet

(TI-1262)

467.0

Product gas outlet

(TIC-1260)

255.6

08:55 21.11 level 32 3/4"

$29.18 \%$

27.14 level 8 nuts

$37.01 \%$

09:02 Stop oil pumpback from $21.11 \rightarrow 27.20$

Still no pumpback from $27.14 \rightarrow 21.11$

Reactor level at $480^{\prime \prime}$.

$10: 29 \quad 21.11$ level 39 3/4" $\quad 39.68 \%$

27.14 level 10 nuts $\quad 43.69 \%$

Reactor level 434"

End of dephlegmator tests. Resume oil pumpback from $27.14 \rightarrow 21.11$ and from $21.11 \rightarrow$ 27.20

10:30 Asked Ray to slow down sample taps because noticed lower than normal $\mathrm{MeOH}$ content in GC analysis of SP 3A.

10:30 Ray took a liquid sample off 22.11 .

10:30 Started increasing 21.11 product gas out temp to heat up separators in preparation for Kingsport cond.

11:00 Reactor level backup to $480^{\prime \prime}$

11:20 Mina did a nuke scan before slump test.

12:10 Performed slump test. Liquid level crossed 375" $11 \mathrm{sec}$ after flows shut off.

12:27 Slump test complete. Making move to Kingsport, SV-4000 conditions (AF-R14.2). During slump test, reactor average temperature dropped from 481 to $473^{\circ} \mathrm{F}$. TI-1240 (bottom of reactor, J11) increased from $473^{\circ} \mathrm{F}$ to $483^{\circ} \mathrm{F}$, . TI-1235 (J7) dropped slowly from 486 to $483^{\circ} \mathrm{F}$.

12:55 Day tank drained to $241 / 2 "$ from 85 1/2" 1076 gal. into trailer \#7486.

14:45 Added oil to 27.14 from $<1$ nut to $61 / 2$ nuts (between sight glasses).

15:30 Added oil to 27.14 from $11 / 2$ to 6 nuts.

17:40 Added oil to 27.14 from $41 / 2$ to 10 nuts. 
18:00 Very nearly at conditions for AF-R14.2.

Recommended start date period AF-R14.2 at $\underline{19: 00}$

18:00 Ed/Dave/Ray have been fighting with flakes and grit coming out of 22.15 and plugging up the control valve, LV-242. A piping run from the 22.15 sight glass to the 22.15 exit stream filter was put in place and is now in use. Another tubing ran to bypass the 22.15 product filter and control valve directly to 22.16 was installed but is not in use so far.

20:30 Took outside liquid levels.

23:25 Nuke scan taken - stable readings.

16 June 1995

00:45 Getting set up for a day tank transfer $122 "$ to $20^{\prime \prime}-1797$ gallons into trailer \#7484

02:25 Matt grabbed a liquid sample off 22.11 .

03:00 Second time the 21.40 tripped out on vibration. No effect on the process.

03:37. Another 21.40 vibration trip.

04:10 Nuke scan - liquid levels taken.

10:30 Ray collected a liquid sample off the 22.11.

11:50 Day tank transfer from $114 "$ to $20 " .1657$ gallon into trailer \#7484.

18:15 Day tank transfer from $72.5^{\prime \prime}$ to $20^{\prime \prime} .925$ gallons to trailer \#7484.

21:00 Nuke scan - very stable; liquid sample taken.

21:30 Outside logs taken.

I7 June 1995

00:05 Liquid level logs taken.

02:40 Outside logs taken ( 22.16 between sight glasses at 0200 ).

03:10 Noticed while working on the mass balance, that FI-196 (27.14 outlet) was reading 0 during the entire mass balance period. Had to adjust the mass balance program accordingly. Matt blew down the taps on FI-196. It is now reading a proper signal again.

04:00 MeOH sample taken; Nuke scan taken.

04:40 Outside readings taken.

06:05 Day tank transfer from 116 3/4" to 20"; 1706 gal to trailer \#7484. Next transfer should be no higher than 69" (873 gallons). 
10:00 MeOH sample taken; nuke scan done.

12:00 Day tank transferred 69" to 20" (863 gallons). Trailer \#7484 is now full.

18:00 Day tank transferred 68" to $20 "$ (845 gallons). First transfer in trailer \#7124.

18:00 MeOH sample taken

21:00 Did some cleanup on the DEC - purge files, etc.

22:25 Nuke scan

Noticed Ft-196 again was reading zero inches. Matt going up to blow down the sample taps and wrap the root valves to prevent condensation.

23:30 Finished outside logs.

18 June 1995

02:00 Liquid methanol sample collected

03:50 Nuke scan done.

04:30 Outside logs taken

05:45 Closed off on LIC-1255 (27.14 to 21.11)

06:00 Closed off oil return to reactor DIC-1242; trying to thicken up before switching conditions (level 480)

06:07 Began 22.16 transfer from 118.5 inches

06:40 Level in reactor at $473.8 "$.

06:45 Finished 22.16 transfer, 1736 gallons.

07:00 Outside liquid levels taken end of AF14.2

07:01 Start morning to AF14.3 conditions. Level above 534" (top of nuke). TI-1255 is 492F indicates slurry up that high ( 2 ' from top face of flange)

08:30 Making fine adjustment in feed composition. Increased $\mathrm{H}_{2} @ 01.10,8.5 \rightarrow 9.5 \mathrm{MSCFH}$

08:34 Discovered DEC problems! "SHO SYS" did not show "TREND_COLLECTOR" indicating DEC was not saving data. Did a "RESTART" to turn on "TREND_COLLECTOR". Did a number of downloads to figure out when DEC stopped saving data. Looked like it stopped right after 0400 on $6 / 18$. So, $14.2 \mathrm{~B}$ will be from $01: 006 / 17$ to $04: 006 / 18$.

09:10 Last few hours GC printer out of ink. 
09:30 Switched from SPI5 to SP6 for D06 and G02.

(Purge 2 will now get correct composition).

Reactor level decreasing: In manual @ 489"

21.11 building up level

27:14 pump back started to evaporate $\mathrm{MeOH}$

12:00 Composition leveling out on Rxt feed.

12:20 Transferred day tank from 100" to 50.5" (872 gallons). Trailer level switch tripped.

12:55 CO feed is being curtailed by HYCO.

Backing out $\mathrm{CO}$ from 18,500 to $10,000 \mathrm{SCFH}$

Decreasing Rxtor pressure to maintain velocity.

14:40 Estimated velocity $=1.07 \mathrm{ft} / \mathrm{sec}$

@138,000 SCFH Rxt feed, 560 psig Rxt Pr.

15:50 High pressure $\mathrm{H}_{2}$ switched from 01.20 suction to $01.10 / 01.20$ discharge

17:00 Adjusting feed composition; lowered $\mathrm{H}_{2}$

Keep CO fixed at $10,000 \mathrm{SCFH}$

18:00 Day tank transfer: $101^{\prime \prime}$ to $20^{\prime \prime} \rightarrow 1428$ gallons

Unit lined out: Mass balance period can begin @ 18:00

Rxt flow $=\sim 143,000$ SCFM

Rxt Pr $=\sim 522$ psig

Rxt Temp $=482^{\circ} \mathrm{F}$

Rxt liquid level $=480^{\prime \prime}$

Has inlet vel $\sim 1.19 \mathrm{ft} / \mathrm{sec}$

20:30 Outside logs taken; GC's sample pots in hot box blown down. Some liquid in third from left.

21:10 Methanol sample collected

23:10 Outside liquid levels taken; sample pot 3 (from left) had liquid drops in it when I blew it down.

23:30 Trying PIC-196 in auto

PIC-247-1 01.20 suction 431.5\#

PIC-196 21.11 inlet 476\#

PIC 1247 reactor $524 \#$

$2323 \mathrm{GC} \quad$ on reactors feed

$54.72 \%$

26.59

11.48

$\mathrm{H}_{2}$

$\mathrm{CO}$

6.12

$\mathrm{CO}_{2}$

$\mathrm{H}_{2}$ 
Matt's increasing $\mathrm{H}_{2}$ again to try bump it

19 June 1995

00:00 Matt was adjusting the manual block valves up and down stream of the $\mathrm{HP}_{2}$ controller PIC-1250. The $\mathrm{H}_{2}$ flow temporarily shot up from $16 \mathrm{MSCFH}$ to $\underline{60} \mathrm{MSCFH}$. PIC vent was in auto so it opened up a bit. (Maybe the blast of $\mathrm{H}_{2}$ will help clear -- some of the $\mathrm{N}_{2}$ ).

Had to reboot the PC again (3rd night in a row - not enough memory). Previously PIC 1200 was controlling 50 or more $\%$ open and still not getting flow. He opened up on the upstream block valve - now at $2-3 \%$ open but getting the flow.

00:40 Latest GC reading

$0025 \quad$ Pressure at 27.20523 .8

$\mathrm{H}_{2} \quad 58.2 \quad$ FI-1216 flow at 136

$\mathrm{CO} \quad 25.13$

$\mathrm{N}_{2} \quad 5.23$

$\mathrm{CO}_{2} \quad 10.49$

Matt's making a move with $\mathrm{H} 2$ to get flow up higher.

00:50 Latest GC 00:43 FI-1216 138

$\mathrm{H} \quad 58.7$

$\mathrm{CO} \quad 24.58$

$\mathrm{N}_{2} \quad 5.3$

$\mathrm{CO} \quad 10.2$

Matt's going to increase $\mathrm{HP} \mathrm{H}_{2}$ again up to 20.5

00:55 Nuke scan - readings are more jumpy $\pm 0.5- \pm 1.0$ in liquid readings.

01:40 Matt changed paper on GC computer printer. It appears (GC's) to still be communicating with the DEC.

$127 \mathrm{GC}$--- reactor feed

$\begin{array}{lll}\mathrm{H}_{2} & 61.59 & \text { FI-1216 at } 139 \\ \mathrm{CO} & 22.87 & \\ \mathrm{~N}_{2} & 4.88 & \\ \mathrm{CO}_{2} & 9.64 & \end{array}$

Reactor $\mathrm{p}$ at 519 (cycle between 517.5-519.5) because PIC-196 has been auto

Matt put PIC-196 in manual again to try "iron out" the cycles in the plant flows.

Only way to increase flow is to increase $\mathrm{H}_{2}$ but we're already slightly $\mathrm{H}_{2}$ rich

Hold here for a while

0145 feed $\mathrm{GC} \quad 62.94 \mathrm{H}_{2}$ reactor feed flow jumped up to 143-144 MSCFH

$22.04 \mathrm{CO}$ pressure up to 52.6

$4.78 \mathrm{~N}_{2} \quad$ PIC 196/PV-201 manual $12 \%$

Matt's backing off $\mathrm{HP} \mathrm{H}_{2}$ - needs to go adjust the 01.13 manual valve 
to get FIC-1200 more controllable, It has been running $2.7 \%$

Now at $5.3 \% \rightarrow 19.7 \mathrm{MSCFH}$

02:20 Liquid logs taken

GC pots blown; liquid in \#3 again

03:10 Methanol liquid sample taken

GC's reactor feed: $247 \quad \mathrm{H}_{2} \quad 64.9 \quad \mathrm{PI}-1247$ down to 513 again

CO 20.81 FI $1246 \mathrm{CO}$ at 142.9

$\mathrm{N}_{2} \quad 9.94$

$\mathrm{CO}_{2} 8.63$

We're cutting back on $\mathrm{H}_{2}$ once more. PV-201 still manual at $12 \%$

05:00 Took liquid levels; blew down GC pots; droplets in \#3.

Began nuke scan - readings still varying $\pm 0.5- \pm 1.0$ in the liquid region.

0451 Gary feed $\mathrm{H}_{2} \quad 61.95$

$\mathrm{CO} \quad 22.47$

$\mathrm{N}_{2} \quad 5.04$

$\mathrm{CO}_{2} \quad 9.34$

05:57 Begin 22.16 transfer.

06:45 1613 gallons transferred

Only room for $462 / 3$ " before filling up the trailer!

07:40 Outside full readings taken.

09:20 Day tank transfer: $46 "$ to $20 "$ (459 gallons)

Trailer \#7124 now full

10:00 Ray pulled a liquid sample off the $22.11 / 22.15$.

11:15 Full set of outside logs.

12:32 Nuke scan Nuke readings in liquid were quite jumpy: ranging \pm 0.5 to \pm 1.5

15:00 Ray pulled a liquid sample from the $22.11 / 22.15$.

16:07 Started reactor shut down test.

16:30 Finished reactor shutdown test.

Conditions at end:

PIC-1247 719 psig

Avg temp. $\quad 474.0^{\circ} \mathrm{F}$

TI-1235 $\quad 483.3^{\circ} \mathrm{F}$

TI-1239 $\quad 476.1^{\circ} \mathrm{F}$

TI- $1240 \quad 478.8^{\circ} \mathrm{F}$

Start move to next condition. AF-R14.4 (Texaco, inlet SV=4000 std $1 / \mathrm{hr} / \mathrm{kg}$ cat.) 
We are still limited to 10,000 SCFM of CO and so may need to run reactor at less than the target 750 psig (lower conversion to $\mathrm{MeOH}$ and less makeup $\mathrm{CO}$ needed).

20:15 "Dennis" GC shot at 20.03 of sample 4 showed erroneous composition results $(52.36 \%$, $4.99 \%$ N2, 2.34\%, CO2 0.46\%). Problems with "Dennis" were confirmed with GC standard shot at 2034. This caused problems with FI measurements and FIC's that were on auto. Matt put FIC-246 on manual but we temporarily dropped pressure in the loop and reactor (reactor pressure had just reached $750 \mathrm{psig}$ ). We entered MW's manually into the Bailey to over write incorrect values sent by "Dennis". Called to consult with Dean.

20:54 Stopped "Dennis to prevent receiving incorrect MW's. Dean is on his way in.

21:20 Stopped pumpback from 27.14 to 21.11 since 27.14 level was at $21 / 4$ nuts (piping level).

21:30 Day tank transfer begun 21.22 GC shot Gary

$$
\begin{array}{ll}
38.43 & \mathrm{H}_{2} \\
44.32 & \mathrm{CO} \\
2.12 & \mathrm{~N}_{2} \\
14.32 & \mathrm{CO}_{2}
\end{array}
$$

\section{1:45 Dean working on GC Dennis}

21:55 End trailer transfer 1498 gallons transferred to new trailer.

GC Dennis back in operation at 22:39 shot. The 22.58 shot of DO5 was really a sample \#4. Changed SP8MW in the Bailey temporarily. To avoid these GC's, errors, should probably start Data period at 23:00.

20 June 1995

00:00 Dennis 4 analysis - right on composition, flow - pressure targets! Outside logs taken.

00:30 Nuke scan taken.

01:00 Methanol sample collected.

02:45 MW-SP3A is incorrect happened around 145\& is staying at 64 (should be $\sim 26$ or so). Doesn't affect any control valves; only FI-196 - inlet reactor composition great! I am investigating whether liquid product rates match the GC reactor outlet predictions. GC's reading $7.9 \% \mathrm{MeOH}$ in effluent, Predicted is $11.94 \%$.

Day tank measurements $\frac{47^{\prime \prime}-35^{\prime \prime}}{(02: 10-00: 00)}=\frac{723-511 \mathrm{gal}}{130 \mathrm{~min}}=\frac{1.63 \mathrm{gal}}{\min }=\frac{2348 \mathrm{gal}}{\text { day }}$

Predicted is 2337 gal/day (matches $11.5 \%$ in effluent)

Hand calc to check predictions. 


$$
\begin{aligned}
\frac{2348 g a l}{d a y} \frac{1 d a y}{24 h r} \frac{50 l b}{f t 3} \frac{f t 3}{7.481 g a l} & =\frac{653.96 l b}{h r} \\
& =\frac{20.43 \mathrm{lb}}{h r}
\end{aligned}
$$

reactor feed $=\sim 81.5 \mathrm{MSCFH} \frac{\mathrm{lb} \text { mole }}{386.67 \mathrm{SCF}} \frac{\sim 21 \mathrm{lb}}{\mathrm{lb} \text { mole }}=\frac{4427 \mathrm{lb} \text { feed }}{\mathrm{hr}}$

$\frac{4427}{h r}$ effluent $\frac{l b \text { mole }}{\sim 26}=\frac{170.3 \mathrm{lb} \text { mole }}{h}$ outlet

$\frac{20.43}{170.3}=11.99 \%$ methanol in the effluent based on 22.16 levels

Both GC's off!!??

Confirm with DMECSTR calc's what expected performance is.

03:10 Another set of levels trying to confirm productn rate.

21.11 level barely in sight glass. 22.14 up to 5 nuts.

Restart pumpback between 27.14 and 27.11 .

Checked GC printouts ; at 108, Bharat analysis showed a large "Pentane peak" in the summary. This would explain the MW jumping up to the 60's, since the Bharat $03 \mathrm{MW}$ portion was 71 (C5H12 is 72 ) instead of 32

Conclusion: Bharat is not believable for SP3A.

Rocco also still shows 7-8\% meoh in the effluent. There are no apparent mysterious peaks. Rocco and Bharat were both reading high concentration (10\% or greater) until $\sim 8$ PM. Since then, they have seen consistently $7-8$ ish!

05:00 Outside logs taken.

06:00 Methanol collected.

07:00 Outside liquid levels taken.

09:25 Nuke scan

10:13 Full set of outside logs taken.

11:40 Start dephlegmator testing.

21.11 Demister is on-line

27.145 nuts $(27.08 \%$ on $1 v 1 \mathrm{xmtr}) 25$ gal

$21.11331 / 2$ " ( $28.31 \%$ on lvl xmtr) 37.9 gal

$27.20480^{\prime \prime}$

11:44 Stop oil pumpback from $27.14 \rightarrow 21.11$

27.20 still on auto level control

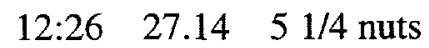




\section{$21.11321 / 4$ nuts}

12:45 Partial set of outside logs.

13:35 27.14 6 nuts (lvl xmtr. 30.28\%) 25.75 gal

21.1127 - 30" (BG) (lvl xmtr. 24.11?) (31.2 - 34.3 gal)

14:30 Ray pulled a liquid sample from $22.11 / 22.15$.

14.40 Reduced LP H2 feed slightly since reactor feed was becoming slightly $\mathrm{H} 2$ rich.

14:56 Full set of outside logs

15:20 Day tank transferred: $124^{\prime}$ to $2-" \Rightarrow 1833$ gallons to trailer \#7406

$16: 40 \quad 27.14 \quad 61 / 2$ nuts (BG) (lvl xmtr. 34.79\%) $\quad 28.33 \mathrm{gal}$

$21.11253 / 4 "$ (lvl xmtr. 18.00\%) $29.85 \mathrm{gal}$

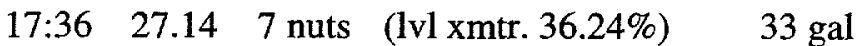

$21.11241 / 4 "$ (lvl xmtr. 16.78\%) 28.25 gal

$27.20480^{\prime \prime}$

17:42 Stopped oil return 22.11 to 27.20

Still no oil return $27.14 \rightarrow 21.11$

$\begin{array}{llllll}18: 20 & 27.14 & 73 / 4 \text { nuts } & \text { (Lvl xmtr. 37.21\%) } & \text { 35.25 gal } & \Delta=2.25 \\ & 21.11 & 261 / 2^{\prime \prime} & \text { (Lvl xmtr. 19.75\%) } & \text { 30.6 gal } & \Delta=2.35\end{array}$

$27.20 \quad 470.4^{\prime \prime}$

reactor delta 10.4 in $=10.4(1.102 \underset{\text { in }}{\text { gal }})=11.5$ gal

19:25 22.11 conditions

Feed gas IN temp (TI-1257) $155.5^{\circ} \mathrm{F}$

Feed gas OUT temp (TI-1263) $313.4^{\circ} \mathrm{F}$

Prod gas IN temp (TI-1262) $461.8^{\circ} \mathrm{F}$

Prod gas OUT temp $\quad$ (TIC-1260) $274.7^{\circ} \mathrm{F}$

$19: 40 \quad 27.14 \quad 81 / 4$ nuts (Lvl xmtr. 39.09\%) 36.75 gal

21.1131 1/4" (Lvl xmtr. 26.44\%) $35.55 \mathrm{gal}$

$27.20 \quad 453.6$ in.

19:59 End of this dephlegmator test

19:59 Return reactor to level control (oil return from $21.11 \rightarrow 21.11$ )

Return 21.11 to level control (oil return from $27.14 \rightarrow 21.11$ )

20:08 Full set of outside logs. Reactor level was below 480" (recovering from dephlegmator test.) Do not use this data point in oil balance. 
21:03 Matt shut oil pumpback from 27.14 to 21.11 to lower 21.11 level in preparation for next dephlegmator test.

21:30 Matt took a liquid sample off the 22.11/22.15.

22:30 Reactor level at 480 inches.

22:35 Demister bypassed on 21.11 .

21.1131 .25 in $(25.85 \%)$

$23: 05 \quad 22.11 \quad 27-30(B G)$ in $\quad(24.43)$

$23: 35 \quad 21.11 \quad 27-30(\mathrm{BG}) \quad(22.96)$

$00: 08 \quad 21.11 \quad 27-30(\mathrm{BG})$

21 June 1995

00:40 Both still in-between sight glasses.

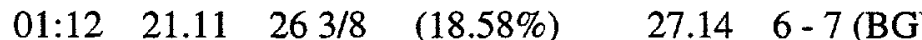

$01: 47 \quad 21.11 \quad 253 / 8 \quad(17.18)$

$02: 17 \quad 21.11 \quad 243 / 4 \quad(16.2)$

02:20 Block in 21.11 return to reactor.

27.14 still blocked; reactor level at 477.6 inches.

02:43 Reactor level 474.6"

$21.11 \quad 26.0 \quad(18.33 \%)$

27.14 8(higher than before but not quantifiable (37.54)

03:25 21.11 BG (21.43\%)

Liquid levels taken

$04: 35 \quad 22.11 \quad 32$

(26.65) $27.14 \quad 9.0$

$(40.04)$

447.6

04:40 Reactor level back in control at 450 inches. (Estimated height for next run condition given increased gas holdup)

21.11 back in auto at $27 \%$ level ( 32 inches)

(pumpback to 21.11 and reactor is now on.)

End dephlegmator test - demister bypass shut!

05:00 Methanol sample taken.

05:30 Nuke scan done.

06:00 Outside levels taken.

06:05 Day tank transfer begun. 
07:05 Last set of liquid levels taken. End of AF-R14.4. Start transition to F-R14.5.

09:00 Rxt temp reached $500^{\circ} \mathrm{F}$ and temp was on manual. Rxt temp on control.

10:00 Rxt lined out. Mass balance period can begin.

10:20 Adjustments to $\mathrm{CO}_{2}$ and $\mathrm{HP}$ or feed flows.

11:50 Adjust CO feed 17.5 to 17.3 MSCFH.

12:55 Adjust CO 17.3 to 17.0 MSCFH

$\mathrm{MPH}_{2} 23.9$ to $23.6 \mathrm{MSCFH}$

13:30 Ray took a liquid sample from $22.11 / 22.15$.

13:45 Cutting back fresh feeds to reduce gas vent flow.

13:50 Day tank transfer $85 "$ to $241 / 2 " 1067$ gal. into trailer \#7406. Trailer is now full!

14:05 to $14: 35 \quad$ Cutting back CO from 16.4 to $15.5 \mathrm{MSCFH}$

15:25 to $16: 00 \quad$ Fresh CO to $16.0 \mathrm{MSCFH} . \mathrm{CO}_{2}$ from 63 to $61 \%$

15:30 FT-237A transmitter is back in service.

18:00 Ray took a liquid sample off the 22.11/22.15

Nuke scan.

18:30 Another move on CO: 16.0 to $16.2 \mathrm{MSCFH}$.

23:33 Completed nuke scan.

Between approx. 1200 and 1800 on $6 / 21 / 95$ chains were installed around the 27.20 reactor to hold tracer $\mathrm{CO}$ (tracer study) detectors in position. Chains are located at 27 , $69,94,120,227,333$ and 401 inches on tape. These would not have affected nuke scan performed at 11:15 on 6/21/95. Looking at 6/21/95 18:00 and 22:43 nuke scan, it appears that readings were affected by the chains at only the $120 \mathrm{in.}$ (on tape) elevation. This does not appear to affect avg. gas hold-up calculated.

23:40 Day tank transfer 109 1/2" to 20". 1578 gal. into trailer \#7207

22 June 1995

00:05 Matt pulled a liquid sample from the 22.11/22.15.

00:28 27:14 $101 / 3 \mathrm{~N}(44.86 \%) 21.1138 "$ (35.43\%)

Start bypass of demister and block in LIC-1255 oil from 27.14 to 22.11

$01: 07 \quad 27.14111 / 2 \mathrm{~N}(48.14) 22.11341 / 8(29.53 \%)$

01:10 Stop oil return to the reactor. 


$\begin{array}{llllll}01: 40 & 27.14 & \text { BG (12-13) (50.77) } & 21.1135 .5(32.18) & 27.20 & 464.8 \\ 02: 09 & 27.14 \quad \text { BG (53.22) } & 21.11371 / 8(34.51) & 27.20 \% & 4521 / 2 \\ 02: 32 & 27.14131 / 2(55.05) & 21.11381 / 8(35.98) & 27.20 & 442\end{array}$

02:40 Demister back in line; Pumpback still blocked out

$03: 12 \quad 27.14141 / 2(58.22) \quad 21.114$ o $1 / 4(38.81) 27.20 \quad 433.6$

$03: 45 \quad 27.14151 / 3(60.58) \quad 21.11413 / 4(40.95) .27 .20 \quad 412.6$

04:15 Reactor back in level control following a nuke scan at 412.6 inches.

04:22 Outside logs taken.

04:40 21.11 level has dropped back; put back in auto at $28 \%$ - begin pumpback from 27.14.

05:55 Last nuke scan done. Results very repeatable to scan done pre-dephlegmator testing.

07:05 Ed is locking out the nuke. We're running with the oil return in manual at $25.1 \%$.

08:40 Day tank transferred: $97.5 "$ to $20^{\prime \prime}$ (1366 gallons) trailer (\#7207).

Tracer Study: Detector Positions

Levels Rxt Ht, Ft "on tape

$\begin{array}{llll}4 \times & 1 & 5 & 18\end{array}$

$\downarrow \begin{array}{lll}1 & 10.7 & 86\end{array}$

$\downarrow 3 \quad 12.7 \quad 110$

$\downarrow \begin{array}{lll}\downarrow & 4 & 21.7\end{array}$

$\downarrow 5 \quad 30.7 \quad 326$

$\downarrow \quad 6 \quad 36.7 \quad 398$

$\downarrow 7 \quad 41.7 \quad 458$

$\begin{array}{llll}1 & 8 & 52.1 & 583\end{array}$

1 Rxt Inlet

1 Rxt Outlet

1 Recycle Line

32 Total

Run No 14.6

12:58 First gas injection made (thru valve V2462).

13:35 Second gas injection made.

15:15 Liquid injection at nozzle $\mathrm{N}_{2}, 41 / 2$ " from wall. First shot too small.

16:00 Double dose shot @ same location. 
16:24 Liquid injection at nozzle $\mathrm{N}_{2}$, wall.

17:00 Day tank transfer 95" to $20^{\prime \prime}, 1322$ gal into trailer \#7207.

19:36 Liquid injection at nozzle N1 at "center" of reactor. Looked like a good injection, although it took " a little long".

20:02 Liquid injection at nozzle N1 at wall of reactor.

20:20 Nuke is re-set to 480 " but traverse is "locked-out" so it can't be moved.

20:30 Moving to next condition AF-R14.7 (Texas gas, SV=4000 std/hr/kg cat). Ed checked position of top detector. Using metal tape, detector was at $487 "=583 "$. This is different from previous table (previous table corrected). GC shot at 2027 (probable reflecting previous condition) showed (Dennis 04).

$\mathrm{H}_{2} \quad 34.93 \%$

$\mathrm{CO} \quad 50.11$

$\mathrm{N}_{2} \quad 0.97$

$\mathrm{CO}_{2} \quad 12.86$

23 June 1995

09:20 Day tank transferred: $122.5^{\prime \prime}$ to $20 "$ (1807 gallons) to trailer \#7207. Room left for one more full load: $125^{\prime \prime}$ max.

12:18 First gas injected Run 14.7.

12:37 Second gas injected.

13:15 Liquid Injection at $\mathrm{N}_{1}$ - center.

13:36 Liquid injection at nozzle $\mathrm{N}_{1}$ - at wall.

14:43 Liquid injection at nozzle $\mathrm{N}_{2}$ - center.

15:03 Liquid Injection at nozzle $\mathrm{N}_{2}$ - wall.

15:15 Nuke moved to $480^{\prime \prime}$ (inside LI) and detector shutter opened traverse locked-out and so can not be moved.

15:45 Liquid level on reactor is $>480$ ". Stop oil return from 21.11 to reactor to swing down level will rise in 27.14 and in 21.11 (because oil carry over rate from 21.11 to 27.14 is slower than 27.20 to 21.11 ).

16:30 Rxtor level below 480" now. Started change to $\underline{\underline{\text { 14.8. }}}$ Decreasing pressure first slowly.

19:00 Matt making move to next condition.

20:30 Plant tripped SD-1 on 01.20 discharge temp high (TI- 609 showed $166^{\circ} \mathrm{F}$ ).

We had been at target pressure, near target flow, and moving in on target composition. 
20:40 Plant is up and running again, flows and pressure are near target again. Adjusting to get target composition.

23:30 Gary 05 has been showing a very large DME peek $(\sim 800 \%)$ in the recycle analysis. MW is off accordingly, but since it doesn't affect a controller, we're not correcting it.

24 June 1995

00:50 Begin day tank transfer.

01:22 End transfer 1754 gallons transferred.

05:12 Outside Logs taken. GC Gary has not been totaling well $(\sim 97-97.5)$ on the reactor feed. See note above on SP4.

10:05 GC's were shut down at 09:15. A standard shot on both "Dennis" and "Gary" was accidentally sent to the DEC as SP4. To avoid upsetting flow at FI-1216A, a manual SP4 MW of 13.5 was entered into the Bailey system.

11:12 01.20 (TI-609) discharge temp has been climbing this morning (as ambient temp rises). It reached $157^{\circ} \mathrm{F}$ and PIC-247-2 (01.20 discharge recycle) was opened from 6.5 to $6.8 \%$ to decrease recycle feed flow and help bring down discharge temp.

Total reactor flow has dropped from 137 MSCFH to $133 \mathrm{MSCFH}$. 01.20 discharge temp. is dropping.

11:39 First gas injection.

11:56 Second gas injection.

6/21/95 LEVELS OF OIL \& SETTLED CATALYST IN SLURRY DRAINED 6/11/95

Empty drum: inside height $=33.5$ " (rim to inside bottom)

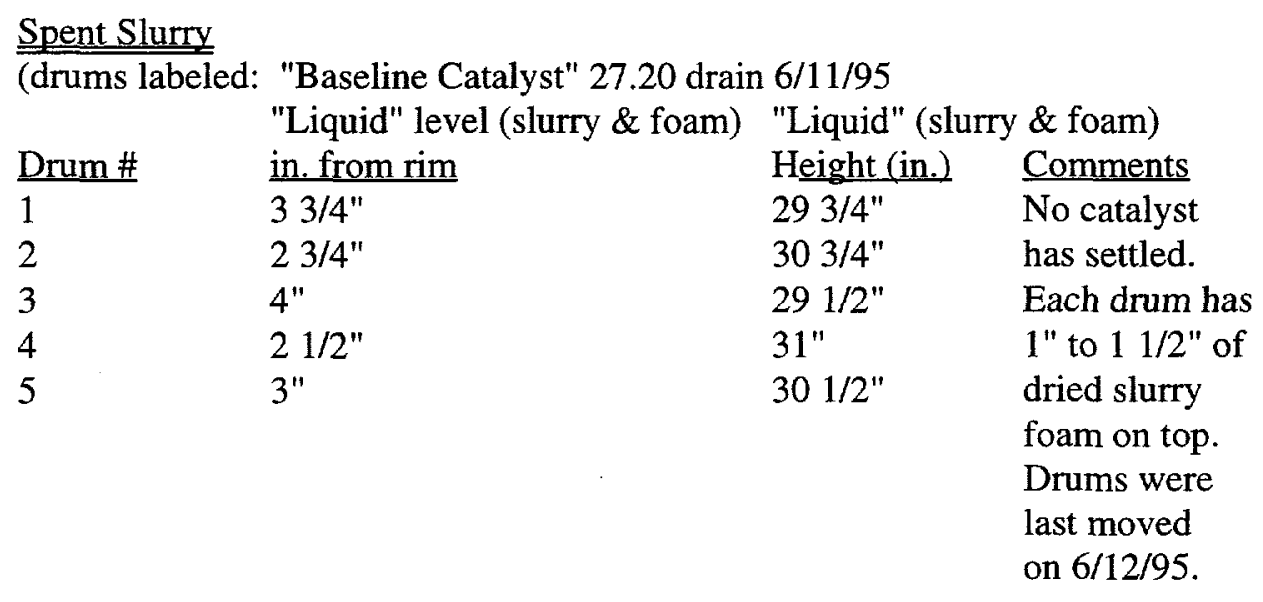

Reactor flush oil

(drums labeled: 27:20 flush drain 6/11/95)

2 drums: black, transparent oil on top approx. $1 / 2$ " of settled catalyst at drum bottom 


\section{7:14 Drain oil 6/11/95}

1 drum: gray but transparent oil

Re-examined 6/26/95

Liquid at top of drain: green $\mathrm{MeOH}$ (very fine catalyst dust?)

"Liquid" at bottom of drum: $\mathrm{MeOH} /$ oil mixture with distribution of catalyst particles (fines up to $2 \mathrm{~mm}$ diam. particles).

13:30 6/22/95 Weight of spent slurry drained 6/11/95

Empty $55 \mathrm{gal}+$ drum lifter $=117 \mathrm{lb}($ empty drum $=5216)$

Empty 5 gal "bucket" $=4 \mathrm{lb}$. (but feels more like $2 \mathrm{lb}$ )

Drums labeled: BASF 27.20 drain 6/11/95

\begin{tabular}{lll} 
& Full wt. & \\
\cline { 1 - 2 } Drum & Drum \& lifter & Slurry \\
\hline 1 & $578 \mathrm{lb}$ & $461 \mathrm{lb}$ \\
3 & 604 & 487 \\
4 & 592 & 475 \\
5 & 607 & 490 \\
& 594 & 477
\end{tabular}

\section{Bucket \# $\quad$ Full wt. Slurry \\ $149 \mathrm{lb} 45 \mathrm{lb}$ \\ $2 \quad 50 \quad 46$ \\ $3 \quad$ est.50 46 \\ $\uparrow$ sample was already shipped \\ TOTAL Slurry $=2527 \mathrm{lb}$.}

12:08 Compressor 01.20 discharge temp

$154.4^{\circ} \mathrm{F}$

Reactor press.

Reactor temp. avg.

Reactor feed flow (FI-1216A)

131.6 MSCFH

12:43 Liquid injection of nozzle $\mathrm{N}_{2}$, center of reactor.

13:05 Liquid injection at nozzle N2, wall of reactor.

13:35 Reactor press at 510 psig. Reactor feed flow at 130.3 MSCFH. 01.20 discharge temp. $=$ $154.2^{\circ} \mathrm{F}$. Unable to increase flow without raising 01.20 discharge temp. Decided to keep pressure at present value (rather than increasing to orig. target of $520 \mathrm{psig}$ ) to "maximize" gas velocity.

13:48 Day tank transfer $122 "$ to $20 " .1797$ gal into trailer \#7323.

14:02 Liquid injection at nozzle N1, reactor center.

14:36 Liquid injection at nozzle N1, reactor wall.

14:48 Reactor pressure $\quad 510.1 \mathrm{psig}$ 
Reactor avg. temp. $\quad 481.5^{\circ} \mathrm{F}$

Reactor feed flow $\quad 129.3 \mathrm{MSCFH}$

01.20 discharge temp. $151.4^{\circ} \mathrm{F}$

14:59 Nuke moved to $480^{\prime \prime}$ and traverse locked out. Seeing vapor at $480 "$.

15:13 Oil levels

$21.11313 / 4 \quad(25.41 \%$ lvl. xmtr.) 36.1 gal.

27.146 nuts $(26.28 \%$ lvl. xmtr)

Put reactor level control in auto to bring reactor level back up to $480 "$.

16:57 21.11 22 1/2 (13.5\% lvl xmtr.) $\quad 26.5$ gal

27.146 nuts (26.63\% lvl. xmtr.)

Reactor 480"

Have added 9.6 gal oil into reactor to bring level back up to $480^{\prime \prime}$

Compare to nuke scans performed under similar conditions (AF-R14.3)

At reactor level $=480^{\prime \prime}$, cat conc. $=44.3 \mathrm{wt} \%$ oxide

Oil amts $=1456 \mathrm{lb}$ oil

Gas holdup $=49.0$ vol\%

Amt oil missing from reactor at $15: 13=9.6 \mathrm{gal}$

Oil density at $350^{\circ} \mathrm{F}=46.81 \mathrm{lb} / \mathrm{ft} 3$

(9.6 gal.) $\frac{1 \mathrm{ft} 3}{7.4805 \mathrm{gal}} \frac{48.81 \mathrm{lb}}{\mathrm{ft} 3}=60.07 \mathrm{lb}$ oil

Therefore at $15: 13$, cat. conc. was $\frac{1158 \mathrm{lb} \text { oxide }}{1395 \mathrm{lb} \text { oil }+1158 \mathrm{lb} \text { oxide }}=45.3 \%$

Amount of gassed oil equivalent to $60.0 \mathrm{lb}$ oil at $482^{\circ} \mathrm{F}$

$(60.0 \mathrm{lb}$ oil $) \frac{f t 3}{43.83 \mathrm{lb}}=1.369 \mathrm{ft} 3$ oil

$(1.369 \mathrm{ft} 3$ oil $)\left(\frac{49.0 \mathrm{ft} 3 \text { gas }}{100-49.0 \mathrm{ft} 3 \text { slurry }}\right)=1.315 \mathrm{ft} 3 \mathrm{gas}$

$\therefore 60.0 \mathrm{lb}$ oil $=1.369+1.315=2.68 \mathrm{ft} 3$ gassed oil

$\frac{2.68 f t 3}{(3.1416 / 4)(1.5 f t) 2} \frac{12 i n}{1 f t}=18.2^{\prime \prime}$

At $15: 13$, reactor level was $\approx 480-18.2^{\prime \prime}=462^{\prime \prime}$

This election compares well to the observation that the trace study detector at $458^{\prime \prime}$ (on tape) saw significant fluctuations in radiation intensity (counts).

18:22 Nuke scan at cond AF-R14.8

19:05 Changing condition to R14.9 
19:40 At R14.9 conditioning

$\begin{array}{lll}\text { Rxt temp }=483.6^{\circ} \mathrm{F} & \text { Feed } & \\ \text { Rxt temp }=747.4 \mathrm{psig} & \mathrm{H}_{2} & 39.7 \% \\ \text { Rxt level }=370.4^{\prime \prime} & \mathrm{CO} & 52.2 \% \\ \mathrm{H} 2 \text { flow }=9.8 \mathrm{MSCFH} & \mathrm{N}_{2} & 2.1 \% \\ \text { CO flow }=14.2 \mathrm{MSCFH} & \mathrm{CO}_{2} & 5.6 \%\end{array}$

$\begin{array}{llllll}20: 30 & \mathrm{H}_{2} & 10 & \rightarrow & 9.6 & \mathrm{MSCFH}\end{array}$

$\mathrm{CO} \quad 14.3 \rightarrow \quad \rightarrow \quad 13.7 \quad \mathrm{MSCFH}$

FI1216C $\rightarrow 27 \mathrm{MSCFH}$

$\begin{array}{lllll}20.39 & \mathrm{H} 2 & 9.6 & \rightarrow & 9.2\end{array}$

$\mathrm{CO} \quad 13.7 \rightarrow 13.1 \quad$ FI1216C $\rightarrow 26 \mathrm{MSCFH}$

Nuke, Rxt temp and DP readings taken at 21:00, 22:00 and 23:00. All readings stable.

23:10 Shutting down !!!!

Cooling down under syngas

$60^{\circ} \mathrm{F} / \mathrm{hr} \quad\left(15^{\circ} \mathrm{F} / 15 \mathrm{mins}\right)$

Rxt Pr at 750 psig

Flow at $26 \mathrm{MSCFH}$

25 June 1995

00:20 Rxt temp at $400^{\circ} \mathrm{F}$ switching to $\mathrm{N}_{2}$, dropping Rxt Pr.

00:40 Stopped pumpback from 27.14 and 21.11.

05:00 Day tank transferred 76" $\rightarrow 0 "$ (1234 gallons). Done with MeOH transfer. All MeOH drained from product collection drain.

07:45 Drained 27.14 into separate drum. Oil looked clear.

07:55 Drained 21.11 into separate drum. The first $\sim 20 \mathrm{sec}$. of flow looked like black slurry. The remainder looked cleaner.

08:15 Added clear flush oil to 27.14 filled to 17 nuts. This oil will be pumped to 21.11 and then to 27.20 .

26 June 1995

11:00 Looked at drum containing 21.11 drain (6/25/95 Alternate Catalyst). 1/2" layer of $\mathrm{MeOH}$ on top (clear). Remainder bottom layer is oil (clear). Small ( $\sim 1 / 2 "$ "?) layer of catalyst particles (gritty) settled) out on bottom. Drum containing 27.14 drain $(6 / 25 / 95$ Alternate Catalyst). "Liquid" at bottom of drum. Mixture of $\mathrm{MeOH}$ and oil with dispersion of catalyst fires. "Liquid" at top of drum: black-gray colored $\mathrm{MeOH}$ (catalyst dust?)

6/26/95 Spent Slurry (Alternate Catalyst) drained from 27.20 on 6/25/95 
Drums labeled:

"27.20 Drain 'Alternate Catalyst'. Run 6/25/95" (Drums 6, 7 mis-labeled 6/26/95)

\begin{tabular}{|c|c|c|c|}
\hline Drum \# & $\begin{array}{c}\text { (with drum lifter } \\
\text { Full Drum }\end{array}$ & $\begin{array}{c}\text { (with drum lifter) } \\
\text { Empty Drum }\end{array}$ & Slurry \\
\hline 1 & $559 \mathrm{lb}$ & $117 \mathrm{lb}$ & $422 \mathrm{lb}$ \\
\hline 2 & $572 \mathrm{lb}$ & $117 \mathrm{lb}$ & $455 \mathrm{lb}$ \\
\hline 3 & $600 \mathrm{lb}$ & $117 \mathrm{lb}$ & $483 \mathrm{lb}$ \\
\hline 4 & $579 \mathrm{lb}$ & $117 \mathrm{lb}$ & $462 \mathrm{lb}$ \\
\hline 5 & $574 \mathrm{lb}$ & $117 \mathrm{lb}$ & $457 \mathrm{lb}$ \\
\hline 6 & $592 \mathrm{lb}$ & $117 \mathrm{lb}$ & $475 \mathrm{lb}$ \\
\hline 7 & $260 \mathrm{lb}$ & $117 \mathrm{lb}$ & $143 \mathrm{lb}$ \\
\hline & & & Total slurry $2,917 \mathrm{lb}$ \\
\hline
\end{tabular}

11 July 1995

DP Calibration

Water DP test on reactor:

Empty

$\begin{array}{lr}\text { PDT-1500 } & 0.07 \\ \text { PDT-1501 } & 0.11 \\ \text { PDT-1502 } & 0.06 \\ \text { PDT-1503 } & -0.08 \\ \text { PDT-1504 } & 0.11 \\ \text { PDT-1505 } & -0.03\end{array}$

Water level $=518 "$ on inside indicator

$\begin{array}{lc}\text { PDT-1500 } & 2.15 \\ \text { PDT-1501 } & 3.15 \\ \text { PDT-1502 } & 4.29 \\ \text { PDT-1503 } & 10.57 \\ \text { PDT-1504 } & 6.49 \\ \text { PDT-1505 } & 4.28 \\ \text { PDT-1241 } & 20.83\end{array}$

Distances between tapes:

$\begin{array}{lc}\text { I2 to } \mathrm{C} & 45^{\prime \prime} \\ \mathrm{C} \text { to } \mathrm{N}_{2} & 86.5^{\prime \prime} \\ \mathrm{N}_{2} \text { to } \mathrm{D} & 119.75^{\prime \prime} \\ \mathrm{D} \text { to } \mathrm{N}_{1} & 120.5^{\prime \prime} \\ \mathrm{N}_{1} \text { to } \mathrm{E} & 120^{\prime \prime} \\ \mathrm{E} \text { to } \mathrm{NDG} & 50^{\prime \prime}\end{array}$




\section{APPENDIX E}

Fluid Dynamic (Methanol) Run Mass Balances 
RUN NO: AF-R13.1A (Rev. 2)

Balance Period:

Start Date

End Date

Reaction Conditions

Temperature $\left({ }^{\circ} \mathrm{F}\right)$

Pressure (psig)

Space Velocity (sL/kg-hr)

$\mathrm{Vg}$ (inlet)

Performance Results

CO Conversion to $\mathrm{H} 2(\%)$

$\mathrm{CO}$ Conversion to $\mathrm{MeOH}(\%)$

Theoretical Conversion \% (1 CSTR)

Alcohol Production (Ton/day)
TITLE: LPMEOH over Baseline Catalyst with TEXACO SYNGAS : SV=7000

$\begin{array}{ll}6 / 4 / 95 & 23: 00 \\ 6 / 5 / 95 & 17: 00\end{array}$

484.00

749.71

7131

0.85

0.15

16.5

13.9

12.1

Time From Start of Run (hr)

Slurry Data

$\begin{array}{ll}\text { Start } & 11.00 \\ \text { End } & 29.00\end{array}$

Catalyst Weight (lb oxide)

Slurry Conc. based on NDG (wt \%)

Slurry Level (\%) 94

Gas Holdup based on NDG (vol \%) $\quad 50.5$

Atomic/Mass Balance ( $\%$ of reactor inlet)

$\begin{array}{lc}\mathrm{C} & 100.01 \\ \mathrm{H} & 98.85 \\ \mathrm{O} & 100.24 \\ \mathrm{~N} & 98.70 \\ & \\ \text { Total Mass } & 100.09\end{array}$

\begin{tabular}{|c|c|c|c|c|c|}
\hline $\begin{array}{c}\text { Sample\# } \\
6: 25 \mathrm{~A}\end{array}$ & $\begin{array}{c}\text { Sample\# } \\
6: 25 \mathrm{~B}\end{array}$ & $\begin{array}{c}\text { Sample\# } \\
\text { 15:45 A }\end{array}$ & $\begin{array}{c}\text { Sample\# } \\
\text { 15:45 B }\end{array}$ & Sample\# & Sample\# \\
\hline 96.75 & 96.14 & 96.363 & 96.108 & & \\
\hline 0.899 & 0.933 & 0.849 & 0.867 & & \\
\hline 0.32 & 0.319 & 0.297 & 0.297 & & \\
\hline 0 & 0 & 0 & 0 & & \\
\hline 0.171 & 0.165 & 0.149 & 0.15 & & \\
\hline 0.056 & 0.059 & 0.055 & 0.061 & & \\
\hline 0.051 & 0.048 & 0.045 & 0.049 & & \\
\hline 0 & 0 & 0 & 0 & & \\
\hline 0.078 & 0.081 & 0.071 & 0.079 & & \\
\hline 0 & 0 & 0 & 0 & & \\
\hline 0 & 0 & 0 & 0 & & \\
\hline 0 & 0 & 0 & 0 & & \\
\hline 0.223 & 0.225 & 0.195 & 0.191 & & \\
\hline 0 & 0 & 0 & 0 & & \\
\hline 0.936 & 0.937 & 0.905 & 0.908 & & \\
\hline 0 & 0 & 0 & 0 & & \\
\hline 0 & 0 & 0 & 0 & & \\
\hline 0.457 & 0.454 & 0.433 & 0.432 & & \\
\hline 0.2 & 0.2 & 0.2 & 0.2 & & \\
\hline 100.141 & 99.561 & 99.562 & 99.342 & & \\
\hline
\end{tabular}


RUN NO: AF-R13.1A (Rev. 2) TITLE: LPMEOH over Baseline Catalyst with TEXACO SYNGAS : SV=7000

\begin{tabular}{|c|c|c|c|c|c|c|c|c|c|c|c|c|c|}
\hline & & $\begin{array}{c}\text { FRESH } \\
\text { MAKE-UP } \\
\end{array}$ & RECYCLE & $\begin{array}{c}\text { HP H2 } \\
\text { MAKEUP }\end{array}$ & $\begin{array}{c}\text { DRY } \\
\text { FEED } \\
\end{array}$ & $\begin{array}{c}\text { ALCOHOL } \\
\text { INJECT. }\end{array}$ & $\begin{array}{c}\text { REACT } \\
\text { FEED } \\
\end{array}$ & $\begin{array}{c}\text { REACT } \\
\text { EFFL }\end{array}$ & $\begin{array}{c}22.10 \\
\text { VAPOR } \\
\end{array}$ & $\begin{array}{l}\text { PURGE 1 } \\
\text { PIC-201 } \\
\end{array}$ & $\begin{array}{c}\text { PURGE } 2 \\
22.11 \\
\end{array}$ & $\begin{array}{c}\text { PURGE } 3 \\
07.20 \\
\end{array}$ & $\begin{array}{c}\text { LIQUID } \\
\text { PROD } \\
\end{array}$ \\
\hline $\mathbf{T}$ & $\mathbf{F}$ & 309.6 & 143.3 & 102.1 & 335.4 & 100.0 & 317.2 & 471.4 & 87.5 & 98.0 & 86.1 & 79.9 & 80.0 \\
\hline $\mathbf{P}$ & psig & 846.9 & 870.3 & 815.1 & 799.1 & 799.1 & 799.1 & 749.7 & 1.3 & 659.4 & 34.9 & 82.5 & 1.0 \\
\hline & $\mathrm{H} 2$ & 8.50 & 25.27 & 100.00 & 35.82 & 0.00 & 35.82 & 22.54 & 25.27 & 25.27 & 35.78 & 0.00 & 0.00 \\
\hline \multirow[t]{23}{*}{ (mole\%) } & $\mathrm{co}$ & 84.76 & 56.76 & 0.00 & 50.77 & 0.00 & 50.77 & 50.53 & 56.76 & 56.76 & 50.58 & 0.00 & 0.00 \\
\hline & N2 & 0.49 & 1.59 & 0.00 & 1.16 & 0.00 & 1.16 & 1.41 & 1.59 & 1.59 & 1.17 & 0.00 & 0.00 \\
\hline & $\mathrm{CH} 4$ & 0.00 & 0.00 & 0.00 & 0.00 & 0.00 & 0.00 & 0.00 & 0.00 & 0.00 & 0.00 & 0.00 & 0.00 \\
\hline & $\mathrm{CO} 2$ & 6.24 & 16.37 & 0.00 & 12.25 & 0.00 & 12.25 & 15.21 & 16.37 & 16.37 & 12.45 & 0.00 & 0.00 \\
\hline & DME & 0.00 & 0.00 & 0.00 & 0.00 & 0.00 & 0.00 & 0.00 & 0.00 & 0.00 & 0.00 & 0.00 & 0.00 \\
\hline & MeAc & 0.00 & 0.00 & 0.00 & 0.00 & 0.00 & 0.00 & 0.00 & 0.00 & 0.00 & 0.00 & 0.00 & 0.09 \\
\hline & EtAc & 0.00 & 0.00 & 0.00 & 0.00 & 0.00 & 0.00 & 0.00 & 0.00 & 0.00 & 0.00 & 0.00 & 0.00 \\
\hline & MeFm & 0.00 & 0.00 & 0.00 & 0.00 & 0.00 & 0.00 & 0.00 & 0.00 & 0.00 & 0.00 & 0.00 & 0.50 \\
\hline & $\mathrm{MeOH}$ & 0.00 & 0.00 & 0.00 & 0.00 & 0.00 & 0.00 & 10.18 & 0.00 & 0.00 & 0.00 & 0.00 & 97.65 \\
\hline & $\mathrm{H} 2 \mathrm{O}$ & 0.00 & 0.00 & 0.00 & 0.00 & 0.00 & 0.00 & 0.00 & 0.01 & 0.00 & 0.01 & 0.00 & 0.80 \\
\hline & Etoh & 0.00 & 0.00 & 0.00 & 0.00 & 0.00 & 0.00 & 0.05 & 0.00 & 0.00 & 0.00 & 0.00 & 0.63 \\
\hline & 1-Proh & 0.00 & 0.00 & 0.00 & 0.00 & 0.00 & 0.00 & 0.01 & 0.00 & 0.00 & 0.00 & 0.00 & 0.17 \\
\hline & iso-Proh & 0.00 & 0.00 & 0.00 & 0.00 & 0.00 & 0.00 & 0.00 & 0.00 & 0.00 & 0.00 & 0.00 & 0.00 \\
\hline & IBOH & 0.00 & 0.00 & 0.00 & 0.00 & 0.00 & 0.00 & 0.00 & 0.00 & 0.00 & 0.00 & 0.00 & 0.02 \\
\hline & 1-Buoh & 0.00 & 0.00 & 0.00 & 0.00 & 0.00 & 0.00 & 0.00 & 0.00 & 0.00 & 0.00 & 0.00 & 0.07 \\
\hline & 2-Buoh & 0.00 & 0.00 & 0.00 & 0.00 & 0.00 & 0.00 & 0.00 & 0.00 & 0.00 & 0.00 & 0.00 & 0.03 \\
\hline & 2-Methyl 1-Buoh & 0.00 & 0.00 & 0.00 & 0.00 & 0.00 & 0.00 & 0.00 & 0.00 & 0.00 & 0.00 & 0.00 & 0.00 \\
\hline & 1-Peoh & 0.00 & 0.00 & 0.00 & 0.00 & 0.00 & 0.00 & 0.00 & 0.00 & 0.00 & 0.00 & 0.00 & 0.03 \\
\hline & 2-Methyl 1-Peoh & 0.00 & 0.00 & 0.00 & 0.00 & 0.00 & 0.00 & 0.00 & 0.00 & 0.00 & 0.00 & 0.00 & 0.00 \\
\hline & 1-hexanol & 0.00 & 0.00 & 0.00 & 0.00 & 0.00 & 0.00 & 0.00 & 0.00 & 0.00 & 0.00 & 0.00 & 0.00 \\
\hline & 2-Methyl 1-Isobutyrate & 0.00 & 0.00 & 0.00 & 0.00 & 0.00 & 0.00 & 0.00 & 0.00 & 0.00 & 0.00 & 0.00 & 0.00 \\
\hline & others & 0.00 & 0.00 & 0.00 & 0.00 & 100.00 & 0.00 & 0.16 & 0.00 & 0.00 & 0.00 & 100.00 & 0.02 \\
\hline & TOTAL & 100.00 & 100.00 & 100.00 & 100.00 & 100.00 & 100.00 & 100.09 & 100.00 & 100.00 & 100.00 & 100.00 & 100.00 \\
\hline Mole Wt & lb/lb mole & 26.798 & 24.061 & 2.020 & 20.659 & 60.163 & 20.659 & 25.064 & 24.060 & 24.061 & 20.701 & 60.163 & 32.311 \\
\hline \multirow[t]{3}{*}{ Flow } & SCFH & 19611 & 100900 & 24531 & 145042 & 0 & 145042 & 119389 & 107402 & 6465 & 52 & 0 & 12647 \\
\hline & lb mole/hr & 50.72 & 260.96 & 63.45 & 375.13 & 0.00 & 375.13 & 308.78 & 277.78 & 16.72 & 0.13 & 0.00 & 32.71 \\
\hline & $\mathrm{lb} / \mathrm{hr}$ & 1359.3 & 6279.0 & 128.2 & 7750.0 & 0.0 & 7750.0 & 7739.3 & 6683.5 & 402.3 & 2.8 & 0.0 & 1056.9 \\
\hline
\end{tabular}


RUN NO: AF-R13.1B (Rev. 1)

Balance Period:

Start Date

End Date

Reaction Conditions

Temperature $\left({ }^{\circ} \mathrm{F}\right)$

Pressure (psig)

Space Velocity (sL/kg-hr)

$\mathrm{Vg}$ (inlet)

Performance Results

$\mathrm{CO}$ Conversion to $\mathrm{H} 2(\%)$

$\mathrm{CO}$ Conversion to $\mathrm{MeOH}(\%)$

Theoretical Conversion \% (1 CSTR)

Alcohol Production (Ton/day)
TITLE: LPMEOH over Baseline Catalyst with TEXACO SYNGAS : SV=7000
29.00

48.00

Slurry Data

Catalyst Weight (lb oxide)

Slurry Conc. based on NDG (wt \%) 48.2

Slurry Level (\%) 94

Gas Holdup based on NDG (vol \%) $\quad 54.7$

\section{Atomlc/Mass Balance ( $\%$ of reactor inlet)}

$\mathrm{C}$
$\mathrm{H}$
$\mathrm{O}$
$\mathrm{N}$

99.91

98.60

100.16

98.99

Total Mass

100.01

\begin{tabular}{|c|c|c|c|c|c|c|c|}
\hline & & $\begin{array}{c}\text { Sample\# } \\
\text { 0:00 A }\end{array}$ & $\begin{array}{c}\text { Sample\# } \\
\text { 0:00 B }\end{array}$ & $\begin{array}{c}\text { Sample\# } \\
11: 45 \mathrm{~A}\end{array}$ & $\begin{array}{c}\text { Sample\# } \\
11: 45 \text { B }\end{array}$ & Sample\# & Sample\# \\
\hline & Methanol & 95.487 & 95.811 & 95.582 & 96.114 & & \\
\hline & Ethanol & 0.949 & 0.913 & 0.822 & 0.834 & & \\
\hline & 1.Propanol & 0.252 & 0.264 & 0.236 & 0.23 & & \\
\hline & iso-Propanol & 0.023 & 0.019 & 0.02 & 0.019 & & \\
\hline & 1-Butanol & 0.166 & 0.164 & 0.174 & 0.164 & & \\
\hline Llquid & 2-Butanol & 0.055 & 0.062 & 0.055 & 0.053 & & \\
\hline Product & iso-Butanol & 0.064 & 0.05 & 0.066 & 0.04 & & \\
\hline Analysis & 2-Methyl-1-Butanol & 0 & 0 & 0 & 0 & & \\
\hline \multirow[t]{12}{*}{$(w t \%)$} & 1-Pentanol & 0.076 & 0.079 & 0.071 & 0.073 & & \\
\hline & 2-Methyl-1-Pentanol & 0 & 0 & 0 & 0 & & \\
\hline & 1-Hexanol & 0.035 & 0.039 & 0.034 & 0.034 & & \\
\hline & 2-Methyl-1-Isobutyrate & 0 & 0 & 0 & 0 & & \\
\hline & Methyl Acetate & 0.237 & 0.201 & 0.179 & 0.176 & & \\
\hline & Ethyl Acetate & $\mathbf{0}$ & 0 & 0 & 0 & & \\
\hline & Methyl Formate & 0.935 & 0.931 & 0.879 & 0.874 & & \\
\hline & DME & 0 & 0 & 0 & 0 & & \\
\hline & $\mathrm{CO} 2$ & 0 & 0 & 0 & 0 & & \\
\hline & Water & 0.414 & 0.417 & 0.426 & 0.43 & & \\
\hline & Oil & 0.2 & 0.2 & 0.2 & 0.2 & & \\
\hline & Total & 98.893 & 99.15 & 98.744 & 99.241 & & \\
\hline
\end{tabular}


RUN NO: AF-R13.1B (Rev. 1) TITLE: LPMEOH over Baseline Catalyst with TEXACO SYNGAS : SV=7000

\begin{tabular}{|c|c|c|c|c|c|c|c|c|c|c|c|c|c|}
\hline & & $\begin{array}{c}\text { FRESH } \\
\text { MAKE-UP }\end{array}$ & RECYCLE & $\begin{array}{c}\text { HP H2 } \\
\text { MAKEUP }\end{array}$ & $\begin{array}{c}\text { DRY } \\
\text { FEED } \\
\end{array}$ & $\begin{array}{l}\text { ALCOHOL } \\
\text { INJECT. }\end{array}$ & $\begin{array}{c}\text { REACT } \\
\text { FEED } \\
\end{array}$ & $\begin{array}{c}\text { REACT } \\
\text { EFFL } \\
\end{array}$ & $\begin{array}{c}22.10 \\
\text { VAPOR } \\
\end{array}$ & $\begin{array}{c}\text { PURGE } 1 \\
\text { PIC-201 } \\
\end{array}$ & $\begin{array}{c}\text { PURGE } 2 \\
22.11 \\
\end{array}$ & $\begin{array}{c}\text { PURGE } 3 \\
07.20 \\
\end{array}$ & $\begin{array}{l}\text { LIQUID } \\
\text { PROD } \\
\end{array}$ \\
\hline $\mathbf{T}$ & $\mathbf{F}$ & 307.1 & 141.3 & 97.8 & 329.3 & 100.0 & 311.4 & 471.9 & 83.8 & 96.8 & 83.6 & 77.7 & 80.0 \\
\hline $\mathbf{P}$ & psig & 846.8 & 871.4 & 817.6 & 799.6 & 799.6 & 799.6 & 750.9 & 2.2 & 659.1 & 34.9 & 81.3 & 1.0 \\
\hline \multirow{24}{*}{$\begin{array}{l}\text { Comp } \\
\text { (mole\%) }\end{array}$} & $\mathrm{H} 2$ & 8.58 & 24.51 & 100.00 & 35.07 & 0.00 & 35.07 & 22.06 & 24.51 & 24.51 & 35.00 & 0.00 & 0.00 \\
\hline & $\mathrm{Co}$ & 84.47 & 58.13 & 0.00 & 51.88 & 0.00 & 51.88 & 52.17 & 58.13 & 58.13 & 51.91 & 0.00 & 0.00 \\
\hline & N2 & 0.48 & 1.44 & 0.00 & 1.06 & 0.00 & 1.06 & 1.28 & 1.44 & 1.44 & 1.07 & 0.00 & 0.00 \\
\hline & $\mathrm{CH} 4$ & 0.00 & 0.00 & 0.00 & 0.00 & 0.00 & 0.00 & 0.00 & 0.00 & 0.00 & 0.00 & 0.00 & 0.00 \\
\hline & $\mathrm{CO} 2$ & 6.48 & 15.92 & 0.00 & 11.99 & 0.00 & 11.99 & 14.47 & 15.92 & 15.92 & 12.01 & 0.00 & 0.00 \\
\hline & DME & 0.00 & 0.00 & 0.00 & 0.00 & 0.00 & 0.00 & 0.00 & 0.00 & 0.00 & 0.00 & 0.00 & 0.00 \\
\hline & MeAc & 0.00 & 0.00 & 0.00 & 0.00 & 0.00 & 0.00 & 0.00 & 0.00 & 0.00 & 0.00 & 0.00 & 0.09 \\
\hline & EtAc & 0.00 & 0.00 & 0.00 & 0.00 & 0.00 & 0.00 & 0.00 & 0.00 & 0.00 & 0.00 & 0.00 & 0.00 \\
\hline & MeFm & 0.00 & 0.00 & 0.00 & 0.00 & 0.00 & 0.00 & 0.00 & 0.00 & 0.00 & 0.00 & 0.00 & 0.49 \\
\hline & $\mathrm{MeOH}$ & 0.00 & 0.00 & 0.00 & 0.00 & 0.00 & 0.00 & 9.65 & 0.00 & 0.00 & 0.00 & 0.00 & 97.70 \\
\hline & $\mathrm{H} 2 \mathrm{O}$ & 0.00 & 0.00 & 0.00 & 0.00 & 0.00 & 0.00 & 0.00 & 0.00 & 0.00 & 0.01 & 0.00 & 0.76 \\
\hline & Etoh & 0.00 & 0.00 & 0.00 & 0.00 & 0.00 & 0.00 & 0.04 & 0.00 & 0.00 & 0.00 & 0.00 & 0.62 \\
\hline & 1-Proh & 0.00 & 0.00 & 0.00 & 0.00 & 0.00 & 0.00 & 0.01 & 0.00 & 0.00 & 0.00 & 0.00 & 0.13 \\
\hline & Iso-Proh & 0.00 & 0.00 & 0.00 & 0.00 & 0.00 & 0.00 & 0.00 & 0.00 & 0.00 & 0.00 & 0.00 & 0.01 \\
\hline & IBOH & 0.00 & 0.00 & 0.00 & 0.00 & 0.00 & 0.00 & 0.00 & 0.00 & 0.00 & 0.00 & 0.00 & 0.02 \\
\hline & 1-Buoh & 0.00 & 0.00 & 0.00 & 0.00 & 0.00 & 0.00 & 0.00 & 0.00 & 0.00 & 0.00 & 0.00 & 0.07 \\
\hline & 2-Buoh & 0.00 & 0.00 & 0.00 & 0.00 & 0.00 & 0.00 & 0.00 & 0.00 & 0.00 & 0.00 & 0.00 & 0.02 \\
\hline & 2-Methyl 1-Buoh & 0.00 & 0.00 & 0.00 & 0.00 & 0.00 & 0.00 & 0.00 & 0.00 & 0.00 & 0.00 & 0.00 & 0.00 \\
\hline & 1-Peoh & 0.00 & 0.00 & 0.00 & 0.00 & 0.00 & 0.00 & 0.00 & 0.00 & 0.00 & 0.00 & 0.00 & 0.03 \\
\hline & 2-Methyl 1-Peoh & 0.00 & 0.00 & 0.00 & 0.00 & 0.00 & 0.00 & 0.00 & 0.00 & 0.00 & 0.00 & 0.00 & 0.00 \\
\hline & 1-hexanol & 0.00 & 0.00 & 0.00 & 0.00 & 0.00 & 0.00 & 0.00 & 0.00 & 0.00 & 0.00 & 0.00 & 0.01 \\
\hline & 2-Methyl 1-Isobutyrate & 0.00 & 0.00 & 0.00 & 0.00 & 0.00 & 0.00 & 0.00 & 0.00 & 0.00 & 0.00 & 0.00 & 0.00 \\
\hline & others & 0.00 & 0.00 & 0.00 & 0.00 & 100.00 & 0.00 & 0.15 & 0.00 & 0.00 & 0.00 & 100.00 & 0.02 \\
\hline & TOTAL & 100.00 & 100.00 & 100.00 & 100.00 & 100.00 & 100.00 & 99.81 & 100.00 & 100.00 & 100.00 & 100.00 & 100.00 \\
\hline Mole Wt & lb/lb mole & 26.817 & 24.187 & 2.020 & 20.812 & 60.521 & 20.812 & 25.035 & 24.187 & 24.187 & 20.833 & 60.521 & 32.317 \\
\hline \multirow[t]{3}{*}{ Flow } & SCFH & 19661 & 101217 & 24096 & 144974 & 0 & 144974 & 120457 & 108043 & 6816 & 4 & 0 & 12488 \\
\hline & Ib mole/hr & 50.85 & 261.78 & 62.32 & 374.95 & 0.00 & 374.95 & 311.54 & 279.44 & 17.63 & 0.01 & 0.00 & 32.30 \\
\hline & $\mathrm{Ib} / \mathrm{hr}$ & 1363.7 & 6331.8 & 125.9 & 7803.5 & 0.0 & 7803.5 & 7799.4 & 6758.8 & 426.4 & 0.2 & 0.0 & 1043.7 \\
\hline
\end{tabular}


Balance Period:

Start Date

End Date

Reaction Conditlons

Temperature $\left({ }^{\circ} \mathrm{F}\right)$

Pressure (psig)

Space Velocity (sL/kg-hr)

$\mathrm{Vg}$ (inlet)

Performance Results

Co Conversion to $\mathrm{H} 2(\%)$

Theoretical Conversion \% (3 CSTR)

Alcohol Production (Ton/day)
$\mathrm{CO}$ Conversion to $\mathrm{MeOH}(\%)$
$6 / 7 / 95$

$6 / 8 / 95$

11:00

5:00

483.86

735.00

3994

0.49

$-2.4$

50.0

46.9

10.0
Time From Start of Run (hr)

Start $\quad 71.00$

End

89.00

Slurry Data

Catalyst Weight (b oxide)

Slurry Conc. based on NDG (wt \%)

Slurry Level (\%)

Gas Holdup based on NDG (vol \%)

Atomic/Mass Balance (\% of reactor inlet)

$\begin{array}{lc}\mathrm{C} & 99.34 \\ \mathrm{H} & 97.76 \\ \mathrm{O} & 100.54 \\ \mathrm{~N} & 100.47 \\ & \\ \text { Total Mass } & 99.94\end{array}$

Sample\# Sample\# Sample\# Sample\# Sample\# Sample\#

17:00 A 17:00 B 03:00 A 03:00 B

Methanol

Ethanol

1-Propanol

iso-Propanol

1-Butanol

Liquid

2-Butanol

Product

Analysis

iso-Butanol

2-Methyl-1-Butanol

1-Pentanol

2-Methyl-1-Pentanol

1-Hexanol

2-Methyl-1-Isobutyrate

Methyl Acetate

Ethyl Acetate

Methyl Formate

DME

$\mathrm{CO} 2$

Water

Oil

Total

\begin{tabular}{rrrr}
96.36 & 97.052 & 97.475 & 96.749 \\
0.321 & 0.322 & 0.312 & 0.288 \\
0.084 & 0.069 & 0.084 & 0.082 \\
0 & 0 & 0 & 0 \\
0.058 & 0.066 & 0.063 & 0.072 \\
0.035 & 0.038 & 0.034 & 0.034 \\
0.018 & 0.016 & 0.017 & 0.018 \\
0 & 0 & 0 & 0 \\
0.025 & 0.024 & 0.023 & 0 \\
0 & 0 & 0 & 0 \\
0 & 0 & 0 & 0 \\
0 & 0 & 0 & 0 \\
0.054 & 0.051 & 0.051 & 0.043 \\
0 & 0 & 0 & 0 \\
0.408 & 0.437 & 0.431 & 0.432 \\
0 & 0 & 0 & 0 \\
0 & 0 & 0 & 0 \\
1.419 & 1.382 & 1.417 & 1.413 \\
0.2 & 0.2 & 0.2 & 0.2 \\
\hline 98.982 & 99.657 & 100.107 & 99.331
\end{tabular}

99.34

7.76

99.94 
RUN NO: AF-R13.2A (Rev. 1) TITLE: LPMEOH over Baseline Catalyst with KINGSPORT SYNGAS : SV=4000

\begin{tabular}{|c|c|c|c|c|c|c|c|c|c|c|c|c|c|}
\hline & & $\begin{array}{c}\text { FRESH } \\
\text { MAKE-UP } \\
\end{array}$ & RECYCLE & $\begin{array}{c}\text { HP H2 } \\
\text { MAKEUP } \\
\end{array}$ & $\begin{array}{c}\text { DRY } \\
\text { FEED } \\
\end{array}$ & $\begin{array}{l}\text { ALCOHOL } \\
\text { INJECT. }\end{array}$ & $\begin{array}{c}\text { REACT } \\
\text { FEED } \\
\end{array}$ & $\begin{array}{c}\text { REACT } \\
\text { EFFL } \\
\end{array}$ & $\begin{array}{c}22.10 \\
\text { VAPOR } \\
\end{array}$ & $\begin{array}{c}\text { PURGE } 1 \\
\text { PIC-201 } \\
\end{array}$ & $\begin{array}{c}\text { PURGE } 2 \\
22.11 \\
\end{array}$ & $\begin{array}{c}\text { PURGE } 3 \\
07.20 \\
\end{array}$ & $\begin{array}{l}\text { LIQUID } \\
\text { PROD }\end{array}$ \\
\hline $\mathbf{T}$ & $\mathbf{F}$ & 293.1 & 125.5 & 103.1 & 278.0 & 100.0 & 258.6 & 463.7 & 88.8 & 93.9 & 86.8 & 80.1 & 80.0 \\
\hline $\mathbf{P}$ & psig & 775.6 & 793.4 & 814.0 & 754.6 & 754.6 & 754.6 & 735.0 & 1.2 & 682.9 & 34.8 & 82.2 & 1.0 \\
\hline \multirow{24}{*}{$\begin{array}{l}\text { Comp } \\
\text { (mole\%) }\end{array}$} & $\mathrm{H}_{2}$ & 10.63 & 57.05 & 100.00 & 60.63 & 0.00 & 60.63 & 46.63 & 57.04 & 57.05 & 12.69 & 0.00 & 0.00 \\
\hline & $\mathrm{Co}$ & 77.13 & 19.85 & 0.00 & 24.73 & 0.00 & 24.73 & 15.96 & 19.85 & 19.85 & 9.25 & 0.00 & 0.00 \\
\hline & N2 & 3.01 & 7.99 & 0.00 & 4.79 & 0.00 & 4.79 & 6.53 & 7.99 & 7.99 & 2.82 & 0.00 & 0.00 \\
\hline & $\mathrm{CH} 4$ & 0.00 & 0.00 & 0.00 & 0.00 & 0.00 & 0.00 & 0.00 & 0.00 & 0.00 & 0.00 & 0.00 & 0.00 \\
\hline & $\mathrm{CO} 2$ & 9.23 & 15.11 & 0.00 & 9.85 & 0.00 & 9.85 & 13.08 & 15.10 & 15.11 & 61.48 & 0.00 & 0.00 \\
\hline & DME & 0.00 & 0.00 & 0.00 & 0.00 & 0.00 & 0.00 & 0.00 & 0.00 & 0.00 & 0.00 & 0.00 & 0.00 \\
\hline & MeAc & 0.00 & 0.00 & 0.00 & 0.00 & 0.00 & 0.00 & 0.00 & 0.00 & 0.00 & 0.00 & 0.00 & 0.02 \\
\hline & EtAc & 0.00 & 0.00 & 0.00 & 0.00 & 0.00 & 0.00 & 0.00 & 0.00 & 0.00 & 0.00 & 0.00 & 0.00 \\
\hline & MeFm & 0.00 & 0.00 & 0.00 & 0.00 & 0.00 & 0.00 & 0.00 & 0.00 & 0.00 & 0.00 & 0.00 & 0.23 \\
\hline & МеOH & 0.00 & 0.00 & 0.00 & 0.00 & 0.00 & 0.00 & 16.85 & 0.00 & 0.00 & 13.72 & 0.00 & 96.91 \\
\hline & $\mathrm{H} 2 \mathrm{O}$ & 0.00 & 0.00 & 0.00 & 0.00 & 0.00 & 0.00 & 0.81 & 0.02 & 0.00 & 0.03 & 0.00 & 2.50 \\
\hline & Etoh & 0.00 & 0.00 & 0.00 & 0.00 & 0.00 & 0.00 & 0.03 & 0.00 & 0.00 & 0.00 & 0.00 & 0.22 \\
\hline & 1-Proh & 0.00 & 0.00 & 0.00 & 0.00 & 0.00 & 0.00 & 0.01 & 0.00 & 0.00 & 0.00 & 0.00 & 0.04 \\
\hline & Iso-Proh & 0.00 & 0.00 & 0.00 & 0.00 & 0.00 & 0.00 & 0.00 & 0.00 & 0.00 & 0.00 & 0.00 & 0.00 \\
\hline & $\mathrm{IBOH}$ & 0.00 & 0.00 & 0.00 & 0.00 & 0.00 & 0.00 & 0.00 & 0.00 & 0.00 & 0.00 & 0.00 & 0.01 \\
\hline & 1-Buoh & 0.00 & 0.00 & 0.00 & 0.00 & 0.00 & 0.00 & 0.00 & 0.00 & 0.00 & 0.00 & 0.00 & 0.03 \\
\hline & 2-Buoh & 0.00 & 0.00 & 0.00 & 0.00 & 0.00 & 0.00 & 0.00 & 0.00 & 0.00 & 0.00 & 0.00 & 0.02 \\
\hline & 2-Methyl 1-Buoh & 0.00 & 0.00 & 0.00 & 0.00 & 0.00 & 0.00 & 0.00 & 0.00 & 0.00 & 0.00 & 0.00 & 0.00 \\
\hline & 1-Peoh & 0.00 & 0.00 & 0.00 & 0.00 & 0.00 & 0.00 & 0.00 & 0.00 & 0.00 & 0.00 & 0.00 & 0.01 \\
\hline & 2-Methyl 1-Peoh & 0.00 & 0.00 & 0.00 & 0.00 & 0.00 & 0.00 & 0.00 & 0.00 & 0.00 & 0.00 & 0.00 & 0.00 \\
\hline & 1-hexanol & 0.00 & 0.00 & 0.00 & 0.00 & 0.00 & 0.00 & 0.00 & 0.00 & 0.00 & 0.00 & 0.00 & 0.00 \\
\hline & 2-Methyl 1-Isobutyrate & 0.00 & 0.00 & 0.00 & 0.00 & 0.00 & 0.00 & 0.00 & 0.00 & 0.00 & 0.00 & 0.00 & 0.00 \\
\hline & others & 0.00 & 0.00 & 0.00 & 0.00 & 100.00 & 0.00 & 0.10 & 0.00 & 0.00 & 0.00 & 100.00 & 0.02 \\
\hline & TOTAL & 100.00 & 100.00 & 100.00 & 100.00 & 100.00 & 100.00 & 100.00 & 100.00 & 100.00 & 100.00 & 100.00 & 100.00 \\
\hline Mole Wt & lb/lb mole & 26.725 & 15.599 & 2.020 & 13.829 & 65.684 & 13.829 & 18.629 & 15.599 & 15.599 & 35.098 & 65.684 & 31.836 \\
\hline \multirow[t]{3}{*}{ Flow } & SCFH & 15485 & 42309 & 23445 & 81240 & 0 & 81240 & 59602 & 48428 & 6010 & 116 & 0 & 11453 \\
\hline & lb mole/hr & 40.05 & 109.43 & 60.64 & 210.11 & 0.00 & 210.11 & 154.15 & 125.25 & 15.54 & 0.30 & 0.00 & 29.62 \\
\hline & $\mathrm{lb} / \mathrm{hr}$ & 1070.4 & 1707.0 & 122.5 & 2905.7 & 0.0 & 2905.7 & 2871.7 & 1953.9 & 242.5 & 10.5 & 0.0 & 943.1 \\
\hline
\end{tabular}


RUN NO: AF-R13.2B (Rev. 1)

Balance Period

Start Date

End Date

Reaction Conditions

Temperature ( $\left.{ }^{\circ} \mathrm{F}\right)$

Pressure (psig)

Space Velocity (sL/kg-hr)

$\mathrm{Vg}$ (inlet)

Performance Results

Co Conversion to $\mathrm{H} 2(\%)$

$\mathrm{CO}$ Conversion to $\mathrm{MeOH}(\%)$

Theoretical Conversion \% (3 CSTR)

Alcohol Production (Ton/day)
$6 / 8 / 95$

$6 / 9 / 95$

5:00

7:00

482.71

735.00

4006

0.49

$-2.5$

49.6

46.9

9.9

TIme From Start of Run (hr)

Start

89.00

End

115.00

Slurry Data

Catalyst Weight (Ib oxide)

Slurry Conc. based on NDG (wt \%) 42

Slurry Level (\%)

Gas Holdup based on NDG (vol \%)

94

Atomic/Mass Balance ( $\%$ of reactor Inlet)

C

H

99.29

97.75

100.49

100.82

Total Mass

99.93

\begin{tabular}{|c|c|c|c|c|c|c|c|}
\hline & & $\begin{array}{c}\text { Sample\# } \\
\text { 11:00 A }\end{array}$ & $\begin{array}{c}\text { Sample\# } \\
11: 00 \mathrm{~B}\end{array}$ & $\begin{array}{c}\text { Sample\# } \\
\text { 19:30 A }\end{array}$ & $\begin{array}{c}\text { Sample\# } \\
\text { 19:30 B }\end{array}$ & $\begin{array}{c}\text { Sample\# } \\
6: 00 \mathrm{~A}\end{array}$ & $\begin{array}{c}\text { Sample\# } \\
6: 00 \mathrm{~B}\end{array}$ \\
\hline & Methanol & 96.382 & 97.26 & 97.384 & 97.598 & 96.844 & 96.941 \\
\hline & Ethanol & 0.317 & 0.372 & 0.29 & 0.288 & 0.324 & 0.295 \\
\hline & 1-Propanol & 0.093 & 0.095 & 0.082 & 0.074 & 0.079 & 0.08 \\
\hline & iso-Propanol & 0 & 0.037 & 0 & 0 & 0 & 0 \\
\hline & 1-Butanol & 0.077 & 0.083 & 0.113 & 0.098 & 0.088 & 0.066 \\
\hline Liquid & 2-Butanol & 0.037 & 0.037 & 0 & 0.032 & 0.032 & 0.032 \\
\hline Product & iso-Butanol & 0.017 & 0.019 & 0 & 0.015 & 0.018 & 0.018 \\
\hline Analysis & 2-Methyl-1-Butanol & 0 & 0 & 0 & 0 & 0 & 0 \\
\hline \multirow[t]{12}{*}{$(w t \%)$} & 1-Pentanol & 0.03 & 0.031 & 0.025 & 0.024 & 0.025 & 0.015 \\
\hline & 2-Methyl-1-Pentanol & 0 & 0 & 0 & 0 & 0 & 0 \\
\hline & 1-Hexanol & 0 & 0 & 0 & 0 & 0 & 0 \\
\hline & 2-Methyl-1-Isobutyrate & 0 & 0 & 0 & 0 & 0 & 0 \\
\hline & Methyl Acetate & 0.046 & 0.129 & 0.04 & 0.049 & 0.066 & 0.044 \\
\hline & Ethyl Acetate & 0 & 0 & 0 & 0 & 0 & 0 \\
\hline & Methyl Formate & 0.399 & 0.402 & 0.419 & 0.422 & 0.429 & 0.431 \\
\hline & DME & 0 & 0 & 0 & 0 & 0 & 0 \\
\hline & $\mathrm{CO} 2$ & 0 & 0 & 0 & 0 & 0 & 0 \\
\hline & Water & 1.453 & 1.473 & 1.473 & 1.471 & 1.433 & 1.436 \\
\hline & Oil & 0.2 & 0.2 & 0.2 & 0.2 & 0.2 & 0.2 \\
\hline & Total & 99.051 & 100.138 & 100.026 & 100.271 & 99.538 & 99.558 \\
\hline
\end{tabular}


RUN NO: AF-R13.2B (Rev. 1) TITLE: LPMEOH over Baseline catalyst with KINGSPORT SYNGAS : SV=4000

\begin{tabular}{|c|c|c|c|c|c|c|c|c|c|c|c|c|c|}
\hline & & $\begin{array}{c}\text { FRESH } \\
\text { MAKE-UP }\end{array}$ & RECYCLE & $\begin{array}{c}\text { HP H2 } \\
\text { MAKEUP }\end{array}$ & $\begin{array}{c}\text { DRY } \\
\text { FEED } \\
\end{array}$ & $\begin{array}{l}\text { ALCOHOL } \\
\text { INJECT. }\end{array}$ & $\begin{array}{c}\text { REACT } \\
\text { FEED } \\
\end{array}$ & $\begin{array}{c}\text { REACT } \\
\text { EFFL } \\
\end{array}$ & $\begin{array}{c}22.10 \\
\text { VAPOR } \\
\end{array}$ & $\begin{array}{c}\text { PURGE } 1 \\
\text { PIC-201 } \\
\end{array}$ & $\begin{array}{c}\text { PURGE } 2 \\
22.11 \\
\end{array}$ & $\begin{array}{c}\text { PURGE } 3 \\
07.20 \\
\end{array}$ & $\begin{array}{c}\text { LIQUID } \\
\text { PROD }\end{array}$ \\
\hline $\mathbf{T}$ & $\mathbf{F}$ & 290.8 & 139.1 & 101.9 & 276.6 & 100.0 & 257.4 & 462.6 & 88.5 & 93.3 & 86.9 & 79.4 & 80.0 \\
\hline $\mathbf{P}$ & psig & 775.8 & 856.7 & 821.1 & 754.8 & 754.8 & 754.8 & 735.0 & 1.2 & 666.0 & 34.8 & 82.1 & 1.0 \\
\hline \multirow{24}{*}{$\begin{array}{l}\text { Comp } \\
\text { (mole\%) }\end{array}$} & H2 & 10.56 & 56.96 & 100.00 & 60.62 & 0.00 & 60.62 & 46.77 & 56.95 & 56.96 & 12.63 & 0.00 & 0.00 \\
\hline & co & 77.05 & 19.64 & 0.00 & 24.65 & 0.00 & 24.65 & 15.94 & 19.64 & 19.64 & 9.13 & 0.00 & 0.00 \\
\hline & N2 & 3.07 & 8.21 & 0.00 & 4.90 & 0.00 & 4.90 & 6.66 & 8.21 & 8.21 & 2.88 & 0.00 & 0.00 \\
\hline & $\mathrm{CH} 4$ & 0.00 & 0.00 & 0.00 & 0.00 & 0.00 & 0.00 & 0.00 & 0.00 & 0.00 & 0.00 & 0.00 & 0.00 \\
\hline & $\mathrm{CO} 2$ & 9.32 & 15.19 & 0.00 & 9.84 & 0.00 & 9.84 & 13.03 & 15.19 & 15.19 & 61.43 & 0.00 & 0.00 \\
\hline & DME & 0.00 & 0.00 & 0.00 & 0.00 & 0.00 & 0.00 & 0.00 & 0.00 & 0.00 & 0.00 & 0.00 & 0.00 \\
\hline & MeAc & 0.00 & 0.00 & 0.00 & 0.00 & 0.00 & 0.00 & 0.00 & 0.00 & 0.00 & 0.00 & 0.00 & 0.03 \\
\hline & EtAc & 0.00 & 0.00 & 0.00 & 0.00 & 0.00 & 0.00 & 0.00 & 0.00 & 0.00 & 0.00 & 0.00 & 0.00 \\
\hline & MeFm & 0.00 & 0.00 & 0.00 & 0.00 & 0.00 & 0.00 & 0.00 & 0.00 & 0.00 & 0.00 & 0.00 & 0.22 \\
\hline & МеOH & 0.00 & 0.00 & 0.00 & 0.00 & 0.00 & 0.00 & 16.62 & 0.00 & 0.00 & 13.89 & 0.00 & 96.82 \\
\hline & $\mathrm{H} 2 \mathrm{O}$ & 0.00 & 0.00 & 0.00 & 0.00 & 0.00 & 0.00 & 0.84 & 0.02 & 0.00 & 0.03 & 0.00 & 2.58 \\
\hline & Etoh & 0.00 & 0.00 & 0.00 & 0.00 & 0.00 & 0.00 & 0.03 & 0.00 & 0.00 & 0.00 & 0.00 & 0.22 \\
\hline & 1-Proh & 0.00 & 0.00 & 0.00 & 0.00 & 0.00 & 0.00 & 0.01 & 0.00 & 0.00 & 0.00 & 0.00 & 0.04 \\
\hline & iso-Proh & 0.00 & 0.00 & 0.00 & 0.00 & 0.00 & 0.00 & 0.00 & 0.00 & 0.00 & 0.00 & 0.00 & 0.00 \\
\hline & $\mathrm{IBOH}$ & 0.00 & 0.00 & 0.00 & 0.00 & 0.00 & 0.00 & 0.00 & 0.00 & 0.00 & 0.00 & 0.00 & 0.01 \\
\hline & 1-Buoh & 0.00 & 0.00 & 0.00 & 0.00 & 0.00 & 0.00 & 0.00 & 0.00 & 0.00 & 0.00 & 0.00 & 0.04 \\
\hline & 2-Buoh & 0.00 & 0.00 & 0.00 & 0.00 & 0.00 & 0.00 & 0.00 & 0.00 & 0.00 & 0.00 & 0.00 & 0.01 \\
\hline & 2-Methyl 1-Buoh & 0.00 & 0.00 & 0.00 & 0.00 & 0.00 & 0.00 & 0.00 & 0.00 & 0.00 & 0.00 & 0.00 & 0.00 \\
\hline & 1-Peoh & 0.00 & 0.00 & 0.00 & 0.00 & 0.00 & 0.00 & 0.00 & 0.00 & 0.00 & 0.00 & 0.00 & 0.01 \\
\hline & 2-Methyl 1-Peoh & 0.00 & 0.00 & 0.00 & 0.00 & 0.00 & 0.00 & 0.00 & 0.00 & 0.00 & 0.00 & 0.00 & 0.00 \\
\hline & 1-hexanol & 0.00 & 0.00 & 0.00 & 0.00 & 0.00 & 0.00 & 0.00 & 0.00 & 0.00 & 0.00 & 0.00 & 0.00 \\
\hline & 2-Methyl 1-Isobutyrate & 0.00 & 0.00 & 0.00 & 0.00 & 0.00 & 0.00 & 0.00 & 0.00 & 0.00 & 0.00 & 0.00 & 0.00 \\
\hline & others & 0.00 & 0.00 & 0.00 & 0.00 & 100.00 & 0.00 & 0.10 & 0.00 & 0.00 & 0.00 & 100.00 & 0.02 \\
\hline & TOTAL & 100.00 & 100.00 & 100.00 & 100.00 & 100.00 & 100.00 & 100.00 & 100.00 & 100.00 & 100.00 & 100.00 & 100.00 \\
\hline Mole Wt & $\mathrm{lb} / \mathrm{lb}$ mole & 26.755 & 15.637 & 2.020 & 13.830 & 65.852 & 13.830 & 18.571 & 15.637 & 15.637 & 35.113 & 65.852 & 31.831 \\
\hline \multirow[t]{3}{*}{ Flow } & SCFH & 15464 & 42504 & 23520 & 81488 & 0 & 81488 & 59949 & 48220 & 5698 & 117 & 0 & 11611 \\
\hline & Ib mole/hr & 40.00 & 109.93 & 60.83 & 210.76 & 0.00 & 210.76 & 155.05 & 124.71 & 14.74 & 0.30 & 0.00 & 30.03 \\
\hline & $\mathbf{l b} / \mathrm{hr}$ & 1070.1 & 1718.9 & 122.9 & 2914.7 & 0.0 & 2914.7 & 2879.5 & 1950.1 & 230.4 & 10.6 & 0.0 & 955.9 \\
\hline
\end{tabular}


RUN NO: AF-R13.3A (Rev. 1)

Balance Period

Start Date

End Date

Reaction Conditions

Temperature $\left({ }^{\circ} \mathrm{F}\right)$

Pressure (psig)

Space Velocity (sL/kg-hr)

$\mathrm{Vg}$ (inlet)

Performance Results

CO Conversion to $\mathrm{H} 2(\%)$

$\mathrm{CO}$ Conversion to $\mathrm{MeOH}(\%)$

Theoretical Conversion \% (3 CSTR)

Alcohol Production (Ton/day)
TITLE: LPMEOH over Baseline Catalyst with KINGSPORT SYNGAS : SV=10,000

$\begin{array}{clc} & \text { Start } & 127.00 \\ & \text { End } & 145.00 \\ \text { Slurry Data } & & \\ & & \\ & \text { Catalyst Weight (lb oxide) } & 1179 \\ & \text { Slurry Conc. based on NDG (wt \%) } & 48.5 \\ & \text { Slurry Level (\%) } & 94 \\ \text { Gas Holdup based on NDG (vol \%) } & 55.7 \\ \text { Atomic/Mass Balance (\% of reactor inlet) } & \\ \text { C } & 100.88 \\ \text { H } & 97.42 \\ \text { O } & 101.44 \\ \text { N } & 102.06 \\ & \\ \text { Total Mass } & 101.02\end{array}$

\begin{tabular}{|c|c|c|c|c|c|}
\hline $\begin{array}{c}\text { Sample\# } \\
\text { 5:15 A }\end{array}$ & $\begin{array}{c}\text { Sample\# } \\
\text { 5:15 B }\end{array}$ & Sample\# & Sample\# & Sample\# & Sample\# \\
\hline 95.809 & 95.686 & & & & \\
\hline 0.174 & 0.174 & & & & \\
\hline 0.039 & 0.039 & & & & \\
\hline 0 & 0 & & & & \\
\hline 0.054 & 0.052 & & & & \\
\hline 0.02 & 0.019 & & & & \\
\hline 0 & 0 & & & & \\
\hline 0 & 0 & & & & \\
\hline 0 & 0.014 & & & & \\
\hline 0 & 0 & & & & \\
\hline 0 & 0 & & & & \\
\hline 0 & 0 & & & & \\
\hline 0.039 & 0.046 & & & & \\
\hline 0 & 0 & & & & \\
\hline 0.287 & 0.303 & & & & \\
\hline 0 & 0 & & & & \\
\hline 0 & 0 & & & & \\
\hline 1.71 & 1.684 & & & & \\
\hline 0.2 & 0.2 & & & & \\
\hline
\end{tabular}


RUN NO: AF-R13.3A (Rev. 1) TITLE: LPMEOH over Baseline Catalyst with KINGSPORT SYNGAS : SV=10,000

\begin{tabular}{|c|c|c|c|c|c|c|c|c|c|c|c|c|c|}
\hline & & $\begin{array}{c}\text { FRESH } \\
\text { MAKE-UP } \\
\end{array}$ & RECYCLE & $\begin{array}{c}\text { HP H2 } \\
\text { MAKEUP }\end{array}$ & $\begin{array}{c}\text { DRY } \\
\text { FEED } \\
\end{array}$ & $\begin{array}{l}\text { ALCOHOL } \\
\text { INJECT. }\end{array}$ & $\begin{array}{c}\text { REACT } \\
\text { FEED } \\
\end{array}$ & $\begin{array}{c}\text { REACT } \\
\text { EFFL }\end{array}$ & $\begin{array}{c}22.10 \\
\text { VAPOR }\end{array}$ & $\begin{array}{c}\text { PURGE } 1 \\
\text { PIC-201 } \\
\end{array}$ & $\begin{array}{c}\text { PURGE } 2 \\
22.11 \\
\end{array}$ & $\begin{array}{c}\text { PURGE } 3 \\
07.20 \\
\end{array}$ & $\begin{array}{l}\text { LIQUID } \\
\text { PROD }\end{array}$ \\
\hline $\mathbf{T}$ & $\mathbf{F}$ & 287.7 & 149.6 & 101.6 & 332.1 & 100.0 & 315.8 & 469.0 & 87.6 & 98.8 & 86.7 & 78.9 & 80.0 \\
\hline $\mathbf{P}$ & psig & 832.1 & 850.5 & 819.7 & 775.2 & 775.2 & 775.2 & 720.7 & 1.3 & 620.8 & 35.1 & 81.9 & 1.0 \\
\hline Comp & H2 & 30.33 & 57.16 & 100.00 & 59.28 & 0.00 & 59.28 & 48.62 & 57.15 & 57.16 & 17.10 & 0.00 & 0.00 \\
\hline \multirow[t]{23}{*}{ (mole\%) } & co & 63.14 & 22.27 & 0.00 & 25.55 & 0.00 & 25.55 & 19.60 & 22.27 & 22.27 & 13.70 & 0.00 & 0.00 \\
\hline & N2 & 1.63 & 9.51 & 0.00 & 6.79 & 0.00 & 6.79 & 8.59 & 9.51 & 9.51 & 4.43 & 0.00 & 0.00 \\
\hline & $\mathrm{CH}_{4}$ & 0.00 & 0.00 & 0.00 & 0.00 & 0.00 & 0.00 & 0.00 & 0.00 & 0.00 & 0.00 & 0.00 & 0.00 \\
\hline & $\mathrm{CO} 2$ & 4.90 & 11.06 & 0.00 & 8.38 & 0.00 & 8.38 & 10.15 & 11.06 & 11.06 & 51.48 & 0.00 & 0.00 \\
\hline & DME & 0.00 & 0.00 & 0.00 & 0.00 & 0.00 & 0.00 & 0.00 & 0.00 & 0.00 & 0.00 & 0.00 & 0.00 \\
\hline & MeAc & 0.00 & 0.00 & 0.00 & 0.00 & 0.00 & 0.00 & 0.00 & 0.00 & 0.00 & 0.00 & 0.00 & 0.02 \\
\hline & EtAc & 0.00 & 0.00 & 0.00 & 0.00 & 0.00 & 0.00 & 0.00 & 0.00 & 0.00 & 0.00 & 0.00 & 0.00 \\
\hline & MeFm & 0.00 & 0.00 & 0.00 & 0.00 & 0.00 & 0.00 & 0.00 & 0.00 & 0.00 & 0.00 & 0.00 & 0.16 \\
\hline & МeOH & 0.00 & 0.00 & 0.00 & 0.00 & 0.00 & 0.00 & 12.22 & 0.00 & 0.00 & 13.25 & 0.00 & 96.58 \\
\hline & $\mathrm{H} 2 \mathrm{O}$ & 0.00 & 0.00 & 0.00 & 0.00 & 0.00 & 0.00 & 0.78 & 0.02 & 0.00 & 0.04 & 0.00 & 3.04 \\
\hline & Etoh & 0.00 & 0.00 & 0.00 & 0.00 & 0.00 & 0.00 & 0.01 & 0.00 & 0.00 & 0.00 & 0.00 & 0.12 \\
\hline & 1-Proh & 0.00 & 0.00 & 0.00 & 0.00 & 0.00 & 0.00 & 0.00 & 0.00 & 0.00 & 0.00 & 0.00 & 0.02 \\
\hline & Iso-Proh & 0.00 & 0.00 & 0.00 & 0.00 & 0.00 & 0.00 & 0.00 & 0.00 & 0.00 & 0.00 & 0.00 & 0.00 \\
\hline & $\mathrm{IBOH}$ & 0.00 & 0.00 & 0.00 & 0.00 & 0.00 & 0.00 & 0.00 & 0.00 & 0.00 & 0.00 & 0.00 & 0.00 \\
\hline & 1-Buoh & 0.00 & 0.00 & 0.00 & 0.00 & 0.00 & 0.00 & 0.00 & 0.00 & 0.00 & 0.00 & 0.00 & 0.02 \\
\hline & 2-Buoh & 0.00 & 0.00 & 0.00 & 0.00 & 0.00 & 0.00 & 0.00 & 0.00 & 0.00 & 0.00 & 0.00 & 0.01 \\
\hline & 2-Methyl 1-Buoh & 0.00 & 0.00 & 0.00 & 0.00 & 0.00 & 0.00 & 0.00 & 0.00 & 0.00 & 0.00 & 0.00 & 0.00 \\
\hline & 1-Peoh & 0.00 & 0.00 & 0.00 & 0.00 & 0.00 & 0.00 & 0.00 & 0.00 & 0.00 & 0.00 & 0.00 & 0.00 \\
\hline & 2-Methyl 1-Peoh & 0.00 & 0.00 & 0.00 & 0.00 & 0.00 & 0.00 & 0.00 & 0.00 & 0.00 & 0.00 & 0.00 & 0.00 \\
\hline & 1-hexanol & 0.00 & 0.00 & 0.00 & 0.00 & 0.00 & 0.00 & 0.00 & 0.00 & 0.00 & 0.00 & 0.00 & 0.00 \\
\hline & 2-Methyl 1-Isobutyrate & 0.00 & 0.00 & 0.00 & 0.00 & 0.00 & 0.00 & 0.00 & 0.00 & 0.00 & 0.00 & 0.00 & 0.00 \\
\hline & others & 0.00 & 0.00 & 0.00 & 0.00 & 100.00 & 0.00 & 0.05 & 0.00 & 0.00 & 0.00 & 100.00 & 0.02 \\
\hline & TOTAL & 100.00 & 100.00 & 100.00 & 100.00 & 100.00 & 100.00 & 100.00 & 100.00 & 100.00 & 100.00 & 100.00 & 100.00 \\
\hline Mole Wt & $\mathrm{lb} / \mathrm{lb}$ mole & 20.909 & 14.925 & 2.020 & 13.944 & 71.328 & 13.944 & 17.436 & 14.925 & 14.925 & 32.332 & 71.328 & 31.712 \\
\hline \multirow[t]{3}{*}{ Flow } & SCFH & 30798 & 124550 & 30757 & 186105 & 0 & 186105 & 147149 & 130073 & 4448 & 123 & 0 & 19650 \\
\hline & lb mole/hr & 79.65 & 322.13 & 79.55 & 481.33 & 0.00 & 481.33 & 380.58 & 336.41 & 11.50 & 0.32 & 0.00 & 50.82 \\
\hline & lb/hr & 1665.5 & 4807.8 & 160.7 & 6711.7 & 0.0 & 6711.7 & 6635.7 & 5021.1 & 171.7 & 10.3 & 0.0 & 1611.7 \\
\hline
\end{tabular}


Balance Period:

Start Date

End Date

Reaction Conditions

Temperature ( ${ }^{\circ} \mathrm{F}$ )

Pressure (psig)

Space Velocity (sL/kg-hr)

$\mathrm{Vg}$ (inlet)

Performance Results

CO Conversion to $\mathrm{H} 2(\%)$

$\mathrm{CO}$ Conversion to $\mathrm{MeOH}(\%)$

Theoretical Conversion \% (3 CSTR)

Alcohol Production (Ton/day)

$6 / 10 / 95$
$6 / 10 / 95$

481.88
720.08
9109
1.13

-2.8
39.9
18.3

18.3
Time From Start of Run (hr)

Start

145.00

156.00

Slurry Data

Catalyst Weight (lb oxide)

Slurry Conc. by NDG (wt \%)

Slurry Level (\%)

Gas Holdup by NDG (vol \%)

1179

48.9

94

55.8

Atomic/Mass Balance (\% of reactor inlet)

C

H

$\mathrm{H}$

Total Mass

100.87

100.65

101.36

100.72

101.08

\begin{tabular}{|c|c|c|c|c|c|}
\hline $\begin{array}{c}\text { Sample\# } \\
18: 15 \text { A }\end{array}$ & $\begin{array}{c}\text { Sample\# } \\
\text { 18:15 B }\end{array}$ & Sample\# & Sample\# & Sample\# & Sample\# \\
\hline 96.174 & 97.094 & & & & \\
\hline 0.161 & 0.173 & & & & \\
\hline 0.04 & 0.052 & & & & \\
\hline 0 & 0 & & & & \\
\hline 0.076 & 0.032 & & & & \\
\hline 0 & 0.019 & & & & \\
\hline 0 & 0 & & & & \\
\hline 0 & 0 & & & & \\
\hline 0 & 0.01 & & & & \\
\hline 0 & 0 & & & & \\
\hline 0 & 0 & & & & \\
\hline 0 & 0 & & & & \\
\hline 0.033 & 0 & & & & \\
\hline 0 & 0 & & & & \\
\hline 0.307 & 0.536 & & & & \\
\hline 0 & 0 & & & & \\
\hline 0 & 0 & & & & \\
\hline 1.761 & 1.581 & & & & \\
\hline 0.2 & 0.2 & & & & \\
\hline
\end{tabular}

Methanol
Ethanol
1-Propanol
iso-Propanol
1-Butanol
2-Butanol
iso-Butanol
2-Methyl-1-Butanol
1-Pentanol
2-Methyl-1-Pentanol
1-Hexanol
2-Methyl-1-Isobutyrate
Methyl Acetate
Ethyl Acetate
Methyl Formate
DME
CO2
Water
Oil
Total

98.752

99.697 
RUN NO: $\quad$ AF-R13.3B (Rev.1) TITLE: LPMEOH over Baseline Catalyst with KINGSPORT SYNGAS : SV=10,000

\begin{tabular}{|c|c|c|c|c|c|c|c|c|c|c|c|c|c|}
\hline & & $\begin{array}{c}\text { FRESH } \\
\text { MAKE-UP }\end{array}$ & RECYCLE & $\begin{array}{c}\text { HP H2 } \\
\text { MAKEUP }\end{array}$ & $\begin{array}{c}\text { DRY } \\
\text { FEED } \\
\end{array}$ & $\begin{array}{l}\text { ALCOHOL } \\
\text { INJECT. }\end{array}$ & $\begin{array}{c}\text { REACT } \\
\text { FEED } \\
\end{array}$ & $\begin{array}{c}\text { REACT } \\
\text { EFFL } \\
\end{array}$ & $\begin{array}{c}22.10 \\
\text { VAPOR } \\
\end{array}$ & $\begin{array}{c}\text { PURGE } 1 \\
\text { PIC-201 } \\
\end{array}$ & $\begin{array}{c}\text { PURGE } 2 \\
22.11 \\
\end{array}$ & $\begin{array}{c}\text { PURGE } 3 \\
07.20 \\
\end{array}$ & $\begin{array}{l}\text { LIQUID } \\
\text { PROD }\end{array}$ \\
\hline $\mathbf{T}$ & $\mathbf{F}$ & 288.0 & 150.7 & 104.2 & 331.2 & 100.0 & 315.2 & 469.6 & 90.3 & 99.8 & 88.9 & 82.1 & 80.0 \\
\hline $\mathbf{P}$ & psig & 831.2 & 847.8 & 804.7 & 774.2 & 774.2 & 774.2 & 720.1 & 1.1 & 621.7 & 34.6 & 81.8 & 1.0 \\
\hline Comp & H2 & 30.87 & 58.70 & 100.00 & 61.12 & 0.00 & 61.12 & 50.51 & 58.69 & 58.70 & 16.97 & 0.00 & 0.00 \\
\hline \multirow[t]{23}{*}{ (mole\%) } & co & 62.63 & 22.00 & 0.00 & 24.89 & 0.00 & 24.89 & 18.70 & 22.00 & 22.00 & 13.05 & 0.00 & 0.00 \\
\hline & N2 & 1.44 & 8.25 & 0.00 & 5.75 & 0.00 & 5.75 & 7.32 & 8.25 & 8.25 & 3.70 & 0.00 & 0.00 \\
\hline & $\mathrm{CH} 4$ & 0.00 & 0.00 & 0.00 & 0.00 & 0.00 & 0.00 & 0.00 & 0.00 & 0.00 & 0.00 & 0.00 & 0.00 \\
\hline & $\mathrm{CO} 2$ & 5.05 & 11.05 & 0.00 & 8.24 & 0.00 & 8.24 & 9.88 & 11.05 & 11.05 & 49.99 & 0.00 & 0.00 \\
\hline & DME & 0.00 & 0.00 & 0.00 & 0.00 & 0.00 & 0.00 & 0.00 & 0.00 & 0.00 & 0.00 & 0.00 & 0.00 \\
\hline & MeAc & 0.00 & 0.00 & 0.00 & 0.00 & 0.00 & 0.00 & 0.00 & 0.00 & 0.00 & 0.00 & 0.00 & 0.01 \\
\hline & EtAc & 0.00 & 0.00 & 0.00 & 0.00 & 0.00 & 0.00 & 0.00 & 0.00 & 0.00 & 0.00 & 0.00 & 0.00 \\
\hline & MeFm & 0.00 & 0.00 & 0.00 & 0.00 & 0.00 & 0.00 & 0.00 & 0.00 & 0.00 & 0.00 & 0.00 & 0.22 \\
\hline & МeOH & 0.00 & 0.00 & 0.00 & 0.00 & 0.00 & 0.00 & 12.64 & 0.00 & 0.00 & 16.25 & 0.00 & 96.61 \\
\hline & $\mathrm{H} 2 \mathrm{O}$ & 0.00 & 0.00 & 0.00 & 0.00 & 0.00 & 0.00 & 0.89 & 0.02 & 0.00 & 0.04 & 0.00 & 2.97 \\
\hline & Etoh & 0.00 & 0.00 & 0.00 & 0.00 & 0.00 & 0.00 & 0.01 & 0.00 & 0.00 & 0.00 & 0.00 & 0.12 \\
\hline & 1-Proh & 0.00 & 0.00 & 0.00 & 0.00 & 0.00 & 0.00 & 0.00 & 0.00 & 0.00 & 0.00 & 0.00 & 0.02 \\
\hline & iso-Proh & 0.00 & 0.00 & 0.00 & 0.00 & 0.00 & 0.00 & 0.00 & 0.00 & 0.00 & 0.00 & 0.00 & 0.00 \\
\hline & IBOH & 0.00 & 0.00 & 0.00 & 0.00 & 0.00 & 0.00 & 0.00 & 0.00 & 0.00 & 0.00 & 0.00 & 0.00 \\
\hline & 1-Buoh & 0.00 & 0.00 & 0.00 & 0.00 & 0.00 & 0.00 & 0.00 & 0.00 & 0.00 & 0.00 & 0.00 & 0.02 \\
\hline & 2-Buoh & 0.00 & 0.00 & 0.00 & 0.00 & 0.00 & 0.00 & 0.00 & 0.00 & 0.00 & 0.00 & 0.00 & 0.00 \\
\hline & 2-Methyl 1-Buoh & 0.00 & 0.00 & 0.00 & 0.00 & 0.00 & 0.00 & 0.00 & 0.00 & 0.00 & 0.00 & 0.00 & 0.00 \\
\hline & 1-Peoh & 0.00 & 0.00 & 0.00 & 0.00 & 0.00 & 0.00 & 0.00 & 0.00 & 0.00 & 0.00 & 0.00 & 0.00 \\
\hline & 2-Methyl 1-Peoh & 0.00 & 0.00 & 0.00 & 0.00 & 0.00 & 0.00 & 0.00 & 0.00 & 0.00 & 0.00 & 0.00 & 0.00 \\
\hline & 1-hexanol & 0.00 & 0.00 & 0.00 & 0.00 & 0.00 & 0.00 & 0.00 & 0.00 & 0.00 & 0.00 & 0.00 & 0.00 \\
\hline & 2-Methyl 1-Isobutyrate & 0.00 & 0.00 & 0.00 & 0.00 & 0.00 & 0.00 & 0.00 & 0.00 & 0.00 & 0.00 & 0.00 & 0.00 \\
\hline & others & 0.00 & 0.00 & 0.00 & 0.00 & 100.00 & 0.00 & 0.06 & 0.00 & 0.00 & 0.00 & 100.00 & 0.02 \\
\hline & TOTAL & 100.00 & 100.00 & 100.00 & 100.00 & 100.00 & 100.00 & 100.00 & 100.00 & 100.00 & 100.00 & 100.00 & 100.00 \\
\hline Mole Wt & lb/lb mole & 20.796 & 14.522 & 2.020 & 13.443 & 69.594 & 13.443 & 16.907 & 14.522 & 14.522 & 32.249 & 69.594 & 31.733 \\
\hline \multirow[t]{3}{*}{ Flow } & SCFH & 31134 & 123326 & 30813 & 185273 & 0 & 185273 & 145567 & 128204 & 4854 & 123 & 0 & 18842 \\
\hline & lb mole/hr & 80.52 & 318.97 & 79.69 & 479.18 & 0.00 & 479.18 & 376.49 & 331.58 & 12.56 & 0.32 & 0.00 & 48.73 \\
\hline & $\mathrm{lb} / \mathrm{hr}$ & 1674.5 & 4631.9 & 161.0 & 6441.6 & 0.0 & 6441.6 & 6365.3 & 4815.4 & 182.3 & 10.3 & 0.0 & 1546.4 \\
\hline
\end{tabular}


RUN NO: AF-R14.1A (Rev. 1)

Balance Period:

Start Date

End Date

Reaction Conditions

Temperature $\left({ }^{\circ} \mathrm{F}\right)$

Pressure (psig)

Space Velocity (sL/kg-hr)

$\mathrm{Vg}$ (inlet)

Performance Results

CO Conversion to $\mathrm{H} 2(\%)$

CO Conversion to $\mathrm{MeOH}(\%)$

Theoretical Conversion \% ( 1 CSTR)

Alcohol Production (Ton/day)
TITLE: L.PMEOH over Alternate Catalyst with Texaco Syngas : SV=7,000

Time From Start of Run (hr)

Start

7.00

$6 / 13 / 95 \quad 18: 00$

$6 / 14 / 95 \quad 12: 00$

End

25.00

Slurry Data

Catalyst Weight (lb oxide)

Slurry Conc. based on NDG (wt \%)

Slurry Level (\%)

Gas Holdup based on NDG (vol \%) 49.6

7184

$-0.12$

16.4

12.0

\section{Atomic/Mass Balance (\% of reactor inlet)}

$\begin{array}{ll}\mathrm{C} & 99.51 \\ \mathrm{H} & 98.17 \\ \mathrm{O} & 99.74 \\ \mathrm{~N} & 98.33 \\ & \\ \text { Total Mass } & 99.59\end{array}$

99.51

8.17

8.33

99.59

\begin{tabular}{|c|c|c|c|c|c|c|c|}
\hline & & $\begin{array}{l}\text { Sample\# } \\
20: 00 \mathrm{~A}\end{array}$ & $\begin{array}{c}\text { Sample\# } \\
04: 05 \mathrm{~A}\end{array}$ & $\begin{array}{c}\text { Sample\# } \\
11: 00 \mathrm{~A}\end{array}$ & Sample\# & Sample\# & Sample\# \\
\hline & Methanol & 95.677 & 95.881 & 96.103 & & & \\
\hline & Ethanol & 1.048 & 0.967 & 0.923 & & & \\
\hline & 1-Propanol & 0.303 & 0.273 & 0.276 & & & \\
\hline & iso-Propanol & 0.022 & 0.013 & 0.017 & & & \\
\hline & 1-Butanol & 0.175 & 0.175 & 0.161 & & & \\
\hline Liquid & 2-Butanol & 0.061 & 0.061 & 0 & & & \\
\hline Product & iso-Butanol & 0.066 & 0.049 & 0.069 & & & \\
\hline Analysis & 2-Methyl-1-Butanol & 0 & 0 & 0 & & & \\
\hline$(w t \%)$ & 1-Pentanol & 0.085 & 0.078 & 0.079 & & & \\
\hline & 2-Methyl-1-Pentanol & 0 & 0 & 0 & & & \\
\hline & 1-Hexanol & 0.038 & 0.037 & 0.038 & & & \\
\hline & 2-Methyl- -1 -Isobutyrate & 0 & 0 & 0 & & & \\
\hline & Methyl Acetate & 0.29 & 0.257 & 0.251 & & & \\
\hline & Ethyl Acetate & 0 & 0 & 0 & & & \\
\hline & Methyl Formate & 1.082 & 1.074 & 1.048 & & & \\
\hline & DME & 0 & 0 & 0 & & & \\
\hline & $\mathrm{CO} 2$ & 0 & 0 & 0 & & & \\
\hline & Water & 0.349 & 0.391 & 0.398 & & & \\
\hline & Oil & 0.2 & 0.2 & 0.2 & & & \\
\hline & Total & 99.396 & 99.456 & 99.563 & & & \\
\hline
\end{tabular}


RUN NO: AF-R14.1A (Rev. 1) TITLE: LPMEOH over Alternate Catalyst with Texaco Syngas : SV=7,000

\begin{tabular}{|c|c|c|c|c|c|c|c|c|c|c|c|c|c|}
\hline & & $\begin{array}{c}\text { FRESH } \\
\text { MAKE-UP }\end{array}$ & RECYCLE & $\begin{array}{c}\text { HP H2 } \\
\text { MAKEUP }\end{array}$ & $\begin{array}{c}\text { DRY } \\
\text { FEED } \\
\end{array}$ & $\begin{array}{l}\text { ALCOHOL } \\
\text { INJECT. }\end{array}$ & $\begin{array}{c}\text { REACT } \\
\text { FEED } \\
\end{array}$ & $\begin{array}{c}\text { REACT } \\
\text { EFFL } \\
\end{array}$ & $\begin{array}{c}22.10 \\
\text { VAPOR }\end{array}$ & $\begin{array}{c}\text { PURGE } 1 \\
\text { PIC-201 }\end{array}$ & $\begin{array}{c}\text { PUAGE } 2 \\
22.11 \\
\end{array}$ & $\begin{array}{c}\text { PURGE } 3 \\
07.20 \\
\end{array}$ & $\begin{array}{l}\text { LIQUID } \\
\text { PROD } \\
\end{array}$ \\
\hline $\mathbf{T}$ & $\mathbf{F}$ & 303.4 & 132.4 & 93.0 & 318.9 & 100.0 & 302.0 & 470.0 & 78.5 & 87.4 & 77.9 & 74.6 & 80.0 \\
\hline $\mathbf{P}$ & psig & 850.0 & 871.6 & 777.1 & 803.7 & 803.7 & 803.7 & 752.4 & 2.4 & 668.6 & 33.5 & 82.2 & 1.0 \\
\hline \multirow{24}{*}{$\begin{array}{l}\text { Comp } \\
\text { (mole\%) }\end{array}$} & $\mathrm{H} 2$ & 7.95 & 23.94 & 100.00 & 35.07 & 0.00 & 35.07 & 21.33 & 23.94 & 23.94 & 35.02 & 0.00 & 0.00 \\
\hline & co & 84.17 & 57.62 & 0.00 & 51.31 & 0.00 & 51.31 & 51.32 & 57.62 & 57.62 & 51.42 & 0.00 & 0.00 \\
\hline & N2 & 0.51 & 1.52 & 0.00 & 1.10 & 0.00 & 1.10 & 1.34 & 1.52 & 1.52 & 1.11 & 0.00 & 0.00 \\
\hline & $\mathrm{CH} 4$ & 0.00 & 0.00 & 0.00 & 0.00 & 0.00 & 0.00 & 0.00 & 0.00 & 0.00 & 0.00 & 0.00 & 0.00 \\
\hline & $\mathrm{CO} 2$ & 7.36 & 16.92 & 0.00 & 12.52 & 0.00 & 12.52 & 15.40 & 16.92 & 16.92 & 12.44 & 0.00 & 0.00 \\
\hline & DME & 0.00 & 0.00 & 0.00 & 0.00 & 0.00 & 0.00 & 0.00 & 0.00 & 0.00 & 0.00 & 0.00 & 0.00 \\
\hline & MeAc & 0.00 & 0.00 & 0.00 & 0.00 & 0.00 & 0.00 & 0.00 & 0.00 & 0.00 & 0.00 & 0.00 & 0.12 \\
\hline & EtAc & 0.00 & 0.00 & 0.00 & 0.00 & 0.00 & 0.00 & 0.00 & 0.00 & 0.00 & 0.00 & 0.00 & 0.00 \\
\hline & MeFm & 0.00 & 0.00 & 0.00 & 0.00 & 0.00 & 0.00 & 0.00 & 0.00 & 0.00 & 0.00 & 0.00 & 0.58 \\
\hline & $\mathrm{MeOH}$ & 0.00 & 0.00 & 0.00 & 0.00 & 0.00 & 0.00 & 10.27 & 0.00 & 0.00 & 0.00 & 0.00 & 97.58 \\
\hline & $\mathrm{H} 2 \mathrm{O}$ & 0.00 & 0.00 & 0.00 & 0.00 & 0.00 & 0.00 & 0.07 & 0.00 & 0.00 & 0.01 & 0.00 & 0.69 \\
\hline & Etoh & 0.00 & 0.00 & 0.00 & 0.00 & 0.00 & 0.00 & 0.07 & 0.00 & 0.00 & 0.00 & 0.00 & 0.69 \\
\hline & 1-Proh & 0.00 & 0.00 & 0.00 & 0.00 & 0.00 & 0.00 & 0.02 & 0.00 & 0.00 & 0.00 & 0.00 & 0.15 \\
\hline & iso-Proh & 0.00 & 0.00 & 0.00 & 0.00 & 0.00 & 0.00 & 0.00 & 0.00 & 0.00 & 0.00 & 0.00 & 0.01 \\
\hline & IBOH & 0.00 & 0.00 & 0.00 & 0.00 & 0.00 & 0.00 & 0.00 & 0.00 & 0.00 & 0.00 & 0.00 & 0.03 \\
\hline & 1-Buoh & 0.00 & 0.00 & 0.00 & 0.00 & 0.00 & 0.00 & 0.00 & 0.00 & 0.00 & 0.00 & 0.00 & 0.07 \\
\hline & 2-Buoh & 0.00 & 0.00 & 0.00 & 0.00 & 0.00 & 0.00 & 0.00 & 0.00 & 0.00 & 0.00 & 0.00 & 0.02 \\
\hline & 2-Methyl 1-Buoh & 0.00 & 0.00 & 0.00 & 0.00 & 0.00 & 0.00 & 0.00 & 0.00 & 0.00 & 0.00 & 0.00 & 0.00 \\
\hline & 1-Peoh & 0.00 & 0.00 & 0.00 & 0.00 & 0.00 & 0.00 & 0.00 & 0.00 & 0.00 & 0.00 & 0.00 & 0.03 \\
\hline & 2-Methyl 1-Peoh & 0.00 & 0.00 & 0.00 & 0.00 & 0.00 & 0.00 & 0.00 & 0.00 & 0.00 & 0.00 & 0.00 & 0.00 \\
\hline & 1-hexanol & 0.00 & 0.00 & 0.00 & 0.00 & 0.00 & 0.00 & 0.00 & 0.00 & 0.00 & 0.00 & 0.00 & 0.01 \\
\hline & 2-Methyl 1-Isobutyrate & 0.00 & 0.00 & 0.00 & 0.00 & 0.00 & 0.00 & 0.00 & 0.00 & 0.00 & 0.00 & 0.00 & 0.00 \\
\hline & others & 0.00 & 0.00 & 0.00 & 0.00 & 100.00 & 0.00 & 0.18 & 0.00 & 0.00 & 0.00 & 100.00 & 0.02 \\
\hline & TOTAL & 100.00 & 100.00 & 100.00 & 100.00 & 100.00 & 100.00 & 100.00 & 100.00 & 100.00 & 100.00 & 100.00 & 100.00 \\
\hline Mole Wt & lb/lb mole & 27.121 & 24.494 & 2.020 & 20.897 & 60.168 & 20.897 & 25.415 & 24.494 & 24.494 & 20.899 & 60.168 & 32.380 \\
\hline \multirow[t]{3}{*}{ Flow } & SCFH & 20860 & 97868 & 24800 & 143527 & 0 & 143527 & 117938 & 105766 & 7859 & 216 & 0 & 12865 \\
\hline & lb mole/hr & 53.95 & 253.12 & 64.14 & 371.21 & 0.00 & 371.21 & 305.03 & 273.55 & 20.33 & 0.56 & 0.00 & 33.27 \\
\hline & $\mathrm{lb} / \mathrm{hr}$ & 1463.2 & 6199.9 & 129.6 & 7757.4 & 0.0 & 7757.4 & 7752.3 & 6700.2 & 497.9 & 11.7 & 0.0 & 1077.4 \\
\hline
\end{tabular}


Balance Period:

Start Date

End Date

Reaction Conditions

Temperature ( $\left.{ }^{\circ} \mathrm{F}\right)$

Pressure (psig)

Space Velocity (sL/kg-hr)

$\mathrm{Vg}$ (inlet)

Performance Results

CO Conversion to $\mathrm{H} 2(\%)$

$\mathrm{CO}$ Conversion to $\mathrm{MeOH}(\%)$

Theoretical Conversion \% (1 CSTR)

Alcohol Production (Ton/day)
$6 / 14 / 95$

$6 / 15 / 95$

12:00

12:00

482.17

753.49

7196

0.84

$-0.1$

16.2

11.7

Time From Start of Run (hr)

Start $\quad 25.00$

Slurry Data

Catalyst Weight (lb oxide)

Slurry Conc. based on NDG (wt \%)

Slurry Level (\%)

Gas Holdup based on NDG (vol \%) $\quad 49.9$

Atomic/Mass Balance ( $\%$ of reactor inlet)

$\begin{array}{lr}\mathrm{C} & 98.81 \\ \mathrm{H} & 100.22 \\ \mathrm{O} & 99.04 \\ \mathrm{~N} & 98.49 \\ & \\ \text { Total Mass } & 98.99\end{array}$

Sample\# Sample\# Sample\# Sample\# Sample\# Sample\#

19:30 A 03:10 A 10:15 A

Methano

Ethanol

1-Propanol

iso-Propanol

1-Butanol

2-Butanol

Liquid

Product

iso-Butanol

2-Methyl-1-Butanol

1-Pentanol

2-Methyl-1-Pentanol

1-Hexanol

2-Methyl-1-Isobutyrate

Methyl Acetate

Ethyl Acetate

Methyl Formate

DME

$\mathrm{CO} 2$

Water

Oil

Total

\begin{tabular}{rrr}
96.213 & 95.583 & 95.296 \\
0.914 & 0.882 & 0.912 \\
0.26 & 0.253 & 0.264 \\
0.024 & 0.016 & 0.013 \\
0.171 & 0.171 & 0.154 \\
0.052 & 0.031 & 0.052 \\
0.055 & 0.055 & 0.053 \\
0 & 0 & 0 \\
0.076 & 0.072 & 0.085 \\
0 & 0 & 0 \\
0.037 & 0.034 & 0.038 \\
0 & 0 & 0 \\
0.235 & 0.221 & 0.21 \\
0 & 0 & 0 \\
1.014 & 1.009 & 0.906 \\
0 & 0 & 0 \\
0 & 0 & 0 \\
0.413 & 0.404 & 0.437 \\
0.2 & 0.2 & 0.2 \\
\hline 99.664 & 98.931 & 98.62
\end{tabular}

3

98.81

00.22

98.99 
RUN NO: $\quad$ AF-R14.1B (Rev. 1) TITLE: LPMEOH over Alternate Catalyst with Texaco Syngas : SV=7,000

\begin{tabular}{|c|c|c|c|c|c|c|c|c|c|c|c|c|c|}
\hline & & $\begin{array}{c}\text { FRESH } \\
\text { MAKE-UP }\end{array}$ & RECYCLE & $\begin{array}{c}\text { HP H2 } \\
\text { MAKEUP }\end{array}$ & $\begin{array}{c}\text { DRY } \\
\text { FEED } \\
\end{array}$ & $\begin{array}{c}\text { ALCOHOL } \\
\text { INJECT. }\end{array}$ & $\begin{array}{c}\text { REACT } \\
\text { FEED } \\
\end{array}$ & $\begin{array}{c}\text { REACT } \\
\text { EFFL }\end{array}$ & $\begin{array}{c}22.10 \\
\text { VAPOR } \\
\end{array}$ & $\begin{array}{c}\text { PURGE } 1 \\
\text { PIC-201 } \\
\end{array}$ & $\begin{array}{c}\text { PURGE } 2 \\
22.11 \\
\end{array}$ & $\begin{array}{c}\text { PURGE } 3 \\
07.20 \\
\end{array}$ & $\begin{array}{c}\text { LIQUID } \\
\text { PROD } \\
\end{array}$ \\
\hline $\mathbf{T}$ & $F$ & 307.0 & 135.9 & 98.6 & 335.7 & 100.0 & 318.8 & 469.2 & 82.5 & 90.3 & 81.1 & 75.4 & 80.0 \\
\hline $\mathbf{P}$ & psig & 853.7 & 875.3 & 776.9 & 806.4 & 806.4 & 806.4 & 753.5 & 1.8 & 671.1 & 42.3 & 82.6 & 1.0 \\
\hline \multirow{24}{*}{$\begin{array}{l}\text { Comp } \\
\text { (mole\%) }\end{array}$} & $\mathrm{H} 2$ & 7.99 & 23.68 & 100.00 & 35.58 & 0.00 & 35.58 & 22.40 & 23.68 & 23.68 & 35.63 & 0.00 & 0.00 \\
\hline & co & 83.83 & 57.40 & 0.00 & 50.59 & 0.00 & 50.59 & 50.49 & 57.40 & 57.40 & 50.64 & 0.00 & 0.00 \\
\hline & N2 & 0.55 & 1.56 & 0.00 & 1.13 & 0.00 & 1.13 & 1.37 & 1.56 & 1.56 & 1.13 & 0.00 & 0.00 \\
\hline & $\mathrm{CH} 4$ & 0.00 & 0.00 & 0.00 & 0.00 & 0.00 & 0.00 & 0.00 & 0.00 & 0.00 & 0.00 & 0.00 & 0.00 \\
\hline & $\mathrm{CO} 2$ & 7.63 & 17.35 & 0.00 & 12.70 & 0.00 & 12.70 & 15.54 & 17.35 & 17.35 & 12.58 & 0.00 & 0.00 \\
\hline & DME & 0.00 & 0.00 & 0.00 & 0.00 & 0.00 & 0.00 & 0.00 & 0.00 & 0.00 & 0.00 & 0.00 & 0.00 \\
\hline & MeAc & 0.00 & 0.00 & 0.00 & 0.00 & 0.00 & 0.00 & 0.00 & 0.00 & 0.00 & 0.00 & 0.00 & 0.10 \\
\hline & EtAc & 0.00 & 0.00 & 0.00 & 0.00 & 0.00 & 0.00 & 0.00 & 0.00 & 0.00 & 0.00 & 0.00 & 0.00 \\
\hline & MeFm & 0.00 & 0.00 & 0.00 & 0.00 & 0.00 & 0.00 & 0.00 & 0.00 & 0.00 & 0.00 & 0.00 & 0.53 \\
\hline & $\mathrm{MeOH}$ & 0.00 & 0.00 & 0.00 & 0.00 & 0.00 & 0.00 & 9.94 & 0.00 & 0.00 & 0.00 & 0.00 & 97.64 \\
\hline & $\mathrm{H} 2 \mathrm{O}$ & 0.00 & 0.00 & 0.00 & 0.00 & 0.00 & 0.00 & 0.06 & 0.00 & 0.00 & 0.01 & 0.00 & 0.76 \\
\hline & Etoh & 0.00 & 0.00 & 0.00 & 0.00 & 0.00 & 0.00 & 0.03 & 0.00 & 0.00 & 0.00 & 0.00 & 0.64 \\
\hline & 1-Proh & 0.00 & 0.00 & 0.00 & 0.00 & 0.00 & 0.00 & 0.01 & 0.00 & 0.00 & 0.00 & 0.00 & 0.14 \\
\hline & iso-Proh & 0.00 & 0.00 & 0.00 & 0.00 & 0.00 & 0.00 & 0.00 & 0.00 & 0.00 & 0.00 & 0.00 & 0.01 \\
\hline & IBOH & 0.00 & 0.00 & 0.00 & 0.00 & 0.00 & 0.00 & 0.00 & 0.00 & 0.00 & 0.00 & 0.00 & 0.02 \\
\hline & 1-Buoh & 0.00 & 0.00 & 0.00 & 0.00 & 0.00 & 0.00 & 0.00 & 0.00 & 0.00 & 0.00 & 0.00 & 0.07 \\
\hline & 2-Buoh & 0.00 & 0.00 & 0.00 & 0.00 & 0.00 & 0.00 & 0.00 & 0.00 & 0.00 & 0.00 & 0.00 & 0.02 \\
\hline & 2-Methyl 1-Buoh & 0.00 & 0.00 & 0.00 & 0.00 & 0.00 & 0.00 & 0.00 & 0.00 & 0.00 & 0.00 & 0.00 & 0.00 \\
\hline & 1-Peoh & 0.00 & 0.00 & 0.00 & 0.00 & 0.00 & 0.00 & 0.00 & 0.00 & 0.00 & 0.00 & 0.00 & 0.03 \\
\hline & 2-Methyl 1-Peoh & 0.00 & 0.00 & 0.00 & 0.00 & 0.00 & 0.00 & 0.00 & 0.00 & 0.00 & 0.00 & 0.00 & 0.00 \\
\hline & 1-hexanol & 0.00 & 0.00 & 0.00 & 0.00 & 0.00 & 0.00 & 0.00 & 0.00 & 0.00 & 0.00 & 0.00 & 0.01 \\
\hline & 2-Methyl 1-Isobutyrate & 0.00 & 0.00 & 0.00 & 0.00 & 0.00 & 0.00 & 0.00 & 0.00 & 0.00 & 0.00 & 0.00 & 0.00 \\
\hline & others & 0.00 & 0.00 & 0.00 & 0.00 & 100.00 & 0.00 & 0.16 & 0.00 & 0.00 & 0.00 & 100.00 & 0.02 \\
\hline & TOTAL & 100.00 & 100.00 & 100.00 & 100.00 & 100.00 & 100.00 & 100.00 & 100.00 & 100.00 & 100.00 & 100.00 & 100.00 \\
\hline Mole Wt & $\mathrm{lb} / \mathrm{lb}$ mole & 27.154 & 24.631 & 2.020 & 20.794 & 60.423 & 20.794 & 25.130 & 24.631 & 24.631 & 20.763 & 60.423 & 32.335 \\
\hline \multirow[t]{3}{*}{ Flow } & SCFH & 20799 & 98157 & 24799 & 143754 & 0 & 143754 & 118814 & 105504 & 7885 & 76 & 0 & 12958 \\
\hline & Ib mole/hr & 53.79 & 253.87 & 64.14 & 371.80 & 0.00 & 371.80 & 307.30 & 272.87 & 20.39 & 0.20 & 0.00 & 33.51 \\
\hline & $\mathrm{lb} / \mathrm{hr}$ & 1460.7 & 6253.0 & 129.6 & 7731.0 & 0.0 & 7731.0 & 7722.3 & 6721.0 & 502.3 & 4.1 & 0.0 & 1083.7 \\
\hline
\end{tabular}


Balance Period:

Start Date

End Date

Reaction Conditions

Temperature $\left({ }^{\circ} \mathrm{F}\right)$

Pressure (psig)

Space Velocity (sL/kg-hr)

$\mathrm{Vg}$ (inlet)

Performance Results

CO Conversion to $\mathrm{H} 2(\%)$

CO Conversion to $\mathrm{MeOH}(\%)$

Theoretical Conversion \% (2 CSTR)

Alcohol Production (Ton/day)
$6 / 15 / 95$

$6 / 17 / 95$

19:00

$1: 00$

482.64

734.97

4042

0.48

$-2$

49.4

48.9

10.0
Time From Start of Run (hr)

Start $\quad 56.00$

End

86.00

Slurry Data

Catalyst Weight (lb oxide)

Slurry Conc. based on NDG (wt \%) $\quad 39.4$

Slurry Level (\%)

Gas Holdup based on NDG (vol \%) $\quad 37.5$

Atomlc/Mass Balance (\% of reactor inlet)

99.00

98.06

100.27

99.40

Total Mass

99.62

\begin{tabular}{|c|c|c|c|c|c|}
\hline $\begin{array}{c}\text { Sample\# } \\
2: 30 \mathrm{~A}\end{array}$ & $\begin{array}{c}\text { Sample\# } \\
\text { 10:30 A }\end{array}$ & $\begin{array}{c}\text { Sample\# } \\
21: 20 A\end{array}$ & Sample\# & Sample\# & Sample\# \\
\hline 96.643 & 97.373 & 96.617 & & & \\
\hline 0.356 & 0.376 & 0.344 & & & \\
\hline 0.096 & 0.097 & 0.091 & & & \\
\hline 0 & 0 & 0 & & & \\
\hline 0.071 & 0.071 & 0.102 & & & \\
\hline 0.037 & 0.037 & 0.038 & & & \\
\hline 0.023 & 0.021 & 0.02 & & & \\
\hline 0 & 0 & 0 & & & \\
\hline 0.029 & 0.026 & 0.023 & & & \\
\hline 0 & 0 & 0 & & & \\
\hline 0 & 0 & 0 & & & \\
\hline 0 & 0 & 0 & & & \\
\hline 0.058 & 0.096 & 0.053 & & & \\
\hline 0 & 0 & 0 & & & \\
\hline 0.535 & 0.516 & 0.456 & & & \\
\hline 0 & 0 & 0 & & & \\
\hline 0 & 0 & 0 & & & \\
\hline 1.167 & 1.207 & 1.283 & & & \\
\hline 0.2 & 0.2 & 0.2 & & & \\
\hline
\end{tabular}


RUN NO: AF-R14.2A (Rev. 1) TITLE: LPMEOH over Alternate Catalyst with KIngsport Syngas : SV=4,000

\begin{tabular}{|c|c|c|c|c|c|c|c|c|c|c|c|c|c|}
\hline & & $\begin{array}{c}\text { FRESH } \\
\text { MAKE-UP }\end{array}$ & RECYCLE & $\begin{array}{c}\text { HP H2 } \\
\text { MAKEUP }\end{array}$ & $\begin{array}{c}\text { DRY } \\
\text { FEED } \\
\end{array}$ & $\begin{array}{l}\text { ALCOHOL } \\
\text { INJECT. } \\
\end{array}$ & $\begin{array}{c}\text { REACT } \\
\text { FEED } \\
\end{array}$ & $\begin{array}{c}\text { AEACT } \\
\text { EFFL }\end{array}$ & $\begin{array}{c}22.10 \\
\text { VAPOR } \\
\end{array}$ & $\begin{array}{c}\text { PURGE } 1 \\
\text { PIC-201 } \\
\end{array}$ & $\begin{array}{c}\text { PURGE } 2 \\
22.11 \\
\end{array}$ & $\begin{array}{c}\text { PURGE } 3 \\
07.20 \\
\end{array}$ & $\begin{array}{l}\text { LIQUID } \\
\text { PROD }\end{array}$ \\
\hline $\mathbf{T}$ & $\mathbf{F}$ & 294.1 & 122.4 & 99.2 & 277.7 & 100.0 & 259.2 & 463.3 & 84.3 & 89.2 & 82.9 & 77.3 & 80.0 \\
\hline $\mathbf{P}$ & psig & 776.6 & 780.0 & 771.4 & 756.4 & 756.4 & 756.4 & 735.0 & 1.4 & 666.9 & 35.9 & 82.4 & 1.0 \\
\hline \multirow{24}{*}{$\begin{array}{l}\text { Comp } \\
\text { (mole\%) }\end{array}$} & $\mathrm{H} 2$ & 10.80 & 56.85 & 100.00 & 60.83 & 0.00 & 60.83 & 46.86 & 56.85 & 56.85 & 60.84 & 0.00 & 0.00 \\
\hline & co & 77.00 & 20.55 & 0.00 & 25.27 & 0.00 & 25.27 & 16.54 & 20.55 & 20.55 & 25.30 & 0.00 & 0.00 \\
\hline & N2 & 2.76 & 7.31 & 0.00 & 4.25 & 0.00 & 4.25 & 5.80 & 7.31 & 7.31 & 4.25 & 0.00 & 0.00 \\
\hline & $\mathrm{CH} 4$ & 0.00 & 0.00 & 0.00 & 0.00 & 0.00 & 0.00 & 0.00 & 0.00 & 0.00 & 0.00 & 0.00 & 0.00 \\
\hline & $\mathrm{CO} 2$ & 9.44 & 15.29 & 0.00 & 9.65 & 0.00 & 9.65 & 12.92 & 15.28 & 15.29 & 9.58 & 0.00 & 0.00 \\
\hline & DME & 0.00 & 0.00 & 0.00 & 0.00 & 0.00 & 0.00 & 0.00 & 0.00 & 0.00 & 0.00 & 0.00 & 0.00 \\
\hline & MeAc & 0.00 & 0.00 & 0.00 & 0.00 & 0.00 & 0.00 & 0.00 & 0.00 & 0.00 & 0.00 & 0.00 & 0.03 \\
\hline & EtAc & 0.00 & 0.00 & 0.00 & 0.00 & 0.00 & 0.00 & 0.00 & 0.00 & 0.00 & 0.00 & 0.00 & 0.00 \\
\hline & MeFm & 0.00 & 0.00 & 0.00 & 0.00 & 0.00 & 0.00 & 0.00 & 0.00 & 0.00 & 0.00 & 0.00 & 0.27 \\
\hline & $\mathrm{MeOH}$ & 0.00 & 0.00 & 0.00 & 0.00 & 0.00 & 0.00 & 17.04 & 0.00 & 0.00 & 0.00 & 0.00 & 97.14 \\
\hline & $\mathrm{H} 2 \mathrm{O}$ & 0.00 & 0.00 & 0.00 & 0.00 & 0.00 & 0.00 & 0.69 & 0.01 & 0.00 & 0.02 & 0.00 & 2.17 \\
\hline & Etoh & 0.00 & 0.00 & 0.00 & 0.00 & 0.00 & 0.00 & 0.03 & 0.00 & 0.00 & 0.00 & 0.00 & 0.25 \\
\hline & 1-Proh & 0.00 & 0.00 & 0.00 & 0.00 & 0.00 & 0.00 & 0.00 & 0.00 & 0.00 & 0.00 & 0.00 & 0.05 \\
\hline & Iso-Proh & 0.00 & 0.00 & 0.00 & 0.00 & 0.00 & 0.00 & 0.00 & 0.00 & 0.00 & 0.00 & 0.00 & 0.00 \\
\hline & $\mathrm{IBOH}$ & 0.00 & 0.00 & 0.00 & 0.00 & 0.00 & 0.00 & 0.00 & 0.00 & 0.00 & 0.00 & 0.00 & 0.01 \\
\hline & 1-Buoh & 0.00 & 0.00 & 0.00 & 0.00 & 0.00 & 0.00 & 0.00 & 0.00 & 0.00 & 0.00 & 0.00 & 0.04 \\
\hline & 2-Buoh & 0.00 & 0.00 & 0.00 & 0.00 & 0.00 & 0.00 & 0.00 & 0.00 & 0.00 & 0.00 & 0.00 & 0.02 \\
\hline & 2-Methyl 1-Buoh & 0.00 & 0.00 & 0.00 & 0.00 & 0.00 & 0.00 & 0.00 & 0.00 & 0.00 & 0.00 & 0.00 & 0.00 \\
\hline & 1-Peoh & 0.00 & 0.00 & 0.00 & 0.00 & 0.00 & 0.00 & 0.00 & 0.00 & 0.00 & 0.00 & 0.00 & 0.01 \\
\hline & 2-Methyl 1-Peoh & 0.00 & 0.00 & 0.00 & 0.00 & 0.00 & 0.00 & 0.00 & 0.00 & 0.00 & 0.00 & 0.00 & 0.00 \\
\hline & 1-hexanol & 0.00 & 0.00 & 0.00 & 0.00 & 0.00 & 0.00 & 0.00 & 0.00 & 0.00 & 0.00 & 0.00 & 0.00 \\
\hline & 2-Methyl 1-Isobutyrate & 0.00 & 0.00 & 0.00 & 0.00 & 0.00 & 0.00 & 0.00 & 0.00 & 0.00 & 0.00 & 0.00 & 0.00 \\
\hline & others & 0.00 & 0.00 & 0.00 & 0.00 & 100.00 & 0.00 & 0.12 & 0.00 & 0.00 & 0.00 & 100.00 & 0.02 \\
\hline & TOTAL & 100.00 & 100.00 & 100.00 & 100.00 & 100.00 & 100.00 & 100.00 & 100.00 & 100.00 & 100.00 & 100.00 & 100.00 \\
\hline Mole Wt & lb/lb mole & 26.713 & 15.680 & 2.020 & 13.744 & 64.659 & 13.744 & 18.566 & 15.680 & 15.680 & 13.727 & 64.659 & 31.910 \\
\hline \multirow[t]{3}{*}{ Flow } & SCFH & 16026 & 40972 & 23754 & 80752 & 0 & 80752 & 59153 & 47243 & 6220 & 4 & 0 & 11695 \\
\hline & Ib mole/hr & 41.45 & 105.97 & 61.44 & 208.85 & 0.00 & 208.85 & 152.99 & 122.19 & 16.09 & 0.01 & 0.00 & 30.25 \\
\hline & $\mathrm{lb} / \mathrm{hr}$ & 1107.2 & 1661.5 & 124.1 & 2870.4 & 0.0 & 2870.4 & 2840.4 & 1915.9 & 252.2 & 0.2 & 0.0 & 965.2 \\
\hline
\end{tabular}


Balance Period:

$$
\text { Start Date }
$$

End Date

Reaction Conditions

$$
\text { Temperature }\left({ }^{\circ} \mathrm{F}\right)
$$

Pressure (psig)

Space Velocity (sL/kg-hr)

$\mathrm{Vg}$ (inlet)

Performance Results

Co Conversion to $\mathrm{H} 2(\%)$

$\mathrm{CO}$ Conversion to $\mathrm{MeOH}(\%)$

Theoretical Conversion \% (2 CSTR)

Alcohol Production (Ton/day)

$6 / 17 / 95$
$6 / 18 / 95$

482.65
735.00
4027
0.48


-2
48.6
48.9
9.8

Sample\#

4:00 A
Sample\# 10:00 A

Methanol

Ethanol

1-Propanol

iso-Propanol

1-Butanol

2-Butanol

Liquld

Product

Analysis

(wt\%)

iso-Butanol

2-Methyl-1-Butanol

1-Pentanol

2-Methyl-1-Pentanol

1-Hexanol

2-Methyl-1-Isobutyrate

Methyl Acetate

Ethyl Acetate

Methyl Formate

DME

$\mathrm{CO} 2$

Water

Oil

Total

\begin{tabular}{rrrr}
95.56 & 96.037 & 95.732 & 95.95 \\
0.337 & 0.339 & 0.325 & 0.372 \\
0.095 & 0.095 & 0.09 & 0.094 \\
0 & 0 & 0 & 0 \\
0.067 & 0.052 & 0.108 & 0.071 \\
0.033 & 0.036 & 0.036 & 0.032 \\
0.02 & 0.022 & 0.018 & 0.02 \\
0 & 0 & 0 & 0 \\
0.026 & 0.028 & 0.026 & 0.027 \\
0 & 0 & 0 & 0 \\
0 & 0 & 0 & 0 \\
0 & 0 & 0 & 0 \\
0.052 & 0.057 & 0.055 & 0.102 \\
0 & 0 & 0 & 0 \\
0.432 & 0.435 & 0.436 & 0.443 \\
0 & 0 & 0 & 0 \\
0 & 0 & 0 & 0 \\
1.273 & 1.291 & 1.289 & 1.268 \\
0.2 & 0.2 & 0.2 & 0.2 \\
\hline 98.095 & 98.592 & 98.315 & 98.579
\end{tabular}

86.00

113.00

Slurry Data

Catalyst Weight (lb oxide)

Slurry Conc. based on NDG (wt \%) $\quad 39.7$

Slurry Level (\%) 94

Gas Holdup based on NDG (vol \%) $\quad 38.1$

Atomic/Mass Balance ( $\%$ of reactor Inlet)

$\begin{array}{lc}\mathrm{C} & 99.53 \\ \mathrm{H} & 98.05 \\ \mathrm{O} & 100.56 \\ \mathrm{~N} & 99.27 \\ & \\ \text { Total Mass } & 99.92\end{array}$

9.92 
RUN NO: AF-R14.2B (Rev. 1) TITLE: LPMEOH over Alternate Catalyst with KIngsport Syngas : SV=4,000

\begin{tabular}{|c|c|c|c|c|c|c|c|c|c|c|c|c|c|}
\hline & & $\begin{array}{c}\text { FRESH } \\
\text { MAKE-UP } \\
\end{array}$ & RECYCLE & $\begin{array}{c}\text { HP H2 } \\
\text { MAKEUP } \\
\end{array}$ & $\begin{array}{c}\text { DRY } \\
\text { FEED } \\
\end{array}$ & $\begin{array}{c}\text { ALCOHOL } \\
\text { INJECT. }\end{array}$ & $\begin{array}{c}\text { REACT } \\
\text { FEED } \\
\end{array}$ & $\begin{array}{c}\text { REACT } \\
\text { EFFL }\end{array}$ & $\begin{array}{c}22.10 \\
\text { VAPOR } \\
\end{array}$ & $\begin{array}{l}\text { PURGE } 1 \\
\text { PIC-201 } \\
\end{array}$ & $\begin{array}{c}\text { PURGE } 2 \\
22.11 \\
\end{array}$ & $\begin{array}{c}\text { PURGE 3 } \\
07.20 \\
\end{array}$ & $\begin{array}{l}\text { LIQUID } \\
\text { PROD }\end{array}$ \\
\hline $\mathbf{T}$ & $\mathbf{F}$ & 295.5 & 123.3 & 99.1 & 278.3 & 100.0 & 259.4 & 463.2 & 85.0 & 90.0 & 83.1 & 77.1 & 80.0 \\
\hline $\mathbf{P}$ & psig & 776.4 & 780.1 & 774.3 & 756.3 & 756.3 & 756.3 & 735.0 & 1.4 & 666.8 & 35.6 & 82.7 & 1.0 \\
\hline \multirow{24}{*}{$\begin{array}{l}\text { Comp } \\
\text { (mole\%) }\end{array}$} & $\mathrm{H} 2$ & 10.62 & 57.24 & 100.00 & 60.93 & 0.00 & 60.93 & 47.31 & 57.23 & 57.24 & 60.96 & 0.00 & 0.00 \\
\hline & co & 77.14 & 20.25 & 0.00 & 25.23 & 0.00 & 25.23 & 16.66 & 20.25 & 20.25 & 25.21 & 0.00 & 0.00 \\
\hline & N2 & 2.89 & 7.50 & 0.00 & 4.37 & 0.00 & 4.37 & 5.93 & 7.50 & 7.50 & 4.36 & 0.00 & 0.00 \\
\hline & $\mathrm{CH} 4$ & 0.00 & 0.00 & 0.00 & 0.00 & 0.00 & 0.00 & 0.00 & 0.00 & 0.00 & 0.00 & 0.00 & 0.00 \\
\hline & $\mathrm{CO} 2$ & 9.35 & 15.01 & 0.00 & 9.47 & 0.00 & 9.47 & 12.63 & 15.01 & 15.01 & 9.44 & 0.00 & 0.00 \\
\hline & DME & 0.00 & 0.00 & 0.00 & 0.00 & 0.00 & 0.00 & 0.00 & 0.00 & 0.00 & 0.00 & 0.00 & 0.00 \\
\hline & MeAc & 0.00 & 0.00 & 0.00 & 0.00 & 0.00 & 0.00 & 0.00 & 0.00 & 0.00 & 0.00 & 0.00 & 0.03 \\
\hline & EtAc & 0.00 & 0.00 & 0.00 & 0.00 & 0.00 & 0.00 & 0.00 & 0.00 & 0.00 & 0.00 & 0.00 & 0.00 \\
\hline & MeFm & 0.00 & 0.00 & 0.00 & 0.00 & 0.00 & 0.00 & 0.00 & 0.00 & 0.00 & 0.00 & 0.00 & 0.24 \\
\hline & $\mathrm{MeOH}$ & 0.00 & 0.00 & 0.00 & 0.00 & 0.00 & 0.00 & 16.65 & 0.00 & 0.00 & 0.00 & 0.00 & 97.05 \\
\hline & $\mathrm{H} 2 \mathrm{O}$ & 0.00 & 0.00 & 0.00 & 0.00 & 0.00 & 0.00 & 0.69 & 0.01 & 0.00 & 0.03 & 0.00 & 2.30 \\
\hline & Etoh & 0.00 & 0.00 & 0.00 & 0.00 & 0.00 & 0.00 & 0.03 & 0.00 & 0.00 & 0.00 & 0.00 & 0.24 \\
\hline & 1-Proh & 0.00 & 0.00 & 0.00 & 0.00 & 0.00 & 0.00 & 0.00 & 0.00 & 0.00 & 0.00 & 0.00 & 0.05 \\
\hline & iso-Proh & 0.00 & 0.00 & 0.00 & 0.00 & 0.00 & 0.00 & 0.00 & 0.00 & 0.00 & 0.00 & 0.00 & 0.00 \\
\hline & $\mathrm{IBOH}$ & 0.00 & 0.00 & 0.00 & 0.00 & 0.00 & 0.00 & 0.00 & 0.00 & 0.00 & 0.00 & 0.00 & 0.01 \\
\hline & 1-Buoh & 0.00 & 0.00 & 0.00 & 0.00 & 0.00 & 0.00 & 0.00 & 0.00 & 0.00 & 0.00 & 0.00 & 0.03 \\
\hline & 2-Buoh & 0.00 & 0.00 & 0.00 & 0.00 & 0.00 & 0.00 & 0.00 & 0.00 & 0.00 & 0.00 & 0.00 & 0.01 \\
\hline & 2-Methyl 1-Buoh & 0.00 & 0.00 & 0.00 & 0.00 & 0.00 & 0.00 & 0.00 & 0.00 & 0.00 & 0.00 & 0.00 & 0.00 \\
\hline & 1-Peoh & 0.00 & 0.00 & 0.00 & 0.00 & 0.00 & 0.00 & 0.00 & 0.00 & 0.00 & 0.00 & 0.00 & 0.01 \\
\hline & 2-Methyl 1-Peoh & 0.00 & 0.00 & 0.00 & 0.00 & 0.00 & 0.00 & 0.00 & 0.00 & 0.00 & 0.00 & 0.00 & 0.00 \\
\hline & 1-hexanol & 0.00 & 0.00 & 0.00 & 0.00 & 0.00 & 0.00 & 0.00 & 0.00 & 0.00 & 0.00 & 0.00 & 0.00 \\
\hline & 2-Methyl 1-Isobutyrate & 0.00 & 0.00 & 0.00 & 0.00 & 0.00 & 0.00 & 0.00 & 0.00 & 0.00 & 0.00 & 0.00 & 0.00 \\
\hline & others & 0.00 & 0.00 & 0.00 & 0.00 & 100.00 & 0.00 & 0.11 & 0.00 & 0.00 & 0.00 & 100.00 & 0.02 \\
\hline & TOTAL & 100.00 & 100.00 & 100.00 & 100.00 & 100.00 & 100.00 & 100.00 & 100.00 & 100.00 & 100.00 & 100.00 & 100.00 \\
\hline Mole Wt & lb/lb mole & 26.746 & 15.537 & 2.020 & 13.691 & 65.152 & 13.691 & 18.385 & 15.537 & 15.537 & 13.676 & 65.152 & 31.879 \\
\hline \multirow[t]{3}{*}{ Flow } & SCFH & 16032 & 40529 & 23882 & 80443 & 0 & 80443 & 59248 & 47174 & 6613 & 18 & 0 & 11575 \\
\hline & lb mole/hr & 41.46 & 104.82 & 61.77 & 208.05 & 0.00 & 208.05 & 153.24 & 122.01 & 17.10 & 0.05 & 0.00 & 29.94 \\
\hline & $\mathrm{lb} / \mathrm{hr}$ & 1109.0 & 1628.6 & 124.8 & 2848.4 & 0.0 & 2848.5 & 2817.3 & 1895.6 & 265.7 & 0.6 & 0.0 & 954.4 \\
\hline
\end{tabular}


Balance Period:

Start Date

End Date

Reaction Conditions

Temperature $\left({ }^{\circ} \mathrm{F}\right)$

Pressure (psig)

Space Velocity (sL/kg-hr)

$\mathrm{Vg}$ (inlet)

Performance Results

CO Conversion to $\mathrm{H} 2(\%)$

$\mathrm{CO}$ Conversion to $\mathrm{MeOH}(\%)$

Theoretical Conversion \% (2 CSTR)

Alcohol Production (Ton/day)
33.0

32.5

11.1

81.90

520.69

7092

1.18

Sample\#

Sample\#

Sample\#

10:00A

Sample\#

15:00A

Sample\#

Sample\#

Slurry Data

Catalyst Weight (lb oxide)

Slurry Conc. based on NDG (wt \%) $\quad 45.6$

Slurry Level (\%)

Gas Holdup based on NDG (vol \%) $\quad 50.4$

Atomic/Mass Balance ( $\%$ of reactor inlet)

$\begin{array}{lr}\mathrm{C} & 99.75 \\ \mathrm{H} & 99.51 \\ \mathrm{O} & 100.11 \\ \mathrm{~N} & 99.72 \\ & \\ \text { Total Mass } & 99.91\end{array}$

$\begin{array}{lllll}\text { Methanol } & 96.214 & 96.405 & 96.85 & 96.863\end{array}$

Ethanol

1-Propanol

iso-Propanol

1-Butanol

Liquild

2-Butanol

iso-Butanol

Analysis 2-Methyl-1-Butanol

(wt\%) 1-Pentanol

2-Methyl-1-Pentanol

1-Hexanol

2-Methyl-1-Isobutyrate

Methyl Acetate

Ethyl Acetate

Methyl Formate

DME

$\mathrm{CO} 2$

Water

Oil

Total
99.75

.51

99.91 
RUN NO: $\quad$ AF-R14.3 (Rev. 1) TITLE: LPMEOH over Alternate Catalyst with KIngsport Syngas : SV=7,000

\begin{tabular}{|c|c|c|c|c|c|c|c|c|c|c|c|c|c|}
\hline & & $\begin{array}{c}\text { FRESH } \\
\text { MAKE-UP }\end{array}$ & RECYCLE & $\begin{array}{c}\text { HP H2 } \\
\text { MAKEUP }\end{array}$ & $\begin{array}{c}\text { DRY } \\
\text { FEED }\end{array}$ & $\begin{array}{c}\text { ALCOHOL } \\
\text { INJECT. }\end{array}$ & $\begin{array}{c}\text { REACT } \\
\text { FEED } \\
\end{array}$ & $\begin{array}{c}\text { REACT } \\
\text { EFFL }\end{array}$ & $\begin{array}{c}22.10 \\
\text { VAPOR }\end{array}$ & $\begin{array}{l}\text { PURGE } 1 \\
\text { PIC-201 } \\
\end{array}$ & $\begin{array}{c}\text { PURGE } 2 \\
22.11 \\
\end{array}$ & $\begin{array}{c}\text { PURGE } 3 \\
07.20 \\
\end{array}$ & $\begin{array}{l}\text { LIQUID } \\
\text { PROD }\end{array}$ \\
\hline $\mathbf{T}$ & $\mathbf{F}$ & 262.0 & 158.0 & 99.9 & 341.8 & 100.0 & 324.9 & 474.9 & 85.4 & 94.7 & 84.3 & 76.0 & 80.0 \\
\hline $\mathbf{P}$ & psig & 610.1 & 631.3 & 814.2 & 571.5 & 571.5 & 571.5 & 520.7 & 1.3 & 432.3 & 34.4 & 82.8 & 1.0 \\
\hline \multirow{24}{*}{$\begin{array}{l}\text { Comp } \\
\text { (mole\%) }\end{array}$} & $\mathrm{H} 2$ & 12.85 & 58.28 & 100.00 & 60.21 & 0.00 & 60.21 & 51.03 & 58.26 & 58.28 & 15.69 & 0.00 & 0.00 \\
\hline & $\mathrm{Co}$ & 80.53 & 22.01 & 0.00 & 23.96 & 0.00 & 23.96 & 19.56 & 22.01 & 22.01 & 11.22 & 0.00 & 0.00 \\
\hline & N2 & 0.48 & 7.07 & 0.00 & 5.49 & 0.00 & 5.49 & 6.69 & 7.07 & 7.07 & 2.76 & 0.00 & 0.00 \\
\hline & $\mathrm{CH}_{4}$ & 0.00 & 0.00 & 0.00 & 0.00 & 0.00 & 0.00 & 0.00 & 0.00 & 0.00 & 0.00 & 0.00 & 0.00 \\
\hline & $\mathrm{CO} 2$ & 6.13 & 12.64 & 0.00 & 10.34 & 0.00 & 10.34 & 11.43 & 12.63 & 12.64 & 43.27 & 0.00 & 0.00 \\
\hline & DME & 0.00 & 0.00 & 0.00 & 0.00 & 0.00 & 0.00 & 0.00 & 0.00 & 0.00 & 0.00 & 0.00 & 0.00 \\
\hline & MeAc & 0.00 & 0.00 & 0.00 & 0.00 & 0.00 & 0.00 & 0.00 & 0.00 & 0.00 & 0.00 & 0.00 & 0.02 \\
\hline & EtAc & 0.00 & 0.00 & 0.00 & 0.00 & 0.00 & 0.00 & 0.00 & 0.00 & 0.00 & 0.00 & 0.00 & 0.00 \\
\hline & MeFm & 0.00 & 0.00 & 0.00 & 0.00 & 0.00 & 0.00 & 0.00 & 0.00 & 0.00 & 0.00 & 0.00 & 0.12 \\
\hline & $\mathrm{MeOH}$ & 0.00 & 0.00 & 0.00 & 0.00 & 0.00 & 0.00 & 9.63 & 0.00 & 0.00 & 27.02 & 0.00 & 94.97 \\
\hline & $\mathrm{H} 2 \mathrm{O}$ & 0.00 & 0.00 & 0.00 & 0.00 & 0.00 & 0.00 & 1.60 & 0.03 & 0.00 & 0.06 & 0.00 & 4.65 \\
\hline & Etoh & 0.00 & 0.00 & 0.00 & 0.00 & 0.00 & 0.00 & 0.02 & 0.00 & 0.00 & 0.00 & 0.00 & 0.16 \\
\hline & 1-Proh & 0.00 & 0.00 & 0.00 & 0.00 & 0.00 & 0.00 & 0.00 & 0.00 & 0.00 & 0.00 & 0.00 & 0.03 \\
\hline & iso-Proh & 0.00 & 0.00 & 0.00 & 0.00 & 0.00 & 0.00 & 0.00 & 0.00 & 0.00 & 0.00 & 0.00 & 0.00 \\
\hline & IBOH & 0.00 & 0.00 & 0.00 & 0.00 & 0.00 & 0.00 & 0.00 & 0.00 & 0.00 & 0.00 & 0.00 & 0.00 \\
\hline & 1-Buoh & 0.00 & 0.00 & 0.00 & 0.00 & 0.00 & 0.00 & 0.00 & 0.00 & 0.00 & 0.00 & 0.00 & 0.02 \\
\hline & 2-Buoh & 0.00 & 0.00 & 0.00 & 0.00 & 0.00 & 0.00 & 0.00 & 0.00 & 0.00 & 0.00 & 0.00 & 0.01 \\
\hline & 2-Methyl 1-Buoh & 0.00 & 0.00 & 0.00 & 0.00 & 0.00 & 0.00 & 0.00 & 0.00 & 0.00 & 0.00 & 0.00 & 0.00 \\
\hline & 1-Peoh & 0.00 & 0.00 & 0.00 & 0.00 & 0.00 & 0.00 & 0.00 & 0.00 & 0.00 & 0.00 & 0.00 & 0.00 \\
\hline & 2-Methyl 1-Peoh & 0.00 & 0.00 & 0.00 & 0.00 & 0.00 & 0.00 & 0.00 & 0.00 & 0.00 & 0.00 & 0.00 & 0.00 \\
\hline & 1-hexanol & 0.00 & 0.00 & 0.00 & 0.00 & 0.00 & 0.00 & 0.00 & 0.00 & 0.00 & 0.00 & 0.00 & 0.00 \\
\hline & 2-Methyl 1-Isobutyrate & 0.00 & 0.00 & 0.00 & 0.00 & 0.00 & 0.00 & 0.00 & 0.00 & 0.00 & 0.00 & 0.00 & 0.00 \\
\hline & others & 0.00 & 0.00 & 0.00 & 0.00 & 100.00 & 0.00 & 0.04 & 0.00 & 0.00 & 0.00 & 100.00 & 0.02 \\
\hline & TOTAL & 100.00 & 100.00 & 100.00 & 100.00 & 100.00 & 100.00 & 100.00 & 100.00 & 100.00 & 100.00 & 100.00 & 100.00 \\
\hline Mole Wt & lb/lb mole & 25.650 & 14.885 & 2.020 & 14.015 & 69.384 & 14.015 & 16.823 & 14.886 & 14.885 & 31.939 & 69.384 & 31.481 \\
\hline \multirow[t]{3}{*}{ Flow } & SCFH & 12598 & 110159 & 18933 & 141690 & 0 & 141690 & 116379 & 110385 & 92 & 20 & 0 & 10919 \\
\hline & Ib mole/hr & 32.58 & 284.91 & 48.97 & 366.46 & 0.00 & 366.46 & 301.00 & 285.49 & 0.24 & 0.05 & 0.00 & 28.24 \\
\hline & $\mathrm{lb} / \mathrm{hr}$ & 835.8 & 4240.9 & 98.9 & 5136.1 & 0.0 & 5136.1 & 5063.7 & 4249.8 & 3.5 & 1.6 & 0.0 & 889.1 \\
\hline
\end{tabular}


RUN NO: AF-R14.4 (Rev. 1)

Balance Period:

Start Date

End Date

Reaction Conditions

Temperature $\left({ }^{\circ} \mathrm{F}\right)$

Pressure (psig)

Space Velocity (sL/kg-hr)

$\mathrm{Vg}$ (inlet)

Performance Results

CO Conversion to $\mathrm{H} 2(\%)$

$\mathrm{CO}$ Conversion to $\mathrm{MeOH}(\%)$

Theoretical Conversion \% (2 CSTR)

Alcohol Production (Ton/day)
TITLE: LPMEOH over Alternate Catalyst with Texaco Syngas : SV=4,000
6/19/95 23:00

$6 / 21 / 95$

7:00

482.68

750.92

4062

0.47

$-0.4$

17.5

17.7

7.2
Time From Start of Run (hr)

$\begin{array}{ll}\text { Start } & 156.00 \\ \text { End } & 188.00\end{array}$

Slurry Data

Catalyst Weight (lb oxide)

Slurry Conc. based on NDG (wt \%)

Slurry Level (\%) 94

Gas Holdup based on NDG (vol \%) $\quad 42.9$

Atomic/Mass Balance ( $\%$ of reactor inlet)

$\begin{array}{lc}\mathrm{C} & 101.36 \\ \mathrm{H} & 95.70 \\ \mathrm{O} & 101.94 \\ \mathrm{~N} & 100.34 \\ & \\ \text { Total Mass } & 101.50\end{array}$

$\begin{array}{lrrrrr}\text { Methanol } & 92.04 & 91.867 & 93.226 & 92.147 & 92.826 \\ \text { Ethanol } & 1.585 & 1.564 & 1.495 & 1.521 & 1.544 \\ \text { 1-Propanol } & 0.489 & 0.492 & 0.458 & 0.478 & 0.477 \\ \text { iso-Propanol } & 0.02 & 0.022 & 0.027 & 0.04 & 0.03 \\ \text { 1-Butanol } & 0.24 & 0.268 & 0.227 & 0.25 & 0.284 \\ \text { 2-Butanol } & 0.092 & 0.09 & 0.088 & 0.086 & 0.08 \\ \text { iso-Butanol } & 0.108 & 0.109 & 0.102 & 0.103 & 0.12 \\ \text { 2-Methyl-1-Butanol } & 0 & 0 & 0 & 0 & 0 \\ \text { 1-Pentanol } & 0.138 & 0.141 & 0.131 & 0.137 & 0.139 \\ \text { 2-Methyl-1-Pentanol } & 0 & 0 & 0 & 0 & 0 \\ \text { 1-Hexanol } & 0.073 & 0.074 & 0.074 & 0.065 & 0.071 \\ \text { 2-Methyl-1-Isobutyrate } & 0 & 0 & 0 & 0 & 0 \\ \text { Methyl Acetate } & 0.491 & 0.501 & 0.473 & 0.497 & 0.488 \\ \text { Ethyl Acetate } & 0 & 0 & 0 & 0 & 0 \\ \text { Methyl Formate } & 1.13 & 1.184 & 1.182 & 1.18 & 1.187 \\ \text { DME } & 0 & 0 & 0 & 0 & 0 \\ \text { CO2 } & 0 & 0 & 0 & 0 & 0 \\ \text { Water } & 0.331 & 0.312 & 0.333 & 0.311 & 0.314 \\ \text { Oil } & 0.2 & 0.2 & 0.2 & 0.2 & 0.2 \\ \text { Total } & 96.937 & 96.824 & 98.016 & 97.015 & 97.76\end{array}$


RUN NO: AF-R14.4 (Rev. 1) TITLE: LPMEOH over Alternate Catalyst with Texaco Syngas : SV=4,000

\begin{tabular}{|c|c|c|c|c|c|c|c|c|c|c|c|c|c|}
\hline & & $\begin{array}{c}\text { FRESH } \\
\text { MAKE-UP } \\
\end{array}$ & RECYCLE & $\begin{array}{c}\text { HP H2 } \\
\text { MAKEUP }\end{array}$ & $\begin{array}{c}\text { DRY } \\
\text { FEED } \\
\end{array}$ & $\begin{array}{c}\text { ALCOHOL } \\
\text { INJECT. }\end{array}$ & $\begin{array}{l}\text { REACT } \\
\text { FEED } \\
\end{array}$ & $\begin{array}{c}\text { REACT } \\
\text { EFFL }\end{array}$ & $\begin{array}{c}22.10 \\
\text { VAPOR } \\
\end{array}$ & $\begin{array}{l}\text { PURGE } 1 \\
\text { PIC-201 }\end{array}$ & $\begin{array}{c}\text { PURGE } 2 \\
22.11 \\
\end{array}$ & $\begin{array}{c}\text { PURGE 3 } \\
07.20 \\
\end{array}$ & $\begin{array}{c}\text { LIQUID } \\
\text { PROD } \\
\end{array}$ \\
\hline $\mathbf{T}$ & $\mathbf{F}$ & 286.7 & 128.0 & 91.4 & 325.6 & 100.0 & 305.6 & 466.3 & 86.0 & 89.3 & 82.9 & 78.6 & 80.0 \\
\hline $\mathbf{P}$ & psig & 803.0 & 860.6 & 814.9 & 775.8 & 775.8 & 775.8 & 750.9 & 1.5 & 723.9 & 34.4 & 82.1 & 1.0 \\
\hline \multirow{24}{*}{$\begin{array}{l}\text { Comp } \\
\text { (mole\%) }\end{array}$} & $\mathrm{H} 2$ & 59.85 & 23.83 & 100.00 & 35.07 & 0.00 & 35.07 & 20.00 & 23.83 & 23.83 & 4.15 & 0.00 & 0.00 \\
\hline & $\mathrm{CO}$ & 37.79 & 56.96 & 0.00 & 50.85 & 0.00 & 50.85 & 50.88 & 56.96 & 56.96 & 21.64 & 0.00 & 0.00 \\
\hline & N2 & 0.22 & 1.95 & 0.00 & 1.39 & 0.00 & 1.39 & 1.72 & 1.95 & 1.95 & 0.58 & 0.00 & 0.00 \\
\hline & CH4 & 0.00 & 0.00 & 0.00 & 0.00 & 0.00 & 0.00 & 0.00 & 0.00 & 0.00 & 0.00 & 0.00 & 0.00 \\
\hline & $\mathrm{CO} 2$ & 2.14 & 17.25 & 0.00 & 12.69 & 0.00 & 12.69 & 15.84 & 17.25 & 17.25 & 61.72 & 0.00 & 0.00 \\
\hline & DME & 0.00 & 0.00 & 0.00 & 0.00 & 0.00 & 0.00 & 0.00 & 0.00 & 0.00 & 0.00 & 0.00 & 0.00 \\
\hline & MeAc & 0.00 & 0.00 & 0.00 & 0.00 & 0.00 & 0.00 & 0.00 & 0.00 & 0.00 & 0.00 & 0.00 & 0.22 \\
\hline & EtAc & 0.00 & 0.00 & 0.00 & 0.00 & 0.00 & 0.00 & 0.00 & 0.00 & 0.00 & 0.00 & 0.00 & 0.00 \\
\hline & MeFm & 0.00 & 0.00 & 0.00 & 0.00 & 0.00 & 0.00 & 0.00 & 0.00 & 0.00 & 0.00 & 0.00 & 0.66 \\
\hline & $\mathrm{MeOH}$ & 0.00 & 0.00 & 0.00 & 0.00 & 0.00 & 0.00 & 11.01 & 0.00 & 0.00 & 11.91 & 0.00 & 96.82 \\
\hline & $\mathrm{H} 2 \mathrm{O}$ & 0.00 & 0.00 & 0.00 & 0.00 & 0.00 & 0.00 & 0.25 & 0.00 & 0.00 & 0.01 & 0.00 & 0.60 \\
\hline & Etoh & 0.00 & 0.00 & 0.00 & 0.00 & 0.00 & 0.00 & 0.00 & 0.00 & 0.00 & 0.00 & 0.00 & 1.12 \\
\hline & 1-Proh & 0.00 & 0.00 & 0.00 & 0.00 & 0.00 & 0.00 & 0.00 & 0.00 & 0.00 & 0.00 & 0.00 & 0.27 \\
\hline & iso-Proh & 0.00 & 0.00 & 0.00 & 0.00 & 0.00 & 0.00 & 0.00 & 0.00 & 0.00 & 0.00 & 0.00 & 0.02 \\
\hline & $\mathrm{IBOH}$ & 0.00 & 0.00 & 0.00 & 0.00 & 0.00 & 0.00 & 0.00 & 0.00 & 0.00 & 0.00 & 0.00 & 0.05 \\
\hline & 1-Buoh & 0.00 & 0.00 & 0.00 & 0.00 & 0.00 & 0.00 & 0.00 & 0.00 & 0.00 & 0.00 & 0.00 & 0.11 \\
\hline & 2-Buoh & 0.00 & 0.00 & 0.00 & 0.00 & 0.00 & 0.00 & 0.00 & 0.00 & 0.00 & 0.00 & 0.00 & 0.04 \\
\hline & 2-Methyl 1-Buoh & 0.00 & 0.00 & 0.00 & 0.00 & 0.00 & 0.00 & 0.00 & 0.00 & 0.00 & 0.00 & 0.00 & 0.00 \\
\hline & 1-Peoh & 0.00 & 0.00 & 0.00 & 0.00 & 0.00 & 0.00 & 0.00 & 0.00 & 0.00 & 0.00 & 0.00 & 0.05 \\
\hline & 2-Methyl 1-Peoh & 0.00 & 0.00 & 0.00 & 0.00 & 0.00 & 0.00 & 0.00 & 0.00 & 0.00 & 0.00 & 0.00 & 0.00 \\
\hline & 1-hexanol & 0.00 & 0.00 & 0.00 & 0.00 & 0.00 & 0.00 & 0.00 & 0.00 & 0.00 & 0.00 & 0.00 & 0.02 \\
\hline & 2-Methyl 1-Isobutyrate & 0.00 & 0.00 & 0.00 & 0.00 & 0.00 & 0.00 & 0.00 & 0.00 & 0.00 & 0.00 & 0.00 & 0.00 \\
\hline & others & 0.00 & 0.00 & 0.00 & 0.00 & 100.00 & 0.00 & 0.29 & 0.00 & 0.00 & 0.00 & 100.00 & 0.02 \\
\hline & TOTAL & 100.00 & 100.00 & 100.00 & 100.00 & 100.00 & 100.00 & 100.00 & 100.00 & 100.00 & 100.00 & 100.00 & 100.00 \\
\hline Mole Wt & lb/lb mole & 12.796 & 24.576 & 2.020 & 20.925 & 59.319 & 20.925 & 25.857 & 24.576 & 24.576 & 37.287 & 59.319 & 32.608 \\
\hline \multirow[t]{3}{*}{ Flow } & SCFH & 28422 & 52729 & 0 & 81151 & 0 & 81151 & 65591 & 57481 & 4290 & 70 & 0 & 7892 \\
\hline & lb mole/hr & 73.51 & 136.38 & 0.00 & 209.88 & 0.00 & 209.88 & 169.64 & 148.67 & 11.09 & 0.18 & 0.00 & 20.41 \\
\hline & $\mathbf{l b} / \mathbf{h r}$ & 940.6 & 3351.5 & 0.0 & 4391.8 & 0.0 & 4391.8 & 4386.4 & 3653.6 & 272.7 & 6.7 & 0.0 & 665.6 \\
\hline
\end{tabular}


RUN NO: AF-R14.5 (Rev. 1)

TITLE: LPMEOH over Alternate Catalyst with Texaco Syngas : SV=7,000

Balance Period

Start Date

End Date

Reaction Conditions

Temperature $\left({ }^{\circ} \mathrm{F}\right)$

Pressure (psig)

Space Velocity (sL/kg-hr)

$\mathrm{Vg}$ (inlet)

Performance Results

Co Conversion to $\mathrm{H} 2(\%)$

$\mathrm{CO}$ Conversion to $\mathrm{MeOH}(\%)$

Theoretical Conversion \% (2 CSTR)

Alcohol Production (Ton/day)

15.9

16.8

11.5

81.72

751.48

7164

0.83

.3

Sample\#

13:30 A

Sample\#
18:00 A

Sample\#

00:05A

Sample\#

06:00A

Sample\#

Sample\#

Methanol

Ethanol

1-Propanol

iso-Propanol

1-Butanol

Liquid

Product

Analysis

(wt\%)
2-Butanol

2-Methyl-1-Butanol

1-Pentanol

2-Methyl-1-Pentanol

1-Hexanol

2-Methyl-1-Isobutyrate

Methyl Acetate

Ethyl Acetate

Methyl Formate

DME

$\mathrm{CO} 2$

Water

Oil

Total

\begin{tabular}{rrrr}
95.237 & 95.747 & 96.088 & 95.457 \\
0.983 & 0.842 & 0.859 & 0.861 \\
0.29 & 0.242 & 0.247 & 0.241 \\
0.015 & 0.026 & 0.02 & 0.011 \\
0.167 & 0.132 & 0.133 & 0.139 \\
0.051 & 0.058 & 0.057 & 0.056 \\
0.052 & 0.046 & 0.047 & 0.045 \\
0 & 0 & 0 & 0 \\
0.083 & 0.051 & 0.074 & 0.074 \\
0 & 0 & 0 & 0 \\
0 & 0.03 & 0.04 & 0.039 \\
0 & 0 & 0 & 0 \\
0.211 & 0.188 & 0.188 & 0.184 \\
0 & 0 & 0 & 0 \\
0.966 & 0.911 & 0.924 & 0.941 \\
0 & 0 & 0 & 0 \\
0 & 0 & 0 & 0 \\
0.395 & 0.485 & 0.462 & 0.45 \\
0.2 & 0.2 & 0.2 & 0.2 \\
\hline 98.65 & 98.958 & 99.339 & 98.698
\end{tabular}

191.00

213.00

Slurry Data

Catalyst Weight (lb oxide) 1158

Slurry Conc. based on NDG (wt \%) $\quad 46.5$

Slurry Level (\%) 94

Gas Holdup based on NDG (vol \%) $\quad 50.8$

Atomic/Mass Balance (\% of reactor inlet)

C

$\mathrm{H}$

00.19

98.56

100.47

99.67

Total Mass

100.30 
RUN NO: AF-R14.5 (Rev. 1) TITLE: LPMEOH over Alternate Catalyst with Texaco Syngas : SV=7,000

\begin{tabular}{|c|c|c|c|c|c|c|c|c|c|c|c|c|c|}
\hline & & $\begin{array}{c}\text { FRESH } \\
\text { MAKE-UP }\end{array}$ & RECYCLE & $\begin{array}{c}\text { HP H2 } \\
\text { MAKEUP }\end{array}$ & $\begin{array}{c}\text { DRY } \\
\text { FEED } \\
\end{array}$ & $\begin{array}{c}\text { ALCOHOL } \\
\text { INJECT. }\end{array}$ & $\begin{array}{c}\text { REACT } \\
\text { FEED } \\
\end{array}$ & $\begin{array}{c}\text { REACT } \\
\text { EFFL } \\
\end{array}$ & $\begin{array}{c}22.10 \\
\text { VAPOR } \\
\end{array}$ & $\begin{array}{c}\text { PURGE } 1 \\
\text { PIC-201 } \\
\end{array}$ & $\begin{array}{c}\text { PURGE } 2 \\
22.11 \\
\end{array}$ & $\begin{array}{c}\text { PURGE } 3 \\
07.20 \\
\end{array}$ & $\begin{array}{c}\text { LIQUID } \\
\text { PROD } \\
\end{array}$ \\
\hline $\mathbf{T}$ & $\mathbf{F}$ & 311.2 & 140.9 & 102.9 & 334.9 & 100.0 & 318.0 & 470.0 & 91.5 & 94.9 & 87.9 & 83.0 & 80.0 \\
\hline $\mathbf{P}$ & psig & 850.9 & 873.0 & 814.7 & 803.6 & 803.6 & 803.6 & 751.5 & 0.9 & 668.6 & 34.7 & 81.5 & 1.0 \\
\hline \multirow{24}{*}{$\begin{array}{l}\text { Comp } \\
\text { (mole } \%)\end{array}$} & H2 & 8.07 & 24.92 & 100.00 & 35.40 & 0.00 & 35.40 & 22.31 & 24.92 & 24.92 & 5.03 & 0.00 & 0.00 \\
\hline & Co & 83.36 & 56.82 & 0.00 & 50.87 & 0.00 & 50.87 & 50.95 & 56.82 & 56.82 & 24.14 & 0.00 & 0.00 \\
\hline & N2 & 0.53 & 1.38 & 0.00 & 1.02 & 0.00 & 1.02 & 1.23 & 1.38 & 1.38 & 0.43 & 0.00 & 0.00 \\
\hline & $\mathrm{CH} 4$ & 0.00 & 0.00 & 0.00 & 0.00 & 0.00 & 0.00 & 0.00 & 0.00 & 0.00 & 0.00 & 0.00 & 0.00 \\
\hline & $\mathrm{CO} 2$ & 8.05 & 16.88 & 0.00 & 12.72 & 0.00 & 12.72 & 15.38 & 16.88 & 16.88 & 62.44 & 0.00 & 0.00 \\
\hline & DME & 0.00 & 0.00 & 0.00 & 0.00 & 0.00 & 0.00 & 0.00 & 0.00 & 0.00 & 0.00 & 0.00 & 0.00 \\
\hline & $\mathrm{MeAc}$ & 0.00 & 0.00 & 0.00 & 0.00 & 0.00 & 0.00 & 0.00 & 0.00 & 0.00 & 0.00 & 0.00 & 0.09 \\
\hline & EtAc & 0.00 & 0.00 & 0.00 & 0.00 & 0.00 & 0.00 & 0.00 & 0.00 & 0.00 & 0.00 & 0.00 & 0.00 \\
\hline & MeFm & 0.00 & 0.00 & 0.00 & 0.00 & 0.00 & 0.00 & 0.00 & 0.00 & 0.00 & 0.00 & 0.00 & 0.51 \\
\hline & $\mathrm{MeOH}$ & 0.00 & 0.00 & 0.00 & 0.00 & 0.00 & 0.00 & 9.75 & 0.00 & 0.00 & 7.95 & 0.00 & 97.65 \\
\hline & $\mathrm{H} 2 \mathrm{O}$ & 0.00 & 0.00 & 0.00 & 0.00 & 0.00 & 0.00 & 0.18 & 0.01 & 0.00 & 0.01 & 0.00 & 0.81 \\
\hline & Etoh & 0.00 & 0.00 & 0.00 & 0.00 & 0.00 & 0.00 & 0.05 & 0.00 & 0.00 & 0.00 & 0.00 & 0.63 \\
\hline & 1-Proh & 0.00 & 0.00 & 0.00 & 0.00 & 0.00 & 0.00 & 0.00 & 0.00 & 0.00 & 0.00 & 0.00 & 0.14 \\
\hline & iso-Proh & 0.00 & 0.00 & 0.00 & 0.00 & 0.00 & 0.00 & 0.00 & 0.00 & 0.00 & 0.00 & 0.00 & 0.01 \\
\hline & IBOH & 0.00 & 0.00 & 0.00 & 0.00 & 0.00 & 0.00 & 0.00 & 0.00 & 0.00 & 0.00 & 0.00 & 0.02 \\
\hline & 1-Buoh & 0.00 & 0.00 & 0.00 & 0.00 & 0.00 & 0.00 & 0.00 & 0.00 & 0.00 & 0.00 & 0.00 & 0.06 \\
\hline & 2-Buoh & 0.00 & 0.00 & 0.00 & 0.00 & 0.00 & 0.00 & 0.00 & 0.00 & 0.00 & 0.00 & 0.00 & 0.02 \\
\hline & 2-Methyl 1-Buoh & 0.00 & 0.00 & 0.00 & 0.00 & 0.00 & 0.00 & 0.00 & 0.00 & 0.00 & 0.00 & 0.00 & 0.00 \\
\hline & 1-Peoh & 0.00 & 0.00 & 0.00 & 0.00 & 0.00 & 0.00 & 0.00 & 0.00 & 0.00 & 0.00 & 0.00 & 0.03 \\
\hline & 2-Methyl 1-Peoh & 0.00 & 0.00 & 0.00 & 0.00 & 0.00 & 0.00 & 0.00 & 0.00 & 0.00 & 0.00 & 0.00 & 0.00 \\
\hline & 1-hexanol & 0.00 & 0.00 & 0.00 & 0.00 & 0.00 & 0.00 & 0.00 & 0.00 & 0.00 & 0.00 & 0.00 & 0.01 \\
\hline & 2-Methyl 1-Isobutyrate & 0.00 & 0.00 & 0.00 & 0.00 & 0.00 & 0.00 & 0.00 & 0.00 & 0.00 & 0.00 & 0.00 & 0.00 \\
\hline & others & 0.00 & 0.00 & 0.00 & 0.00 & 100.00 & 0.00 & 0.15 & 0.00 & 0.00 & 0.00 & 100.00 & 0.02 \\
\hline & TOTAL & 100.00 & 100.00 & 100.00 & 100.00 & 100.00 & 100.00 & 100.00 & 100.00 & 100.00 & 100.00 & 100.00 & 100.00 \\
\hline Mole Wt & $\mathrm{lb} / \mathrm{lb}$ mole & 27.200 & 24.233 & 2.020 & 20.845 & 60.222 & 20.845 & 25.106 & 24.233 & 24.233 & 37.012 & 60.222 & 32.307 \\
\hline \multirow[t]{3}{*}{ Flow } & SCFH & 20349 & 99279 & 23493 & 143120 & 0 & 143121 & 118683 & 106100 & 6838 & 52 & 0 & 12424 \\
\hline & lb mole/hr & 52.63 & 256.77 & 60.76 & 370.16 & 0.00 & 370.16 & 306.95 & 274.41 & 17.69 & 0.13 & 0.00 & 32.13 \\
\hline & $\mathrm{lb} / \mathrm{hr}$ & 1431.5 & 6222.4 & 122.7 & 7716.1 & 0.0 & 7716.1 & 7706.5 & 6649.8 & 428.6 & 4.9 & 0.0 & 1038.1 \\
\hline
\end{tabular}




\section{APPENDIX F}

Residual Oil Analysis of Methanol Liquid 
To: Bharat Bhatt

From: Dean Chin-Fatt

Date: 5 July 1995
Dept./Loc.: Proc. Eng. / A12A3

Dept./Ext.: CRSD-ATC R3204/X3666

Subject: Residual Oil Analysis of Liquid Phase Methanol Reaction Product

Sample: See Table

cc: CS File; P.J. Clark, A.J. Di Gioia, LB File

\section{SUMMARY}

Thirteen samples of methanol (MeOH) reaction product from the Alternative Fuels Development Unit in LaPorte, TX were submitted for analysis. The methanol samples were analyzed for residual oil content using a method developed at the plant. The weight percent oil in each of the methanol samples are listed in the table below.

\begin{tabular}{|c|c|c|}
\hline DATE & TIME & Wt. \% Oil \\
\hline 5 June & 0625 & 0.21 \\
5 June & 1500 & 0.21 \\
5 June & 1545 & 0.18 \\
6 June & 0000 & 0.20 \\
6 June & 1145 & 0.17 \\
7 June & 1700 & 0.13 \\
8 June & 0300 & 0.19 \\
8 June & 1100 & 0.14 \\
8 June & 1930 & 0.24 \\
9 June & 0600 & 0.18 \\
10 June & 1815 & 0.10 \\
10 June & 0515 & 0.09 \\
11 June & 0220 & 0.10 \\
\hline
\end{tabular}

\section{PROBLEM DEFINITION}

The composition of the methanol produced during the June 1995 methanol run is monitored to determine mass balance data for the Liquid Phase Methanol Process. The bulk composition of the methanol samples were determined by gas chromatographic analysis at the LaPorte facility during the run. However, this gas chromatographic method is not capable of determining the residual oil content of the samples. The samples were submitted for analysis for residual oil to determine the full composition.

Request No.: 031263

Charge No.: $\quad$ ATTALTF22

Notebook No.: 11664-19

Data Captured: 30 June, 1995

Data Reported: 30 June, 1995
CS File No.:

Analyst:

Sample Received:

Data Analyzed:

File name:
1829

DAC

29 June, 1995

30 June, 1995

d:IWTNWORDVREPORT 1829 bhat.DOC 
Residual oil content of the methanol samples were determined by weighing $25 \mathrm{ml}$. of each sample into vial of known weight. The vials were then placed in a nitrogen purged oven at $80^{\circ} \mathrm{C}$, over night, to allow the methanol and other volatile components to evaporate. Any residual left after eight hours in the oven is assumed to be oil. The vials are then weighed again to determine the weight of any residue. The weight percent oil is determined by dividing the weight of the residue by the weight of the $25 \mathrm{ml}$ of methanol multiplied by 100 . 


\section{APPENDIX G}

Characterization of Slurry Phase Flow in the LaPorte AFDU using DP Measurements 


\title{
ADDENDUM TO DOE REPORT
}

\section{Characterization of Slurry-Phase Flow in the LaPorte Alternative Fuels Development Unit (AFDU) using Differential Pressure Measurements*}

\author{
Kim A. Shollenberger and Timothy J. O'Hern \\ Sandia National Laboratories, Albuquerque, NM
}

\section{EXECUTIVE SUMMARY}

A methanol production run was performed at the LaPorte Alternative Fuels Development Unit (AFDU), a pilot scale slurry-phase bubble-column reactor in LaPorte, Texas, owned by the DOE and operated by Air Products and Chemicals, Inc. Slurry-phase bubble-column reactors are used extensively by chemical manufacturers to perform a wide variety of gas/liquid/solid reactions such as oxidation, hydrogenation, chlorination, aerobic fermentation and coal liquefaction (Shah and Deckwer, 1983). Differential pressure taps were added to the AFDU by Air Products prior to the run to allow measurement of average gas holdups along the column. The differential pressure technique was being tested for suitability in making gas holdup measurements for three-phase mixtures in columns too large to accommodate the gamma densitometer diagnostic currently used on the AFDU. Sandia contributed to this effort by providing a portable high-speed data acquisition system to monitor real-time pressures on site and by performing data analysis on the differential pressure data to determine gas holdup values. Validation of the technique was successfully completed and mean gas holdups up to $47 \%$ were measured. In addition, statistical analysis of the fluctuations in the pressure data confirmed that the column is generally operating in the churnturbulent regime with up to $2 \%$ fluctuations in the gas holdup. Finally, differential pressures were measured during three Dynamic Gas Disengagement, or quick shutdown, experiments to estimate mean bubble diameters.

\section{INTRODUCTION}

The LaPorte AFDU, shown schematically in Figure 1, is a slurry-phase bubble column reactor. It is a tall cylindrical vessel, 18 in. $(0.457 \mathrm{~m})$ in diameter and $50 \mathrm{ft} .(15.24 \mathrm{~m})$ high, that contains a bundle of tubes which serves as an internal heat exchanger. During methanol production the column is filled with a slurry-phase mixture of an organic liquid and solid metallic oxide catalyst into which a gas mixture is injected at the bottom of the column. The gases adsorb into the liquid and react at catalytic sites on the solids to produce methanol and other hydrocarbon products which are continuously removed as a mixture of gases from the top of the vessel. Both temperature and pressure are controlled to optimize product distribution. The driving force for liquid recirculation is the gas rising through the liquid. A slurry-phase bubble column is used for this process because the organic liquid serves as an excellent heat sink for the highly exothermic reaction. The LaPorte AFDU can also be used for the Fischer-Tropsch reaction, where the liquid medium is molten wax and the product is additional liquid wax, which is continuously removed.

Drakeol 10, a light-weight mineral oil, was used as the organic liquid for the methanol production run reported here. At $482{ }^{\circ} \mathrm{F}\left(250^{\circ} \mathrm{C}\right)$ its dynamic viscosity is $0.863 \mathrm{cSt}$ and its density is

* Sandia is a multiprogram laboratory operated by Sandia Corporation, a Lockheed Martin Company, for the United States Department of Energy under Contract DE-ACO4-94AL85000. 
$701.7 \mathrm{~kg} / \mathrm{m}^{3}$. Two commercially available catalysts (which we label catalyst A and catalyst B) and two gas mixtures (Texaco and Kingsport) were tested. Both catalysts are a combination of copper oxide, zinc oxide, and alumina with densities of $5.73 \mathrm{~g} / \mathrm{cm}^{3}$ and $4.88 \mathrm{~g} / \mathrm{cm}^{3}$ and reduction factors in weight $(\phi)$ after oxidation of 0.750 and 0.794 for catalyst $A$ and $B$, respectively. Catalyst loadings $\omega_{S}=\left(m_{S} / \phi\right) /\left(m_{S}+m_{L}\right)$ for catalyst A ranged from $43.0 \%$ to $49.4 \%$ giving a volume fraction of solids in the slurry of $5.5 \%$ to $6.7 \%$. Loadings for catalyst B ranged from $38.9 \%$ to $44.9 \%$ giving a volume fraction of solids in the slurry of $6.0 \%$ to $7.4 \%$. The main components for the two gas mixtures used are as follows: Texaco is $34.7 \% \mathrm{H}_{2}, 50.6 \% \mathrm{CO}, 1.0 \% \mathrm{~N}_{2}$ and $12.9 \% \mathrm{CO}_{2}$ giving a molar mass of $20.81 \mathrm{~kg} / \mathrm{kg}$-mol, and Kingsport is $60.9 \% \mathrm{H}_{2}, 24.5 \% \mathrm{CO}, 3.9 \% \mathrm{~N}_{2}$ and $10.0 \% \mathrm{CO}_{2}$ giving a molar mass of $13.59 \mathrm{~kg} / \mathrm{kg}-\mathrm{mol}$.

The superficial gas velocity, pressure, and temperature for the LaPorte AFDU are all generally kept very high, and it is assumed that good mixing with a uniform distribution of solids in the liquid is present. However, high gas velocities also dictate that the flow is in the churn-turbulent or strongly coalescing regime. Eventually, this flow regime will result in large inhomogeneities in the flow both spatially and temporally. If the individual gas pockets or fluctuations become large enough to push the reactor into a hydrodynamics-limited operation where the reaction rates are limited by mass transport to the catalyst, the efficiency of the process could suffer greatly. Therefore, it is important to monitor average gas holdups, their fluctuations, and bubble size distributions. Many previous researchers have measured these quantities, and some have done so in organic fluids and slurries (e.g. Krishna and Ellenberger, 1996; Wilkinson et al., 1992; Patel et al., 1989, Bukur et al.,1987; and O'Dowd et al.,1987), but always in much smaller diameter columns and never under the same operating conditions found in the AFDU. Because of the inability to extend correlations, particularly those for multiphase flows, outside the region for which they were derived, gas holdup must be monitored continuously while the AFDU is operating.

A standard, non-intrusive technique used for measuring gas holdup is gamma densitometry (GD). This technique is calibrated to relate the measured attenuation of a beam of gamma photons through a two or three-phase flow to its gas volume fraction or gas holdup. GD is currently used on the AFDU; however, because of the thick walls on the AFDU (1 in. or $2.54 \mathrm{~cm}$ steel) and the presence of an internal heat exchanger, it is only possible to obtain accurate measurements along the diameter of the column. If the gas holdup varies radially, GD cannot measure the volume averaged gas holdup without some knowledge of the gas holdup profile. Again, because of the highly attenuating walls, it is impossible to resolve temporal variations in gas holdup using GD. An alternative technique that can be used to determine gas holdup and its temporal fluctuations is the differential pressure technique where gas holdup is related to the static pressure head of a two or three-phase mixture located between the two pressure taps. Many previous researchers have used DP measurements to calculate average and instantaneous gas holdup, but not under the operating conditions found in the AFDU. Thus, the first objective for this project was to validate the use of the DP technique to measure average gas holdups under industrial conditions. The second objective was to determine the extent to which the instantaneous gas holdup values deviate from their mean and the frequency of these deviations. Finally, bubble size distributions and Sauter mean bubble diameters were estimated for three sets of operating conditions by measuring differential pressures during a Dynamic Gas Disengagement experiment, or quick shutdown test. 


\section{GAS HOLDUP CALCULATIONS}

Gas holdup $\left(\varepsilon_{G}\right)$ is a measure of the ratio of gas volume $\left(V_{G}\right)$ to the total three-phase mixture volume $(V)$. Thus, it quantifies how much gas is "held" up in the three-phase mixture. It can be related to the densities of the various components in the flow using a mass balance as follows:

$$
m=m_{S}+m_{L}+m_{G}
$$

where $m$ is the total mass and the subscripts $S, L$ and $G$ correspond to solid, liquid and gas, respectively. Dividing through by total volume $V$ yields:

$$
\frac{m}{V}=\frac{m_{S}}{V_{S}} \frac{V_{S}}{V}+\frac{m_{L}}{V_{L}} \frac{V_{L}}{V}+\frac{m_{G}}{V_{G}} \frac{V_{G}}{V}
$$

Substituting in the solid, liquid, gas and total density (or three phase density, $\rho$ ) and the gas and solids holdup ( $\left.\varepsilon_{S}\right)$ and solving for $\varepsilon_{G}$ :

$$
\varepsilon_{G}=\frac{\left(\rho_{L}-\rho\right)+\varepsilon_{S}\left(\rho_{S}-\rho_{L}\right)}{\left(\rho_{L}-\rho_{G}\right)}
$$

Differential pressure measurements are then used to calculate $\rho$ within a bubble column using the fully developed momentum equation for upward turbulent flow in a tube:

$$
\frac{d P}{d z}=\frac{\rho}{r} \frac{d}{d r}\left[\left(v_{m}+v_{t}\right) r \frac{d U}{d r}\right]_{r=R}+\rho g
$$

where $U$ is the local mean velocity of the slurry near the walls, and $v_{m}$ and $v_{t}$ are the momentum and turbulent diffusivity of the liquid, respectively. We can greatly simplify (4) by assuming that for a bubble column, where the net liquid flow is negligible, the shear stress term is small compared to the gravity force, giving the simple hydrostatic equation:

$$
\rho=\frac{\Delta P}{g \Delta z}
$$

This assumption has been validated for laboratory-scale slurry-phase bubble-column experiments at low gas flow rates by Daly (1990). However, in larger columns, as the liquid flow recirculation increases in velocity and turbulence intensity, this assumption needs to be verified for its continuing validity at all scales.

The final quantity needed to calculate gas holdup in (3) is the slurry density. For the AFDU, the total weight of catalyst initially added to the reactor is known, but the weight of liquid in the system varies as it is sometimes withdrawn and recirculated. Thus, one more independent measurement of the three-phase flow is needed to calculate the slurry density. For this experiment, a gamma densitometer is used to determine the total expanded height of the three-phase slurry mixture. The initial catalyst weight is then divided by the total volume to find the solids holdup: 


$$
\varepsilon_{S}=\frac{m_{S} / \rho_{S}}{V}
$$

It should be noted that because a total volume method was used to close the three-phase equations, one of the phases must be assumed to be uniform throughout the column. In the following results, the solids are assumed to be uniformly dispersed throughout the liquid, which is in general a good assumption for a well mixed, high velocity flow in a large diameter column (Daly, 1990). Thus, (3), (5) and (6) can be used to calculate volume-averaged gas holdups between two locations using the corresponding differential pressure measurement and total expanded three-phase height.

\section{DYNAMIC GAS DISENGAGEMENT TECHNIQUE}

The gas holdup, together with the bubble size distribution, can be used to calculate interfacial area $\left(A_{S}\right)$ using the following relations for spherical bubbles:

$$
\begin{gathered}
A_{S}=\frac{6 \varepsilon_{G} V}{D_{32}} \\
D_{32}=\frac{\sum n_{i} D_{i}^{3}}{\sum n_{i} D_{i}^{2}}
\end{gathered}
$$

where $D_{32}$ is the Sauter mean diameter and $n_{i}$ is the fraction of bubbles with diameter $D_{i}$. If the bubbles are too large to be spherical, an equivalent diameter is often used to relate surface area to volume. An estimate of the bubble size distribution can be obtained using the Dynamic Gas Disengagement (DGD) technique developed by Sriram and Mann (1977). A typical DGD experiment is performed in a transparent column and consists of quickly shutting down the gas being delivered to the column and measuring the rate at which the height or interface of the gas/ liquid or gas/liquid/solid mixture falls with time. The velocity of the falling interface is then used to determine the velocity of the gas leaving the system. Differential pressures, however, measure the rate at which the gas holdup evolves with time between two pressure taps. Other researchers such as Daly et al. (1992), who have performed DGD experiments using differential pressure data, have simply used the data to estimate the rate at which the interface falls, assuming that the gas holdup measured between the taps equals the total volume-averaged gas holdup, and then followed the original derivation for determining bubble velocities. This is not necessary since the technique can easily be rederived to relate the velocity of the gas or bubble velocity $\left(U_{B}\right)$ to the evolution of gas holdup in the volume between the pressure taps:

$$
U_{B, i}=-\frac{\Delta z}{\varepsilon_{G, 0}} \frac{d \varepsilon_{G, i}}{d t}
$$

where $\Delta z$ is the distance between the differential pressure taps, the subscript $i$ indicates a bubble diameter range, and the subscript 0 represents an initial value. For this derivation, it is assumed that one bubble size class is disengaging between the pressure taps for each velocity calculated. This approximation is best for the taps located closest to the top interface and improves as the taps are 
moved closer together. Of course, it must also be assumed for either method of analysis that the bubbles do not coalesce or break up during the disengagement process.

The number of bubbles in each bubble size class can be derived from conservation of mass:

$$
N_{B, i}=\frac{\Delta \varepsilon_{G, i} \Delta z A}{\frac{\pi}{6} D_{B, i}^{3}}
$$

Finally, the velocities are used to estimate the bubble diameter distribution using either Stokes' Law for small bubbles,

$$
D_{B}=\left[\frac{18 \mu_{S L} U_{B}}{g\left(\rho_{S L}-\rho_{G}\right)}\right]^{1 / 2}, R e<2
$$

a correlation by Peebles and Garber (1953) for midsize bubbles,

$$
D_{B}=4.67\left(\frac{\mu_{S L}}{\rho_{S L}}\right)^{0.41} \frac{U_{B}^{0.78}}{g^{0.59}}, 2 \leq R e \leq 4.02\left(\frac{g \mu_{L}^{4}}{\rho_{L} \sigma^{3}}\right)^{-0.214}
$$

or a correlation by Clift et al. (1978) for larger sized bubbles

$$
U_{B}=\left[\frac{2.14 \sigma_{S L}}{\rho_{S L} d_{B}}+0.505 g D_{B}\right]^{1 / 2}, D_{B}>1.3 \mathrm{~mm}
$$

Alternatively, a more recent correlation by Jamialahmadi, et al. (1994) can be used that has been tested for a wider range of fluid properties and is valid for all liquid Reynolds numbers.

$$
\begin{gathered}
U_{B}=\frac{U_{s p} U_{w}}{\sqrt{U_{s p}^{2}+U_{w}^{2}}} \\
U_{s p}=\frac{1}{18}\left(\frac{\rho_{S L}-\rho_{G}}{\mu_{S L}}\right) g D_{B}^{2}\left(\frac{3 \mu_{S L}+3 \mu_{G}}{2 \mu_{S L}+3 \mu_{G}}\right) \\
U_{w}=\sqrt{\frac{2 \sigma}{D_{B}\left(\rho_{S L}+\rho_{G}\right)}+\frac{g D_{B}}{2}}
\end{gathered}
$$

All of these relations were developed for single bubbles rising through a quiescent liquid and it must be assumed that during the disengagement process neither liquid recirculation nor bubble interactions (i.e. swarming, wall effects, etc.) invalidate their use. The validity of this assumption improves for smaller gas holdups. In addition, these relations were developed for a continuous, pure liquid phase; clearly, the slurry properties, such as viscosity $\left(\mu_{S L}\right)$ and surface tension $\left(\sigma_{S L}\right)$, 
must be measured carefully. Finally, it is also assumed that negligible solid settling occurs during the disengagement process.

\section{STATISTICAL ANALYSIS}

The Introduction outlined the importance of determining the flow regime within the bubble column. Figure 2 shows differential pressure data that were recorded during a stable period of operation. Note that there are significant temporal fluctuations in the signal. Statistical techniques for analyzing the fluctuations in the pressure signal can be used to determine when the transition from a laminar, homogeneous bubbly flow to an inhomogeneous, churn-turbulent flow occurs. A review of previous efforts to use these techniques for quantifying various transitions in multiphase flows is given by Daly (1990).

One way to analyze the time varying component of the pressure signal involves calculating the magnitude of the fluctuations or standard deviation in the differential pressures. For bubbly flow where a single log normal distribution of gas bubbles exists, it is expected that the fluctuations should be negligible because of the uniformly distributed gas holdup. In churn-turbulent flow, if large slugs of gas are separated in the flow, the pressure will measure increasing fluctuations as the large waves of gas holdup rise in the column. A second technique is to use a Fourier transform to analyze the characteristic frequencies of the pressure readings. For bubbly flow, there should be no strong characteristic frequencies, but for churn-turbulent flow, the frequency should be a measure of the rate at which gas pockets move through the column.

\section{UNCERTAINTY ANALYSIS}

An uncertainty analysis provides information to determine the range of conditions under which it is feasible to use differential pressure measurements to calculate gas holdup. Moffat (1988) shows that when several independent variables are used to calculate a function $R\left(X_{1}, X_{2}, \ldots, X_{i}\right)$, the individual terms contribute to the uncertainty $\delta R$ by a root-sum-square as follows

$$
\delta R=\left[\sum_{i=1}^{N}\left(\frac{\partial R}{\partial X_{i}} \delta X_{i}\right)^{2}\right]^{1 / 2}
$$

Applying this to the gas holdup, and assuming that the uncertainties in the single phase densities are negligible compared to the uncertainty in the measured three-phase density (i.e., $\left.\delta \rho_{G}, \delta \rho_{L}, \delta \rho_{S} \ll \delta \rho\right)$ leads to

$$
\delta \varepsilon_{G}=\left[\left(\frac{\partial \varepsilon_{G}}{\partial \rho} \delta \rho\right)^{2}+\left(\frac{\partial \varepsilon_{G}}{\partial \varepsilon_{S}} \delta \varepsilon_{S}\right)^{2}\right]^{1 / 2}
$$

and then substitute in (3) to obtain:

$$
\delta \varepsilon_{G}=\left\{\left[\frac{1}{\left(\rho_{L}-\rho_{G}\right)} \delta \rho\right]^{2}+\left[\frac{\left(\rho_{S}-\rho_{L}\right)}{\left(\rho_{L}-\rho_{G}\right)} \delta \varepsilon_{S}\right]^{2}\right\}^{1 / 2}
$$


Performing the same analysis on (5) and (6) gives:

$$
\begin{aligned}
& \frac{\delta \rho}{\rho}=\left[\left(\frac{\delta \Delta P}{\Delta P}\right)^{2}+\left(\frac{\delta \Delta z}{\Delta z}\right)^{2}\right]^{1 / 2} \\
& \frac{\delta \varepsilon_{S}}{\varepsilon_{S}}=\left[\left(\frac{\delta m_{S}}{m_{S}}\right)^{2}+\left(\frac{\delta V}{V}\right)^{2}\right]^{1 / 2}
\end{aligned}
$$

Finally, combine (19), (20), and (21) and rearrange to get

$$
\delta \varepsilon_{G}=\left[\frac{\left(\rho_{S}-\rho_{L}\right)}{\left(\rho_{L}-\rho_{G}\right)} \varepsilon_{S}\right]\left\{\left[\frac{\Delta P /(g \Delta z)}{\varepsilon_{S}\left(\rho_{S}-\rho_{L}\right)}\right]^{2}\left(u_{\Delta P}{ }^{2}+u_{\Delta z}{ }^{2}\right)+u_{m_{S}}{ }^{2}+u_{V}{ }^{2}\right\}^{1 / 2}
$$

where $u$ denotes relative uncertainty in the subscripted variable. If we substitute in values for the above variables that represent typical operating conditions in the AFDU $(\Delta z=3 \mathrm{~m} \pm 0.03 \mathrm{~m}$, $m_{S}=400 \mathrm{~kg} \pm 4 \mathrm{~kg}, V=70 \mathrm{ft}^{3} \pm 0.7 \mathrm{ft}^{3}$ ), use property values for Texaco gas and catalyst A (listed in the Introduction Section), and use the uncertainty specified for the pressure transducers (given in the Experimental Equipment Section), we can calculate the relative uncertainty in the gas holdup $\left(u_{\varepsilon_{G}}=\delta \varepsilon_{G} / \varepsilon_{G}\right)$ as a function of gas holdup as shown in Figure 3 (a). For gas holdups greater than $35 \%$ the relative uncertainty is less than 0.029 corresponding to $\delta \varepsilon_{\mathrm{G}}=1.03 \%$. Figure 3 (b) shows the relative uncertainty in the gas holdup as a function of the distance between the pressure taps $(\Delta z)$ obtained by again starting with (22), substituting in the above values, and by using $\varepsilon_{G}=35 \%$. This figure shows that $\Delta z$ can decrease to $0.5 \mathrm{~m}$ before any significant increases in uncertainty are experienced. Thus, gas holdup can theoretically be measured with good accuracy using the differential pressure technique under industrial conditions if the assumptions made to reduce the full momentum equation to the hydrostatic equation are correct.

\section{EXPERIMENTAL EQUIPMENT}

Rosemount Alphaline pressure transducers (model 1151) were selected and installed on the AFDU by Air Products and Chemicals. They are industrial-quality transducers that measure differential pressures directly using a diaphragm and a $\delta$-cell capacitance sensing element. The maximum span of the selected transducers is $0-10.8 \mathrm{psid}(74.4 \mathrm{kPa})$ with an accuracy of $\pm 0.003 \mathrm{psid}(20.7 \mathrm{~Pa})$. The stability of the readings is guaranteed to $0.005 \mathrm{psid}(34.5 \mathrm{~Pa})$ with a zero error of less than $0.0135 \mathrm{psid}(93.1 \mathrm{~Pa}$ ) for up to six months of operation. Remote seal systems, from the same manufacturer, were used to measure the differential pressure directly between nozzles $C$ to $N 2, N 2$ to $\mathrm{D}$ and $\mathrm{D}$ to $\mathrm{N} 1$ as shown in Figure 1. Differential pressures at nozzles N1 and E were both taken with reference to the gas pressure above the liquid slurry. The transducers themselves have adjustable damping with a minimum damping of 0.2 seconds. The remote seals, which use oil filled transmission lines, also add some damping to the measurement. The extent of this damping can be determined experimentally as shown in the next section, Temporal Analysis of Differential Pressures.

Readings from the transducers were recorded using an existing Bailey operations control and monitoring unit. However, this system is currently configured to collect data at a rate of 1 sample 
every 5 seconds. It was desired to sample data at higher frequencies for the DGD tests and for the statistical analysis. Sandia provided a portable data acquisition unit to accomplish this. The system consisted of a National Instruments SCXI (Signal Conditioning and Instrumentation System) that was connected via a parallel port to a notebook computer. Data acquisition was automated using a LabView program. The SCXI is capable of acquiring data using an enhanced parallel port at rates up to $100 \mathrm{kHz}$. An isolation amplifier was required for use as one of the plug-in modules in the SCXI to protect the equipment from surges and ground loops that result from having two independent data acquisition systems recording the same signal. Finally, an external mass data storage unit (150 MB Bernoulli Transportable) was needed to handle the large volume of data acquired during the entire run.

\section{TEMPORAL ANALYSIS OF DIFFERENTIAL PRESSURES}

Several pressure data files were acquired for analysis at different sampling rates. These files were first examined to determine what sampling frequency would be adequate. Although very fast data rates are possible, data management becomes more cumbersome, eventually without adding any information due to the frequency response limitations of the transducers. Shown in Figure 2 is a time trace of pressures measured at three different frequencies for the transducer located between nozzles N2 and D acquired during Run No. 13.1 (see Table 1). The difference between the $2.0 \mathrm{~Hz}$ data and the $1.0 \mathrm{~Hz}$ data is negligible, but there is significant filtering of the higher frequencies at $0.2 \mathrm{~Hz}$. Thus, these data suggest for this flow rate that the higher sampling rate of $1.0 \mathrm{~Hz}$ is required to analyze the measured frequencies of the flow. Furthermore, the sampling rate of $1.0 \mathrm{~Hz}$ is shown to be sufficiently fast by comparison to the $2.0 \mathrm{~Hz}$ data. Pressures were also collected at a rate of $1000 \mathrm{~Hz}$. This rate is significantly higher than the response time of the transducers, and variations in readings should be an indication of the amount of noise in the signal. Fluctuations of pressures were measured to be less than $0.003 \mathrm{psid}(20.7 \mathrm{~Pa})$ which agrees with the specifications for the transducers and is $0.3 \%$ of the magnitude of fluctuations being measured at the $1.0 \mathrm{~Hz}$ sampling rate. Thus, the pressure fluctuations being measured in the column are significantly greater than the signal noise and represent actual fluctuations in pressure.

\section{EXPERIMENTAL RESULTS}

The LaPorte AFDU was operated over a period of one month over a range of flow conditions that are outlined in Table 1. The following conditions were kept constant throughout the run: three phase mixture height at $43.5 \mathrm{ft}$. $(13.26 \mathrm{~m}$ or $\mathrm{L} / \mathrm{D}=29)$ and temperature at $482{ }^{\circ} \mathrm{F}\left(250^{\circ} \mathrm{C}\right)$. Pressure during each run was held constant, usually at $750 \mathrm{psia}(5.17 \mathrm{MPa})$ or $765 \mathrm{psia}(5.27 \mathrm{MPa})$, except for R13.3 whose pressure was 735 psia (5.07 MPa) and R14.3 whose pressure was 535 psia (3.69 MPa). Two commercially available catalysts were used (catalyst A for the R13 series and catalyst B for the R14 series). Both catalysts were added in one measured dose at the beginning of each run series and, because liquid was added or withdrawn to keep the total expanded three-phase height constant as gas holdup varied, the catalyst loading also varied. The loadings by mass $\left(\omega_{S}\right)$ ranged from $43 \%$ to $49 \%$ for catalyst $\mathrm{A}$ and from $39 \%$ to $45 \%$ for catalyst $\mathrm{B}$. Finally, two gas mixtures (Texaco and Kingsport) and four inlet superficial gas velocities $\left(U_{G}=0.046,0.15,0.26\right.$ and $0.36 \mathrm{~m} / \mathrm{s}$ ) were tested. 


\section{Average Gas Holdups}

Volume-averaged gas holdup values were obtained by averaging differential pressure measurements over long periods of time and along the column during a stable run. Each run was broken into two periods to check the stability of the catalyst and measurements. Tables 2 and 3 show the averaged data and calculated catalyst loadings along with values obtained using a gamma densitometer system and from a shutdown test. The gamma densitometer measures gas holdup by comparing the attenuation for the three phase-flow to that of the empty and full vessel using a ray through the diameter of the vessel and by using the three-phase expanded height measurement. The gamma densitometer measurements can be made at any elevation and were taken along the length of the vessel and averaged. Scans were recorded about every 5 hours during each stable operating period. A shutdown test consists of measuring the expanded three-phase mixture height $(H)$, using the gamma densitometer, shutting off the gas supply, and then measuring the two-phase mixture height $\left(H_{S}\right)$. The gas holdup is then calculated using $\varepsilon_{G}=\left(H-H_{S}\right) / H$. Because $H$ and $H_{S}$ can be measured with good accuracy, the shutdown test provides the most accurate measurement of gas holdup volume averaged over the entire vessel.

The gas holdups given in Tables 2 and 3 are shown graphically in Figure 4. As can be seen in the figures, the gamma densitometer measured gas holdups are systematically $7.0 \%$ to $14.3 \%$ higher than the values obtained using the differential pressure technique. For the three gas holdups obtained using the shutdown test, the agreement with the differential pressure measurements is very good (within $3.0 \%$ ). Thus, it appears there is a systematic error in the densitometry readings which can be linked to the assumption that the flow is radially homogeneous (needed to calculate area averaged gas holdup using only one chord of data). However, a radial distribution of gas holdup is generally observed in two-phase and slurry-phase flows, such that gas holdup is highest at the centerline and decreases toward the edges (Bukur et al., 1987, Dudukovic et al., 1991). For such a profile, the data averaged along the diameter would give too much weight to the area with highest gas holdup at the centerline and therefore would overestimate the average gas holdup. This appears to be the case for the gamma densitometer measurements made on the AFDU. Since the radial gas holdup distribution in the AFDU cannot currently be directly measured or predicted, this result is useful in letting us infer that a customary gas holdup profile is present.

To consider the effect of changing the catalyst or volume fraction of solids, we can compare Figure $4 \mathrm{a}$ to Figure $4 \mathrm{~b}$. It is found that the $0.5 \%$ to $1.9 \%$ increase in solids volume fraction resulted in a $7.0 \%$ to $8.4 \%$ decrease in gas holdup at the same superficial velocity. It is difficult to conclude why this occurs from the limited data set. Two factors that probably contribute are (1) the increase in the volume of solids will simply displace the gas, and (2) the increased volume of solids will probably decrease surface tension and increase viscosity which enhances coalescence and decreases gas holdup.

In Figures $4 \mathrm{a}$ and $4 \mathrm{~b}$, the Texaco and Kingsport gases are represented by closed and open symbols, respectively. The best comparison of the effect of gas composition on gas holdup can be made by looking at run numbers R14.2 and R14.4 which are at approximately the same flow conditions (see Table 1). We find that the gas holdup is $4.7 \%$ lower for the Kingsport gas at $U_{G}=0.15 \mathrm{~m} / \mathrm{s}$. Furthermore, if we linearly extrapolate a gas holdup value for the Kingsport gas to compare to the measured Texaco gas values we calculate decreases in gas holdup of $5.7 \%$ for catalyst $\mathrm{A}$ and $6.7 \%$ 
for catalyst B, both at $U_{G}=0.26 \mathrm{~m} / \mathrm{s}$. For the same superficial gas velocity (or volume flow rate) the mass flowrate for the Kingsport gas will be lower because its density is lower $\left(16.3 \mathrm{~kg} / \mathrm{m}^{3}\right.$ versus $25.0 \mathrm{~kg} / \mathrm{m}^{3}$ at typical AFDU conditions). If we compare gas holdups for the same mass flow rate $\left(U_{G, \text { Texaco }}=\left(\rho_{G, \text { Kingsport }} / \rho_{G, \text { Texaco }}\right) U_{G, \text { Kingsport }}\right.$ giving $U_{G, \text { Texaco }}=0.26 \mathrm{~m} / \mathrm{s}$ for $U_{G, \text { Kingsport }}=0.36 \mathrm{~m} / \mathrm{s}$ ) the differences in gas holdup reduce to $1.75 \%$ for catalyst $\mathrm{A}$ and $2.83 \%$ for catalyst $\mathrm{B}$. This suggests that both the volume and momentum flux of the gas leaving the sparger are important for correlating gas holdup.

Figure $4 \mathrm{~b}$ also demonstrates trends in the gas holdup with superficial gas velocity. It is seen that the slope of the straight line fit between the three points decreases with superficial gas velocity. This corresponds again to the type of curve one would expect to see in any two or three-phase flow in a large-diameter column where slugs do not form. Generally, the curves have two regions. The first region has a constant steep slope corresponding to bubbly flow where bubbles move through the column without interaction and the slope can be derived from continuity. When the bubbles begin interacting (i.e. coalescing and swarming) the gas holdup increases less as the gas velocity continues to increase. This region corresponds to the churn-turbulent regime. From the graphs, it appears that the three highest flow rates may be in the churn-turbulent regime and that the lowest flow rate is either in a bubbly flow or transition regime. As stated in the Introduction, a statistical analysis will be used later as a more definitive means for determining which flow regimes is present.

Figures 5 through 11 show the variations in gas holdups averaged over one-hour periods for the duration of each run where $L / D$ is the axial distance above the sparger, non-dimensionalized with respect to the diameter of the AFDU. Graphs for run numbers R13.2 and R14.9 are omitted because data were taken for only 3 hours in each case and the values are relatively constant over that period. In all of these plots, gas holdups tend to drift both up and down with time and occasionally experience fairly large disturbances. For example, Figure 6 shows a large increase in gas holdup at the uppermost location that coincides with a decrease of similar magnitude at the bottom three locations. These disturbances were observed for both gases and catalysts and appear in the column for each velocity tested. Looking at the hourly run schedule, it was found that the fluctuations correspond to periods when the GD system is taken from its normal operation of monitoring overall expanded three-phase mixture height to scan the axial variation in gas holdup. While this is done, liquid is no longer added to maintain a constant height. Apparently, the liquid level drops enough during this period, possibly below the uppermost tap, resulting in an increase in gas holdup between the top two pressure taps. Conversely, between the lower pressure taps, the decrease in liquid level decreases gas holdup. This can be explained by realizing that the solids loading will increase as the liquid level drops, but, for these calculations we must use the original solids loading obtained before the axial gamma scan. From (3), the underestimated solids holdup will also lead to calculated gas holdups that are artificially low for this time period.

\section{Axial Variations in Average Gas Holdups}

From the four differential pressure sections along the column (see Figure 1), the axial variation of the gas holdup along the column length can be measured. The data are presented in Tables 4 and 5 
and plotted in Figures $12 \mathrm{a}$ and $12 \mathrm{~b}$. For each superficial gas velocity and for both catalysts and gases, the variations in gas holdup with axial location follow the same trends. This suggests that all of the trends noted above for the volume-averaged data remain valid at each elevation. In Figures $12 \mathrm{a}$ and $12 \mathrm{~b}$, it is also shown that the gas holdup initially decreases with elevation (by about $3 \%$ ) and then increases (by 2.3\%) and finally increases significantly (by $7 \%$ ). This seems contrary to the anticipated drop in gas holdup expected as a result of the gases reacting to form a denser gas. Compositions of the inlet and exiting gases were monitored during each of the runs. For the Texaco gas, the densities were typically $25.0 \mathrm{~kg} / \mathrm{m}^{3}$ at the inlet and $30.2 \mathrm{~kg} / \mathrm{m}^{3}$ at the outlet corresponding to a decrease in gas holdup of about $7 \%$ for an initial gas holdup of $40 \%$. For the Kingsport gas, the densities were typically $16.0 \mathrm{~kg} / \mathrm{m}^{3}$ at the inlet and $21.9 \mathrm{~kg} / \mathrm{m}^{3}$ at the outlet corresponding to a decrease in gas holdup of about $10 \%$ for an initial gas holdup of $40 \%$ (except for the highest velocity cases). The axial gas holdup distributions never reflect these changes in gas holdup which are expected from the gas contraction during reaction. A possible explanation for the shape of this profile (i.e. increasing gas holdup versus decreasing at higher $\mathrm{L} / \mathrm{D}$ ) is that there are two competing effects determining the axial gas holdup distribution. Initially, a high gas holdup is seen near the sparger where a dense "bubble cloud" forms. As the gas moves up the column, it forms distinct bubbles with a distribution of sizes that begin to react resulting in an initial drop in gas holdup. The bubbles continue to decrease in size further along the column until a significant decrease in their rise velocity causes the gas holdup to begin increasing. This continues and possibly results in a foaming region at the top of the vessel.

\section{Statistical Analysis of Gas Holdups}

The use of statistical analysis to discern flow regime transitions will be discussed here. The data are presented in Tables 6 and 7. Figures 13a and 13b show standard deviations in gas holdup $(\sigma)$ versus superficial gas velocities $\left(U_{G}\right)$ and axial distance for each catalyst. Note that in these figures closed and open symbols again denote the Texaco and Kingsport gases, respectively. For both catalysts, we see that $\sigma$ increases with $U_{G}$ as expected, possibly showing that gas pockets are increasing in size and/or number. For the lowest velocity case, $\sigma$ is $0.25 \%$ which corresponds to a pressure standard deviation of $0.01 \mathrm{psid}(68.9 \mathrm{~Pa})$. This is higher than the 0.003 psid $(20.7 \mathrm{~Pa})$ range of the transducers and shows that even for the lowest velocity case there exists measurable fluctuations in the flow. Comparing Figures $13 \mathrm{a}$ and $13 \mathrm{~b}$ we see that there is a measurable decrease in standard deviation as $\mathrm{L} / \mathrm{D}$ increases for catalyst $\mathrm{A}$ that is not seen for catalyst $\mathrm{B}$, whose gas holdup is about $7.7 \%$ lower. In Figure 13b, we also see that $\sigma$ no longer depends on gas type, which also changes gas holdups by about $6.0 \%$. Thus, the change in gas holdup caused by switching gases does not appear to be a critical parameter in determining the flow regime and other variables, such as volume of solids, may play a greater role. Finally, in Figures 13a and 13b we see that at the highest elevation in the column $(L / D=24.5)$ there is a significant increase in standard deviation. This may be the result of the liquid level falling below the top pressure nozzle for a significant period of time.

An example of a frequency spectrum obtained from a Fourier transform analysis of 3600 points of differential pressure data is shown in Figure 14 for a high velocity case (R14.3). This spectrum shows that there is a wide band of frequencies present but that there is a fairly broad peak in the spectrum centered at about $0.05 \mathrm{~Hz}$. This suggests that a large pocket of gas either enters or leaves the region between the pressure nozzles every 20 seconds. An experimental effort is currently 
being pursued at Sandia to verify which physical phenomena relate to the various frequency components being measured. Figures $15 \mathrm{a}$ and $15 \mathrm{~b}$ show the strongest frequency components for each catalyst as a function of superficial gas velocity. The points represent values taken from each elevation and for each gas but are not noted separately on the graphs because there is no discernible dependency on either of these parameters. For both cases we see that the frequency increases with $U_{G}$ and that there does not appear to be a dominant frequency for $U_{G}$ less than $0.15 \mathrm{~m} / \mathrm{s}$. As stated earlier, the beginning of the appearance of a dominant frequency is an indication that gas pockets are present and that a transition to churn-turbulent flow has begun. Thus, the flow appears to be in the churn-turbulent regime for all but three of the run conditions tested. If we compare the graphs for the two catalysts, we see that the frequencies at $0.25 \mathrm{~m} / \mathrm{s}$ are much lower for catalyst $\mathrm{A}$, indicating that increasing the volume fraction of the catalyst results in an earlier transition to churnturbulent flow.

\section{Dynamic Gas Disengagement}

Gas holdups were recorded after a quick shutdown of the gas entering the column for a Dynamic Gas Disengagement (DGD) analysis. The general technique for obtaining bubble size distributions using DGD has been outlined in an earlier section. Data were recorded for three sets of conditions, each following one of the long stable run periods (R13.2, R14.1 and R14.3). Table 1 shows that these cases represent three different flow rates, both gases and both catalysts. Shown in Figures 16 through 18 are DGD curves of gas holdup versus time for each of the runs, where the shutdown occurred at time zero. After shutdown, gas holdups between the bottom three nozzles (from $L / D=$ 3.1 to 14.4) fall to approximately zero, indicating that all three nozzles are submerged in the pure slurry. The final gas holdup between $\mathrm{L} / \mathrm{D}=14.4$ and 21.0 is between zero and unity, showing that the final slurry height is located between the two pressure taps. Finally, at the top location ( $L / D=$ 21.0 to 27.6) the gas holdup increases to unity, indicating that both upper nozzles are above the slurry level after shutdown.

One issue to address before interpreting the DGD data obtained from the differential pressures is that we are using the steady state momentum equation to calculate a dynamic effect. Assuming the Navier-Stokes equations are still valid for the catalyst suspension, the unsteady momentum equation includes an acceleration term that should be used, in addition to the viscous damping term (that we already neglected in the steady state analysis). These new terms require values for the liquid velocities and turbulent viscosity to be calculated. Because we do not know the magnitude of these variables, we can only assume that these terms are negligible with respect to the hydrostatic pressure. To numerically test this assumption would be difficult since a full model simulation is intractable. The best validation that could be achieved at this time was to measure DGD curves in a three-phase system (air/water/80 micron glass beads) in a $0.19 \mathrm{~m}$ column at atmospheric temperature and pressure using the differential pressure technique along with a high-speed video system. Figure 19 shows DGD curves for the three-phase system for two sets of differential pressures along the column, where the initial height of the liquid was $L / D=6$, the solids loading is $40 \%$ by mass and the superficial gas velocity is $0.088 \mathrm{~m} / \mathrm{s}$. In this figure, the gas holdups from the two sets of differential pressure data should be averaged to compare them with the volume averaged video observations. We see that the measurements agree reasonably well. These graphs were obtained by averaging the differential pressure data over a 0.5 -second interval because the signals contained many large-scale fluctuations. These fluctuations must be the result of the 
ignored acceleration terms, but the numerical averaging of the differential pressures used to obtain these curves results in a disengagement curve that agrees with the high-speed video data. These results provide some validation for the use of averaged differential pressure data to obtain DGD disengagement curves.

Comparing Figures 16 through 18 to Figure 19, we see that none of the oscillations observed in the air/water/glass test case are present in the AFDU data. One explanation for the difference in the curves could be the difficulty in obtaining a quick enough shutdown of the gas supply to the AFDU. The inlet gas line is about 2 inches in diameter and is closed using a pneumatic flow control valve that will experience some lag. In future tests, monitoring the pressure downstream of the control valve would give a direct measurement of the rate at which the gas stops flowing and would make more accurate interpretation of the DGD curves possible. In addition, increased viscosity, measurement volume, and column height probably contributed to the smoothing of these curves. The other difference between these graphs is the shape of the disengagement curves. For a bubbly flow with a homogeneous distribution, one would expect the bubbles to disengage uniformly, leading to a single slope. For churn-turbulent flow, it was shown by Patel et al. (1989) that the two bubble classes usually lead to two distinct slopes: an initial steep slope for the large, high velocity gas pockets followed by the gradual slope of the slower moving small bubbles. These two slope regions are distinctly visible in Figure 19 but are not present in Figures 16 through 18. Again, this seems to indicate that the gas shutdown may have been too slow to measure both bubble classes, especially since the average and statistical gas holdup data give good evidence that the churnturbulent regime exists at these flow rates.

Figures 20 through 24 compare the disengagement curves for all four elevations. At the lowest elevation, Figure 20, there is only a small change in slope between the lowest velocity case (R13.2) and the other two curves. At the next elevation, shown in Figure 21, there is a significant time lag between all three curves and again a similar change in slope. Thus, in the lowest portion of the column, there appears to be little difference in the disengagement process for the different flow conditions, but further up significant differences become present. We also see in Figures 20 and 21 that the disengagement curves do not quite go to zero, yielding final (post-shutdown) gas holdups of $2.32 \%, 2.40 \%$ and $0.75 \%$ at $\mathrm{L} / \mathrm{D}=3.1$ to 7.9 and $-1.63 \%,-1.34 \%$ and $-1.46 \%$ at $\mathrm{L} / \mathrm{D}=7.9$ to 14.4 for run numbers R13.2, R14.1 and R14.6, respectively. These offsets are slightly greater than the $1 \%$ gas holdup error that would be expected from drifts in the zeroing of the transducers alone. Therefore, these offsets represent a slight deviation from uniform solids loading. If the slurry density is lower at the top of the column, this would cause an overestimate in gas holdup, and correspondingly the higher slurry density at the bottom would result in an underestimate of gas holdup. In all of the cases, however, the deviations from zero are very small, confirming that the uniform solids loading assumption for the AFDU conditions is fairly good.

Next, Figure 22 shows the disengagement curves for pressure taps between $L / D=14.4$ and 21.0. Here we see the that all three curves begin responding to the disengagement after about 10 seconds, and that they finish disengaging in the order of highest to lowest gas holdup. After complete disengagement, the final L/D location of the slurry level agrees with the average gas holdup measurements made during the stable run. Finally, Figure 23 shows the disengagement curves for pressure taps between $L / D=21.0$ and 27.6. Again, the slopes are increasing and the duration of the disengagement is decreasing as the superficial gas velocity increases. 
The gas holdups calculated between nozzles D and N2 are next converted to bubble velocities using (9). Bubble diameters can then be determined using either (11)-(13) or (14)-(16). Figure 24 shows the differences in the predicted terminal velocities between the correlations. It is seen that they agree reasonably well except for bubbles less than $0.2 \mathrm{~cm}$ in diameter. However, because we need to calculate bubble diameter from bubble velocity and since the graphs are non-monotonic, bubbles in the range of $0.1-0.3 \mathrm{~cm}$ for (11)-(13) and $0.05-0.25 \mathrm{~cm}$ for (14)-(16) cannot be measured using this kind of DGD analysis. This is a significant limitation of the technique and should be acknowledged when looking at the bubble diameter histograms presented later in this section.

The correlation by Jamialahmadi's et al. (1994) was tested for a wider range of fluid properties so it was used for the current DGD analysis. The properties of the slurry mixture used in (14)-(16) can be difficult to predict and will vary throughout the column, therefore Figures 25 through 27 are included to show the effects of surface tension, slurry viscosity and slurry density on the correlation by Jamialahmadi et al. (1994). For these figures and in the following analysis the slurry viscosity is estimated as a function of the volume fraction of solids in the liquid using a correlation by Thomas (1965). It ranges from $7.93 \times 10^{-4}$ to $8.35 \times 10^{-4} \mathrm{~N} \cdot \mathrm{m} / \mathrm{s}^{2}$. The surface tension used is 0.02 $\mathrm{N} \cdot \mathrm{m}$ which was given by the manufacturer of Drakeol 10 for pure liquid at $482^{\circ} \mathrm{F}\left(250^{\circ} \mathrm{C}\right)$. Gas density and gas viscosity had a negligible effect on the correlation. In all of the figures it is seen that the effect of variations in fluid properties is most pronounced for smaller bubble sizes and that there will be significant uncertainty in the analysis as fluid properties change. However, the graphs do become monotonic at low surface tension or for high viscosities which could, for certain operating conditions, help improve the accuracy of a DGD analysis.

Figures 28 through 30 show (a) the number of bubbles in each diameter class measured and (b) the corresponding volume distribution. Each of the number histograms (a) generally look like typical log-normal distributions with increasing bubble sizes as we go from R13.2 to R14.1 to R14.3. For the R14.3 histogram it appears that a second peak in the larger diameter range may be beginning to appear. The volume distributions in Figures 28 (b) to 30 (b) show one peak for R13.2 and roughly two peaks for R14.1 and R14.3.These results agree with the conclusions drawn in the Statistical Analysis section. For the low-velocity case, where the statistical analysis predicted a homogeneous bubbly flow, the DGD analysis produced a single small bubble size class. For the two higher velocity cases, where the statistical analysis predicted a heterogeneous, churn-turbulent flow, the DGD analysis suggests that two bubble size classes may have emerged with regards to volume fraction. In all three cases it is also shown in Figures 28 through 30 (b) that the bulk of the gas volume is carried by the largest bubbles which are vastly outnumbered by the smaller bubbles.

Finally, Sauter mean diameters can be calculated from the bubble size distributions. The results are as follows: $D_{32}=0.436 \mathrm{~mm}$ for R13.2, $D_{32}=0.958 \mathrm{~mm}$ for R 14.1 , and $D_{32}=1.21 \mathrm{~mm}$ for R14.3. As the above histograms suggested, Sauter mean diameter appears to be increasing with gas velocity, but recall that both the gas and catalyst type also changed for these three runs and may be contributing to these changes. Interestingly, even though the superficial gas velocity and Sauter mean diameter are highest for R14.3, because of the change in gas composition, its average gas holdup is lower than that for R14.1. The only reasonable comparison for these values currently available was reported by Daly et al. (1992) who also used the DGD technique. They obtained Sauter mean diameters ranging from 0.5 to $2.0 \mathrm{~mm}$ for superficial gas velocities ranging from 0.02 to $0.1 \mathrm{~m} / \mathrm{s}$ for nitrogen flowing through paraffin based reactor waxes in a $0.21 \mathrm{~m}$ column at $265^{\circ} \mathrm{C}$ 
and atmospheric pressure. The velocities for the LaPorte data were all higher $(0.15-0.36 \mathrm{~m} / \mathrm{s})$, pressures were much higher (535-765 psia or 3.69-5.89 MPa), and the continuous phase was a slurry (catalyst loadings of $39 \%$ to $49 \%$ by weight). The diameters obtained in this study lie within the range measured by Daly et al. (1992).

\title{
CONCLUSIONS
}

The ability to use differential pressure measurements, combined with a knowledge of the solids loading, to accurately determine gas holdups in a slurry-phase bubble column reactor has been established as an industrially viable technique. Differential pressures were recorded for four different superficial gas flow rates, two gases and two catalysts at four axial locations. Increasing superficial gas velocity increased gas holdups as expected. Switching from Texaco to Kingsport gas, which contains a higher percentage of hydrogen and is less dense, decreased the total volumeaveraged gas holdup by about $6 \%$. Increasing the volume fraction of solids in the slurry by $0.5 \%$ to $1.9 \%$ decreased the total volume-averaged gas holdup by $7.0 \%$ to $8.4 \%$. Variations in gas holdups along the vessel were similar for all conditions tested. In general, they decreased by about $3 \%$ and then actually increased overall by about $10 \%$ (where a total decrease in volume for the reacting gas would be expected). Using data obtained with the gamma densitometer, we were also able to hypothesize that the gas holdup profile is highest in the center of the vessel and decreases towards the walls.

Fluctuations in the differential pressure measurements were investigated using statistical analyses to determine when transitions in flow regime occur. Standard deviations and peaks in the frequency spectrum have been used to indicate that all but the lowest two velocity cases are in the churnturbulent flow regime. The transition to the churn-turbulent flow regime did not seem to depend on the variations in gas holdup caused by switching gases but was accelerated by increasing the volume fraction of catalyst. Finally, a dynamic gas disengagement analysis was performed to determine bubble size distributions. This diameter was found to increase with superficial gas velocity. The shutdown tests were also used to infer that solids loading was axially uniform under the AFDU operating conditions.

\section{ACKNOWLEDGMENTS}

The authors wish to thank the Air Products and Chemicals personnel at the LaPorte AFDU for their cooperation and assistance, especially Bharat Bhatt, Ed Heydorn and Steve Cochrain. The authors also wish to acknowledge the efforts of John O'Hare and John Henfling of Sandia National Laboratories. The financial support of DOE PETC is gratefully acknowledged.

\section{NOMENCLATURE}

\author{
Variables \\ A \\ $A_{S}$ \\ $D$ \\ $D_{32}$ \\ $D_{B}$ \\ cross-sectional area of bubble column, $\mathrm{m}^{2}$ \\ gas/liquid interfacial area, $\mathrm{m}^{2}$ \\ column diameter, $\mathrm{m}$ \\ Sauter mean diameter, $m$ \\ bubble diameter, $\mathrm{m}$
}




$\begin{array}{ll}g & \text { gravitational acceleration, } \mathrm{m} / \mathrm{s}^{2} \\ L & \text { axial distance along column, } \mathrm{m} \\ m & \text { mass, } \mathrm{kg} \\ n_{\mathrm{A}} & \text { molar fraction of component } A \\ P & \text { pressure, psi } \\ r & \text { radial location, } \mathrm{m} \\ R & \text { radius of bubble column, } \mathrm{m} \\ R e & \text { Reynolds Number } \\ u_{x} & \text { percent error in } x \\ U & \text { average liquid velocity, } \mathrm{m} / \mathrm{s} \\ U_{B} & \text { bubble velocity, } \mathrm{m} / \mathrm{s} \\ U_{G} & \text { superficial gas velocity, } \mathrm{m} / \mathrm{s} \\ V & \text { total (three-phase) volume, } \mathrm{m}^{3} \\ z & \text { axial location, } \mathrm{m} \\ \delta R & \text { uncertainty in value of } R \\ \Delta z & \text { distance between pressure taps, } \mathrm{m} \\ \varepsilon_{n} & \text { holdup, ratio of volume of nth component to total volume } \\ \phi & \text { catalyst weight reduction factor } \\ \mu & \text { viscosity, } \mathrm{N} \bullet \mathrm{m} / \mathrm{s}^{2} \\ v_{m} & \text { momentum diffusivity, } \mathrm{m}^{2} / \mathrm{s} \\ v_{t} & \text { turbulent diffusivity, } \mathrm{m}^{2} / \mathrm{s} \\ \rho & \text { density, } \mathrm{kg} / \mathrm{m}^{3} \\ \sigma & \text { surface tension, } \mathrm{N} / \mathrm{m} \\ \omega_{S} & \text { catalyst loading by weight, }\left(m_{S} / \phi\right) /\left(m_{S}+m_{L}\right)\end{array}$

\section{Subscripts}

0

initial

G gas

$L \quad$ liquid

$S \quad$ solid

$S L \quad$ slurry

\section{REFERENCES}

Bukur, D. B., Patel, S. A., and Matheo, R., "Hydrodynamic Studies in Fischer-Tropsch Derived Waxes in a Bubble Column," Chemical Engineering Communication, 60, 63, 1987.

Clift, R., Grace, J. R., and Weber, M. E., Bubbles Drops and Particles, Academic Press, 1978.

Daly, J. G., Hydrodynamic Studies in Two and Three-Phase Slurry Bubble Column Reactors, Ph. D. Dissertation, Texas A\&M University, 1990.

Daly, J. G., Patel, S. A., and Bukur, D. B., "Measurement of Gas Holdups and Sauter Mean Diameters in Bubble Column Reactors by Dynamic Gas Disengagement Method," Chemical Engineering Science, 47, 3647, 1992.

Dudukovic, M. P., Devanathan, N., and Holub, R., "Multiphase Reactors: Models and Experimental Verification," Revue De L'Institut Francais Du Petrole, 46, 1991. 
Jamialahmadi, M., Branch, C., and Müller-Steinhagen, H., "Terminal Bubble Rise Velocity in Liquids," Chemical Engineering Research \& Design, 72, 119, 1994.

Krishna, R., and Ellenberger, J., "Gas Holdup in Bubble Column Reactors Operating in the ChurnTurbulent Flow Regime," AIChE Journal, 42, 2627, 1996.

Moffat, R. J., "Describing the Uncertainties in Experimental Results," Experimental Thermal and Fluid Science, 1, 3, 1988.

O’Dowd, W., Smith, D. N., Reuther, J. A., and Saxena, S. E., "Gas and Solids Behavior in a Baffled and Unbaffled Slurry Bubble Column," AIChE Journal, 33, 1959, 1987.

Patel, S. A., Daly, J. G., and Bukur, D. B., "Holdup and Interfacial Area Measurements Using Dynamic Gas Disengagement," AIChE Journal, 35, 931, 1989.

Peebles, F. N., and Garber, H. J., "Studies on the Motion of Gas Bubbles in Liquids," Chemical Engineering Progress, 49, 88, 1953.

Shah, Y. T., and Deckwer, W. D., "Hydrodynamics of Bubble Columns," Handbook of Fluids in Motion, ed. Cheremisinoff, N. P., and Gupta, R., Ann Arbor Science Publishers, Michigan, 1983.

Sriram, K., and Mann, R., "Dynamic Gas Disengagement: A New Technique for Assessing the Behavior of Bubble Columns," Chemical Engineering Science, 32, 571, 1977.

Thomas, D. G., "Transport Characteristics of Suspension: VIII. A Note on the Viscosity of Newtonian Suspensions of Uniform Spherical Particles," Journal of Colloid Science, 20, 267, 1965.

Wilkinson, P. M., Spek, A. P., and Van Dierendonck, L. L., "Design Parameters Estimation for Scale-up of High-Pressure Bubble Columns," AlChE Journal, 38, 544, 1992. 
Table 1. Table of conditions for a methanol/hydrodynamics run at the LaPorte Alternative Fuels Development Unit (AFDU) during June 1995.

\begin{tabular}{|c|c|c|c|c|c|c|}
\hline $\begin{array}{l}\text { Run } \\
\text { No. }\end{array}$ & $\begin{array}{l}\text { Hours } \\
\text { Running }\end{array}$ & $\begin{array}{l}\text { Gas } \\
\text { Type }\end{array}$ & $\begin{array}{c}\text { Reactor } \\
\text { Pressure } \\
\text { (psia) }\end{array}$ & $\begin{array}{l}\text { Reactor } \\
\text { Temp. } \\
\text { (deg. F) }\end{array}$ & $\begin{array}{c}\text { Superficial } \\
\text { Gas Velocity } \\
(\mathrm{m} / \mathrm{s})\end{array}$ & $\begin{array}{l}\text { Weight } \% \\
\text { of Catalyst } \\
\text { Oxide }\end{array}$ \\
\hline \multicolumn{7}{|c|}{ Catalyst A Runs } \\
\hline R13.1 & 58.5 & Texaco & 765 & 482 & 0.26 & $49 \%$ \\
\hline $\mathrm{R} 13.2$ & 182 & Kingsport & 750 & 482 & 0.15 & $43 \%$ \\
\hline $\mathrm{R} 13.3$ & 286.5 & Kingsport & 735 & 482 & 0.34 & $48 \%$ \\
\hline \multicolumn{7}{|c|}{ Catalyst B Runs } \\
\hline R14.1 & 53 & Texaco & 765 & 482 & 0.26 & $44 \%$ \\
\hline $\mathrm{R} 14.2$ & 170.5 & Kingsport & 750 & 482 & 0.15 & $39 \%$ \\
\hline $\mathrm{R} 14.3$ & 138 & Kingsport & 535 & 482 & 0.36 & $42 \%$ \\
\hline $\mathrm{R} 14.4$ & 172 & Texaco & 765 & 482 & 0.14 & $41 \%$ \\
\hline $\mathrm{R} 14.5$ & 202 & Texaco & 765 & 482 & 0.25 & $45 \%$ \\
\hline $\mathrm{R} 14.9$ & 5 & Kingsport & 765 & 482 & 0.046 & $40 \%$ \\
\hline
\end{tabular}


Table 2. Comparison of average gas holdup values and solids loading obtained using differential pressures, gamma densitometry and shutdown tests for catalyst A runs.

\begin{tabular}{|c|c|c|c|c|c|c|c|}
\hline \multirow[b]{2}{*}{$\begin{array}{l}\text { Run } \\
\text { No. }\end{array}$} & \multirow[b]{2}{*}{$\begin{array}{l}\text { Gas } \\
\text { Type }\end{array}$} & \multirow[b]{2}{*}{$\begin{array}{c}\mathrm{U}_{\mathrm{G}} \\
(\mathrm{m} / \mathrm{s})\end{array}$} & \multicolumn{2}{|c|}{ Densitometry } & \multicolumn{2}{|c|}{ Pressures } & \multirow{2}{*}{$\begin{array}{c}\text { Shutdown } \\
\text { Gas } \\
\text { Holdup } \\
\end{array}$} \\
\hline & & & $\begin{array}{c}\text { Gas } \\
\text { Holdup }\end{array}$ & $\begin{array}{l}\text { Catalyst } \\
\text { Loading }\end{array}$ & $\begin{array}{c}\text { Gas } \\
\text { Holdup }\end{array}$ & $\begin{array}{l}\text { Catalyst } \\
\text { Loading }\end{array}$ & \\
\hline $\mathrm{R} 13.1 \mathrm{~A}$ & Texaco & 0.26 & $50.5 \%$ & $45.8 \%$ & $45.4 \%$ & $48.4 \%$ & \\
\hline R13.1B & Texaco & 0.26 & $54.7 \%$ & $48.2 \%$ & $47.0 \%$ & $49.4 \%$ & \\
\hline $\mathrm{R} 13.2 \mathrm{~A}$ & Kingsport & 0.15 & $42.3 \%$ & $41.7 \%$ & $35.3 \%$ & $43.0 \%$ & \\
\hline R13.2B & Kingsport & 0.15 & $43.1 \%$ & $42.0 \%$ & & & $35.2 \%$ \\
\hline $\mathrm{R} 13.3 \mathrm{~A}$ & Kingsport & 0.34 & $55.7 \%$ & $48.5 \%$ & $44.5 \%$ & $47.7 \%$ & \\
\hline R13.3B & Kingsport & 0.34 & $55.8 \%$ & $48.9 \%$ & $44.4 \%$ & $48.0 \%$ & \\
\hline
\end{tabular}

Table 3. Comparison of average gas holdup values and solids loading obtained using differential pressures, gamma densitometry and shutdown tests for catalyst B runs.

\begin{tabular}{|c|c|c|c|c|c|c|c|}
\hline \multirow[b]{2}{*}{$\begin{array}{l}\text { Run } \\
\text { No. }\end{array}$} & \multirow[b]{2}{*}{$\begin{array}{l}\text { Gas } \\
\text { Type }\end{array}$} & \multirow[b]{2}{*}{$\begin{array}{c}\mathrm{U}_{\mathrm{G}} \\
(\mathrm{m} / \mathrm{s})\end{array}$} & \multicolumn{2}{|c|}{ Densitometry } & \multicolumn{2}{|c|}{ Pressures } & \multirow{2}{*}{$\begin{array}{c}\text { Shutdown } \\
\text { Gas } \\
\text { Holdup }\end{array}$} \\
\hline & & & $\begin{array}{c}\text { Gas } \\
\text { Holdup }\end{array}$ & $\begin{array}{l}\text { Catalyst } \\
\text { Loading }\end{array}$ & $\begin{array}{l}\text { Gas } \\
\text { Holdup }\end{array}$ & $\begin{array}{l}\text { Catalyst } \\
\text { Loading }\end{array}$ & \\
\hline R14.4 & Texaco & 0.14 & $42.9 \%$ & $42.2 \%$ & $33.0 \%$ & $41.4 \%$ & \\
\hline $\mathrm{R} 14.1 \mathrm{~A}$ & Texaco & 0.26 & $49.6 \%$ & $45.4 \%$ & $38.3 \%$ & $43.6 \%$ & \\
\hline R14.1B & Texaco & 0.26 & $49.9 \%$ & $45.3 \%$ & $38.8 \%$ & $43.6 \%$ & $41.8 \%$ \\
\hline R14.5 & Texaco & 0.25 & $50.8 \%$ & $46.5 \%$ & $39.7 \%$ & $44.9 \%$ & \\
\hline R14.9 & Kingsport & 0.046 & $25.8 \%$ & $41.2 \%$ & $13.4 \%$ & $40.5 \%$ & \\
\hline $\mathrm{R} 14.2 \mathrm{~A}$ & Kingsport & 0.15 & $37.5 \%$ & $39.4 \%$ & $28.1 \%$ & $38.9 \%$ & \\
\hline $\mathrm{R} 14.2 \mathrm{~B}$ & Kingsport & 0.15 & $38.1 \%$ & $39.7 \%$ & $28.5 \%$ & $39.1 \%$ & \\
\hline R14.3 & Kingsport & 0.36 & $50.4 \%$ & $45.6 \%$ & $36.1 \%$ & $42.3 \%$ & $39.2 \%$ \\
\hline
\end{tabular}


Table 4. Mean gas holdup data for runs with catalyst A.

\begin{tabular}{ccccccc}
$\begin{array}{c}\text { Run } \\
\text { No. }\end{array}$ & $\begin{array}{c}\mathrm{U}_{\mathrm{G}} \\
(\mathrm{m} / \mathrm{s})\end{array}$ & $\begin{array}{c}\text { Gas } \\
\text { Type }\end{array}$ & $\begin{array}{c}\mathrm{C} \text { to } \mathrm{N} 2 \\
\mathrm{~L} / \mathrm{D}=5.4\end{array}$ & $\begin{array}{c}\mathrm{N} 2 \text { to } \mathrm{D} \\
\mathrm{L} / \mathrm{D}=11.1\end{array}$ & $\begin{array}{c}\mathrm{D} \text { to } \mathrm{N} 1 \\
\mathrm{~L} / \mathrm{D}=17.8\end{array}$ & $\begin{array}{c}\mathrm{N} 1 \text { to } \mathrm{E} \\
\mathrm{L} / \mathrm{D}=24.5\end{array}$ \\
\hline $\mathrm{R} 13.1$ & 0.26 & Texaco & $44.7 \%$ & $42.4 \%$ & $44.9 \%$ & $52.8 \%$ \\
$\mathrm{R} 13.2$ & 0.15 & Kingsport & $34.5 \%$ & $31.6 \%$ & $33.8 \%$ & $41.3 \%$ \\
$\mathrm{R} 13.3$ & 0.34 & Kingsport & $43.7 \%$ & $41.1 \%$ & $43.0 \%$ & $50.2 \%$
\end{tabular}

Table 5. Mean gas holdup data for runs with catalyst B.

\begin{tabular}{ccccccc}
$\begin{array}{c}\text { Run } \\
\text { No. }\end{array}$ & $\begin{array}{c}\mathrm{U}_{\mathrm{G}} \\
(\mathrm{m} / \mathrm{s})\end{array}$ & $\begin{array}{c}\text { Gas } \\
\text { Type }\end{array}$ & $\begin{array}{c}\mathrm{C} \text { to } \mathrm{N} 2 \\
\mathrm{~L} / \mathrm{D}=5.4\end{array}$ & $\begin{array}{c}\mathrm{N} 2 \text { to } \mathrm{D} \\
\mathrm{L} / \mathrm{D}=11.1\end{array}$ & $\begin{array}{c}\mathrm{D} \text { to N1 } \\
\mathrm{L} / \mathrm{D}=17.8\end{array}$ & $\begin{array}{c}\mathrm{N} 1 \text { to } \mathrm{E} \\
\mathrm{L} / \mathrm{D}=24.5\end{array}$ \\
\hline $\mathrm{R} 14.4$ & 0.14 & Texaco & $32.1 \%$ & $29.0 \%$ & $32.2 \%$ & $38.7 \%$ \\
$\mathrm{R} 14.1$ & 0.26 & Texaco & $37.7 \%$ & $34.7 \%$ & $37.7 \%$ & $44.2 \%$ \\
$\mathrm{R} 14.5$ & 0.25 & Texaco & $38.2 \%$ & $35.5 \%$ & $38.5 \%$ & $46.4 \%$ \\
$\mathrm{R} 14.9$ & 0.046 & Kingsport & $16.3 \%$ & $11.4 \%$ & $12.5 \%$ & \\
$\mathrm{R} 14.2$ & 0.15 & Kingsport & $28.8 \%$ & $24.7 \%$ & $27.0 \%$ & $32.8 \%$ \\
$\mathrm{R} 14.3$ & 0.36 & Kingsport & $36.0 \%$ & $32.8 \%$ & $34.4 \%$ & $41.1 \%$
\end{tabular}

Table 6. Standard deviations in gas holdup data for runs with catalyst A.

\begin{tabular}{ccccccc}
$\begin{array}{c}\text { Run } \\
\text { No. }\end{array}$ & $\begin{array}{c}\mathrm{U}_{\mathrm{G}} \\
(\mathrm{m} / \mathrm{s})\end{array}$ & $\begin{array}{c}\text { Gas } \\
\text { Type }\end{array}$ & $\begin{array}{c}\mathrm{C} \text { to N2 } \\
\mathrm{L} / \mathrm{D}=5.4\end{array}$ & $\begin{array}{c}\mathrm{N} 2 \text { to } \mathrm{D} \\
\mathrm{L} / \mathrm{D}=11.1\end{array}$ & $\begin{array}{c}\mathrm{D} \text { to } \mathrm{N} 1 \\
\mathrm{~L} / \mathrm{D}=17.8\end{array}$ & $\begin{array}{c}\mathrm{N} 1 \text { to } \mathrm{E} \\
\mathrm{L} / \mathrm{D}=24.5\end{array}$ \\
\hline $\mathrm{R} 13.1$ & 0.26 & Texaco & $0.65 \%$ & $0.59 \%$ & $0.49 \%$ & $1.06 \%$ \\
$\mathrm{R} 13.2$ & 0.15 & Kingsport & $0.57 \%$ & $0.45 \%$ & $0.32 \%$ & $0.89 \%$ \\
$\mathrm{R} 13.3$ & 0.34 & Kingsport & $0.93 \%$ & $0.88 \%$ & $0.71 \%$ & $1.53 \%$
\end{tabular}

Table 7. Standard deviations in gas holdup data for runs with catalyst B.

\begin{tabular}{ccccccc}
$\begin{array}{c}\text { Run } \\
\text { No. }\end{array}$ & $\begin{array}{c}\mathrm{U}_{\mathrm{G}} \\
(\mathrm{m} / \mathrm{s})\end{array}$ & $\begin{array}{c}\text { Gas } \\
\text { Type }\end{array}$ & $\begin{array}{c}\mathrm{C} \text { to N2 } \\
\mathrm{L} / \mathrm{D}=5.4\end{array}$ & $\begin{array}{c}\mathrm{N} 2 \text { to } \mathrm{D} \\
\mathrm{L} / \mathrm{D}=11.1\end{array}$ & $\begin{array}{c}\mathrm{D} \text { to N1 } \\
\mathrm{L} / \mathrm{D}=17.8\end{array}$ & $\begin{array}{c}\mathrm{N} 1 \text { to } \mathrm{E} \\
\mathrm{L} / \mathrm{D}=24.5\end{array}$ \\
\hline $\mathrm{R} 14.4$ & 0.14 & Texaco & $0.46 \%$ & $0.38 \%$ & $0.35 \%$ & $1.04 \%$ \\
$\mathrm{R} 14.1$ & 0.26 & Texaco & $0.75 \%$ & $0.71 \%$ & $0.64 \%$ & $1.30 \%$ \\
$\mathrm{R} 14.5$ & 0.25 & Texaco & $0.77 \%$ & $0.71 \%$ & $0.65 \%$ & $1.29 \%$ \\
$\mathrm{R} 14.9$ & 0.046 & Kingsport & $0.32 \%$ & $0.23 \%$ & $0.31 \%$ & $0.48 \%$ \\
$\mathrm{R} 14.2$ & 0.15 & Kingsport & $0.51 \%$ & $0.44 \%$ & $0.39 \%$ & $0.84 \%$ \\
$\mathrm{R} 14.3$ & 0.36 & Kingsport & $1.05 \%$ & $1.04 \%$ & $0.88 \%$ & $1.85 \%$
\end{tabular}




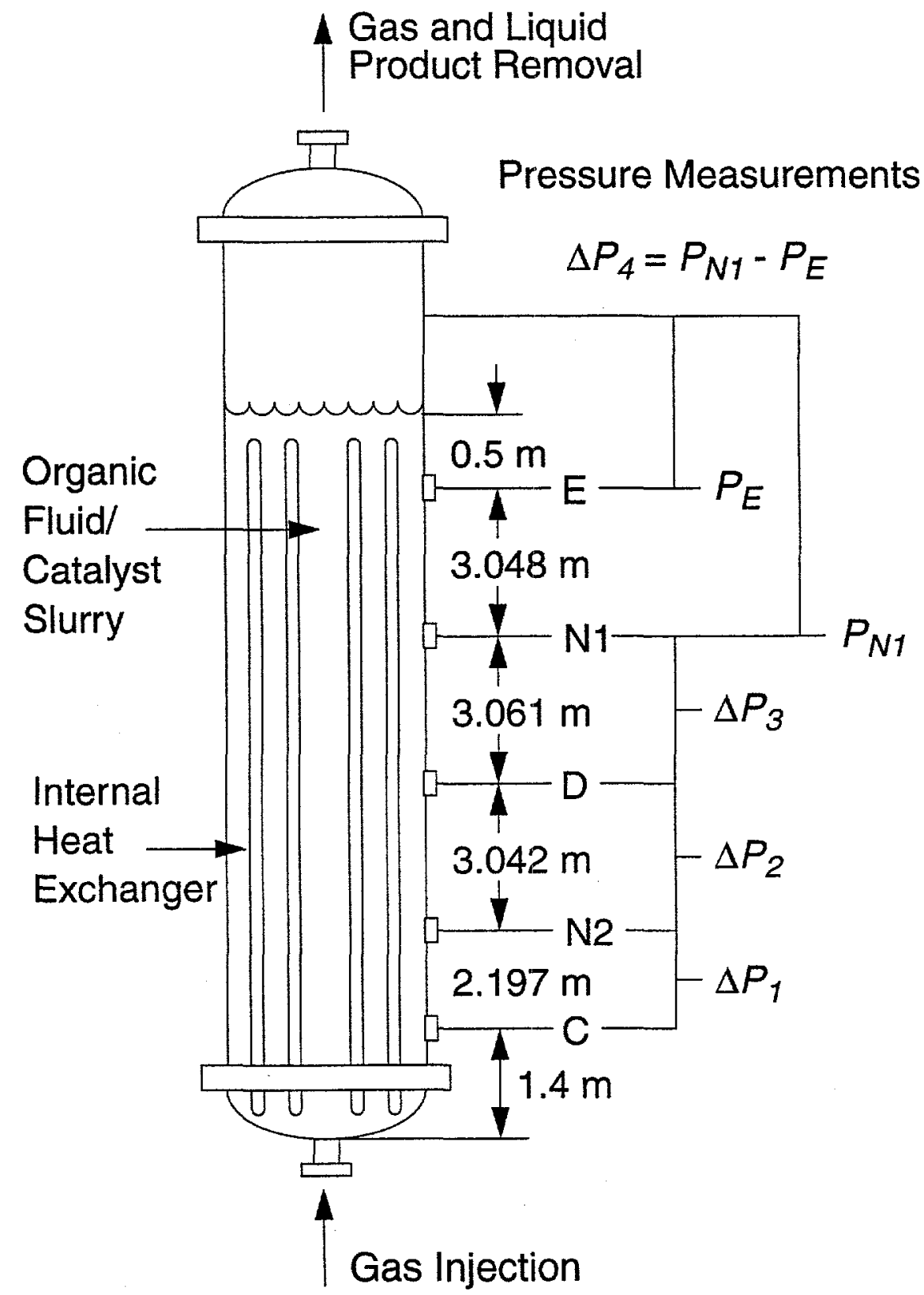

Figure 1. Schematic diagram of LaPorte Alternative Fuels Development Unit (AFDU); 18 in. $(0.457 \mathrm{~m})$ inside diameter, $50 \mathrm{ft}$. $(15.24 \mathrm{~m})$ normal liquid level during operation, 2000 psig (13.8 $\mathrm{MPa})$ design pressure, $700^{\circ} \mathrm{F}\left(371^{\circ} \mathrm{C}\right)$ design temperature. 


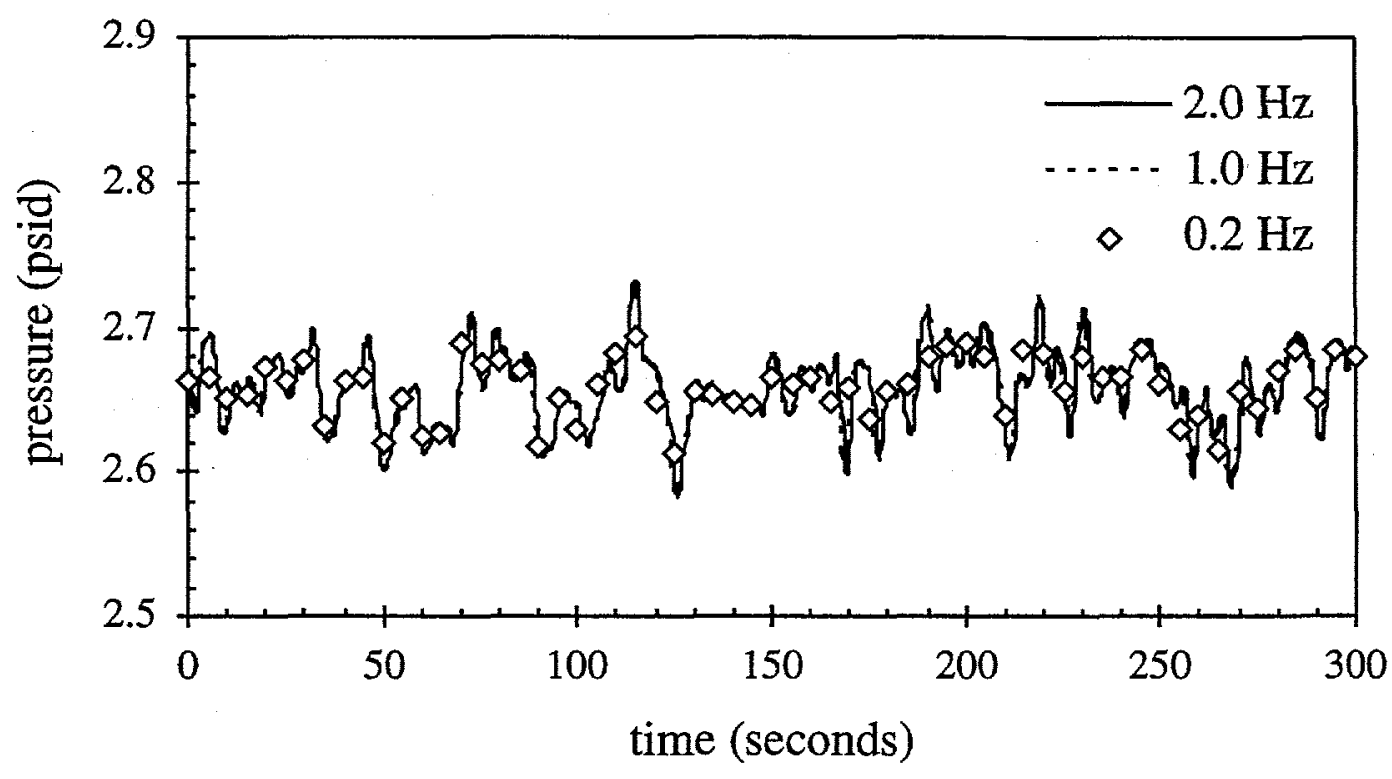

Figure 2. Time trace of differential pressure signal between nozzles N2 and $D(L / D=11.1)$ at different sampling rates for Run No. R13.1, $U_{G}=0.26 \mathrm{~m} / \mathrm{s}$, Texaco gas, $\omega_{S}=49 \%, 765$ psia $(5.27 \mathrm{MPa}), 482^{\circ} \mathrm{F}\left(250^{\circ} \mathrm{C}\right)$. 

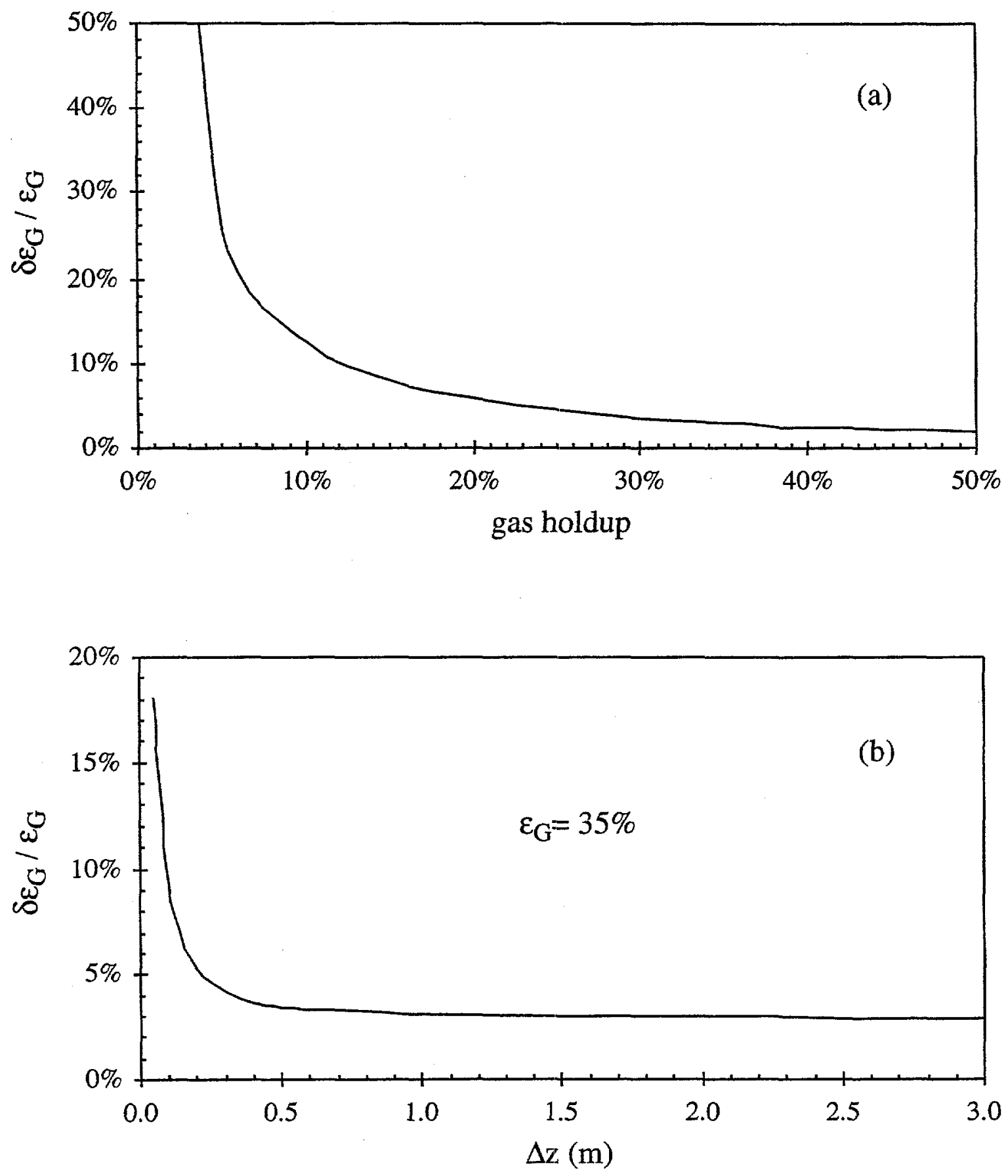

Figure 3. Relative uncertainty in gas holdup ( $\delta \varepsilon_{G} / \varepsilon_{G}$ ) as function of (a) gas holdup and (b) distance between pressure taps under AFDU operating conditions, Texaco gas, and catalyst A. 

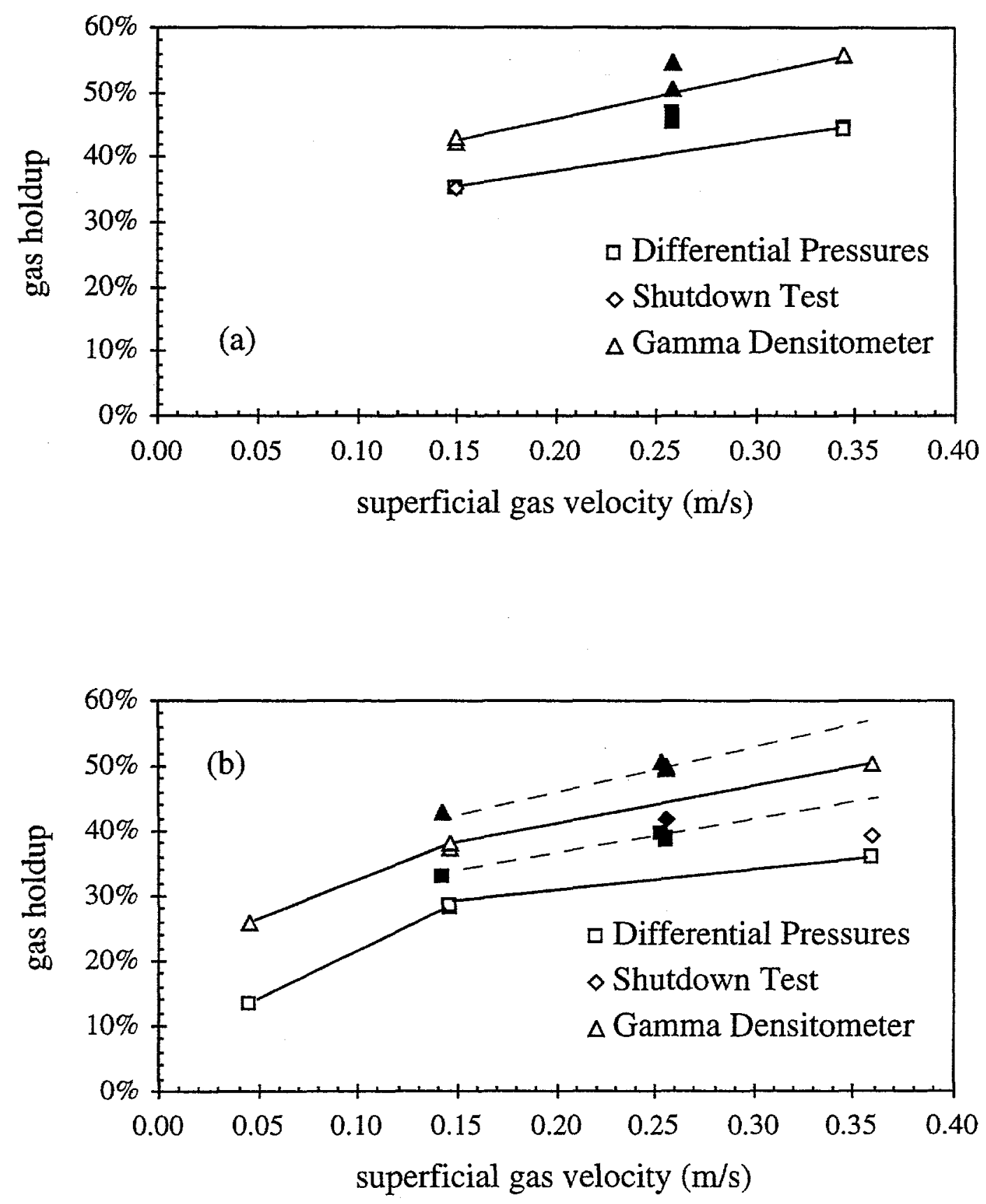

Figure 4. Comparison of gas holdups measured using differential pressures, gamma densitometer and shutdown test for (a) catalyst A runs (R13) and (b) catalyst B runs (R14); closed and open symbols denote Texaco and Kingsport gas, $\omega_{S}=39 \%-49 \%$, 535-765 psia (3.69$5.27 \mathrm{MPa}), 482^{\circ} \mathrm{F}\left(250^{\circ} \mathrm{C}\right)$. 


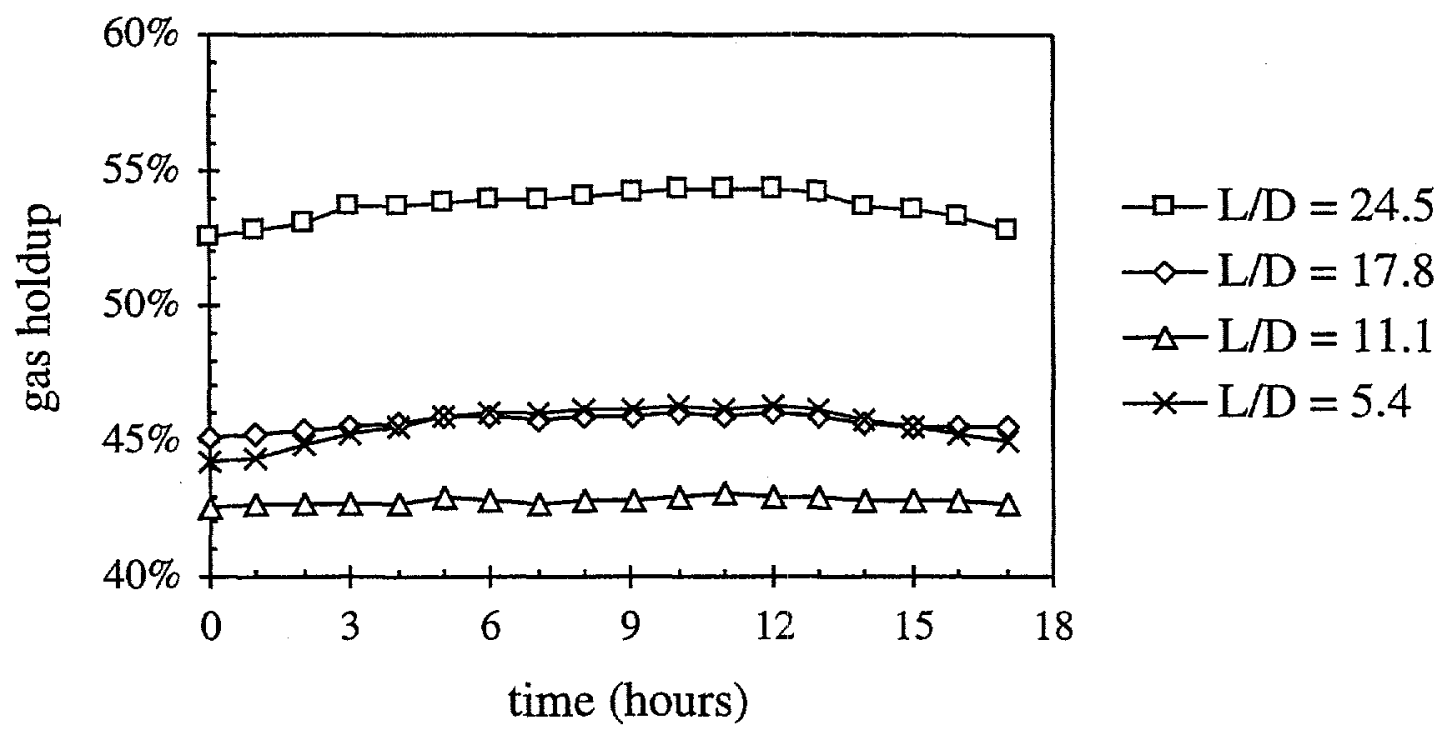

Figure 5. Gas holdups averaged over one-hour periods for catalyst A run number R13.1; $U_{G}=0.26 \mathrm{~m} / \mathrm{s}$, Texaco gas, $\omega_{S}=49 \%, 765 \mathrm{psia}(5.27 \mathrm{MPa}), 482^{\circ} \mathrm{F}\left(250^{\circ} \mathrm{C}\right)$.

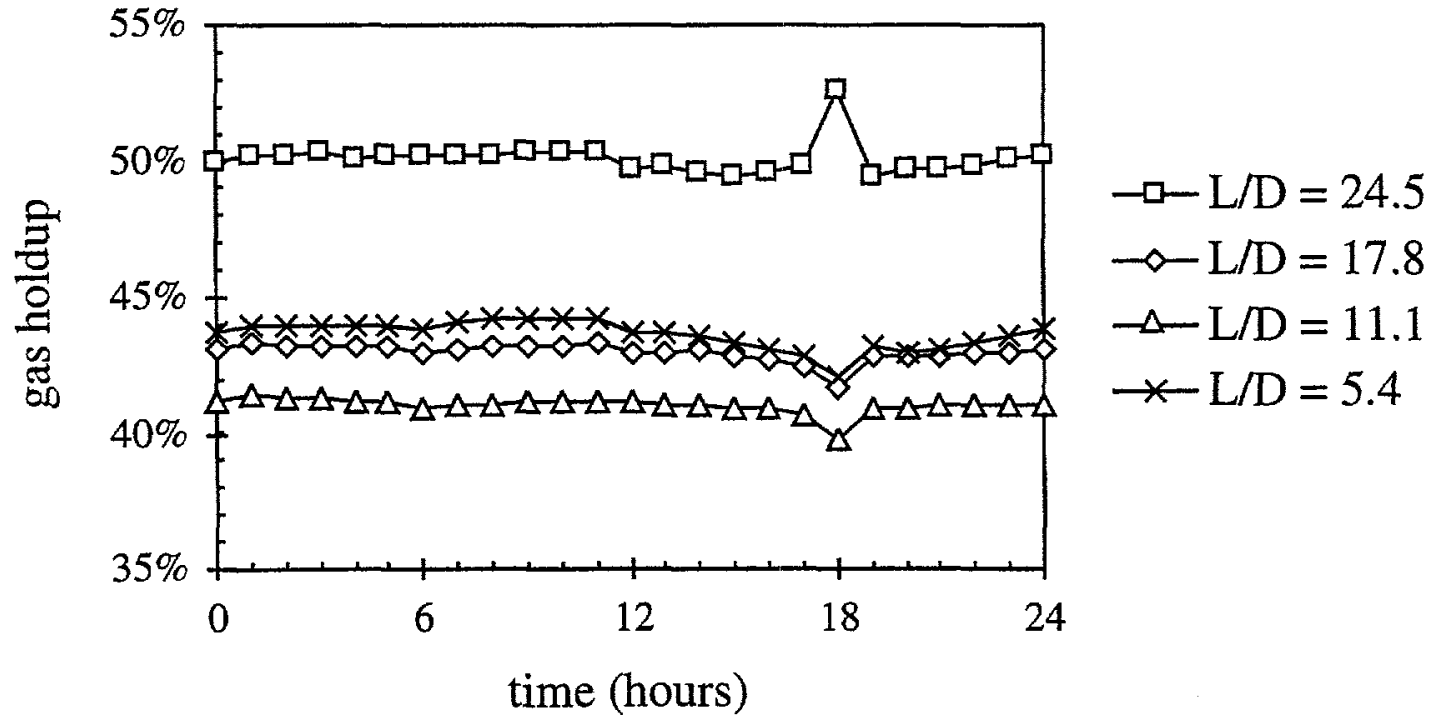

Figure 6. Gas holdups averaged over one-hour periods for catalyst A run number R13.3; $U_{G}=0.34 \mathrm{~m} / \mathrm{s}$, Kingsport gas, $\omega_{S}=48 \%, 735 \mathrm{psia}(5.07 \mathrm{MPa}), 482^{\circ} \mathrm{F}\left(250^{\circ} \mathrm{C}\right)$. 


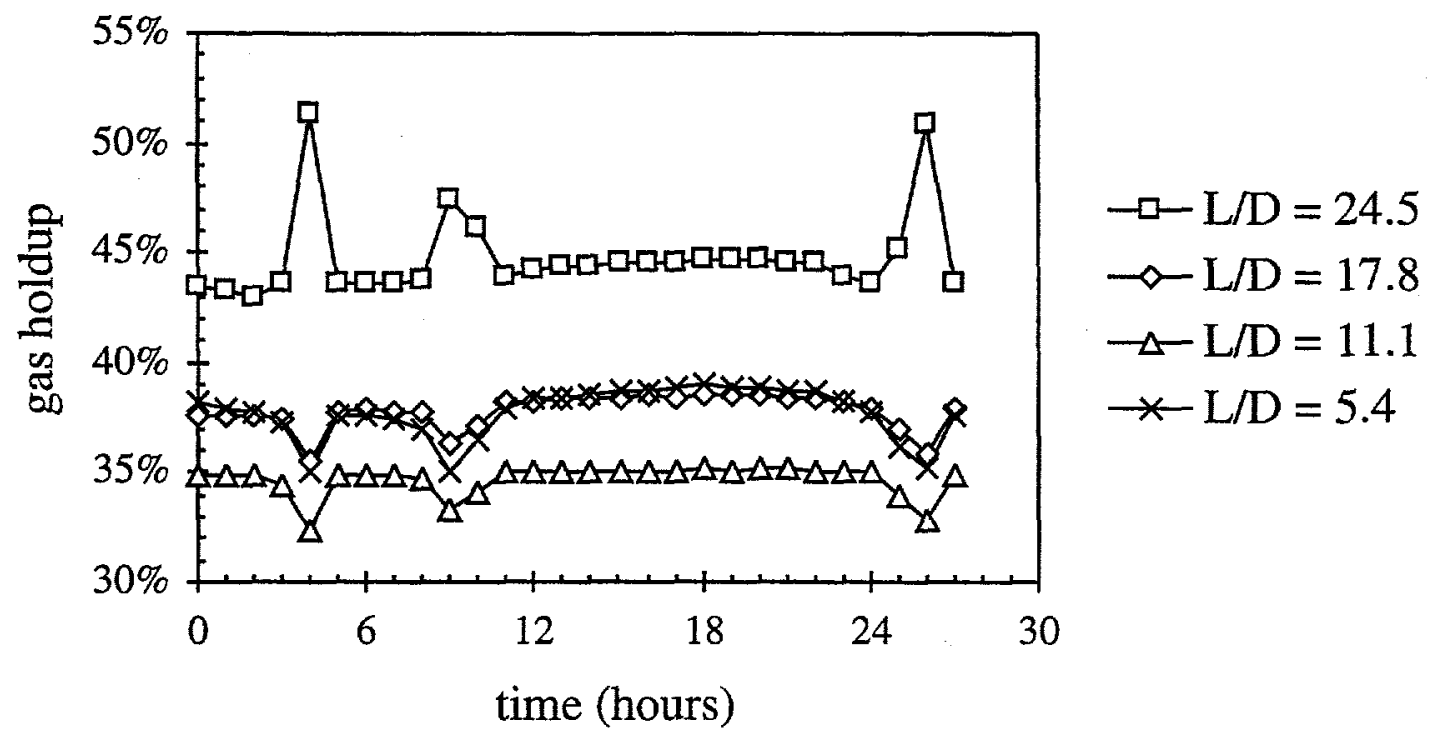

Figure 7. Gas holdups averaged over one-hour periods for catalyst B run number R14.1; $U_{G}=0.26 \mathrm{~m} / \mathrm{s}$, Texaco gas, $\omega_{S}=44 \%, 765 \mathrm{psia}(5.27 \mathrm{MPa}), 482^{\circ} \mathrm{F}\left(250^{\circ} \mathrm{C}\right)$.

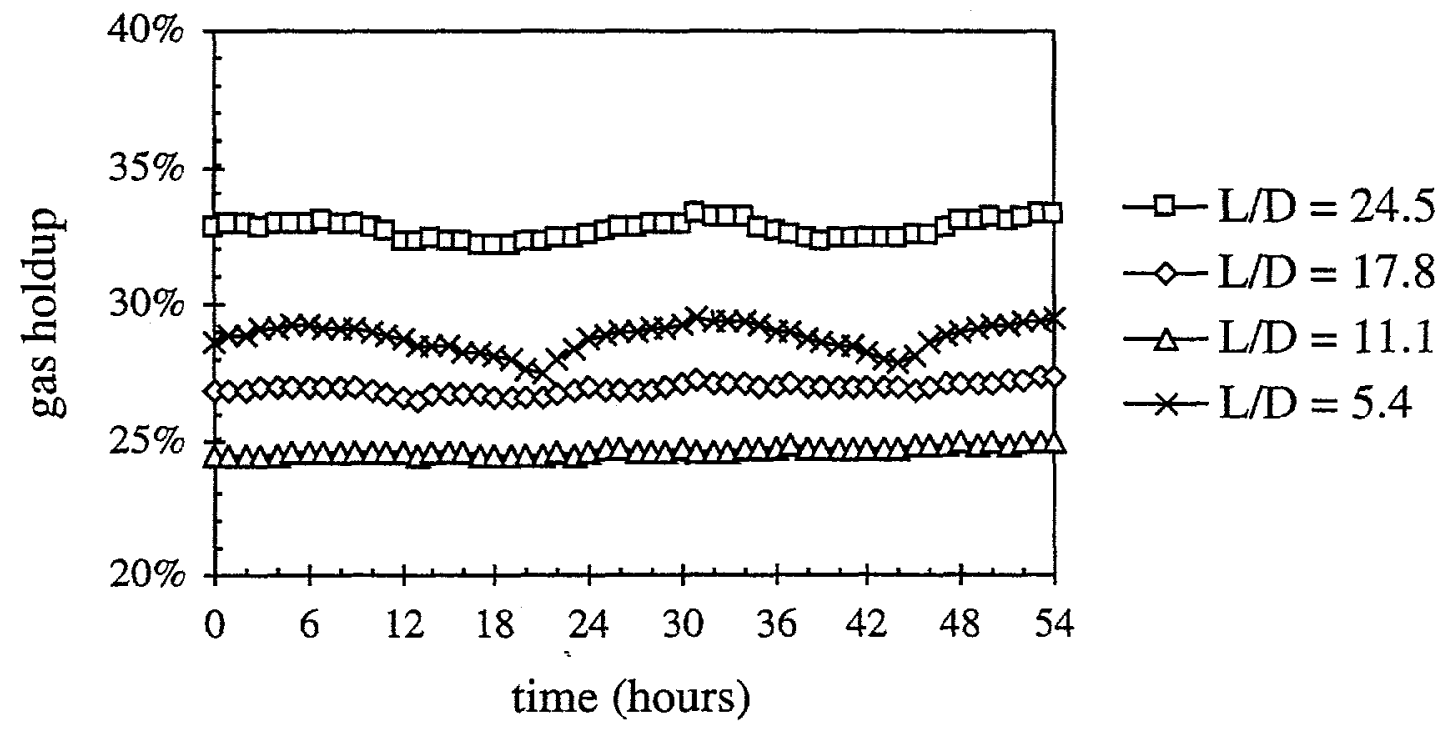

Figure 8. Gas holdups averaged over one-hour periods for catalyst B run number R14.2; $U_{G}=0.15 \mathrm{~m} / \mathrm{s}$, Kingsport gas, $\omega_{S}=39 \%, 750 \mathrm{psia}(5.17 \mathrm{MPa}), 482^{\circ} \mathrm{F}\left(250^{\circ} \mathrm{C}\right)$. 


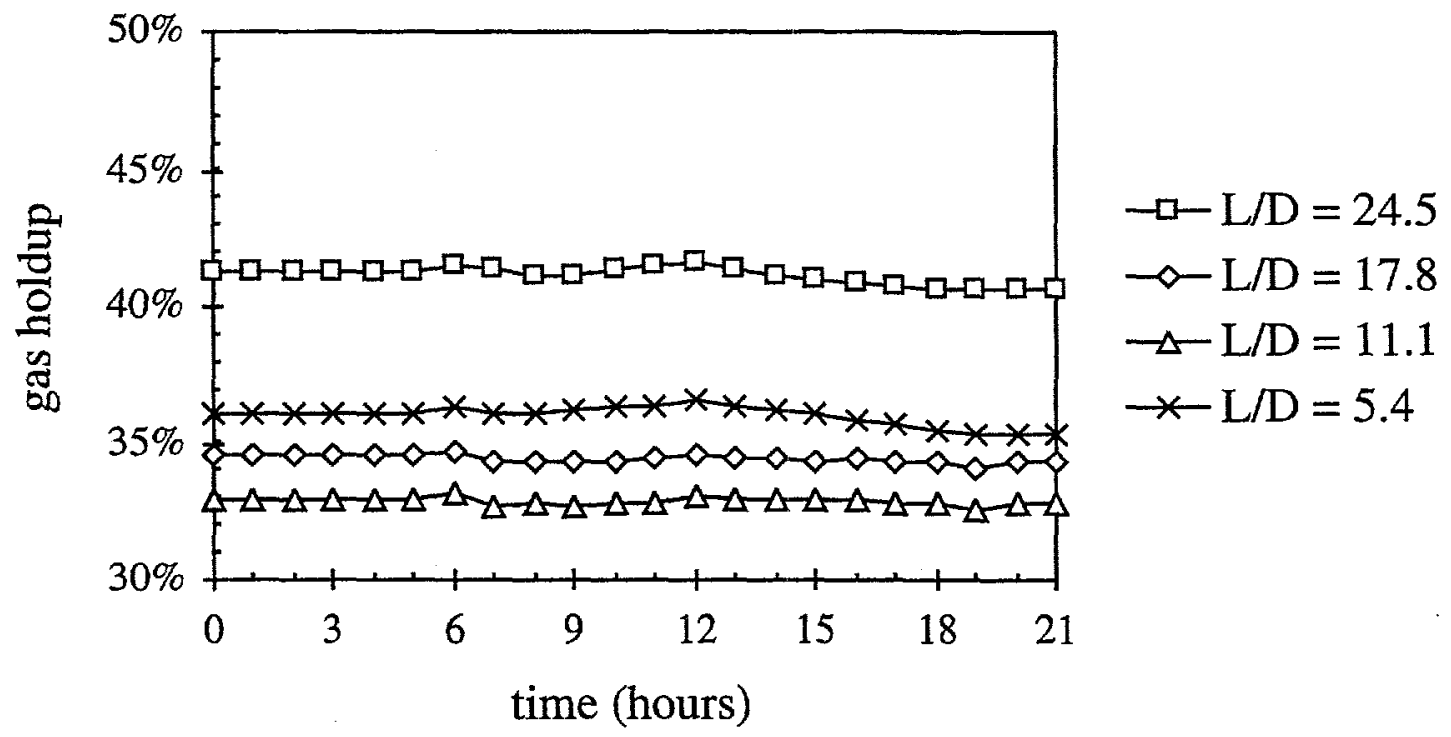

Figure 9. Gas holdups averaged over one-hour periods for catalyst B run number R14.3; $U_{G}=0.36 \mathrm{~m} / \mathrm{s}$, Kingsport gas, $\omega_{S}=42 \%, 535 \mathrm{psia}(3.69 \mathrm{MPa}), 482^{\circ} \mathrm{F}\left(250^{\circ} \mathrm{C}\right)$.

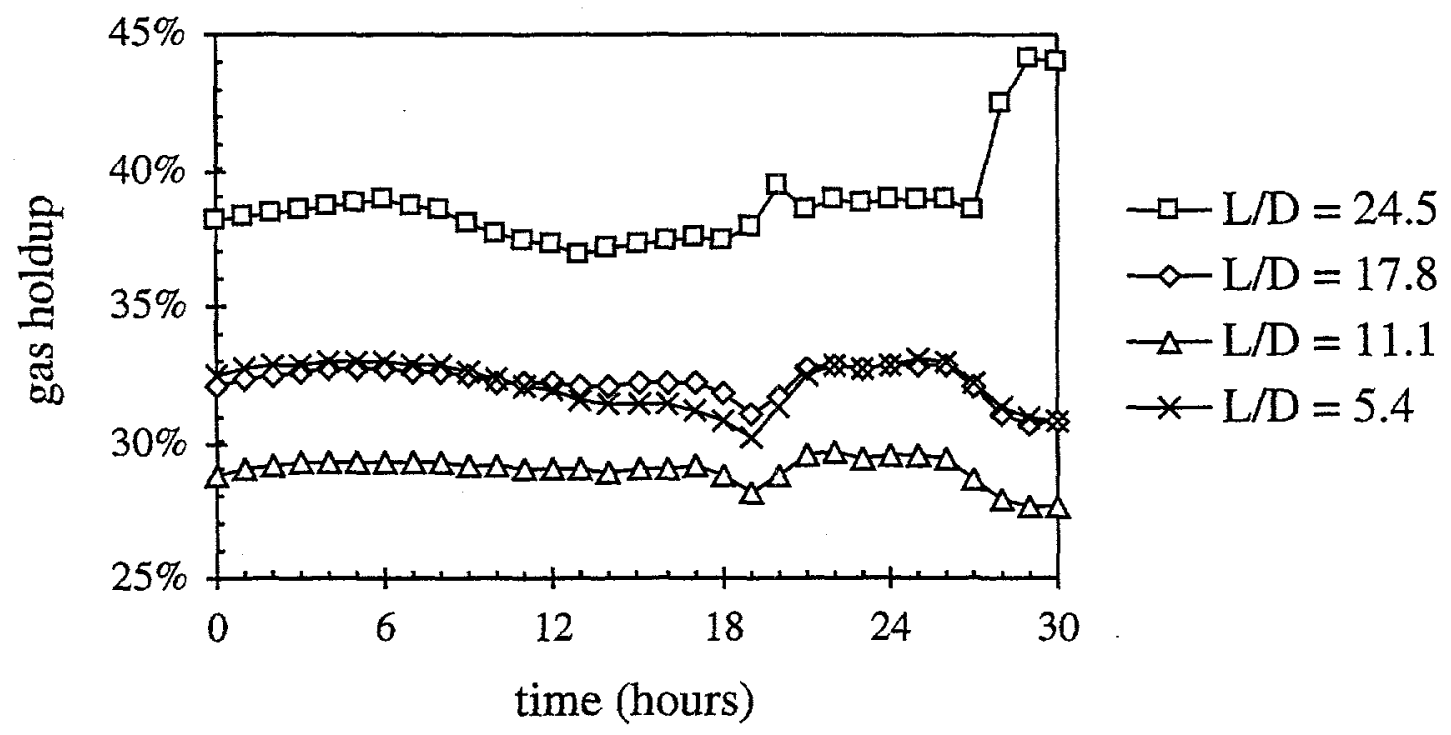

Figure 10. Gas holdups averaged over one-hour periods for catalyst B run number R14.4; $U_{G}=0.14 \mathrm{~m} / \mathrm{s}$, Texaco gas, $\omega_{S}=41 \%, 765 \mathrm{psia}(5.27 \mathrm{MPa}), 482^{\circ} \mathrm{F}\left(250^{\circ} \mathrm{C}\right)$. 


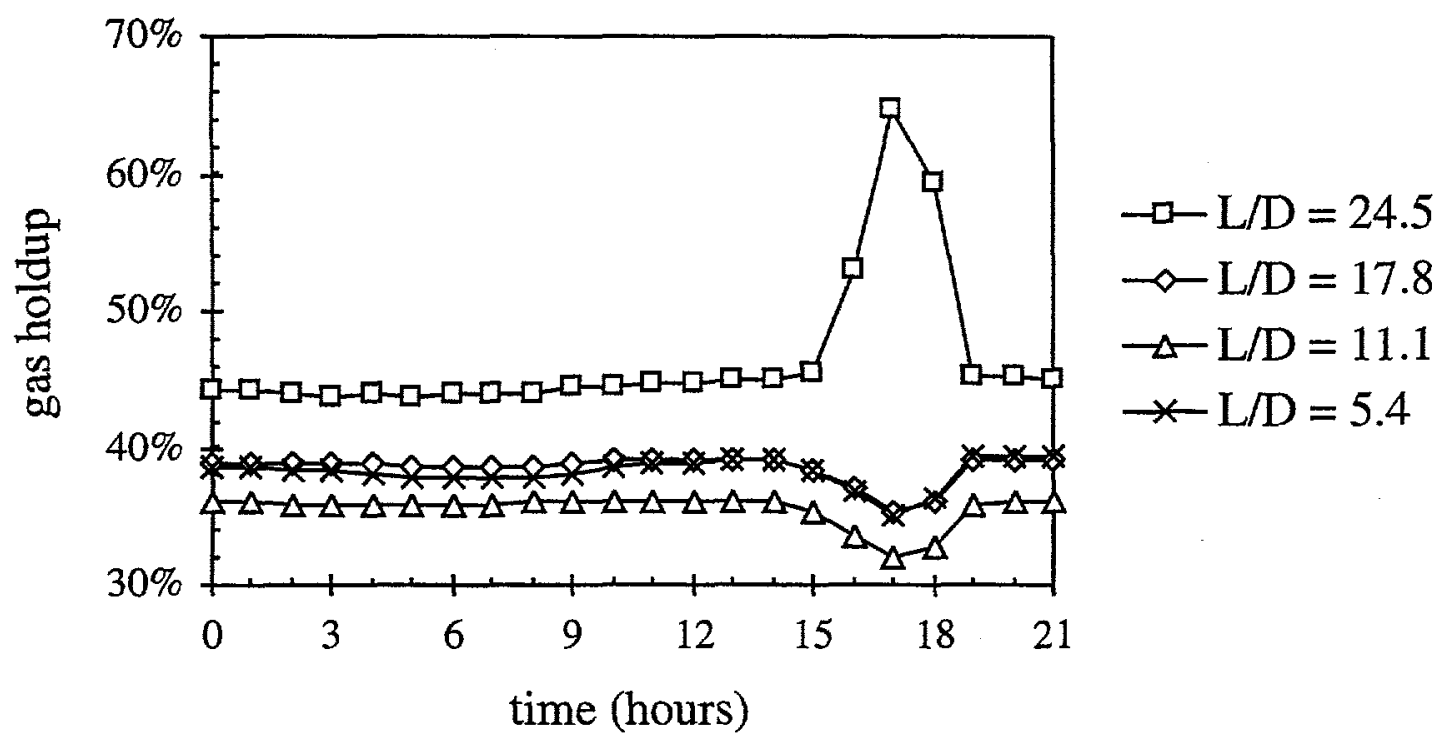

Figure 11. Gas holdups averaged over one-hour periods for catalyst $B$ run number R14.5; $U_{G}=0.25 \mathrm{~m} / \mathrm{s}$, Texaco gas, $\omega_{S}=45 \%, 765 \mathrm{psia}(5.27 \mathrm{MPa}), 482^{\circ} \mathrm{F}\left(250^{\circ} \mathrm{C}\right)$. 

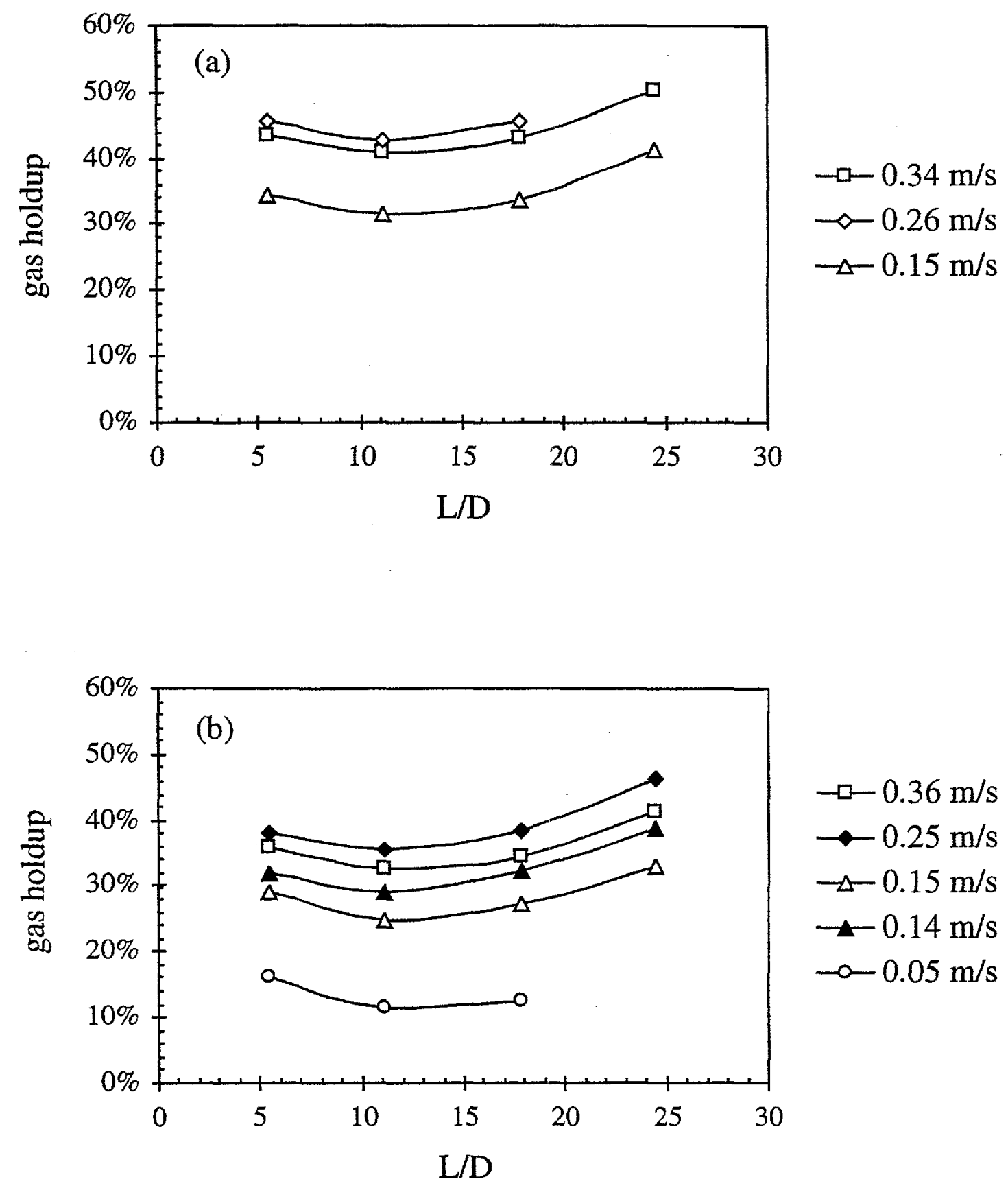

Figure 12. Gas holdup versus axial distance from sparger and superficial gas velocity in the AFDU for (a) catalyst A and (b) catalyst B; closed and open symbols denote Texaco and Kingsport gas, $\omega_{S}=39-44 \%, 535-765$ psia $(3.69-5.27 \mathrm{MPa}), 482^{\circ} \mathrm{F}\left(250^{\circ} \mathrm{C}\right)$. 

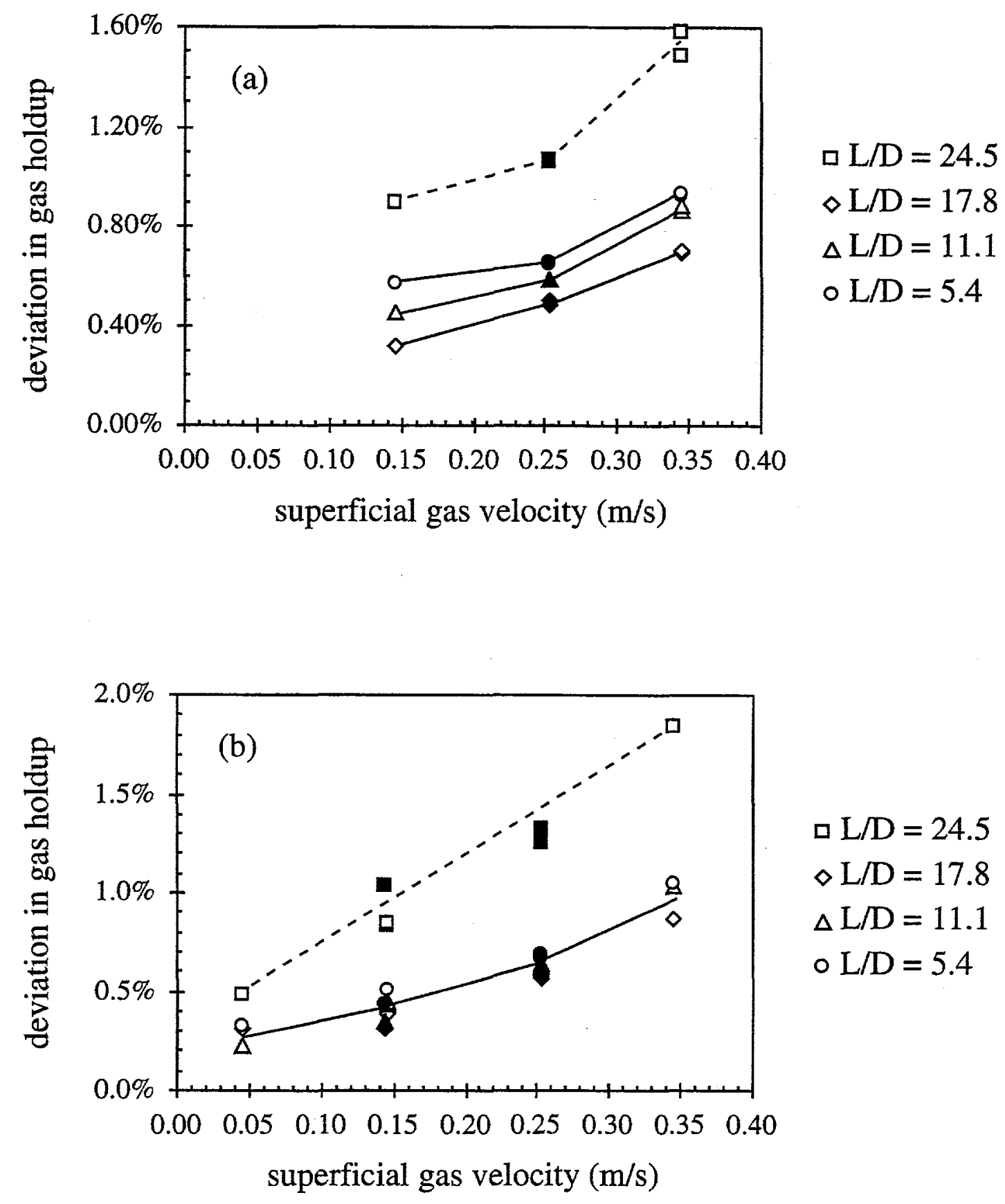

Figure 13. Standard deviation of gas holdup versus superficial gas velocity and axial distance from sparger in the AFDU for (a) catalyst A and (b) catalyst B; closed and open symbols denote Texaco and Kingsport gas, $\omega_{S}=39-44 \%, 535-765 \mathrm{psia}(3.69-5.27 \mathrm{MPa}), 482^{\circ} \mathrm{F}\left(250^{\circ} \mathrm{C}\right)$. 


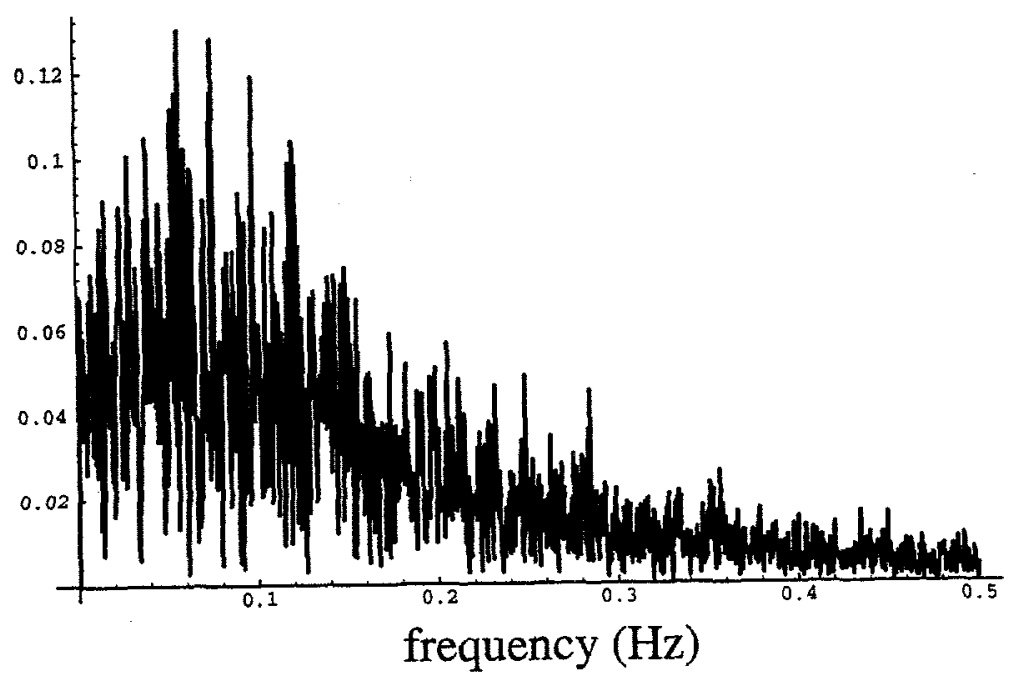

Figure 14. Frequency spectrum of differential pressure for catalyst $\mathrm{B}$ run number R14.3; $U_{G}=0.36 \mathrm{~m} / \mathrm{s}$, Kingsport gas; $\omega_{S}=42 \%, 535 \mathrm{psia}(3.69 \mathrm{MPa}), 482^{\circ} \mathrm{F}\left(250^{\circ} \mathrm{C}\right)$. 

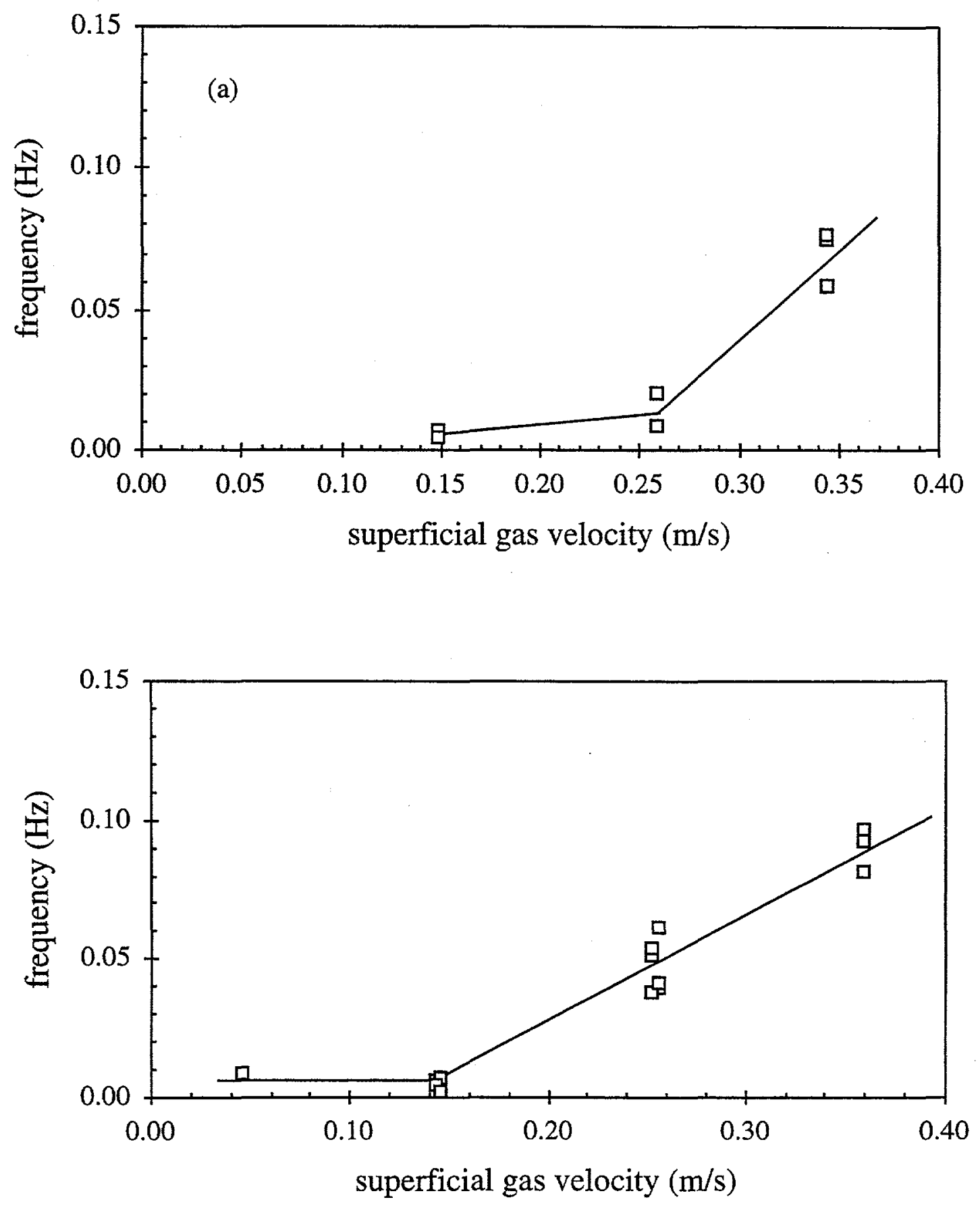

Figure 15. Dominant frequency component from Fourier analysis of differential pressures versus superficial gas velocity in the AFDU for (a) catalyst A and (b) catalyst B; $\omega_{S}=39-44 \%, 535-$ 765 psia $(3.69-5.27 \mathrm{MPa}), 482^{\circ} \mathrm{F}\left(250^{\circ} \mathrm{C}\right)$. 


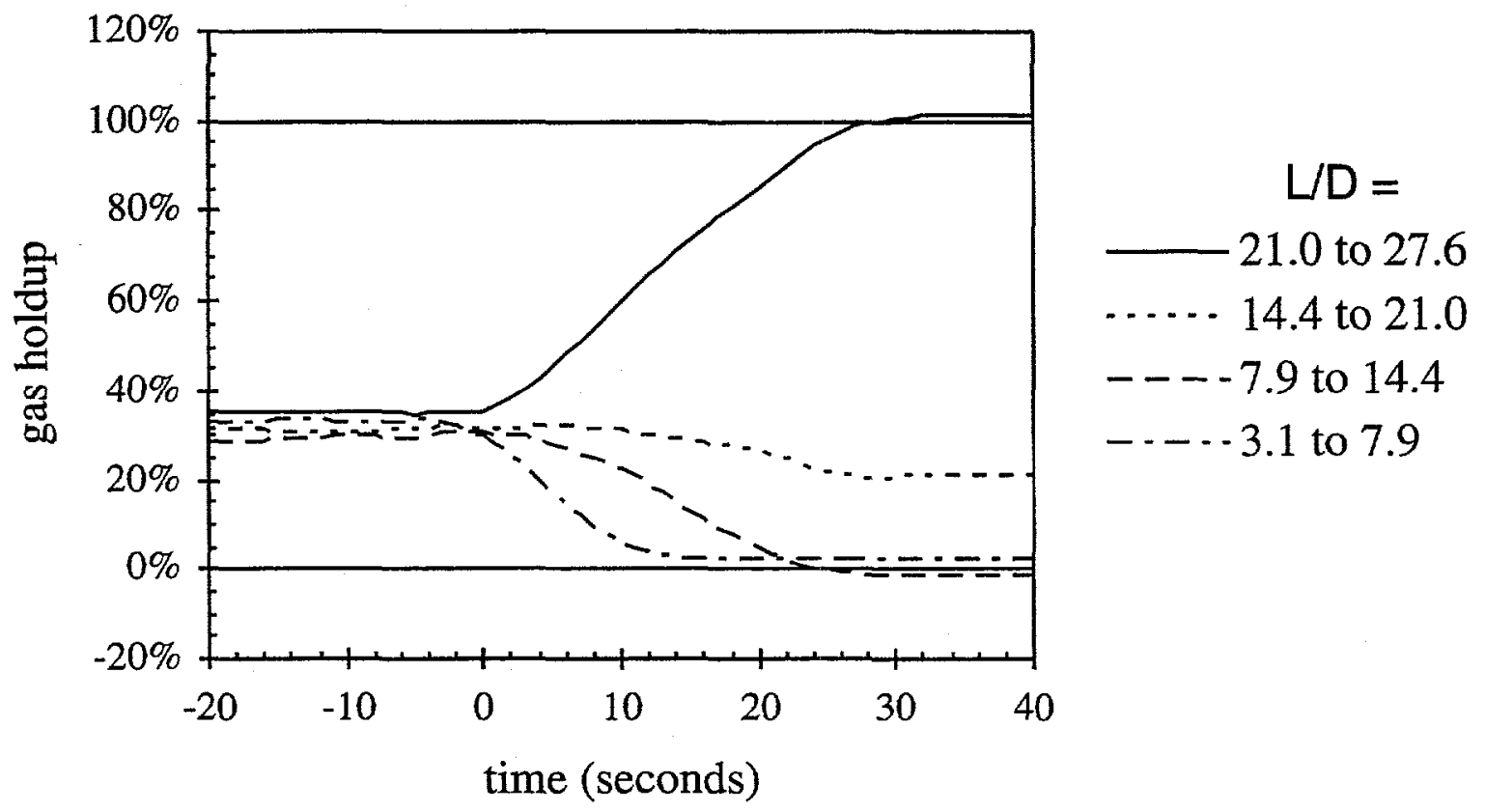

Figure 16. Dynamic Gas Disengagement curves from differential pressure measurements in AFDU for Run No. R13.2; $U_{G}=0.15 \mathrm{~m} / \mathrm{s}$, Kingsport gas, $\omega_{S}=43 \%$, catalyst A, 750 psia $(5.17 \mathrm{MPa})$ and $482^{\circ} \mathrm{F}\left(250^{\circ} \mathrm{C}\right)$.

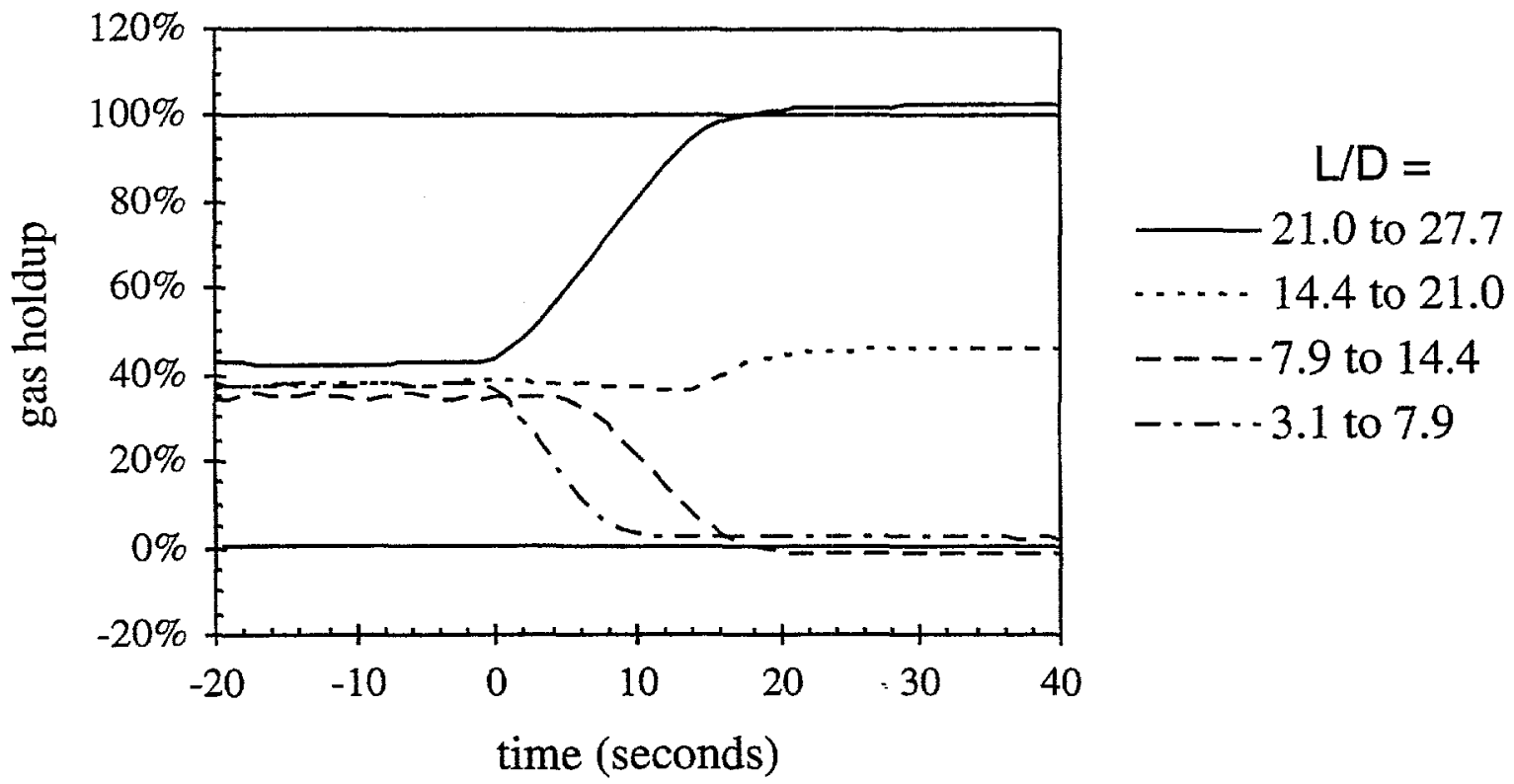

Figure 17. Dynamic Gas Disengagement curves from differential pressure measurements in AFDU for Run No. R $14.1 ; U_{G}=0.25 \mathrm{~m} / \mathrm{s}$, Texaco gas, $\omega_{S}=43 \%$, catalyst $\mathrm{B}, 765$ psia $(5.27 \mathrm{MPa})$ and $482^{\circ} \mathrm{F}\left(250^{\circ} \mathrm{C}\right)$. 


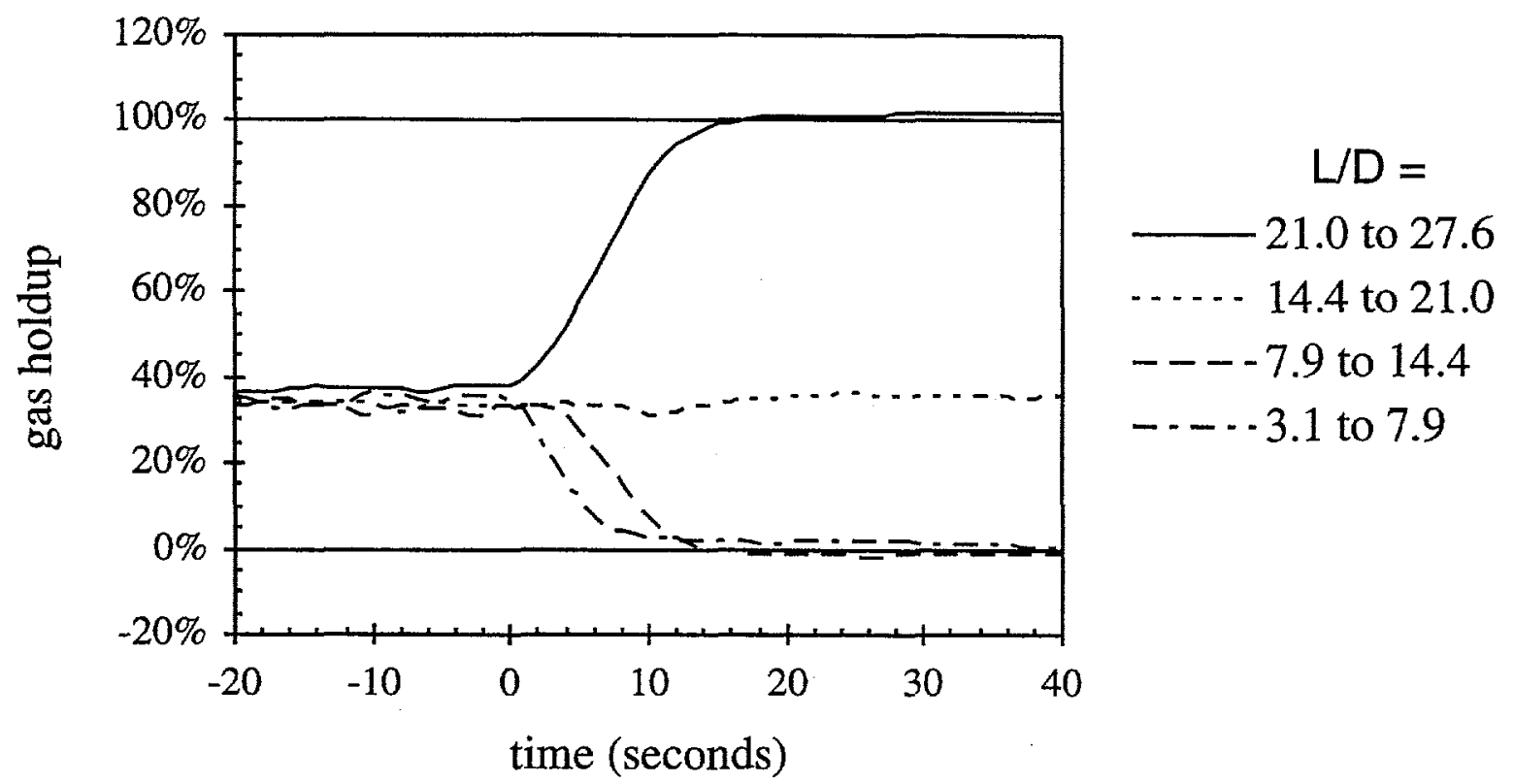

Figure 18. Dynamic Gas Disengagement curves from differential pressure measurements in AFDU for Run No. R14.3; $U_{G}=0.36 \mathrm{~m} / \mathrm{s}$, Kingsport gas, $\omega_{S}=43 \%$, 535 psia (3.69 MPa) and $482^{\circ} \mathrm{F}\left(250^{\circ} \mathrm{C}\right)$.

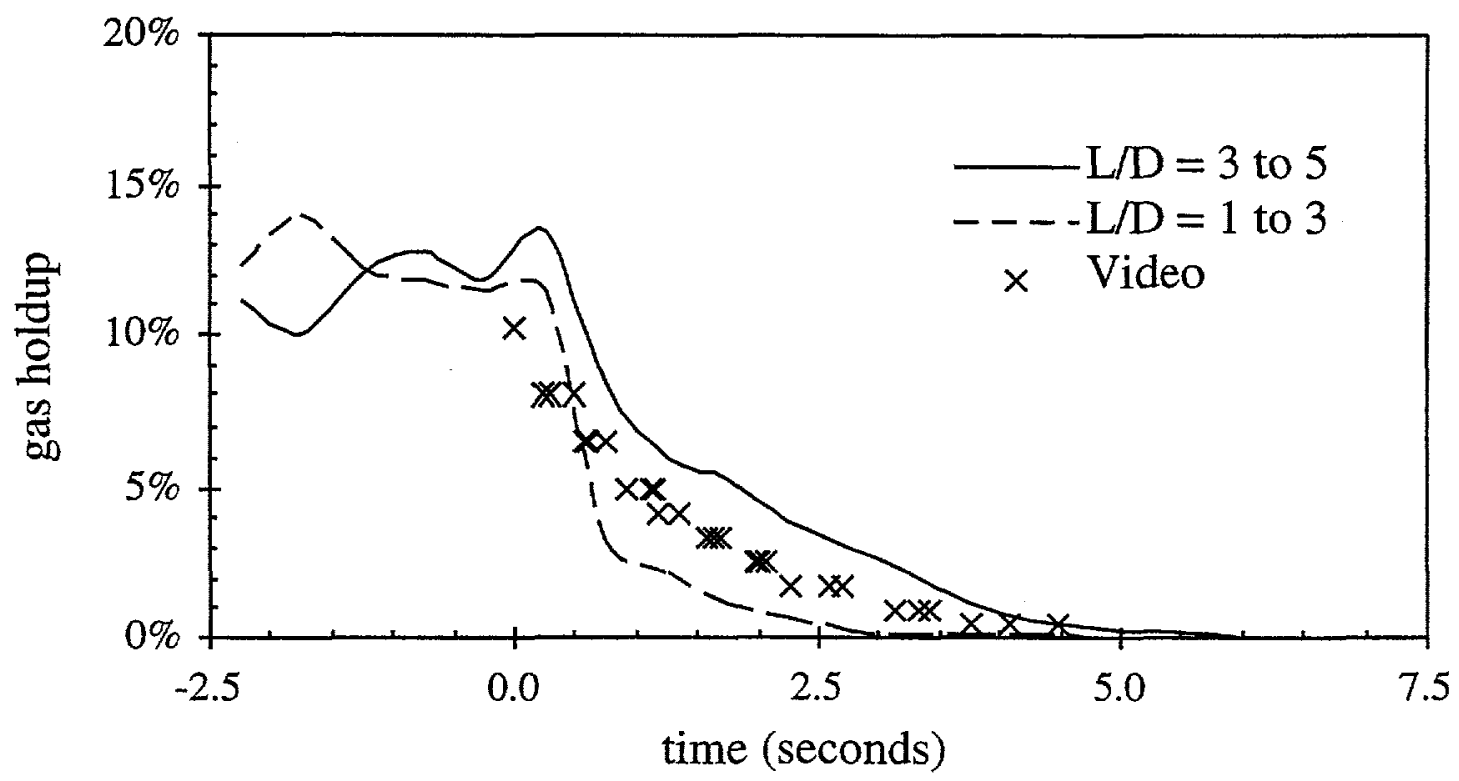

Figure 19. Dynamic Gas Disengagement curves from differential pressure measurements and high-speed video in $0.19 \mathrm{~m}$ Lexan column with air, water and 80 micron glass beads at atmospheric pressure and temperature; $U_{G}=0.088 \mathrm{~m} / \mathrm{s}, \omega_{S}=40 \%$. 


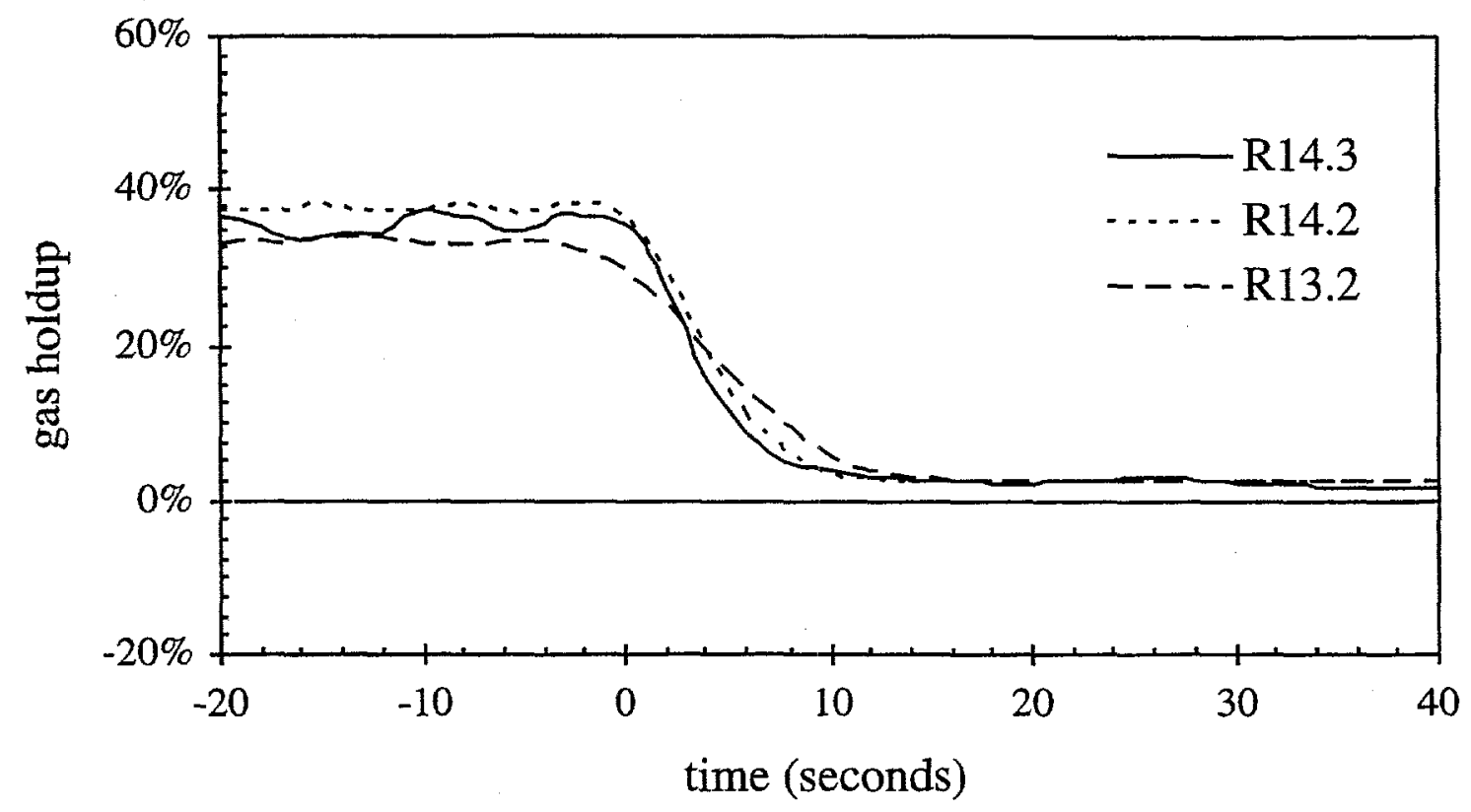

Figure 20. Dynamic Gas Disengagement curves in AFDU after run numbers R13.2, R14.1 and $\mathrm{R} 14.3$ at $\mathrm{L} / \mathrm{D}$ between 3.1 and 7.9.

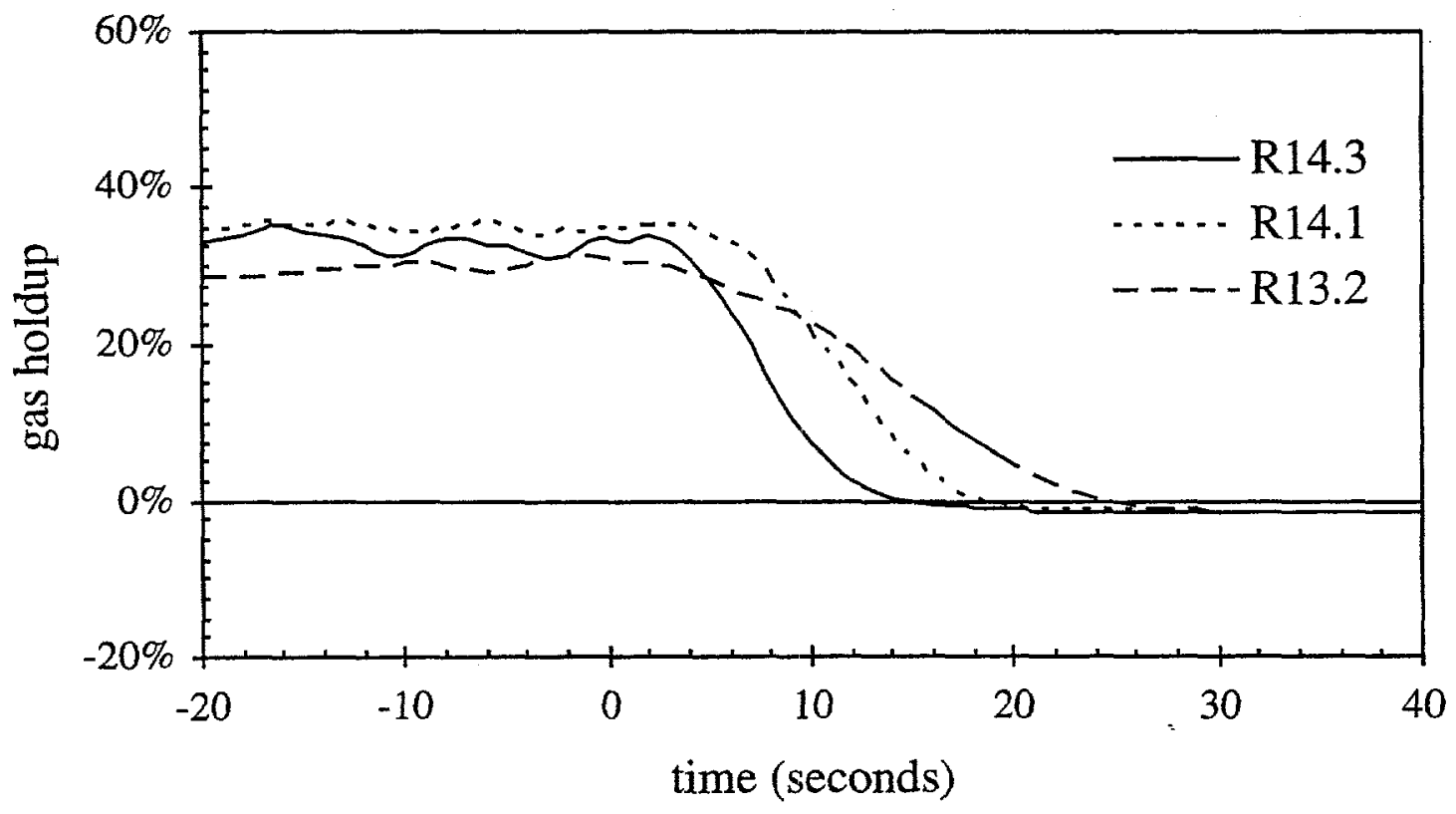

Figure 21. Dynamic Gas Disengagement curves in AFDU after run numbers R13.2, R14.1 and $R 14.3$ at $L / D$ between 7.9 and 14.4. 


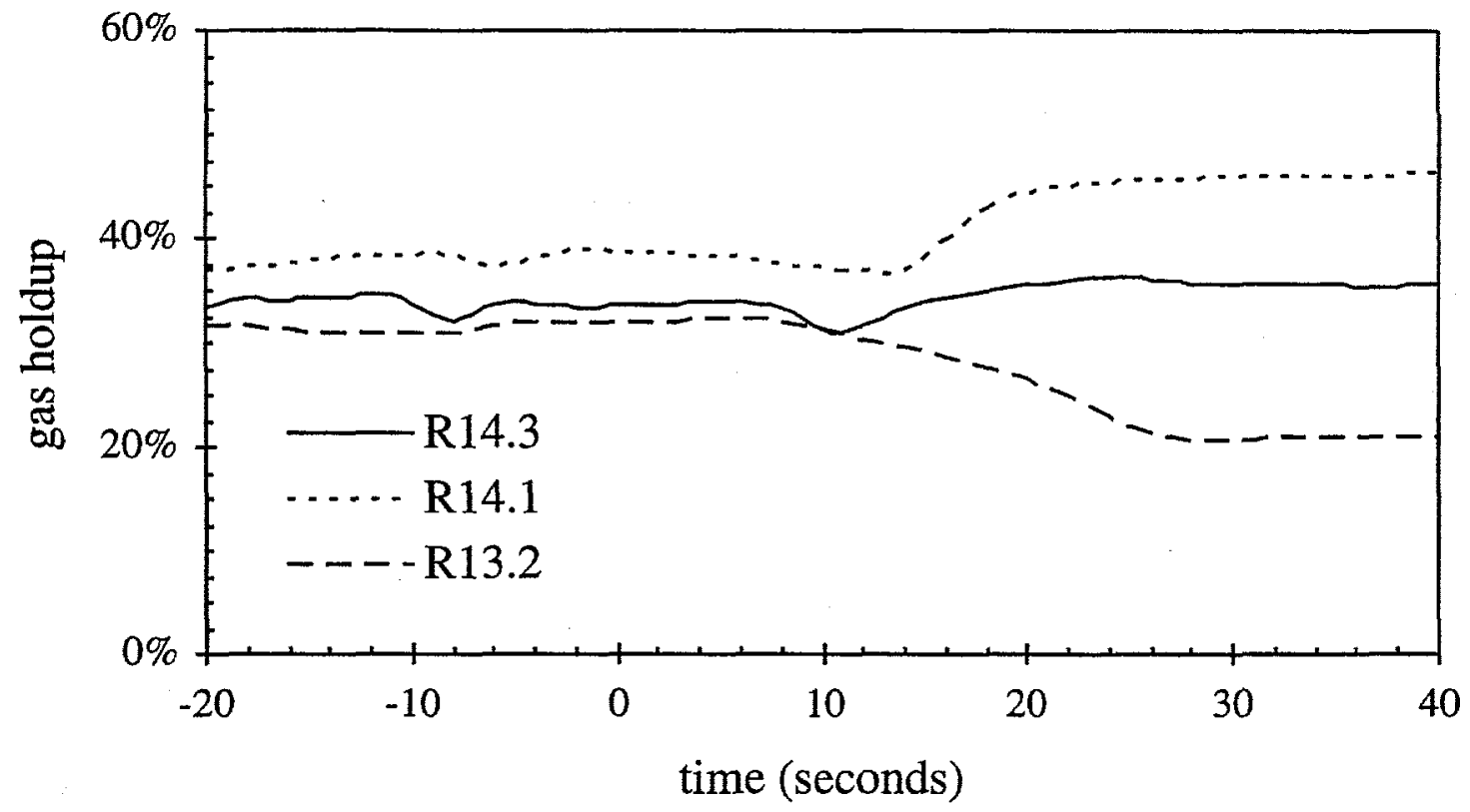

Figure 22. Dynamic Gas Disengagement curves in AFDU after run numbers R13.2, R14.1 and R14.3 at L/D between 14.4 and 21.0 .

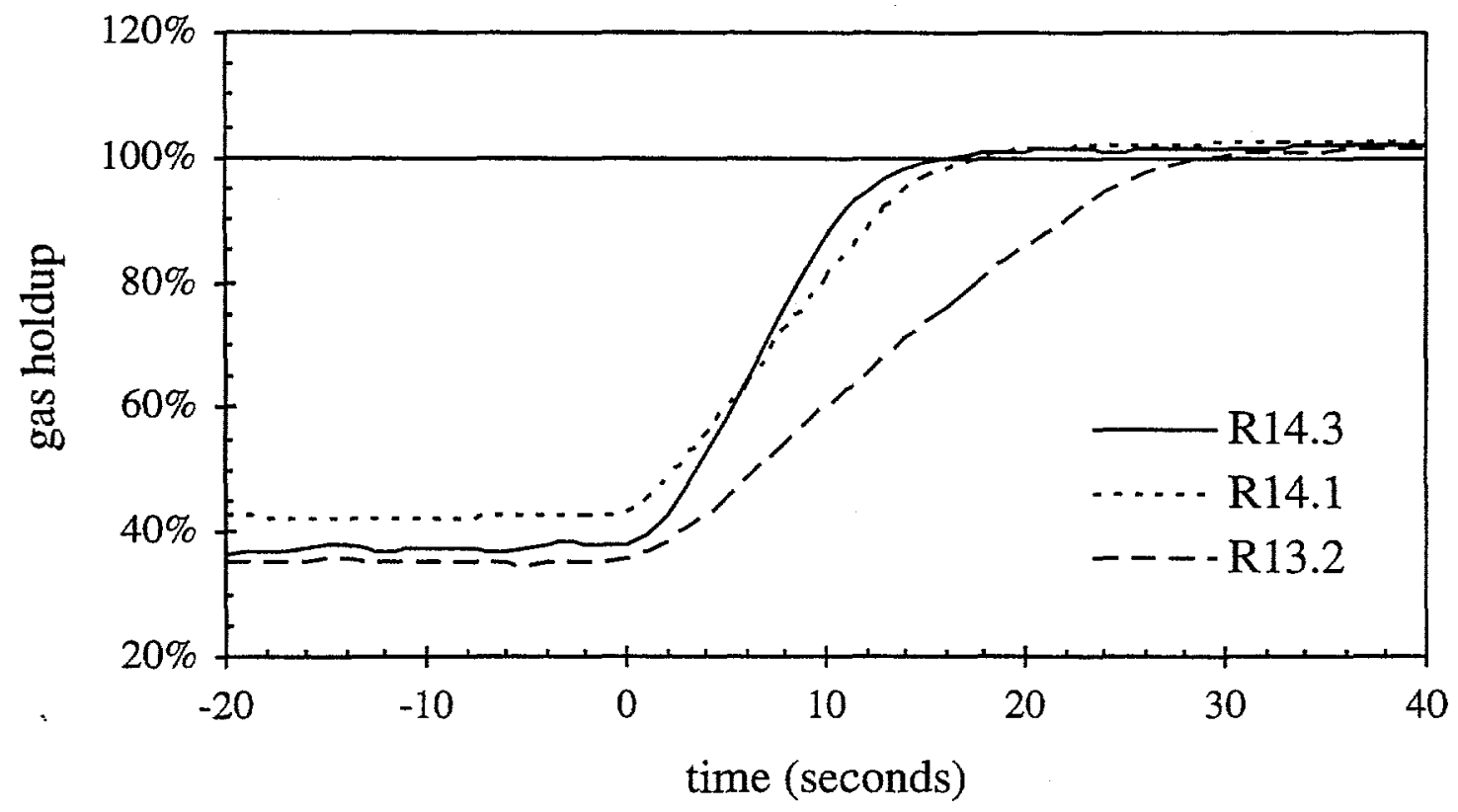

Figure 23. Dynamic Gas Disengagement curves in AFDU after run numbers R13.2, R14.1 and R14.3 at L/D between 21.0 and 27.6. 


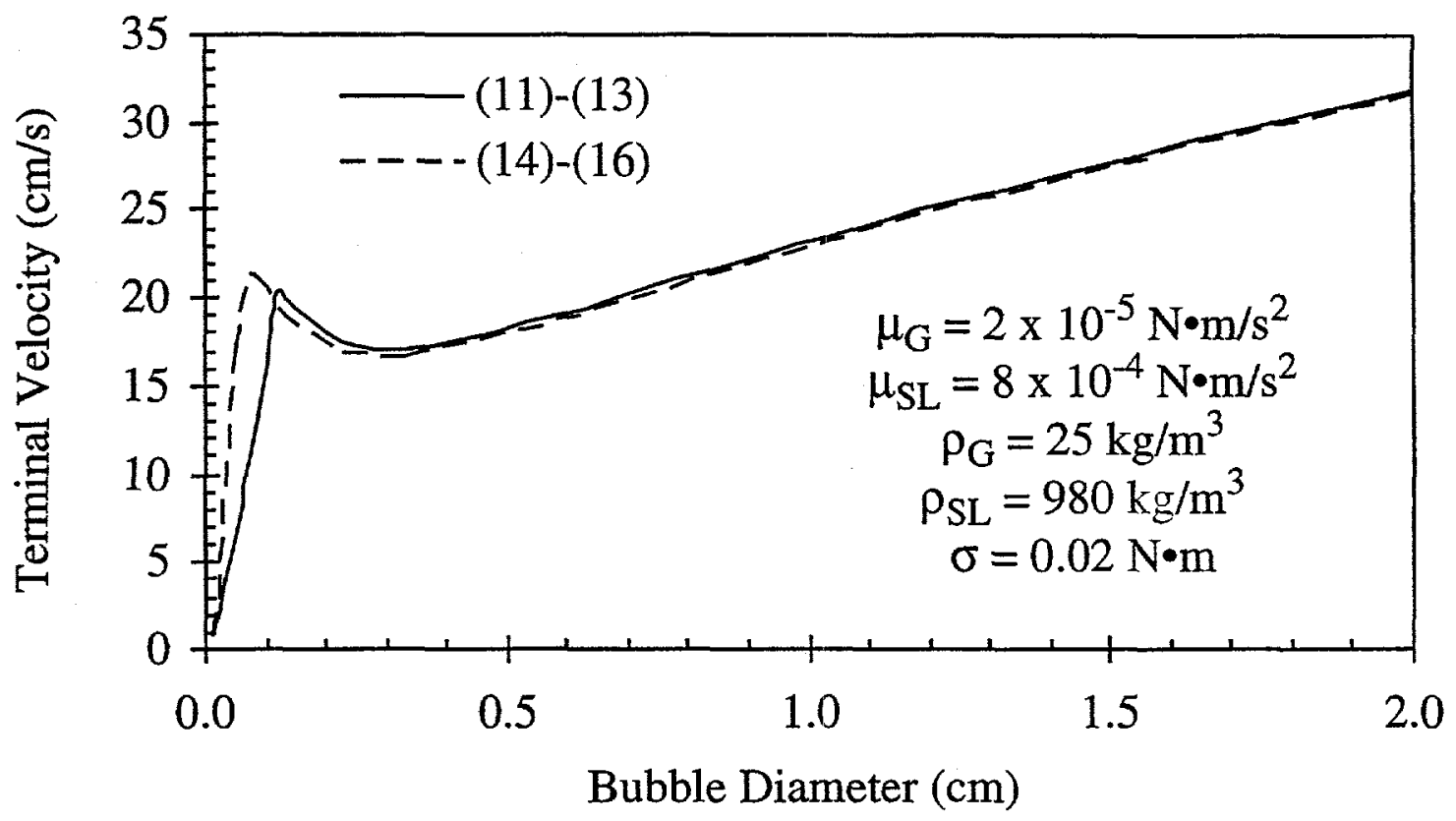

Figure 24. Comparison of terminal bubble velocity versus bubble diameter using (11)-(13) (Stokes' Law; Peebles and Garber, 1953; Clift et al., 1978) and (14)-(16) (a correlation by Jamialahmadi, 1994).

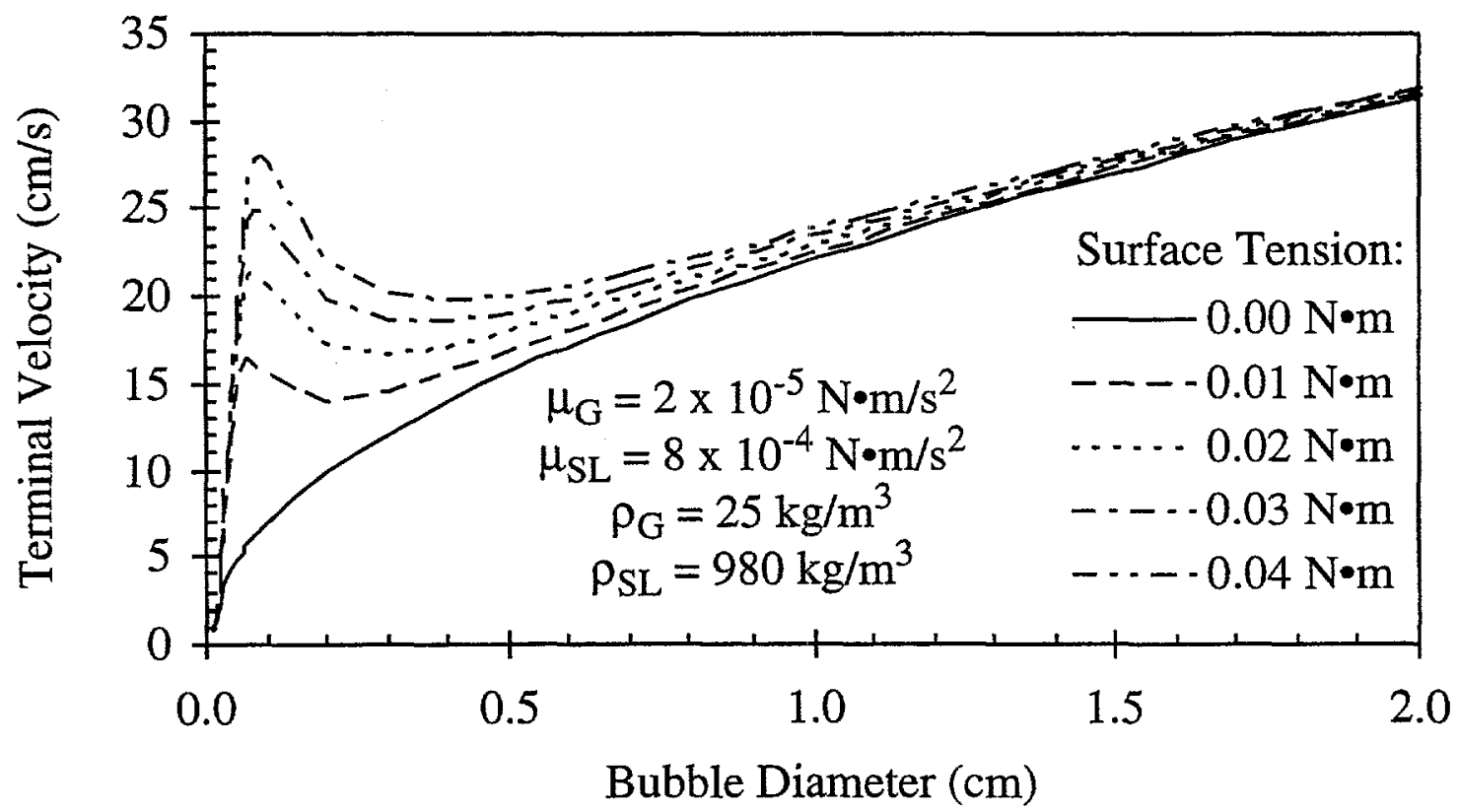

Figure 25. Terminal bubble velocity versus bubble diameter and surface tension using correlation by Jamialahmadi (1994). 


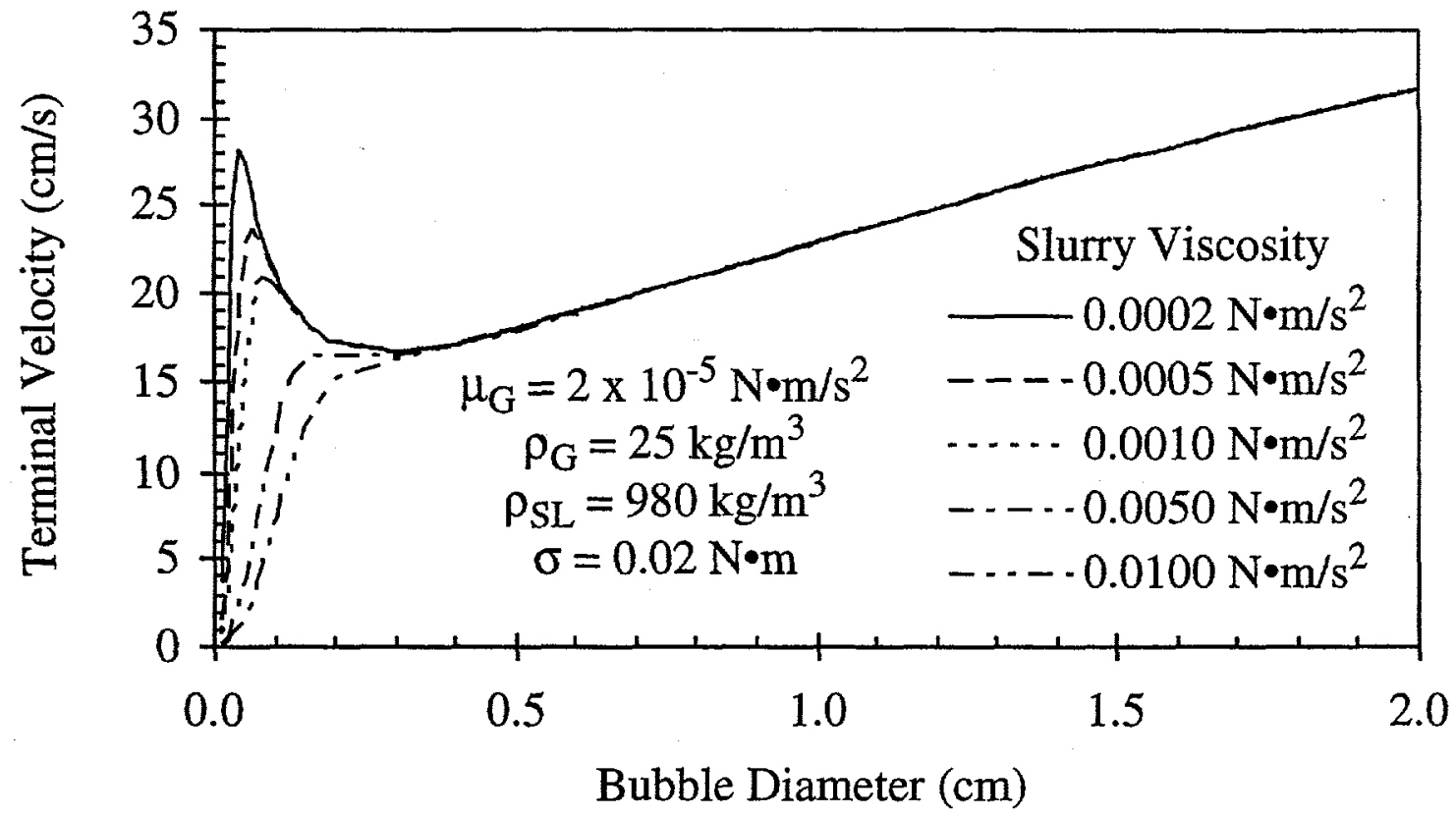

Figure 26. Terminal bubble velocity versus bubble diameter and liquid viscosity using correlation by Jamialahmadi (1994).

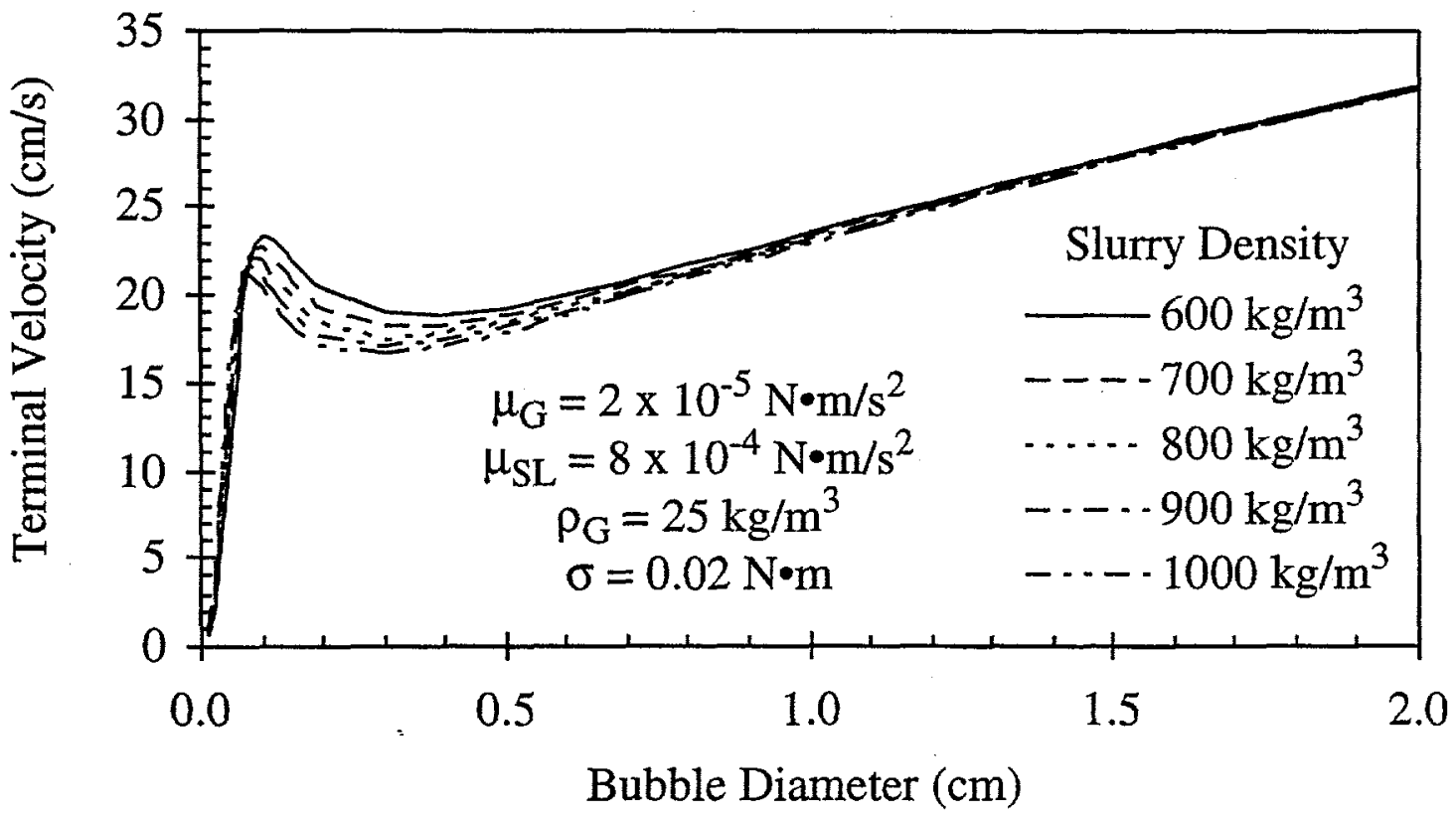

Figure 27. Terminal bubble velocity versus bubble diameter and liquid density using correlation by Jamialahmadi (1994). 

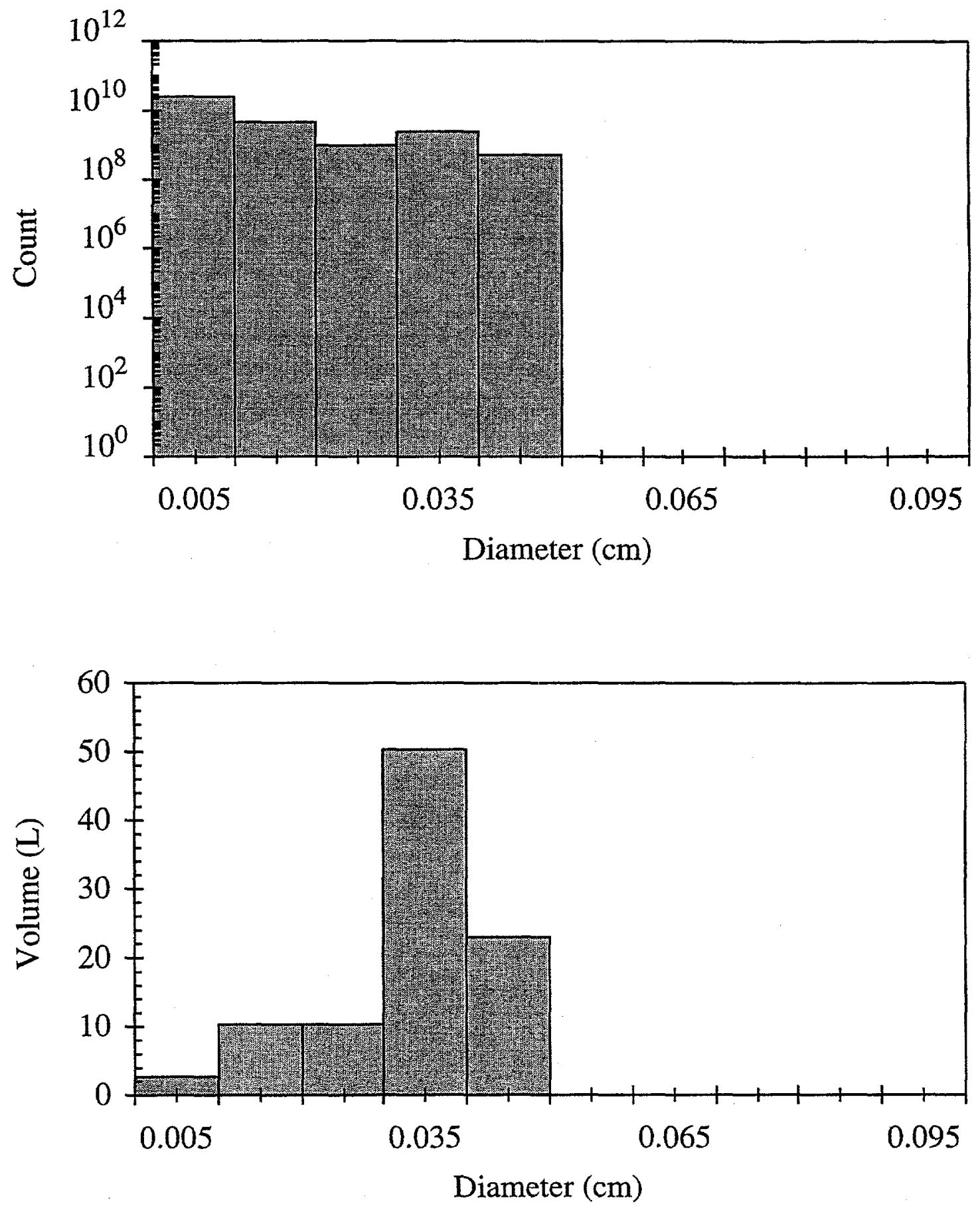

Figure 28. Number density and bubble volume histograms from DGD analysis and differential pressure measurements in AFDU for Run No. R13.2; $U_{G}=0.15 \mathrm{~m} / \mathrm{s}$, Kingsport gas, $\omega_{S}=43 \%$, catalyst $\mathrm{A}, 750$ psia $(5.17 \mathrm{MPa})$ and $482^{\circ} \mathrm{F}\left(250^{\circ} \mathrm{C}\right)$. 

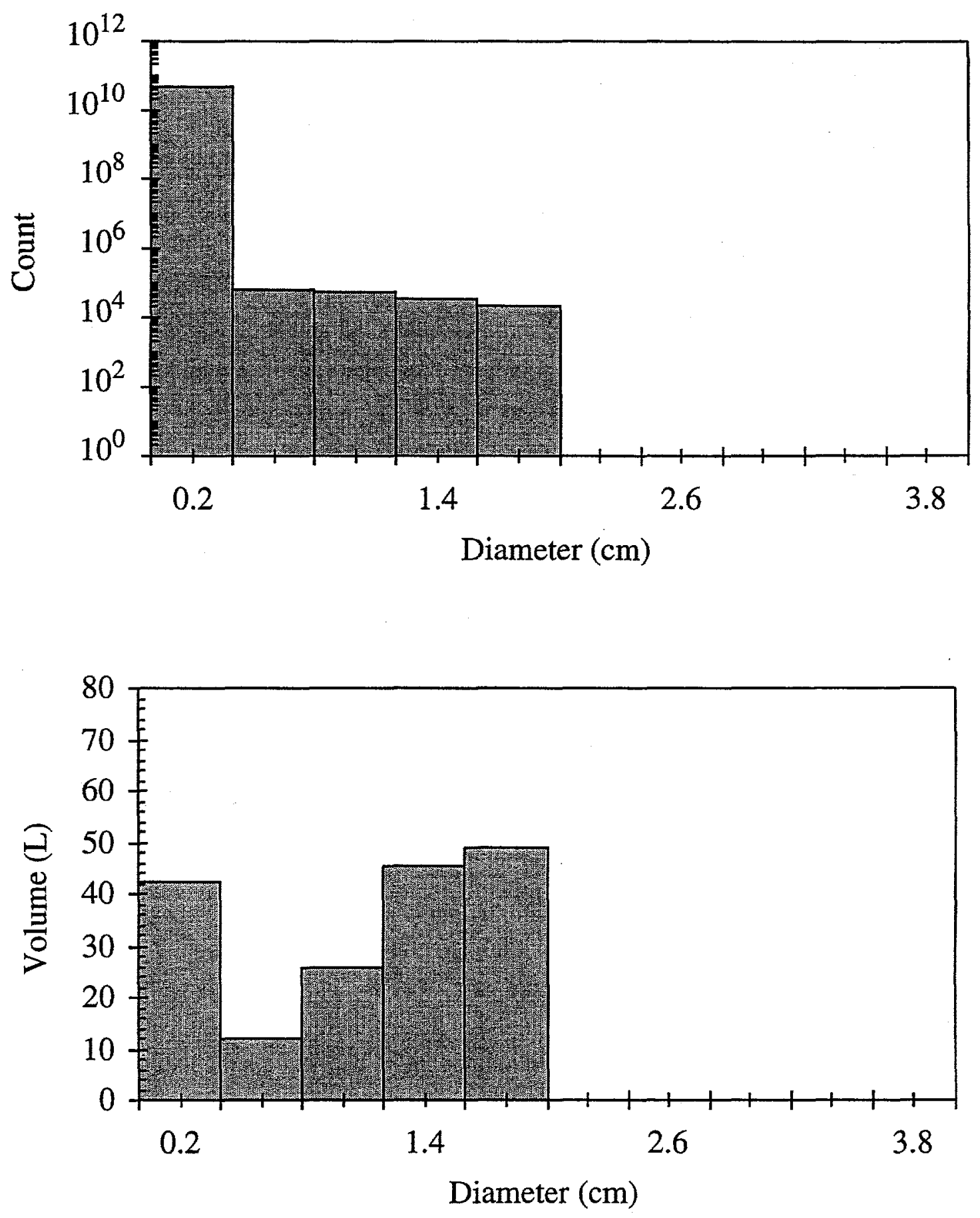

Figure 29. Number density and bubble volume histograms from DGD analysis and differential pressure measurements in AFDU for Run No. R14.1; $U_{G}=0.25 \mathrm{~m} / \mathrm{s}$, Texaco gas, $\omega_{S}=43 \%$, catalyst $\mathrm{B}, 750 \mathrm{psia}(5.17 \mathrm{MPa})$ and $482^{\circ} \mathrm{F}\left(250^{\circ} \mathrm{C}\right)$. 

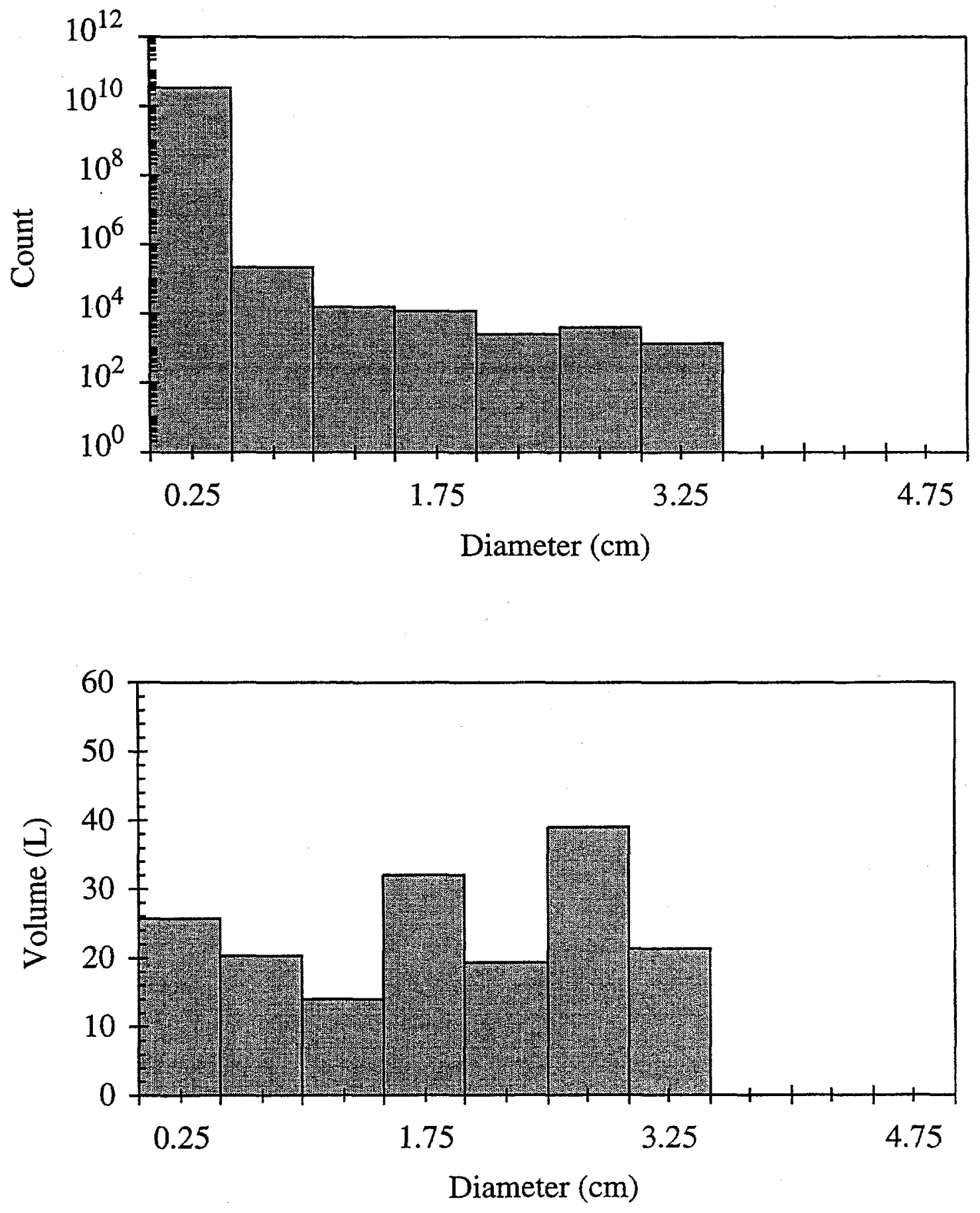

Figure 30. Number density and bubble volume histograms from DGD analysis and differential pressure measurements in AFDU for Run No. R14.3; $U_{G}=0.36 \mathrm{~m} / \mathrm{s}$, Kingsport gas, $\omega_{S}=43 \%$, catalyst $\mathrm{B}, 535$ psia $(3.69 \mathrm{MPa})$ and $482^{\circ} \mathrm{F}\left(250^{\circ} \mathrm{C}\right)$. 